\title{
The Electrochemistry of Metal Carbides: From Salt Melt Synthesis to Voltammetry of Microparticles
}

\author{
Rachel Lee Tani Walker
}

Follow this and additional works at: https://researchrepository.wvu.edu/etd

\section{Recommended Citation}

Walker, Rachel Lee Tani, "The Electrochemistry of Metal Carbides: From Salt Melt Synthesis to Voltammetry of Microparticles" (2018). Graduate Theses, Dissertations, and Problem Reports. 7271. https://researchrepository.wvu.edu/etd/7271

This Dissertation is protected by copyright and/or related rights. It has been brought to you by the The Research Repository @ WVU with permission from the rights-holder(s). You are free to use this Dissertation in any way that is permitted by the copyright and related rights legislation that applies to your use. For other uses you must obtain permission from the rights-holder(s) directly, unless additional rights are indicated by a Creative Commons license in the record and/ or on the work itself. This Dissertation has been accepted for inclusion in WVU Graduate Theses, Dissertations, and Problem Reports collection by an authorized administrator of The Research Repository @ WVU. For more information, please contact researchrepository@mail.wvu.edu. 


\title{
The Electrochemistry of Metal Carbides: From Salt Melt Synthesis to Voltammetry of Microparticles
}

\author{
Rachel Lee Tani Walker \\ Dissertation submitted \\ to the Eberly College of Arts and Sciences \\ at West Virginia University \\ in partial fulfillment of the requirements for the degree of \\ Doctor of Philosophy in Chemistry/Physical Chemistry \\ Charles Jaffè, Ph.D., Chair \\ Alfred Stiller, Ph.D. \\ Harry Finklea, Ph.D. \\ Charter Stinespring, Ph.D. \\ Fabien Goulay, Ph.D. \\ Kenneth Showalter, Ph.D. \\ C. Eugene Bennett Department of Chemistry \\ Morgantown, West Virginia \\ 2018
}

Keywords: metal carbides, salt-like carbides, salt melt synthesis, solid-state electrochemistry, voltammetry of microparticles, carbon materials

Copyright 2018 Rachel Lee Tani Walker 


\title{
Abstract \\ The Electrochemistry of Metal Carbides: From Salt Melt Synthesis to Voltammetry of Microparticles
}

\author{
Rachel Lee Tani Walker
}

Metal carbides have gained attention for their unique properties which lie at the boundary of high-performance ceramics and metals. These properties indicate their potential applications in many different areas. They have been studied as precursors for carbon nanomaterials with tunable structures using halogenation, vacuum decomposition or hydrothermal synthesis routes. More recently, they have gained ground in the literature for direct application as electrode materials and catalyst support in fuel cells. In this work, we present a hitherto unexplored method for producing graphitic materials from calcium carbide in salt melts and galvanic reactions in nonaqueous electrolytes. Results and characterization of the carbon material produced from these reactions by scanning electron microscopy (SEM), energy dispersive X-ray spectroscopy (EDS), X-ray photoelectron spectroscopy (XPS) and micro-Raman spectroscopy are described. These results introduce a new avenue to carbons and new opportunities for their materials design.

Although there has been much recent work focused on their applications in electrochemical devices, there are comparatively fewer studies investigating the basic electrochemistry of these systems. Therefore, we have initiated voltammetry of microparticles (VMP) at a solid electrode experiments for the electrochemical solid-state analysis of various metal carbides with varying properties. For this purpose, we fabricated a paraffin impregnated graphite electrodes (PIGE) and a glassy carbon electrode (GCE). A thorough characterization of the PIGE morphology and electrode behavior via microRaman spectroscopy, SEM, XPS and cyclic voltammetry (CV) is presented. Challenges arising from the application of PIGE in nonaqueous electrolytes will also be discussed. Results of VMP analyses of various carbides at a PIGE electrode in in aqueous electrolyte and at a GCE electrode in nonaqueous electrolyte are also described. 


\section{Dedication}

To my parents and my husband for their constant love and support 


\section{Acknowledgements}

I would like to express my appreciation to my committee members for the time and effort they have expended in guiding my research. I would like to thank Dr. Jaffè and Dr. Stiller for their joint supervision which taught me many valuable lessons. I would like to thank Dr. Stinespring for his consistent encouragement and support. I also want to thank Dr. Finklea for his comments and suggestions, as well as his criticism, which always pushed me to improve my research. I would also like to express my gratitude to Dr. Goulay and Dr. Showalter for their kind suggestions and critiques.

I would like to acknowledge and thank Closed Loop, LLC and the NASA West Virginia Space Grant Consortium (WVSGC) for funding of research projects described in this work.

Additionally, I would like to thank Rebecca Secrist for the tireless assistance she provides chemistry graduate students in navigation through University paperwork and procedures. I am grateful to Sherman Adams for his skill and artistry in designing the glassware systems used in my research. Finally, I would like to thank Jim Hall for his technical support and friendship. 


\section{Foreword}

The work in this dissertation was done as part of a broader, collaborative project focusing on new methods of carbon materials synthesis from carbides. In its beginning stages, this research was privately funded as part of an effort to produce diamond and graphitic materials. During this time, synthesis routes investigated included carbide reactions with molten salts and galvanic reactions in nonaqueous electrolyte systems. The goal of the work in this dissertation was to examine the electrochemical behavior of carbides in nonaqueous media. Interest in this area of research began when Dr. Alfred Stiller, the principal investigator for the project and my research advisor, looked over a 1925 patent for producing elemental potassium from the reaction of calcium carbide and potassium fluoride. 


\section{Contents}

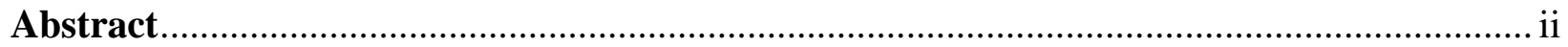

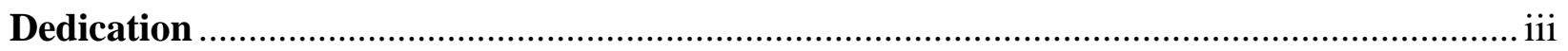

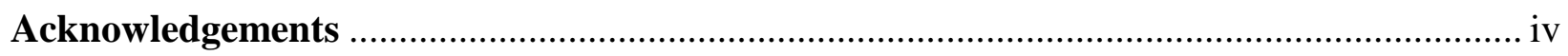

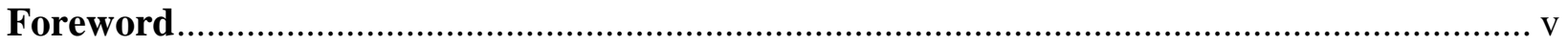

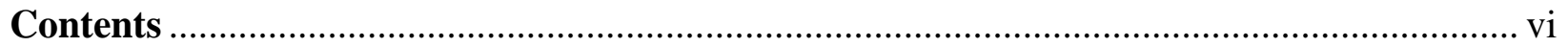

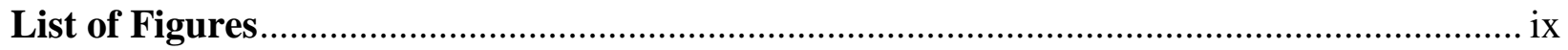

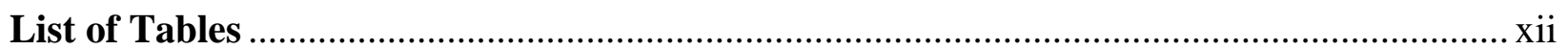

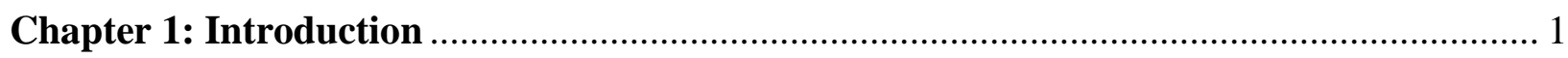

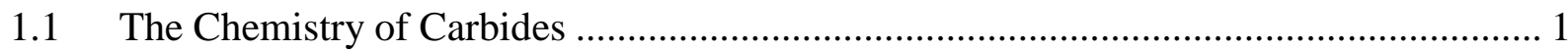

1.2 Carbide Materials and their Classification ………………………........................... 2

1.2.1 Covalent Carbides ...................................................................................... 3

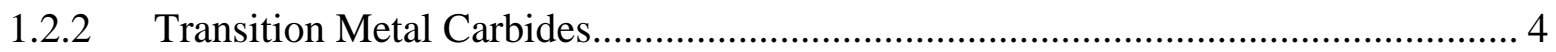

1.2.3. Alkali-metal Graphite Intercalation Compounds (GICs) ........................................... 7

1.2.4 Nanophase Metal Carbides - MXenes and Met-cars................................................... 9

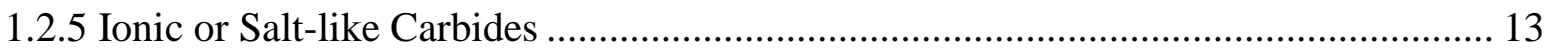

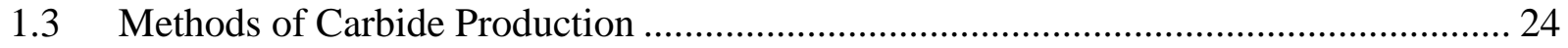

1.3.1 Carbothermal Reduction of Metal Oxides ......................................................... 25

1.3.1.2 Synthesis from the elements ................................................................................ 27

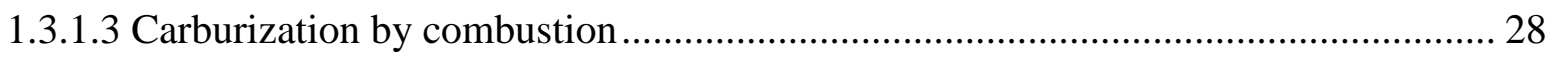

1.3.1.4 Gas Phase Synthesis Processes ........................................................................ 29

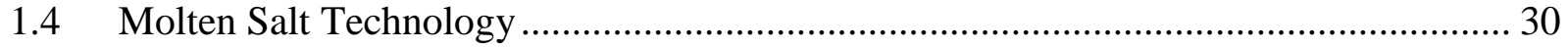

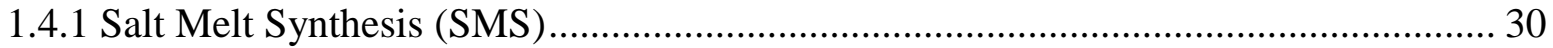

1.4.1 Studies of Salt-like Carbides in High Salt Melts ................................................... 31

1.4.2 Electrochemical Studies of Calcium Carbide ……………………………......... 32

1.4.3 Salt Melt Synthesis of Metal Carbides................................................................ 33

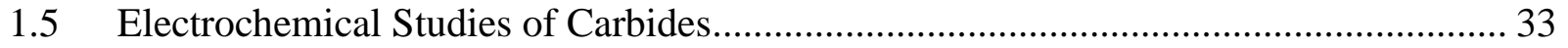

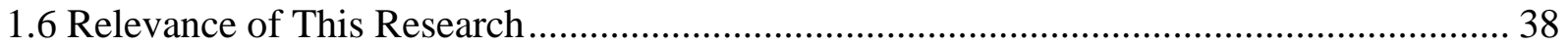

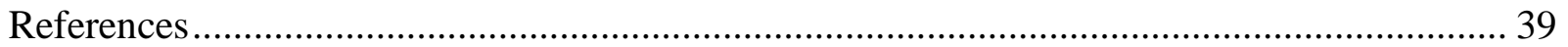

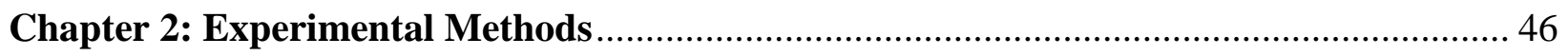

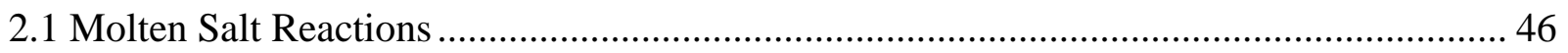

2.2 Solution State Reactions ............................................................................................ 49

2.2.1 Galvanic Reactions of Calcium Carbide and Zinc Chloride........................................ 51 
2.2.2 Controlled Potential Electrolysis ............................................................................. 52

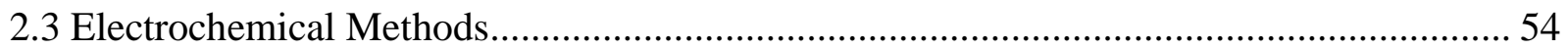

2.3.1 General Experimental Considerations for Electrochemical Analyses ........................ 54

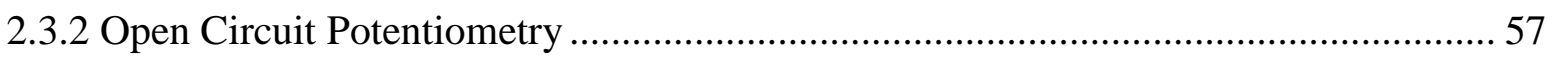

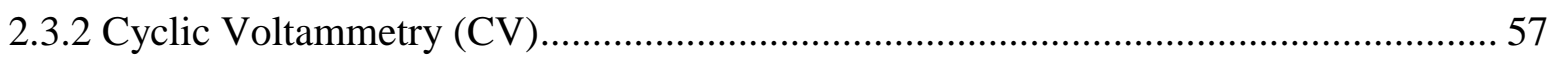

2.3.3 Methods for the Electrochemical Analysis of Solids in Liquid Electrolytes................ 61

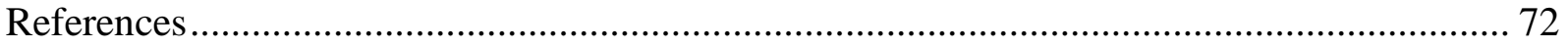

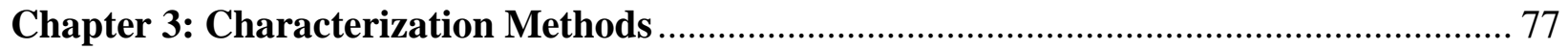

3.1 Micro-Raman Spectroscopy........................................................................................ 77

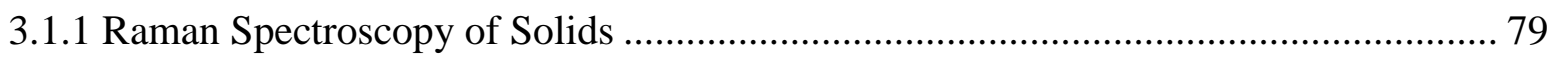

3.1.2 Artifacts and anomalies in Solid-State Raman Spectroscopy...................................... 83

3.1.3 Interpretation of Raman Spectra of Carbon Materials ................................................. 83

3.2 Scanning Electron Microscopy (SEM) ………............................................................. 91

3.3 X-ray Photoelectron Spectroscopy (XPS) …………........................................................ 94

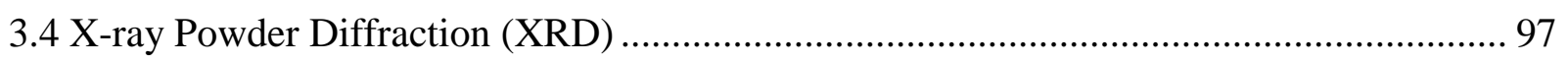

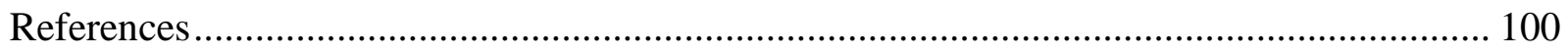

Chapter 4: Molten Salt Reactions of Salt-like Carbides ………………………….............. 103

4.1 Reaction of Aluminum Carbide with Tin Chloride ……………....................................... 103

4.2 Reaction of Calcium Carbide with Tin Chloride ............................................................. 109

4.4 Reaction of Calcium Carbide with Zinc Chloride ………………………………….... 110

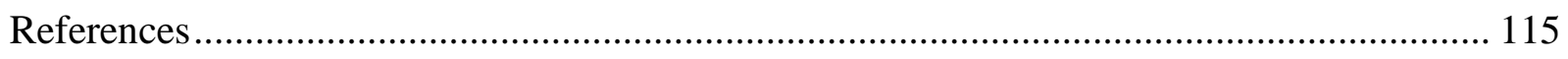

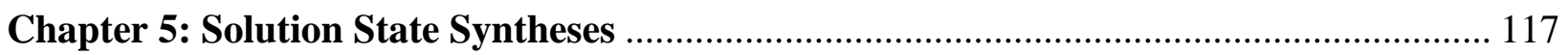

5.0 Reactions of Ionic Carbides with Metal Chloride Salts in the Solution State .................. 117

5.1 Solution State Galvanic Reactions........................................................................ 118

5.2 Solution State Controlled Potential Electrolysis................................................................ 123

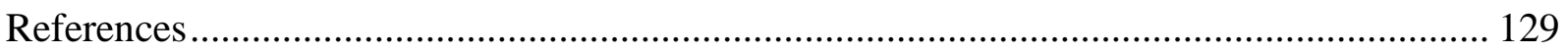

Chapter 6: Voltammetry of Carbide Microparticles at a Solid Electrode .......................... 130

6.0 Preparation and Characterization of a Paraffin Impregnated Graphite Electrode ............ 130

6.1 PIGE and Nonaqueous Electrolyte Compatibility …………............................................. 132

6.2 CV Analyses of various Metal Carbide Particles Immobilized on a Solid Electrode ...... 136

6.2.1 Analysis of $\mathrm{SiC}$ in 0.5 $\mathrm{M} \mathrm{H}_{2} \mathrm{SO} 4$ immobilized on a PIGE ...................................... 136

6.2.2 Analyses of $\mathrm{WC}$ in $0.5 \mathrm{M} \mathrm{H}_{2} \mathrm{SO}_{4}$ immobilized on a PIGE ...................................... 140 
6.2.3 Analysis of $\mathrm{Cr}_{3} \mathrm{C}_{2}$ in $0.5 \mathrm{H}_{2} \mathrm{SO}_{4}$ immobilized on a PIGE ..................................... 144

6.2.4 Analysis of $\mathrm{Cr}_{23} \mathrm{C}_{6}$ in $0.5 \mathrm{M} \mathrm{H}_{2} \mathrm{SO}_{4}$ immobilized on a PIGE ................................. 148

6.2.5 Analysis of $\mathrm{Al}_{4} \mathrm{C}_{3}$ in $0.1 \mathrm{M} \mathrm{KPF6/MeCN}$ immobilized on a GCE............................. 151

6.2.6 Analysis of $\mathrm{CaC}_{2}$ in 0.1M TBAHFP/MeCN immobilized on a GCE...................... 155

6.2.7 Analysis of $\mathrm{CaC}_{2}$ in 0.1M CaTf/MeCN immobilized on a GCE .............................. 157

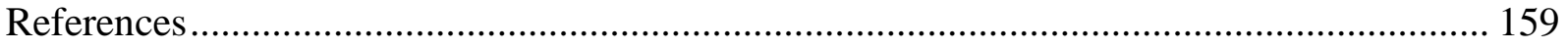

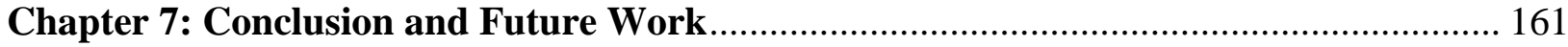

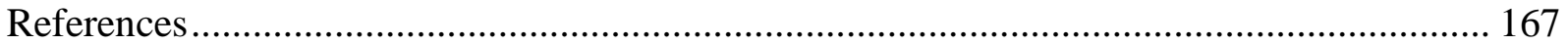

Appendix A. Analysis of Calcium Carbide and Aluminum Carbide and Their Impurities 169

A.1 Methodology for Analysis of Calcium Carbide Impurities .......................................... 170

A.2 ICP-OES Results and Analysis ................................................................................. 171

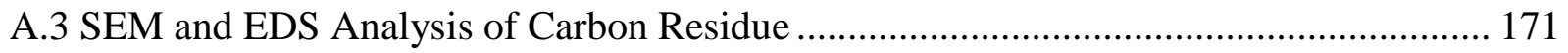

A.4 Raman and Optical Microscopy Analysis of Carbon Residue.......................................... 175

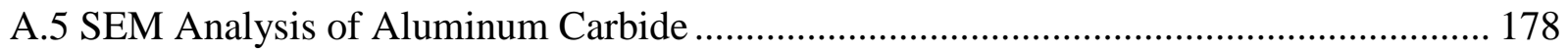

References........................................................................................................ 180

Appendix B. Experiments to Establish Working Potential Window of Each System ........ 181

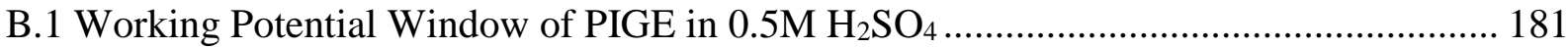

B2. Working Potential Window of GCE in 0.1M KPF $/ \mathrm{MeCN}^{2 . . . \ldots \ldots . . . . . . . . . . . . . . . . . . . . . . . . . . . . . . . . . ~} 183$

B3. Working Potential Window of GCE in 0.1M TBAHFP/MeCN .................................... 185

B4. Working Potential Window of GCE in 0.1M CaTf/MeCN ……….............................. 188

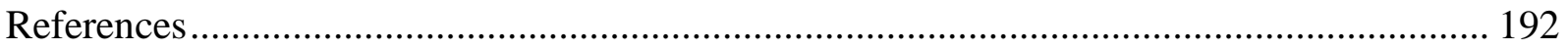




\section{List of Figures}

Figure 1.1 Classification scheme for carbides. ${ }^{13}$

Figure 1.2 Structures of $\mathrm{Cr}_{23} \mathrm{C}_{6}, \mathrm{Cr}_{7} \mathrm{C}_{3}$ and $\mathrm{Cr}_{3} \mathrm{C}_{2}$. $\mathrm{CrC}$, hexagonal (h-CrC) and cubic (c-CrC) and $\mathrm{Cr}_{3} \mathrm{C}^{4}$ 7

Figure 1.3 Structure of varying stoichiometries of potassium intercalated graphite. Source: https://catalog.flatworldknowledge.com/bookhub/4309?e=averill_1.0-ch21_s03 .................... 9

Figure 1.4 Mass spectrum of met-car $\mathrm{Ti}_{8} \mathrm{C}_{12}{ }^{36,41}$ 10

Figure 1.5 Pentagonal dodecahedron structure, $\mathrm{T}_{\mathrm{h}}$ point group. Titatanium atoms (dark spheres) appear at the edge of a cube-like arrangement and are similarly coordinate to three-carbon atoms (light spheres) at all equivalent positions ${ }^{40}$ 10

Figure 1.6 Analysis of $\mathrm{Ti}_{3} \mathrm{AlC}_{2}$ before and after exfoliation, a) XRD results before $\mathrm{HF}$ treatment, compared with simulated XRD patterns of $\mathrm{Ti}_{3} \mathrm{C}_{2} \mathrm{~F}_{2}$ and $\left.\mathrm{Ti}_{3} \mathrm{C}_{2}() \mathrm{H}\right)_{2}$ and measured XRD patterns of $\mathrm{Ti}_{3} \mathrm{AlC}_{2}$ after exfoliation, b) Raman spectra of $\mathrm{Ti}_{3} \mathrm{AlC}_{2}$ before and after HF treatment, c) XPS spectra and $\mathrm{SEM} \mathrm{d}$ ) of $\mathrm{Ti}_{3} \mathrm{AlC}_{2}$ before and after $\mathrm{HF}$ treatment, and e) a cold-pressed $25 \mathrm{~mm}$ disk of etched and exfoliated material ${ }^{46}$ 12

Figure 1.7 Crystal structure of aluminum carbide ${ }^{62}$ 16

Figure 1.8 Crystal structure of calcium carbide ${ }^{1}$

Figure 1.9 Diagram of calcium carbide furnace. The crucible (A) is made of brick walls and a carbon lined bottom, which is cooled by a fan (B). A cover $(\mathrm{C})$ isolates the furnace. The hydraulic cylinders (E) support and move the electrodes (D) in and out of the furnace and are fitted with a slipping device $(F)$. The contact plates $(\mathrm{G})$ connect the the transformer $(\mathrm{H})$ to the electrodes. The tapping electrode (I) directs the liquid carbide from the taphole (J) to a cart for cooling (K). Bins (L) store raw precursors and charging chutes (M) introduce them to the furnace. Particulate raw precursors are stored in bins $(\mathrm{N})$ and supplied through a screw conveyor 
$(\mathrm{O})$, connector $(\mathrm{P})$ and hollow electrode $(\mathrm{Q})$. Gasses escape through duct (R). A crane (U)

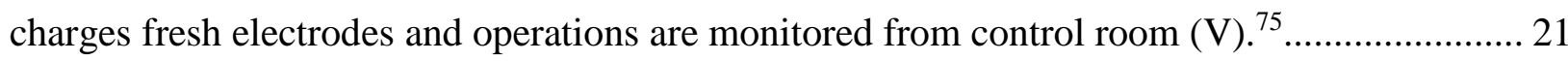

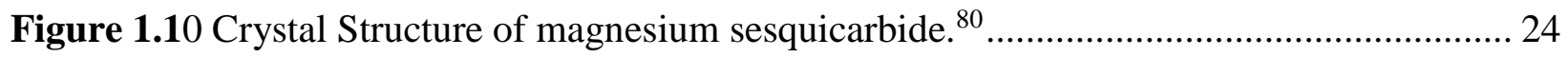

Figure 1.11 Schematic of Acheson furnace for $\mathrm{SiC}$ production. Image source:

http://materials.iisc.ernet.in/ govind/silicon_carbide_manufacture.htm

Figure 1.12 Cross-sectional view of $\mathrm{SiC}$ melt in Acheson furnace. Image source:

http://materials.iisc.ernet.in/ govind/silicon_carbide_manufacture.htm ................................ 27

Figure 1.13 Schematic of solid-solid combustion synthesis using Ti-C as a model ${ }^{85}$............. 29

Figure 2.1 Pipe bomb reactor and glass ampoules for molten salt reactions .......................... 47

Figure 2.2 Two compartment cell with glass fritted salt bridge for solution reactions ............. 51

Figure 2.3 Diagram of three-electrode set-up for controlled potential electrolysis experiment in

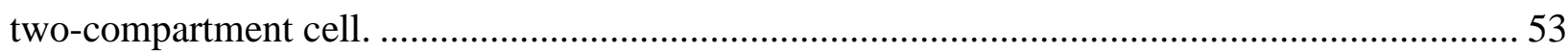

Figure 2.4 Schematic of three compartment electrochemical cell ..................................... 55

Figure 2.5 PalmSens Potentiostat model Emstat blue 3+ (Left) and electrochemical cell (Right)

Figure 2.6 Plot showing excitation signal vs. time in CV experiments................................. 59

Figure 2.7 Cyclic voltammogram of $6 \mathrm{mM} \mathrm{K}_{3} \mathrm{Fe}(\mathrm{CN})_{6}$ in $1 \mathrm{M} \mathrm{KNO}_{3}$. Scan initiated at $0.8 \mathrm{~V}$ v.

$\mathrm{SCE}$ in the negative direction at $50 \mathrm{mV} / \mathrm{s}$ at a platinum $\mathrm{WE}$

Figure 2.8 The electrochemical cell for a corrosion study of 316L stainless steel samples in artificial bone fluid solution. This experimental set up consists of a graphite counter electrode, a sample of steel as the working electrode and a reference electrode with a Luggin capillary to minimize iR drop ${ }^{16}$ 
Figure 2.9 Process for fabrication of carbon paste modified with MCNTs for the selective determination of trace bismuth using differential pulse anodic stripping voltammetry. The paste is prepared by mixing carbon powder, mineral oil as a binder and MCNTs together in a mortar and pestle. The paste is packed into an electrode body and inserted into an electrochemical cell for the acquisition of data.

Figure 2.10 Ensembles of solid-microparticles (in red) immobilized on the surface of a solid working electrode (WE)

Figure 2.11 Cathodic voltammograms of a) $\mathrm{CuS}, \mathrm{CuSe}$ and $\mathrm{CuS}_{0.6} \mathrm{Se}_{0.4}$ and b) a mechanical mixture of $\mathrm{CuS}$ and $\mathrm{CuSe}(1: 2)$. Electrolyte: $1 \mathrm{M} \mathrm{H}_{2} \mathrm{SO}_{4}$, scan rate: $0.011 \mathrm{~V} / \mathrm{s}^{47}$ 68 Figure 2.12 Electrochemical reduction of red tetragonal $\mathrm{PbO}$ (litharge) in situ coupled with $\mathrm{X}$ ray diffraction. $\mathrm{PbO}$ was mechanically immobilized on the surface of a paraffin impregnated graphite electrode, electrolyte: $1 \mathrm{M} \mathrm{KCl}$, a) linear sweep voltammogram with scan rate $0.1 \mathrm{mV} / \mathrm{s}$, b) corresponding diffraction pattern showing simultaneous decrease in $\mathrm{PbO}$ reflection and increase in $\mathrm{Pb}$ reflections. Signal pairs between -0.5 and $-0.8 \mathrm{~V}$ are $\mathrm{PbO}$ reflections at $\mathrm{d}=2.51 \mathrm{~A}$, signal pairs between -1.1 and $-1.5 \mathrm{~V}$ are $\mathrm{Pb}$ reflections at $\mathrm{d}=2.48 \mathrm{~A}$ (for further details see text $^{58}$ ), c) atomic force micrograph of a $\mathrm{PbO}$ crystal on a gold surface in $1 \mathrm{M} \mathrm{KCl}$ after a reduction for 1 showing a step at the reaction front of the $\mathrm{PbO}$ to $\mathrm{Pb}$ transformation ${ }^{59}$..... 69

Figure 2.13 70 


\section{List of Tables}

Table 1.1 Table of intermediate stoichiometries of transition metal carbides ........................... 5

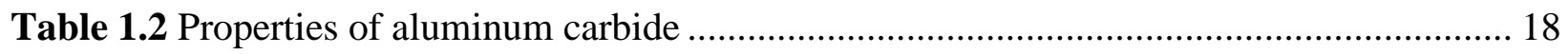

Table 1.3 Typical certificate of analysis for industrial grade calcium carbide. ${ }^{75}$..................... 20

Table 1.4 Properties of calcium carbide ........................................................................... 23

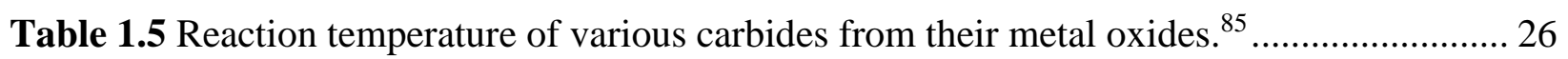

Table 1.6 Solubility of calcium carbide in different salt melts ${ }^{106}$....................................... 31

Table 2.1 Selected properties of metal chloride salts used in this research. Note: $E^{0}$ are standard

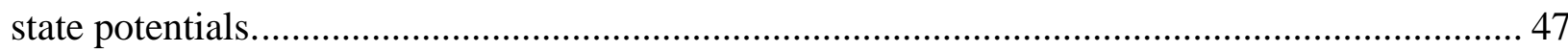

Table 3.1 Raman band assignments for diamond and nanodiamond .................................... 87

Table 3.2 Raman band assignments for graphite and graphene …......................................... 89

Table 3.3 Suggested C1s peak assignments for the interpretation of XPS spectra in carbon ${ }^{57} \ldots 97$

Table 6.1 Scan rates $(v)$ and peak potential splitting $(\Delta E)$ for ferrocene scan rate studies at gold, graphite and PIGE working electrodes.

Table A.1 . Mass percent of elements detected after hydrolysis via ICP-OES elemental analysis.

Carbon amount determined by weighing; however, analysis of carbon residue by SEM/EDS

indicates the residue is not pure carbon.

Table A.2 Elemental composition selected area in Figure 7.2 a) ........................................ 173

Table A.3 Elemental composition selected area in Figure 7.3 a)....................................... 174

Table A.4 Elemental composition selected are in Figure 7.4 a). ........................................ 175

Table A.5 Elemental Composition According to Alfa Aesar's Certificate of Analysis ........... 178

Table A.6 EDS spectrum of aluminum carbide powder ............................................... 179

Table A.7 Elemental Composition Determined via EDS ............................................... 179 


\subsection{The Chemistry of Carbides}

\section{Chapter 1: Introduction}

Carbides are a family of refractory materials traditionally used in high-temperature processes. Carbide materials have wide variations in structure and properties and rich history of research from many different fields. There are few texts in the literature containing comprehensive, interdisciplinary reviews on the subject of metal carbides. Of these the first was Kosolapova's Review "Carbides" translated from the original Russian in 1968. ${ }^{1}$ The most recent "The Physics and Chemistry of Carbides, Nitrides and Borides" 1990. Both however lack information on recent work on nanophase carbide materials. ${ }^{2}$

Recently, there has been growing interest in studying carbides, particularly nanophase and ternary carbides, to exploit their unique properties for a new generation of materials for electronic and energy devices and catalysis. For example, calculations for the electronic densities of states (DOS) of tungsten carbide (WC) showing platinum-like behavior ushered in studies of the catalytic properties of transition metal carbides. ${ }^{3}$ However, there are still significant gaps in the literature regarding the basic chemistry of various metal carbides. For instance, there are few studies of the electrochemical stability of pure transition metal carbides. To date most electrochemical studies investigating these compounds are corrosion studies of carbide coatings, alloys or composites due to their historical use as metallurgical and refractory materials.

In view of the attention metal carbides are receiving for their potential electrochemical applications, a more detailed understanding of their basic electrochemical mechanisms is necessary. Therefore, the overall aim of this work is to fill these gaps in the literature and contribute information on the electrochemical stability and mechanisms of various carbides in various 
environments. Older research on the oxidation of ionic carbides in salt melts has been revisited and expanded. In addition, research in the electrochemical of microparticles of metal carbides has also been explored.

\subsection{Carbide Materials and their Classification}

Carbides have rich diversity in stoichiometries and structure which give rise to unique and varied physical and chemical properties. It is customary to group carbides according to their structure and the supposed nature of their bonding, i.e. metallic, ionic, covalent etc. However, this is not always satisfactory as the structures of the carbides can be very complex and the nature of carbide bonds can be mixed and shifts in properties can be observed in the carbide of one metal depending on changes in its structure, e.g. the carbide phases of chromium. ${ }^{4,5}$ It should be noted that this circumstance is not exclusive to carbides, and that this oversimplification of the nature of bonding in chemical compounds applies to borides, sulfides, silicides etc. Nevertheless, it is commonly accepted that carbides can be broadly classified into four major families of compounds. Ternary, composite, alloys, intermetallic complexes and solid solutions of metallic carbides are not included in the following brief survey but have been reviewed elsewhere. ${ }^{6-12}$

Carbides can be divided into four different categories: (1) salt-like carbides, (2) covalent carbides, (3) interstitial carbides and (4) intermediate carbides. The salt-like carbides can be further separated into three groups: (1a) the methanides, (1b) acetylides and (1c) sesquicarbides, named as such because upon hydrolysis these carbides yield methane, acetylene and methyl acetylene respectively. The covalent carbides are inert upon hydrolysis and consist of carbon and another atom close to carbon in electronegativity. The interstitial carbides are compounds in which the carbon anions fit into the tetrahedral holes of the close packed lattice of metal atoms. Intermediate carbides have multiple stoichiometries and react upon hydrolysis with dilute acids to yield 
hydrocarbons and hydrogen. The classification of carbides and some examples are shown in Figure

1.1.

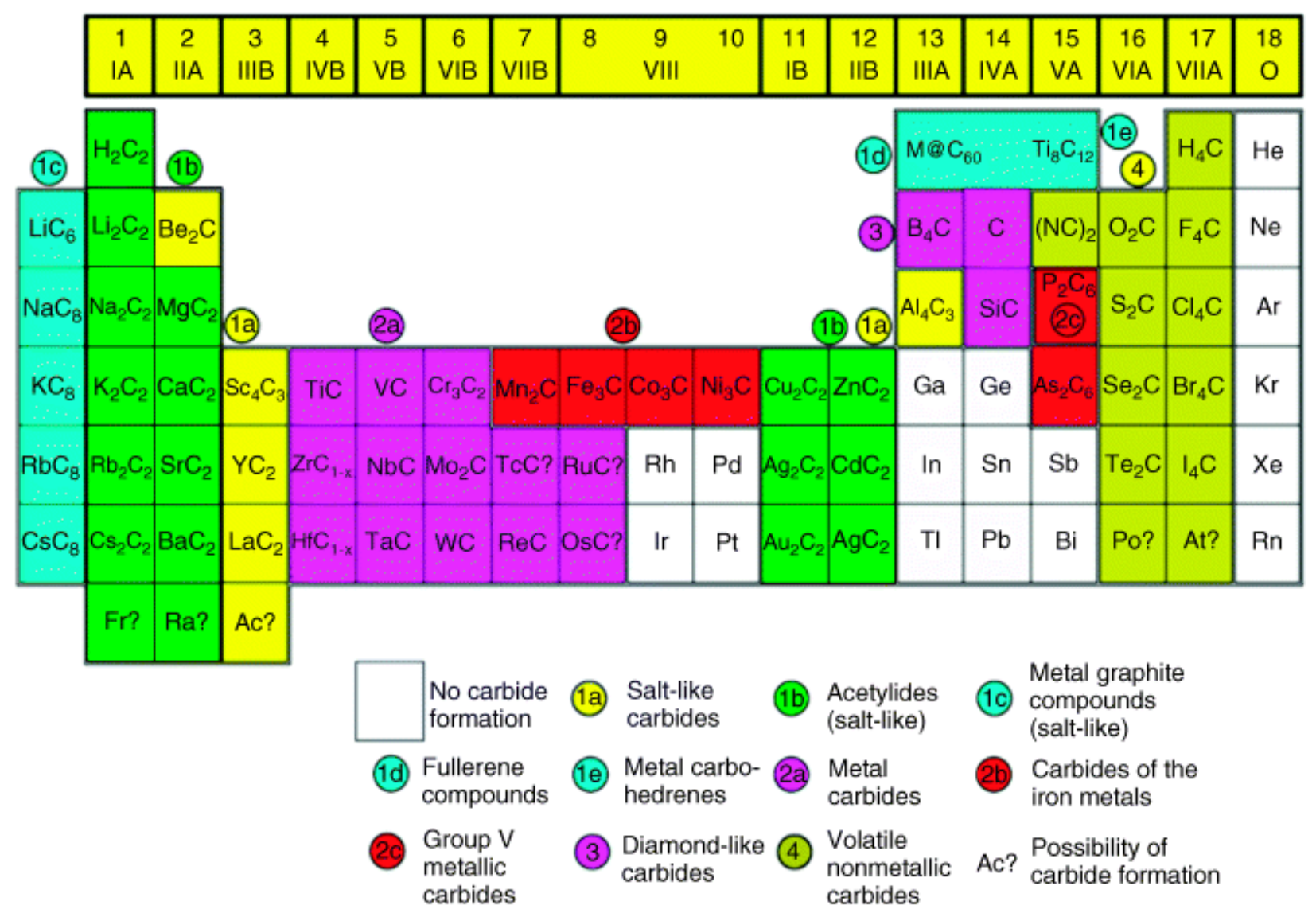

Figure 0.1 Classification scheme for carbides. ${ }^{13}$

\subsubsection{Covalent Carbides}

The covalent carbides are the carbides of silicon and boron. They are referred to as such because boron and silicon are more electronegative metalloids, so their bonding with carbon is more covalent in nature. The definite structure of boron carbide, traditionally given the structural formula, $\mathrm{B}_{4} \mathrm{C}$, has been disputed since it was synthesized in by $\mathrm{H}$. Moissan in 1899. It is now believed that the correct formula is $\mathrm{B}_{13} \mathrm{C}_{2},{ }^{14}$ but there can be a wide variation composition for this phase due to vacancies or substitutions in the boron icosahedra. ${ }^{1,15}$ Due to boron carbide's high 
melting point, thermal stability and hardness it is commonly used in high temperature processes as coatings for heat and abrasion resistance. ${ }^{16}$

250 polymorphs of silicon carbide have been identified in the literature; however, only the cubic, hexagonal and rhombohedral structures have been observed. The cubic phase is referred to as $\beta$-SiC and the hexagonal and rhombohedral phases are designated $\alpha$-SiC. ${ }^{17}$ In general, silicon carbide has a wide range of applications used as abrasives, coatings for tools, crucibles and automobile parts. ${ }^{15}$ Silicon carbide has found prolific use in electronic circuit elements as a semiconductor material. Recently, new research applications for silicon carbide has developed such as the use of $\beta$-SiC for heterogeneous catalyst support (citation) and hexagonal $\mathrm{SiC}$ for the production of graphene by epitaxial growth. ${ }^{18}$

\subsubsection{Transition Metal Carbides}

The most well studied group of carbides are the transition metal carbides. The following sections provide an overview of these compounds. For further information on the transition metal carbides, the author recommends Pearson's Handbook ${ }^{19}$ and the works of Ward, de Novion ${ }^{2}$ and Lengauer. ${ }^{20}$ They are closely related to the transition metal nitrides and borides in terms of structure and properties. Transition metal carbides exhibit a mixture of metallic, covalent and ionic bonding, ${ }^{21}$ and may be split into two categories based on their structure and stoichiometries: interstitial and intermediate.

\subsubsection{Interstitial Carbides}

It is most appropriate to describe the transition metals of Group 4 and 5, M = Ti, Zr, Hf, V, $\mathrm{Nb}$, Ta, Mo, W, as interstitial carbides, and the empirical formula is MC. ${ }^{15}$ This classification is based more on structure type than bonding type, in which the $\mathrm{C}$ atoms occupy the interstitial octahedral holes in the close packed metal lattice. In this case the metal ions must have an atomic radius $>135 \mathrm{pm}$ to accommodate the $\mathrm{C}$ atom in the octahedral interstices. ${ }^{22}$ These carbides are 
known to have high hardness and high thermal stability with melting points in excess of $3000^{\circ} \mathrm{C}$. They also exhibit metallic properties such as high electrical conductivity and luster. The properties of these carbides have led to their use in a wide range of applications from coatings for high temperature processes, abrasives, industrial machinery and tools, armor and ammunitions to jewelry. Tungsten carbide (WC), specifically, is a neutron reflector ${ }^{23}$ and played a critical role in the early development of nuclear weapons.

\subsubsection{Intermediate Carbides}

Metals or metallic ions with radii $<135 \mathrm{pm}$ form carbides with highly varied structures and stoichiometries (Table 1.1). ${ }^{15}$ These are classed as intermediate transition metal carbides. Metals with these smaller radii and a close-packed hexagonal arrangement only have half the octahedral interstitial sites occupied by a $\mathrm{C}$ atom. This leads to variations in stacking sequence, oxidation number and defects leads to wide variation in stoichiometries and structure.

\begin{tabular}{llllll}
\hline Vandium & Chromium & Managanese & Iron & Cobalt & Nickel \\
\hline $\mathrm{V}_{2} \mathrm{C}, \mathrm{V}_{4} \mathrm{C}_{3}$, & $\mathrm{Cr}_{23} \mathrm{C}_{6}$ & $\mathrm{Mn}_{23} \mathrm{C}_{6}$, & $\mathrm{Fe}_{3} \mathrm{C}, \mathrm{Fe}_{7} \mathrm{C}_{3}$ & $\mathrm{Co}_{3} \mathrm{C}$ & $\mathrm{Ni}_{3} \mathrm{C}$ \\
$\mathrm{V}_{6} \mathrm{C}_{5}, \mathrm{~V}_{8} \mathrm{C}_{7}$, & $\mathrm{Cr}_{7} \mathrm{C}_{3}$ & $\mathrm{Mn}_{15} \mathrm{C}_{4}$ & $\mathrm{Fe}_{2} \mathrm{C}$ & $\mathrm{Co}_{2} \mathrm{C}$ & \\
$\mathrm{VC}$ & $\mathrm{Cr}_{3} \mathrm{C}_{2}$ & $\mathrm{Mn}_{3} \mathrm{C}, \mathrm{Mn}_{5} \mathrm{C}_{2}$ & & & \\
& & $\mathrm{Mn}_{7} \mathrm{C}_{3}$ & & & \\
\hline
\end{tabular}

Table 0.1 Table of intermediate stoichiometries of transition metal carbides

$\mathrm{Cr}, \mathrm{Mn}, \mathrm{Fe}, \mathrm{Co}$ and $\mathrm{Ni}$ carbides are more reactive than interstitial transition metal carbides and can hydrolyze with dilute acids and sometimes water to produce $\mathrm{H}_{2}$ and a mixture of hydrocarbon gases. For example hydrolysis of $\mathrm{Mn}_{7} \mathrm{C}_{3}$ yields manganese hydroxide, methane and a $C_{l n}$ hydrocarbon series which decreases in concentration as shown in $\mathrm{R} 1.1 .{ }^{24}$ The hydrocarbon series is produced from polymerization reactions of methane triggered by the activated hydrogen radical, $H^{*}$. This specific behavior is attributed to the metallic nature of the bonding in transition metal carbides. 


$$
\mathrm{Mn}_{7} \mathrm{C}_{3}+14 \mathrm{H}_{2} \mathrm{O} \rightarrow 7 \mathrm{Mn}(\mathrm{OH})_{2}+3 \mathrm{CH}_{4}+2 \mathrm{H}^{\cdot} \rightarrow \sum_{n} C_{1 n}
$$

Lanthanum dicarbide, $\mathrm{LaC}_{2}$ follows a similar pattern: ${ }^{25}$

$$
\mathrm{LaC}_{2}+2 \mathrm{H}_{2} \mathrm{O} \rightarrow \mathrm{LaO}(\mathrm{OH})+\mathrm{C}_{2} \mathrm{H}_{2}+H^{\cdot} \rightarrow \sum_{n} C_{2 n}
$$

Intermediate carbides are hard, refractory materials with industrial applications similar to other transition metal borides, nitrides and silicides. Cementite $\left(\mathrm{Fe}_{3} \mathrm{C}\right)$ is an important component in cast iron and steel, ${ }^{26}$ and $\mathrm{Cr}_{3} \mathrm{C}_{2}$ is used as temperature and corrosion resistant coatings or additives for metallurgical parts. ${ }^{27}$

Figure 1.2 illustrates the versatility in structure of the intermediate carbides, using the carbides of chromium as an example. The stable forms of chromium which have been experimentally observed are $\mathrm{Cr}_{23} \mathrm{C}_{6}, \mathrm{Cr}_{7} \mathrm{C}_{3}$ and $\mathrm{Cr}_{3} \mathrm{C}_{2}$. $\mathrm{CrC}$, hexagonal (h-CrC) and cubic (c-CrC) and $\mathrm{Cr}_{3} \mathrm{C}$ are metastable phases. Li et al. used first principles calculations to determine electronic, mechanical and theoretical hardness of all six chromium carbide phases. Their calculations indicated that although all bonding six phases was a combination of metallic, covalent and ionic, the metallic nature roughly increases from $\mathrm{h}-\mathrm{CrC}<\mathrm{c}-\mathrm{CrC}<\mathrm{Cr}_{3} \mathrm{C}<\mathrm{Cr}_{23} \mathrm{C}_{6}<\mathrm{Cr}_{7} \mathrm{C}_{3}$. The theoretical hardness increases with increasing carbon concentration. ${ }^{4}$ 

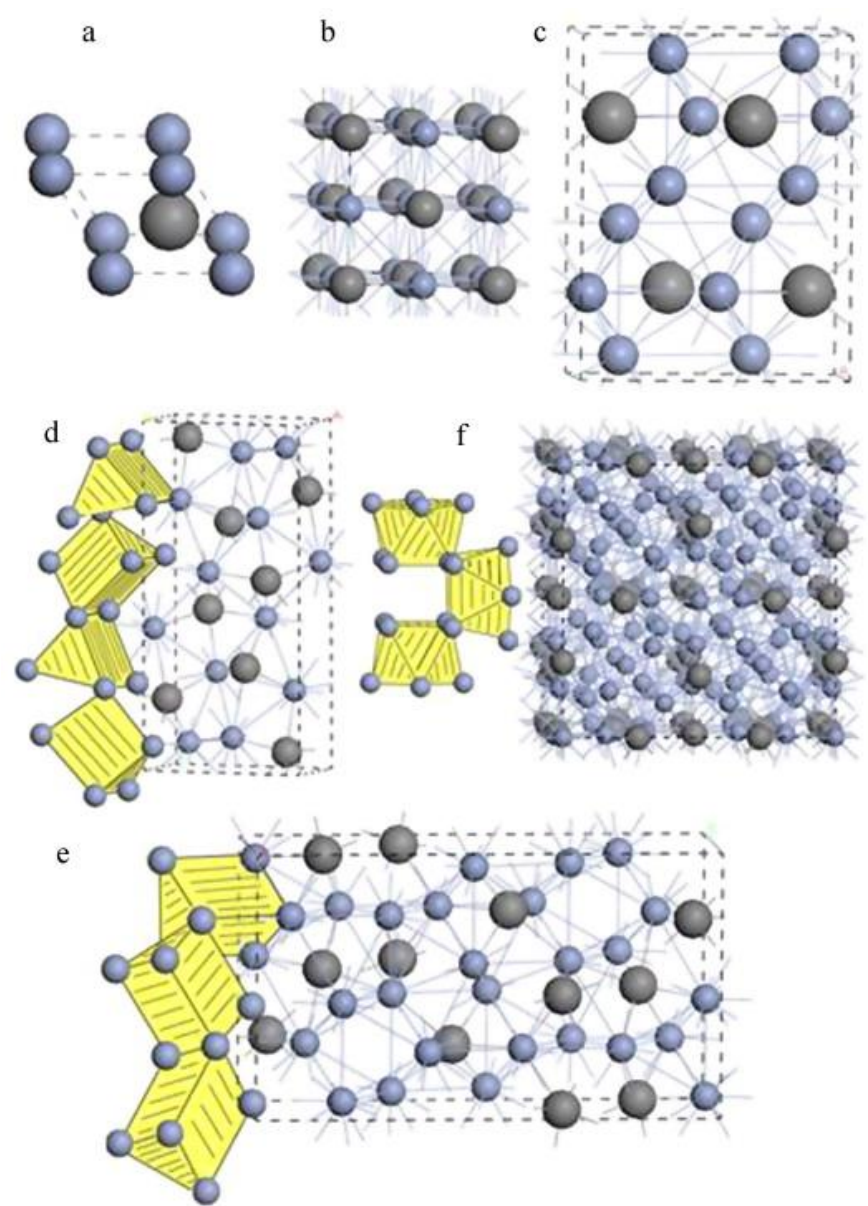

Figure 0.2 Structures of $\mathrm{Cr}_{23} \mathrm{C}_{6}, \mathrm{Cr}_{7} \mathrm{C}_{3}$ and $\mathrm{Cr}_{3} \mathrm{C}_{2} . \mathrm{CrC}$, hexagonal (h-CrC) and cubic (c-CrC) and $\mathrm{Cr}_{3} \mathrm{C}^{4}$

Carbides of the post-transition metals, particularly $\mathrm{Zn}, \mathrm{Cd}, \mathrm{Hg}$ or $\mathrm{Pb}$, are either poorly characterized, highly unstable or do not exist. ${ }^{15}$

\subsubsection{Alkali-metal Graphite Intercalation Compounds (GICs)}

Graphite can react with strong oxidizing and reducing agents to form graphite intercalation compounds (GICs). This process is usually reversible.

$$
C_{n}+M \rightarrow C_{n} M
$$

In these reactions, the guest ion $(M)$ inserts between the planes of the graphite lattice $\left(C_{n}\right)$, and the graphite layers remain intact. ${ }^{28}$ The increase in electrical conductivity of GICs indicates that the 
bonding between occurs via transfer of electrons from the metal atoms to the conduction band of the graphite host. ${ }^{15}$

The first reported and most well studied GIC system was with the alkali metal, potassium. $\mathrm{C}_{8} \mathrm{~K}$ was prepared by reaction of potassium vapor and graphite at $300^{\circ} \mathrm{C}$. GICs of rubidium and cesium may be prepared in a similar fashion. ${ }^{29}$ Intercalation has only been observed with the most electropositive elements. Theoretical calculations have shown that $\mathrm{Na}$ and $\mathrm{Mg}$ do not readily intercalate due to competition between ionization of the metal atoms and the ion-substrate coupling. ${ }^{30}$ The stoichiometry $\mathrm{MC}_{6}$ has been observed for smaller ions, $\mathrm{M}=\mathrm{Li}^{+}, \mathrm{Sr}^{2+}, \mathrm{Ba}^{2+}, \mathrm{Eu}^{2+}$, $\mathrm{Yb}^{3+}$ and $\mathrm{Ca}^{2+} .31,32$ These compounds can also be synthesized by electrolysis of molten alkalimetal salts with graphite electrodes and by reaction of graphite with nonaqueous solutions containing $\mathrm{M}^{+}$.

GICs of successively decreasing metal content can be prepared by heating at low pressures at approximately $360^{\circ} \mathrm{C}^{33}$

$$
\begin{gathered}
C_{8} M(\text { bronze }- \text { red }) \rightarrow C_{24} M(\text { steel }- \text { blue }) \rightarrow C_{36} M(\text { dark blue }) \\
\rightarrow C_{48} M(\text { black }) \rightarrow C_{60} M(\text { black })
\end{gathered}
$$




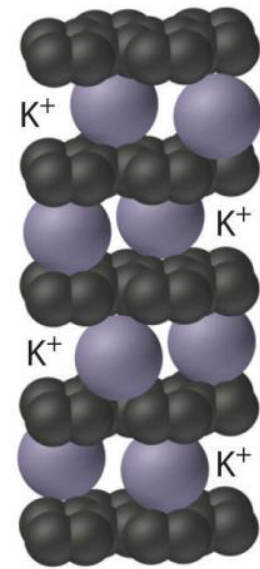

(a) $\mathrm{KC}_{8}$
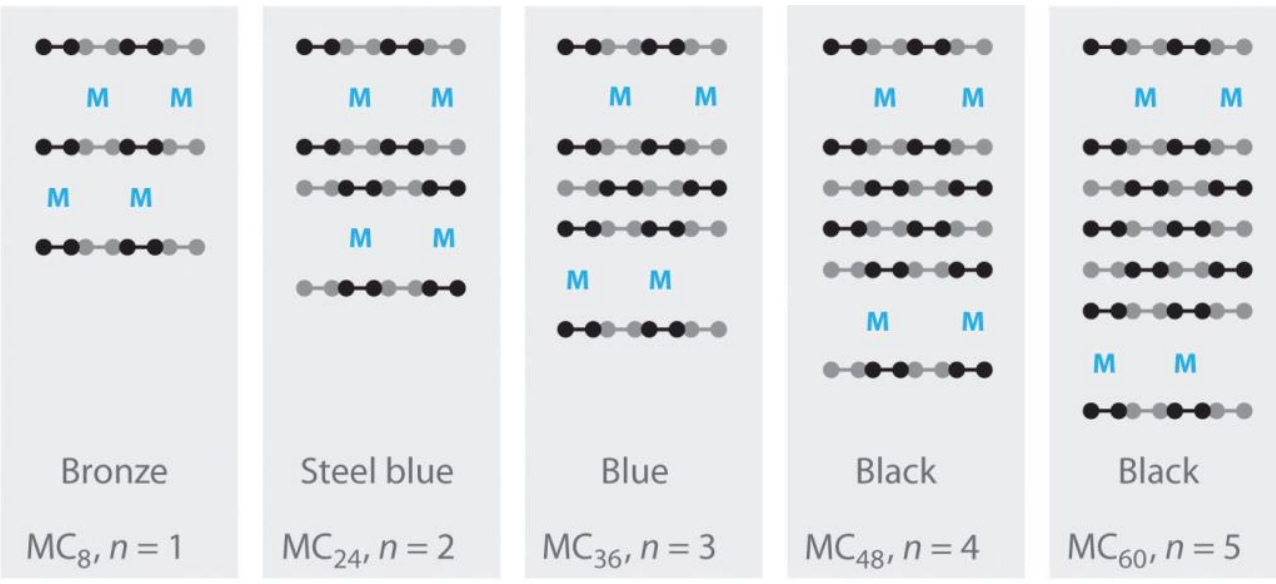

(b) Layer arrangements and stoichiometries

Figure 0.3 Structure of varying stoichiometries of potassium intercalated graphite. Source: https://catalog.flatworldknowledge.com/bookhub/4309?e=averill 1.0-ch21 s03

Alkali-metal GICs are highly reactive and can spontaneously ignite in open atmosphere. They react with water or alcohols to hydrogen, graphite and metal hydroxides.

$$
M C_{n}+\mathrm{H}_{2} \mathrm{O} \rightarrow C_{n(\text { graphite })}+\mathrm{MOH}+\mathrm{H}_{2}
$$

Due to graphite's ability to undergo successive reduction and oxidation with subsequent intercalation of metal guest ions, it has been widely used as an anode material for commercial, rechargeable lithium ion batteries..$^{34,35}$

\subsubsection{Nanophase Metal Carbides - MXenes and Met-cars}

Among the newest developments in the materials chemistry of binary metal carbides is the preparation of transition metal carbides with novel nano-phase structures and stoichiometries. Metallocarbohedrenes, often abbreviated as met-cars, were first synthesized in 1992 by vaporizing a metal with a laser in the presence of a hydrocarbon gas and detected by means of mass spectrometry (Figure 1.4). ${ }^{36,37}$ These nano-clusters have the general formula $\mathrm{M}_{8} \mathrm{C}_{12}$, and it was initially proposed that their crystal structure was similar to fullerenes, with $T_{h}$ symmetry (Figure 
1.5). However, further experimental and computational data now indicate that met-cars with $\mathrm{M}_{8} \mathrm{C}_{12}$ predomninat isomer has $T_{d}$ symmetry(Figure 1.5). ${ }^{38-40}$

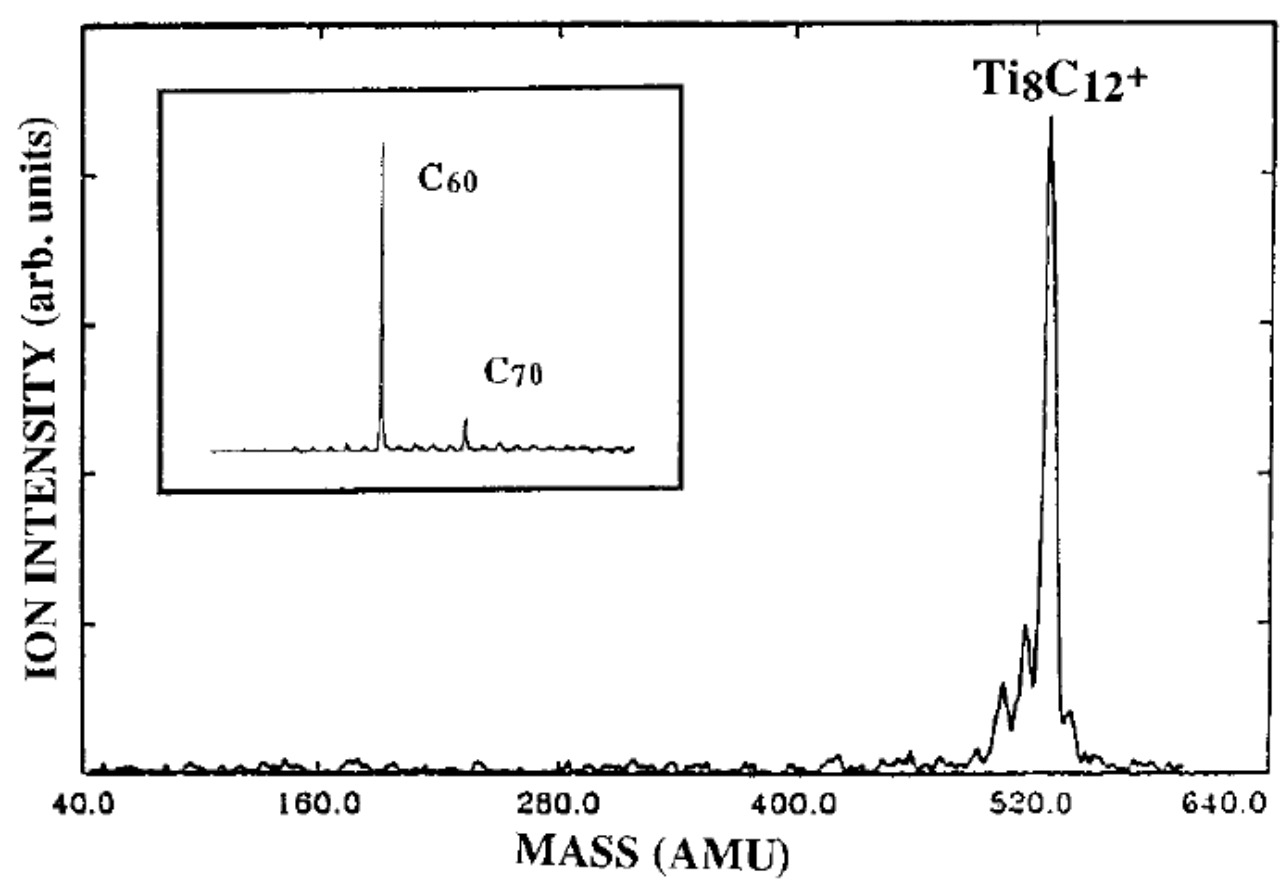

Figure 0.4 Mass spectrum of met-car $\mathbf{T i}_{\mathbf{8}} \mathbf{C}_{\mathbf{1 2}}{ }^{36,41}$

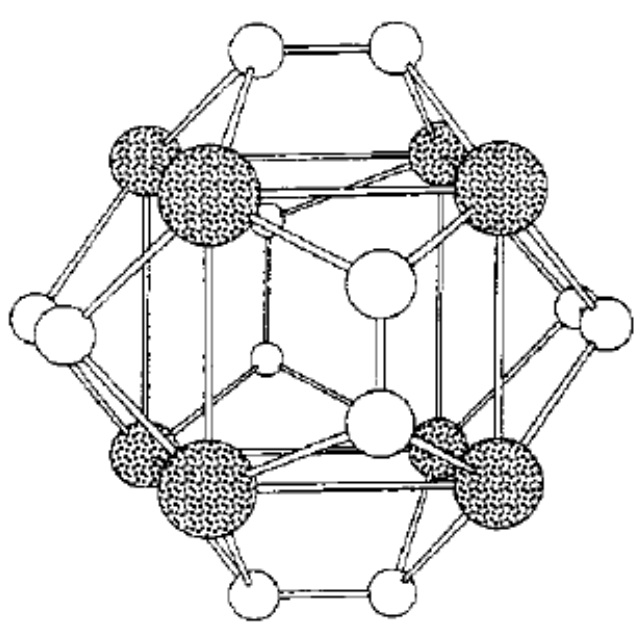

a

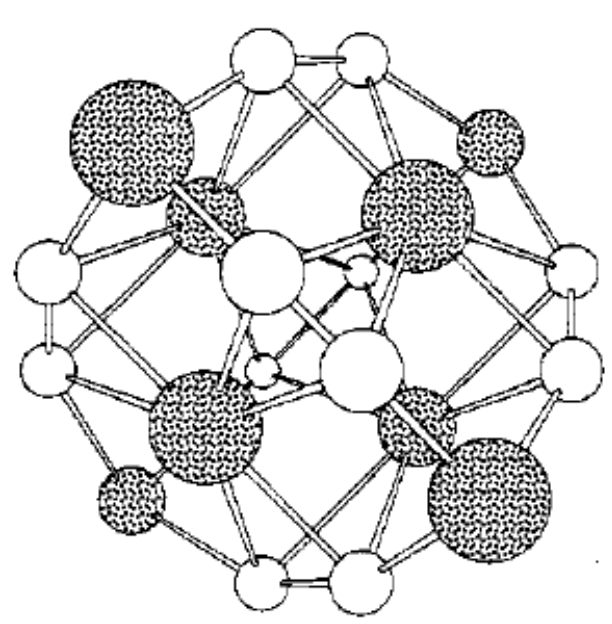

b

Figure 0.5 Pentagonal dodecahedron structure, $T_{h}$ point group. Titatanium atoms (dark spheres) appear at the edge of a cube-like arrangement and are similarly coordinate to three-carbon atoms (light spheres) at all equivalent positions ${ }^{40}$ 
Met-cars of vandadium, ${ }^{36}$ chromium and metals of Group 5 and $6^{42}$ have also been produced. Investigations into the mechanism and cluster growth of zirconium carbon clusters led to the detection and identification of met-cars with stoichiometries $\mathrm{Zr}_{13} \mathrm{C}_{22}, \mathrm{Zr}_{14} \mathrm{C}_{23}, \mathrm{Zr}_{18} \mathrm{C}_{29}$ and $\mathrm{Zr}_{22} \mathrm{C}_{35}{ }^{36}$ Although it has been suggested that met-cars have promise as catalysts ${ }^{43}$ and as highsurface area materials for hydrogen fuel storage, ${ }^{44}$ research on these carbides has declined since the early 2000s. This may be due to the difficulty in purification and large scale synthesis of metcars clusters..$^{40,45}$

The MXenes are a class of two-dimensional (2D) transition metal carbides, nitrides or carbonitrides. This brief review will only consider the MXene binary carbides, which have the general formula $M_{n+1} X_{n}$, where $M$ is the transition metal and $X$ is carbon. These compounds are synthesized by selective etching of ternary carbides, also known as MAX ${ }^{6,10-12}$ phases with general formulas of $\mathrm{M}_{\mathrm{n}+1} \mathrm{AX}$, where $\mathrm{M}=$ transition metal, $\mathrm{X}=$ carbon, and $\mathrm{A}=$ atoms which are extracted, usually an element from Group IIIA and IVA. The name "MXene" originate from the fact that the 2D morphology is similar to that of graphene. The research teams of Gogotsi and Barsoum were the first to synthesize an MXene compound, $\mathrm{Ti}_{3} \mathrm{C}_{2}$ by etching $\mathrm{Ti}_{3} \mathrm{AlC}_{2}$ with hydrofluoric acid (HF) at room temperature (Figure 1.6). ${ }^{46}$

This etching proceeds by the following reaction:

$$
T i_{3} A l C_{2}+3 H F \rightarrow A l F_{3}+\frac{3}{2} H_{2}+T i_{3} C_{2}
$$

$\mathrm{R} 1.6$ is then followed by $\mathrm{R} 1.7$ and/or $\mathrm{R} 1.8$ in which the carbide nano-sheet is end terminated with $-\mathrm{OH}$ and/or $-\mathrm{F}$ groups. 


$$
\begin{gathered}
\mathrm{Ti}_{3} \mathrm{C}_{2}+2 \mathrm{H}_{2} \mathrm{O} \rightarrow \mathrm{Ti}_{3} \mathrm{C}_{2}(\mathrm{OH})_{2}+\mathrm{H}_{2} \\
\mathrm{Ti}_{3} \mathrm{C}_{2}+2 \mathrm{HF} \rightarrow \mathrm{Ti}_{3} \mathrm{C}_{2} \mathrm{~F}_{2}+\mathrm{H}_{2}
\end{gathered}
$$

These reactions are supported by the data presented below in Figure 1.6. The bottom black spectrum in Figure 1.6 a) shows the XRD pattern of $\mathrm{Ti}_{3} \mathrm{AlC}_{2}$, the purple spectrum is the XRD pattern after HF treatment and the pink is after sonication which leads to loss of diffraction in the out-of-plane direction and, thus, peak broadening. The gold and red spectra shown in the middle are simulated XRD patterns for $\mathrm{Ti}_{3} \mathrm{C}_{2} \mathrm{~F}_{2}$ and $\mathrm{Ti}_{3} \mathrm{C}_{2}(\mathrm{OH})_{2}$ respectively, which show good agreement with the post-HF spectrum (purple curve).
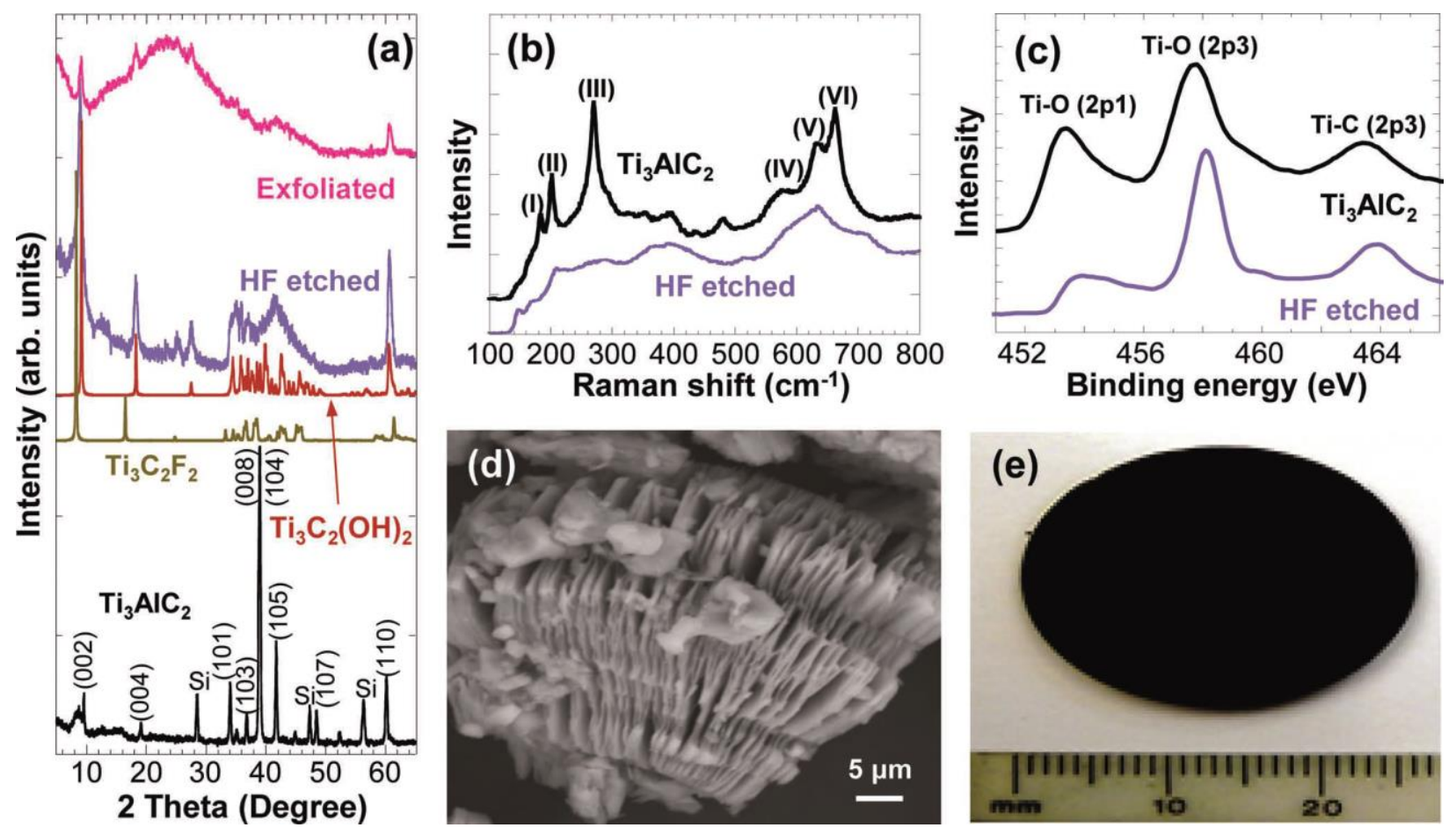

Figure 0.6 Analysis of $\mathrm{Ti}_{3} \mathrm{AlC}_{2}$ before and after exfoliation, a) XRD results before $\mathrm{HF}$ treatment, compared with simulated XRD patterns of $\mathrm{Ti}_{3} \mathrm{C}_{2} \mathrm{~F}_{2}$ and $\left.\mathrm{Ti}_{3} \mathrm{C}_{2}() \mathrm{H}\right)_{2}$ and measured XRD patterns of $\mathrm{Ti}_{3} \mathrm{AlC}_{2}$ after exfoliation, b) Raman spectra of $\mathrm{Ti}_{3} \mathrm{AlC}_{2}$ before and after $\mathrm{HF}$ treatment, c) XPS spectra and SEM d) of $\mathrm{Ti}_{3} \mathrm{AlC}_{2}$ before and after $\mathrm{HF}$ treatment, and e) a cold-pressed $25 \mathrm{~mm}$ disk of etched and exfoliated material ${ }^{46}$. 
Figure $1.6 \mathrm{~b}$ ) shows Raman spectra of $\mathrm{Ti}_{3} \mathrm{AlC}_{2}$ before and after $\mathrm{HF}$ treatment, in which the peaks I, II, and III assigned to Al-Ti vibrations vanish after etching. The XPS spectra in Figure $1.6 \mathrm{c}$ ) shows the presence of the Ti-O and Ti-C bonds in both spectra, supporting the formation of $\mathrm{Ti}_{3} \mathrm{C}_{2}(\mathrm{OH})_{2}$ in reaction $\mathrm{R}$ 1.7. The SEM image in Figure $\left.1.6 \mathrm{~d}\right)$ demonstrates the planar morphology of the $\mathrm{Ti}_{3} \mathrm{C}_{2}$ nano-sheets, and Figure 1.6 e) shows the material cold pressed into a pellet.

In addition to $\mathrm{Ti}_{3} \mathrm{C}_{2}$, other MXenes have been synthesized and characterized including $\mathrm{Ti}_{2} \mathrm{C}, \mathrm{Nb}_{2} \mathrm{C}, \mathrm{V}_{2} \mathrm{C}, \mathrm{Ta}_{4} \mathrm{C}_{3}$, and complex, ternary MXenes such as $\left(\mathrm{Ti}_{0.5}, \mathrm{Nb}_{0.5}\right)_{2} \mathrm{C},\left(\mathrm{V}_{0.5}, \mathrm{Cr}_{0.5}\right)_{3} \mathrm{C}_{2}$, $\mathrm{Ti}_{3} \mathrm{CN}^{47,48}$ Extraction of A in MAX phase carbides can also be accomplished via heating under vacuum or protective atmosphere or through halogenation. However, the heat treatment can lead to significant structural changes including the loss of layering. ${ }^{49}$ Additionally, halogenation at high temperatures removes the $\mathrm{M}$ atoms as well as the $\mathrm{A}$ atoms leaving behind porous carbon material which is referred to as carbide derived carbons (CDCs) ${ }^{50}$ The high surface area morphology in combination with good electrical conductivity and chemical and thermal stability exhibited by MXenes have spurred interest in their applications for energy storage devices such as rechargeable lithium ion batters, capacitors and pseudocapacitors. ${ }^{51}$ These exceptional properties have also shown promise for catalyst support in solid oxide fuel cells (SOFC), ${ }^{52}$ adsorption materials for hydrogen storage ${ }^{53}$ and additives to lubricants. ${ }^{54}$

\subsubsection{Ionic or Salt-like Carbides}

This family of carbides is termed "salt-like" or ionic because the bonding in these compounds is characterized as more polar or ionic, as illustrated by their reactivity with water and dilute acids to produce hydrocarbon gases and metal hydroxides. Salt-like carbides can be further 
divided into three subcategories, methanides, acetylides and sesquicarbides, based on the structure of the carbon anions.

Inclusion of graphite intercalation compounds (GICs) of the alkali metals in the classification of carbides varies in the literature. Kosolapova considers alkali-metal GICs carbide phases, ${ }^{1}$ whereas Greenwood and Earnshaw group them as a separate family of carbon compounds. ${ }^{15}$ However, alkali-metal GICs readily hydrolyze to form $\mathrm{H}_{2}$, metal hydroxides and graphite. Additionally, studies indicate that electrons are transferred from the metal to the conduction band of the graphite which accounts for the enhanced electrical conductivity of these compounds. Based on this reasoning, alkali-metal GICs have been included as a subgroup of the salt-like carbides in this work.

\subsubsection{Methanides}

The carbon anions in this class of carbides consist of individual carbon anions, which yield mainly methane, $\mathrm{CH}_{4}$, upon hydrolysis. Aluminum carbide $\left(\mathrm{Al}_{4} \mathrm{C}_{3}\right)$ and beryllium carbide $\left(\mathrm{Be}_{2} \mathrm{C}\right)$ are the best-known examples. $\mathrm{Be}_{2} \mathrm{C}$ may be synthesized directly from the elements ${ }^{55}$ or from $\mathrm{BeO}$ and carbon at $1900-2000^{\circ} \mathrm{C}$. Density functional theory (DFT) calculations indicate that the Be and $\mathrm{C}$ are significantly ionized, with a nominal ionic charges of $\mathrm{Be}^{2+}$ and $\mathrm{C}^{4-}$ on the constituent atoms. ${ }^{56}$

To the best of the author's knowledge aluminum carbide is the only methanide commercially available. Therefore, $\mathrm{Al}_{4} \mathrm{C}_{3}$ is the representative compound from this family of carbides which was studied in this work. An overview of aluminum carbide is given in the following section.

\section{2.5.2 Aluminum Carbide Structure and Properties}

Aluminum carbide is most commonly used as an abrasive material for cutting tools. However, it is also recognized as an important component in the production and synthesis of 
certain ceramics ${ }^{57}$ and aluminum metallurgy. ${ }^{58}$ Formation of aluminum carbide and alumina has been observed in situ during aluminum alloying after the addition of organic process control agents. This lowers the tendency of the metal to creep or resist strain due to mechanical stress. ${ }^{58,59}$ TEM and EDS studies of carbon fiber reinforced aluminum alloys have shown that aluminum carbide forms at the interface of the fiber and metal, nucleating heterogeneously on the fiber and growing into the alloy matrix. ${ }^{60}$ A 2004 study on diamond synthesis the Al-C system under high temperatures and high pressures reported that the reaction first forms $\mathrm{Al}_{4} \mathrm{C}_{3}$ which melts after formation and diamond crystallizes in the aluminum-carbide melt. ${ }^{61}$

$\mathrm{Al}_{4} \mathrm{C}_{3}$ is the only stable phase in the aluminum carbon system. ${ }^{1,15,62}$ It has a complex rhombohedral crystal structure in which alternating layers of $\mathrm{Al}_{2} \mathrm{C}$ and $\mathrm{Al}_{2} \mathrm{C}_{2}$ are stacked in the cdirection. ${ }^{62,63}$ The carbon atoms in the $\mathrm{Al}_{2} \mathrm{C}$ layers coordinated to 6 aluminum atoms in a distorted octahedron at a distance of $217 \mathrm{pm}$. The carbon atoms in the $\mathrm{Al}_{2} \mathrm{C}_{2}$ are coordinated to 4 aluminum atoms at a distance of $190-194 \mathrm{pm}$ and a fifth $\mathrm{Al}$ atom at $221 \mathrm{pm}$. The smallest $\mathrm{C}$ to $\mathrm{C}$ distance is $316 \mathrm{pm}$. Although the accepted formal description of the separation of charge in this compound is $\left(\mathrm{Al}^{3+}\right)_{4}\left(\mathrm{C}^{4-}\right)_{3}$ may not be a true representation of the charge distribution in this carbide over such large interatomic distances. ${ }^{15}$ 


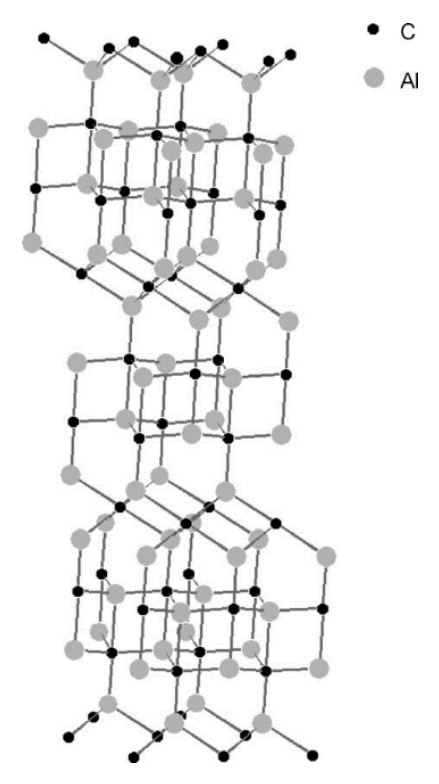

\section{Figure 0.7 Crystal structure of aluminum carbide ${ }^{62}$}

Aluminum carbide can be prepared from reaction of aluminum and carbon in an electric arc furnace at temperatures of $1200-1400^{\circ} \mathrm{C}$ :

$$
4 A l+3 C \rightarrow A l_{3} C_{3}
$$

Additionally, aluminum carbide can be prepared by the reduction of alumina by carbon at $2000^{\circ} \mathrm{C}$.

$$
2 \mathrm{Al}_{2} \mathrm{O}_{3}+9 \mathrm{C} \rightarrow \mathrm{Al}_{4} \mathrm{C}_{3}+6 \mathrm{CO}
$$

Studies of the $\mathrm{Al}_{2} \mathrm{O}_{3}-\mathrm{Al}_{4} \mathrm{C}_{3}$ system reveal that the reaction proceeds via two oxycarbide intermediates, $\mathrm{Al}_{4} \mathrm{O}_{4} \mathrm{C}$ and $\mathrm{Al}_{2} \mathrm{OC} .{ }^{64}$ In 1957 Union Carbide filed a patent for the synthesis of aluminum carbide from powdered aluminum, carbon in the form of lamp black or carbon black and a catalyst, cryolite $\left(\mathrm{Na}_{3} \mathrm{AlF}_{6}\right){ }^{65}$ The catalyst enables the reaction at much lower temperatures, i.e. $700^{\circ} \mathrm{C}$, and significantly increases the rate of reaction. The method used to produce the 
aluminum carbide in this dissertation is proprietary, but it is likely that Union Carbide's method or some variation thereof may be used.

The hydrolysis of aluminum carbide produces methane and aluminum hydroxide hence it's classification as a methanide. Note the striking difference in the hydrolysis behavior of the transition metal carbides (R 1.1 and R 1.2) and ionic carbides (R 1.11). Whereas the hydrolysis of $\mathrm{Mn}_{7} \mathrm{C}_{3}$ yields the metal hydroxide and methane and a complex mixture of other hydrocarbons, hydrolysis of aluminum carbide only produces methane as the hydrocarbon product. This contrasting hydrolysis behavior and the low electrical conductivity of aluminum carbide imply a strong ionic bonding character.

$$
\mathrm{Al}_{4} \mathrm{C}_{3}+12 \mathrm{H}_{2} \mathrm{O} \rightarrow 4 \mathrm{Al}(\mathrm{OH})_{3}+3 \mathrm{CH}_{4}
$$

The physical and chemical properties of aluminum carbide that are reported in the literature is limited compared to the breadth of research on calcium carbide. Due to aluminum carbide's historical applications in metallurgy and ceramic processes, many of the properties in the literature were measured at high temperatures. For example, the free energy of formation $(\Delta G)$ of $\mathrm{Al}_{4} \mathrm{C}_{3}$ at $1873 \mathrm{~K}$ and its resistivity $(\rho)$ at $1225 \mathrm{~K}$ are presented in Table 1.1 below. These data indicate that although aluminum carbide may be an insulator at high temperatures it is semiconducting. 


\begin{tabular}{ccc}
\hline Properties & Values & Reference(s) \\
\hline Melting point & $2100^{\circ} \mathrm{C}^{38}$ & 66 \\
Boiling point & $>2200^{\circ} \mathrm{C}^{38}$ & 66 \\
Density & $2.36 \mathrm{~g} / \mathrm{cm}^{3(38)}$ & 66 \\
$\Delta H_{f}^{0}$ & $-208 \pm 5 \mathrm{~kJ} / \mathrm{mol}$ & 67 \\
& $-150.1 \pm 12.5 \mathrm{~kJ} / \mathrm{mol}^{39}$ & 68 \\
& $-215.69 \mathrm{~kJ} / \mathrm{mol}^{69}$ & 69 \\
$\Delta G$ & & 70 \\
$\rho$ & & \\
& & \\
& & \\
& & \\
& & \\
\end{tabular}

\section{Table 0.2 Properties of aluminum carbide}

\subsubsection{Acetylides}

Carbides containing acetylide $\left(\mathrm{C}_{2}{ }^{2-}\right)$ units are the most well studied group of the salt-like carbides. They typically form with the alkali $\left(\mathrm{M}_{2} \mathrm{C}_{2}\right)$, alkaline earth metals $\left(\mathrm{MC}_{2}\right)$ and lanthanoids $\left(\mathrm{LnC}_{2}\right.$ and $\left.\mathrm{Ln}_{4}\left(\mathrm{C}_{2}\right)_{3}\right) .{ }^{25,72}$ Carbide compounds containing the noble metals of Group 11, $\mathrm{Cu}, \mathrm{Ag}$ and $\mathrm{Au}$, also form acetylides which are shock sensitive explosives. ${ }^{73}$ By far the most well-known and industrially important carbide in this family is calcium carbide, $\mathrm{CaC}_{2}$. Calcium carbide is discussed in detail in the following section.

\subsubsection{Calcium Carbide Structure and Properties}

$\mathrm{CaC}_{2}$ is the only carbide phase in the calcium-carbon system known to exist. Four crystal structures have been observed: $\mathrm{CaC}_{2}$-I has a face centered tetragonal lattice, $\mathrm{CaC}_{2}$-II has a triclinic structure, $\mathrm{CaC}_{2}$-III has a monoclinic structure and $\mathrm{CaC}_{2}$-IV has a face centered cubic structure. ${ }^{74}$ The tetragonal structure is the only phase stable at room temperature. It forms a distorted rock-salt 
structure with 6 calcium cations in the corners of the unit cell and one in the center. The acetylide units are aligned along the c-axis (Figure 1.7).

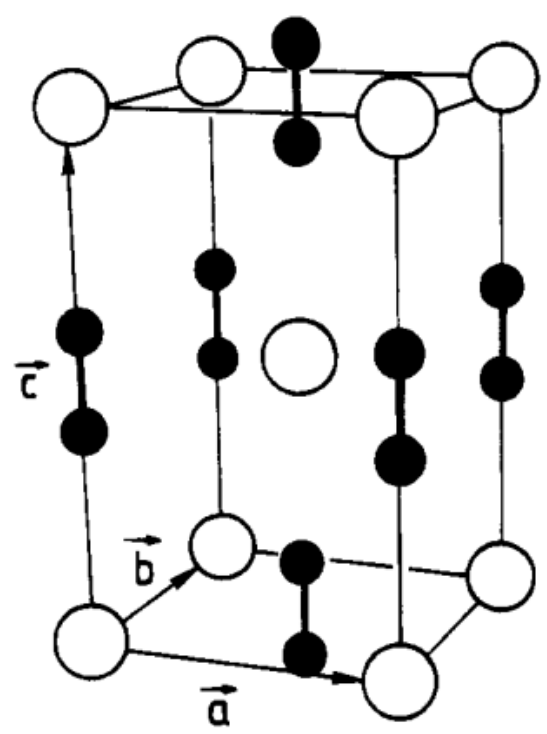

\section{Figure 0.8 Crystal structure of calcium carbide ${ }^{1}$}

The most commonly used production method is the reaction of calcium oxide in the form of lime and carbon containing materials such as anthracite, coke and wood charcoal at 2200$2250^{\circ} \mathrm{C}$.

$$
\mathrm{CaO}+3 \mathrm{C} \rightarrow \mathrm{CaC}_{2}+\mathrm{CO}
$$

Metallurgical grade coke is usually the carbon feedstock used in carbide production and is comprised of $85-88 \%$ carbon, $9-11 \%$ ash and $2 \%$ volatiles. ${ }^{75}$ The predominant use for calcium carbide is the production of acetylene, so methods for purity and grade specifications are primarily based on gas yield analyses. Phosphorous, sulfur and arsenic content are determined from analysis of phosphine, hydrogen sulfide and arsine levels in evolved acetylene during hydrolysis. ${ }^{75}$ Typical impurities in industrial calcium carbide are shown in Table 1.2. 


\section{Calcium Carbide \%}

$\begin{array}{lr}\mathrm{CaC}_{2} & 79.0 \\ \mathrm{CaO} & 13.2 \\ \mathrm{C} & 0.7 \\ \mathrm{CaS} & 0.9 \\ \mathrm{Mineral} \text { impurities } & 6.2 \\ \left(\mathrm{Al}_{2} \mathrm{O}_{3}, \mathrm{SiO}_{2}, \mathrm{MgO}, \mathrm{FeSi}\right) & \end{array}$

\section{Table 0.3 Typical certificate of analysis for industrial grade calcium carbide. ${ }^{75}$}

Calcium carbide production is accomplished on an industrial scale in an electric arc furnace. The capacity of these furnaces range from 25,000t/y to 130,000t/year depending on their power requirements. A diagram of a 40MW electric arc furnace is shown below (Figure 1.8). 


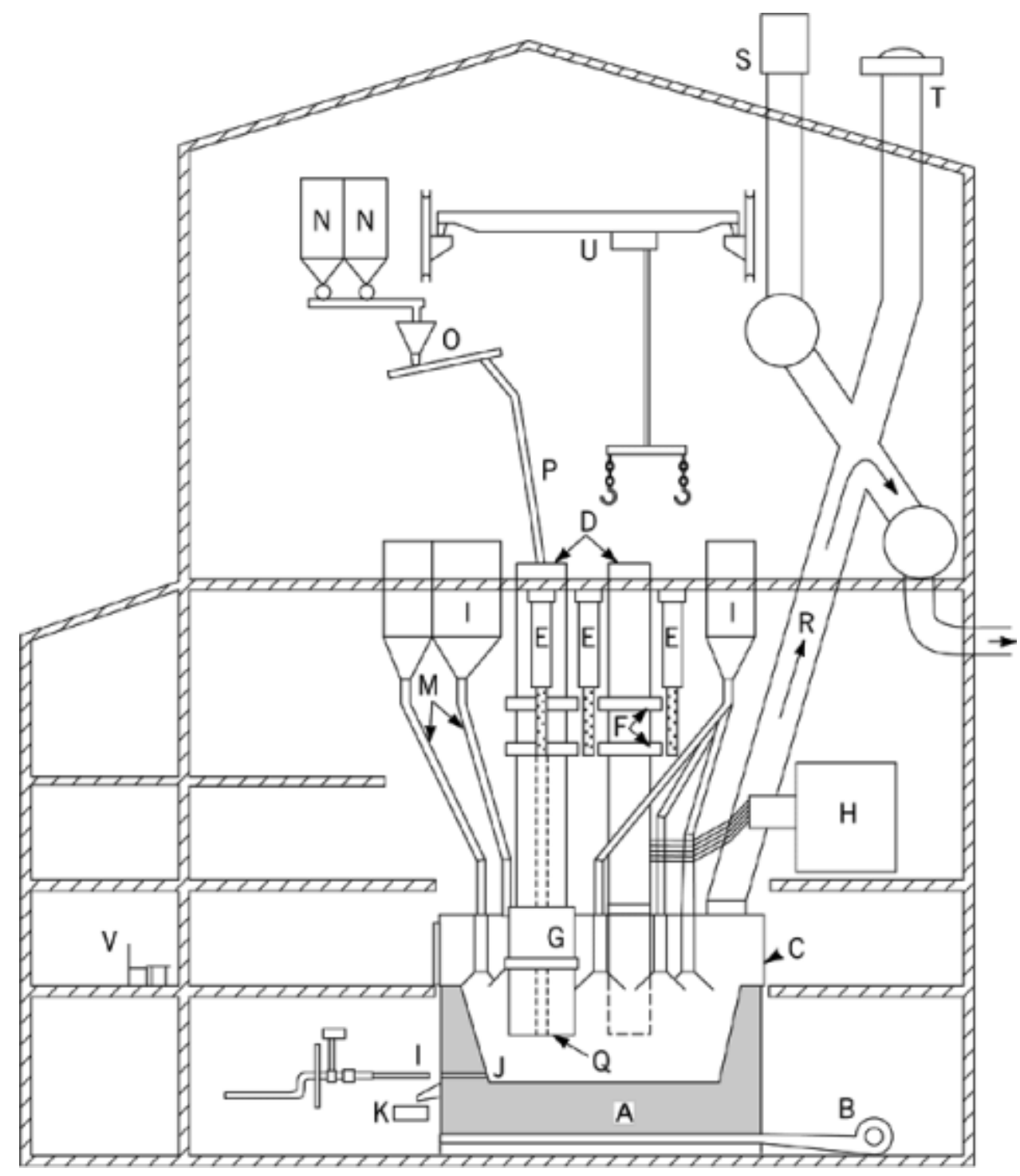

Figure 0.9 Diagram of calcium carbide furnace. The crucible (A) is made of brick walls and a carbon lined bottom, which is cooled by a fan $(B)$. A cover $(C)$ isolates the furnace. The hydraulic cylinders (E) support and move the electrodes (D) in and out of the furnace and are fitted with a slipping device $(F)$. The contact plates $(G)$ connect the the transformer $(H)$ to the electrodes. The tapping electrode (I) directs the liquid carbide from the taphole (J) to a cart for cooling $(\mathrm{K})$. Bins $(\mathrm{L})$ store raw precursors and charging chutes $(\mathrm{M})$ introduce them to the furnace. Particulate raw precursors are stored in bins $(\mathrm{N})$ and supplied through a screw conveyor $(O)$, connector $(P)$ and hollow electrode $(Q)$. Gasses escape through duct $(\mathrm{R})$. A crane $(\mathrm{U})$ charges fresh electrodes and operations are monitored from control room $(\mathrm{V}) .^{75}$

Hydrolysis of calcium carbide produces calcium hydroxide and acetylene. This hydrolysis behavior contrasts with that of lanthanum dicarbide $\left(\mathrm{LaC}_{2}\right)$ which also has structural acetylide 
units but generates a mixture of hydrocarbon gases ( $\mathrm{R}$ 1.13). The production of only acetylene implies primarily ionic bonding.

$$
\mathrm{CaC}_{2}+2 \mathrm{H}_{2} \mathrm{O} \rightarrow \mathrm{C}_{2} \mathrm{H}_{2}+\mathrm{Ca}(\mathrm{OH})_{2}
$$

R 0.13

This reaction is the basis for calcium carbide's main industrial application. Production of acetylene, which is a precursor for many commodity chemicals, accounts for $94 \%$ of calcium carbide production. $^{75}$

Other applications of calcium carbide include the desulfurization in iron and steel making (R 1.14),

$$
\mathrm{CaC}_{2}+S \rightarrow \mathrm{CaS}+2 \mathrm{C}
$$

R 0.14

and to produce calcium cyanamide, a fertilizer ( $\mathrm{R} 1.15)$.

$$
\mathrm{CaC}_{2}+\mathrm{N}_{2} \rightarrow \mathrm{CaCN}_{2}+\mathrm{C}
$$

Therefore, high purity calcium carbide is not generally commercially available because high purity is not a necessity for its primary uses. Most calcium carbide is technical grade (80-88\% purity). The calcium carbide used in this research was technical grade, and analyses of its impurities are reported in Appendix A.

Properties of calcium carbide are in Table 1.3 below. Information on its electrical conducting properties is conflicting. Some sources describe $\mathrm{CaC}_{2}$ as an electrical insulator, ${ }^{13,15,75}$ which is consistent with its characterization as a salt-like carbide with mostly ionic bonding character. However, measurements have indicated that calcium carbide is seminconducting even at low temperatures, e.g. $24 \Omega \cdot \mathrm{cm}$ at $20^{\circ} \mathrm{C}{ }^{76}$ This attributed to the anisotropy of the acetylide units in calcium carbide. Conductivity is also dependent on the carbide's purity and thermal treatment. ${ }^{1,77}$ The outer layers of a calcium carbide ingot, which cool more rapidly, have higher resistivity than the inner layers, which cool slowly. Annealing calcium carbide at temperatures above $500^{\circ} \mathrm{C}$ irreversibly decreases the resistivity. ${ }^{76}$ 


\begin{tabular}{ccc}
\hline Properties & Values & Reference(s) \\
\hline Melting point & $2300^{\circ} \mathrm{C}$ & 66 \\
Boiling point & $\mathrm{NA}$ & \\
Density & $2.22 \mathrm{~g} / \mathrm{cm}^{3}$ & $1,66,75$ \\
$\Delta H_{f}^{0}$ & $-59.8 \mathrm{~kJ} / \mathrm{mol}^{38}$ & 68,75 \\
& $-58.9 \pm 8.4 \mathrm{~kJ} / \mathrm{mol}$ & 66 \\
$\Delta S_{f}^{0}$ & $70.0 \mathrm{~J} / \mathrm{mol} \mathrm{K}^{38}$ & 66 \\
$\Delta G_{f}^{0}$ & $-64.9 \mathrm{~kJ} / \mathrm{mol}^{38}$ & 66 \\
$\mathrm{C}_{\mathrm{p}}$ & $62.7 \mathrm{~J} / \mathrm{mol} \mathrm{K}^{38}$ & 66 \\
$\rho\left(20^{\circ} \mathrm{C}\right)$ & $24.0 \mathrm{ohm}-\mathrm{cm}^{2}$ & 76 \\
\hline
\end{tabular}

\section{Table 0.4 Properties of calcium carbide}

\subsubsection{Sesquicarbides}

The sequicarbides, which contain the linear $\mathrm{C}_{3}{ }^{4-}$ unit, have been suggested as a synthetic route to the theorized one dimensional carbon allotrope, carbyne, which is expected to have superior electronic and mechanical properties. ${ }^{78}$ In spite of this hypothesized application for sesquicarbides, their own interesting properties and possible applications, the literature regarding these compounds is sparse relative to the other classes of metal carbides.

Only a few of these compounds have been identified and characterized. None are commercially available due to their high reactivity, thermal instability and difficulty in synthesis. The first to be discovered, magnesium sesquicarbide, $\mathrm{Mg}_{2} \mathrm{C}_{3}$, was synthesized and identified in $1910,{ }^{79}$ but direct characterization of its structure (Figure 1.9) by powder X-ray and neutron diffraction was not accomplished until $1999 .{ }^{80} \mathrm{Li}_{4} \mathrm{C}_{3}$ was synthesized by the reaction of carbon vapor and lithium at $800-850^{\circ} \mathrm{C}$ and characterized by indirect analysis of the carbide's hydrolysis products via mass spectrometry, ${ }^{81}$ and directly via nuclear magnetic resonance (NMR). ${ }^{82}$ 


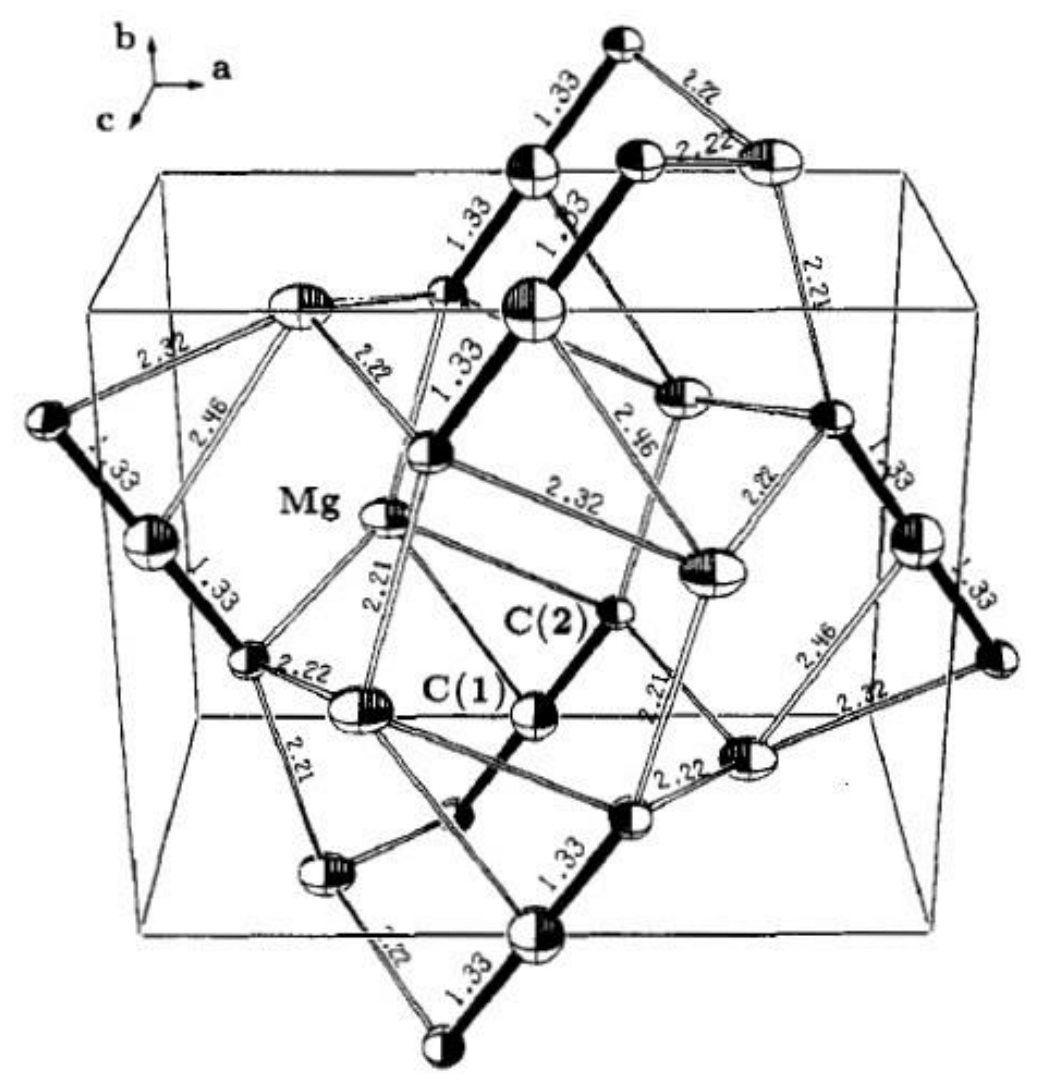

Figure 0.10 Crystal Structure of magnesium sesquicarbide. ${ }^{80}$

Scandium carbide $\left(\mathrm{Sc}_{3} \mathrm{C}_{4}\right)$ and the ternary compound calcium chloride carbide, $\mathrm{Ca}_{3} \mathrm{Cl}_{2} \mathrm{C}_{3}$, are the most recently studied sesquicarbides. $\mathrm{Sc}_{3} \mathrm{C}_{4}$ is produced from reaction of scandium and graphite under inert atmosphere at $900^{\circ} \mathrm{C}^{83}$ and $\mathrm{Ca}_{3} \mathrm{Cl}_{2} \mathrm{C}_{3}$ is produced from the reaction of $\mathrm{CaCl}_{2}$ and graphite at the same temperature. Huckel calculations and fragment molecular orbital analysis (FMO) indicated the interaction between $\mathrm{Ca}$ and $\mathrm{Cl}$ in the ternary carbide was mostly ionic and the energy levels of the $\mathrm{C}_{3}$ units relatively unchanged, suggesting that this carbide is insulating. The same analyses show that $\mathrm{Sc}_{3} \mathrm{C}_{4}$ have partially filled $\mathrm{Sc}$ " $d$ " orbitals and $\mathrm{C}_{2}$ bands indicating that the compound is a metallic conductor Pauli paramagnetism. ${ }^{84}$

\subsection{Methods of Carbide Production}

There are many techniques for preparing metal carbides and there is considerable overlap with each other. Historically, high temperature processes were first used to obtain carbides. High 
temperatures (1500-2300K) are necessary to overcome diffusion limitations in the solid-state. Recently, methods with lower working temperatures have been developed with the aim of obtaining nanostructured carbide materials. However, prolonged high temperature treatment promotes aggregation of particles into bulk product, impedes the synthesis of metastable products, and can compromise electrical and magnetic properties. Recent interest in nanostructure carbons has dramatically increased. Due to the great number of techniques only a few examples will be highlighted. Nano-structured carbides are not directly aligned with our work, but a brief review is given of their synthesis methods because this is the "hot" topic currently in carbide research.

\subsubsection{Carbothermal Reduction of Metal Oxides}

Carbothermal reduction consists of the reduction of a metal oxide by a carbon precursor to produce the metal carbide. This is the primary chemistry for the preparation of non-oxide ceramics including carbides, nitrides and borides. The carbon source can take on a variety of forms such as petroleum coke, graphite, carbon black, pyrolyzed organics, e.g. polymers, cellulose etc. These reactions are usually carried out under atmospheric pressure but at extremely high temperatures, i.e. $>1500^{\circ} \mathrm{C}$. The crude products are composed of the desired carbide material and residual traces of the unreacted raw starting materials. Carbon monoxide $(\mathrm{CO})$ is also generated as a byproduct. These reactions require extremely high temperatures to be thermodynamically favorable. Table 1.3.1.1 from Weimer's text ${ }^{85}$ show the minimum temperatures required for the synthesis of various carbides via reduction of their oxides. 


\begin{tabular}{cll}
\hline Reaction & $\mathrm{T}$ at $\Delta \mathrm{G}=0(\mathrm{~K})$ & $\begin{array}{l}\Delta \mathrm{H} \text { at } \Delta \mathrm{G}=0 \\
(\mathrm{~kJ} / \mathrm{kg})\end{array}$ \\
\hline $2 \mathrm{Al}_{2} \mathrm{O}_{3}+9 \mathrm{C} \rightarrow \mathrm{Al}_{4} \mathrm{C}_{3}+6 \mathrm{CO}$ & 2239 & +16478 \\
$2 \mathrm{~B}_{2} \mathrm{O}_{3}+7 \mathrm{C} \rightarrow \mathrm{B}_{4} \mathrm{C}+6 \mathrm{CO}$ & 1834 & +29901 \\
$3 \mathrm{Cr}_{2} \mathrm{O}_{3}+13 \mathrm{C} \rightarrow 2 \mathrm{Cr}_{3} \mathrm{C}_{2}+9 \mathrm{CO}$ & 1383 & +5966 \\
$2 \mathrm{MoO}_{3}+7 \mathrm{C} \rightarrow \mathrm{Mo}_{2} \mathrm{C}+6 \mathrm{CO}$ & 742 & +3265 \\
$\mathrm{SiO}_{2}+3 \mathrm{C} \rightarrow \mathrm{SiC}+2 \mathrm{CO}$ & 1788 & +14688 \\
$\mathrm{WO}_{3}+4 \mathrm{C} \rightarrow \mathrm{WC}+3 \mathrm{CO}$ & 950 & +2338 \\
\hline
\end{tabular}

Table 0.5 Reaction temperature of various carbides from their metal oxides. ${ }^{85}$

This carbothermal reduction of metal oxides to produce carbides is usually accomplished on an industrial scale in an electric arc furnace. The process of producing calcium carbide from lime and coke in an electric arc furnace is reviewed in Section 1.2.5.3. Silicon carbide, however, is produced from silica $\left(\mathrm{SiO}_{2}\right)$ and graphite in an Acheson furnace (Figure 1.11). This furnace configuration consists of heating by direct resistance in which two electrodes connect to a graphite core within a mixture of carbon and $\mathrm{SiO}_{2}$. Current passing through the graphite core causes resistive heating of reactants. Figure 1.12 shows the form of the products in the Acheson process. The production of $\mathrm{CO}$ acts as a transport mechanism for crystal growth. The escaping gas lead to a hollow cylinder the center of which is the graphite core. The layer surrounding the core is $\mathrm{SiC}$ product, which varies in purity and crystal quality with distance from the core. The outer reaction zone consists of metal oxides and unreacted material. The Acheson furnace can reach temperatures of $1700-2500 \mathrm{~K}$ allowing for the formation of $\alpha-\mathrm{SiC} .{ }^{85}$ 


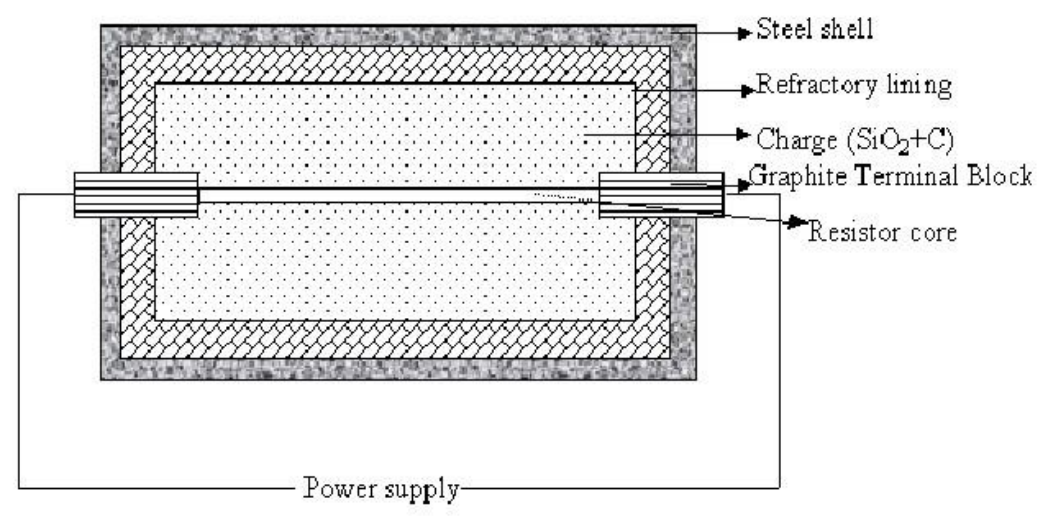

Figure 0.11 Schematic of Acheson furnace for $\mathrm{SiC}$ production. Image source: http://materials.iisc.ernet.in/ govind/silicon_carbide_manufacture.htm

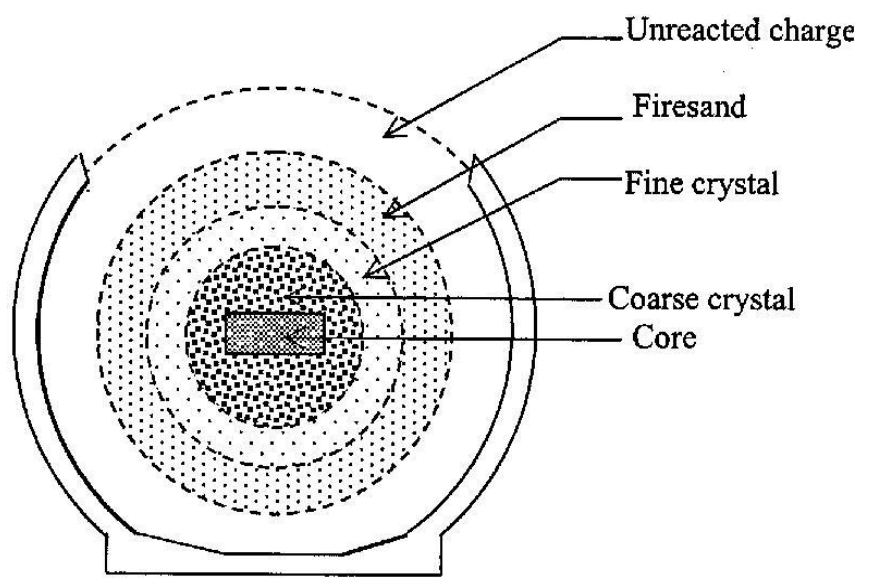

Figure 0.12 Cross-sectional view of $\mathrm{SiC}$ melt in Acheson furnace. Image source: http://materials.iisc.ernet.in/ govind/silicon_carbide_manufacture.htm

Other reactor and furnace configurations used in carbide production include tube/pusher/moving bed furnaces, rotary tube reactors and fluidized bed reactors.

\subsubsection{Synthesis from the elements}

Synthesis of carbides from their constituent elements can be carried out in an electric arc furnace, in the presence of a protective gas, ${ }^{22}$ under vacuum or in a liquid metal bath, which is often referred to in metallurgical literature as, menstruum. ${ }^{86}$ Tunsten carbide (WC), for example, 
is most commonly prepared from fine tungsten metal powder and carbon heated under a hydrogen atmosphere.

$$
W+C \stackrel{1400-1600^{\circ} \mathrm{C}}{\longrightarrow} W C
$$

\subsubsection{Carburization by combustion}

Carburization by combustion synthesis takes advantage of highly exothermic reactions of ceramic, intermetallic and composite materials. Once the reaction has been initiated a substantial amount of energy is released resulting in self-propagation of the reaction. Thus, these processes are also termed self-propagating high-temperature synthesis (SHS). ${ }^{87}$ The Ti-C system is considered a model for SHS processes. ${ }^{88}$

$$
\mathrm{Ti}+\mathrm{C} \stackrel{1700-2200^{\circ} \mathrm{C}}{\longrightarrow} \mathrm{TiC}
$$

This process involves a solid mixture of metal and carbon powders, which is pelletized to increase contact between reactants. The pellet is placed in a container composed of a refractory material. The reactants are degassed and ignited under vacuum or inert atmosphere via electrical, chemical or localized heating methods. ${ }^{85}$ Figure 1.13 below shows an example of the solid-solid phase combustion synthesis of Ti and C. 

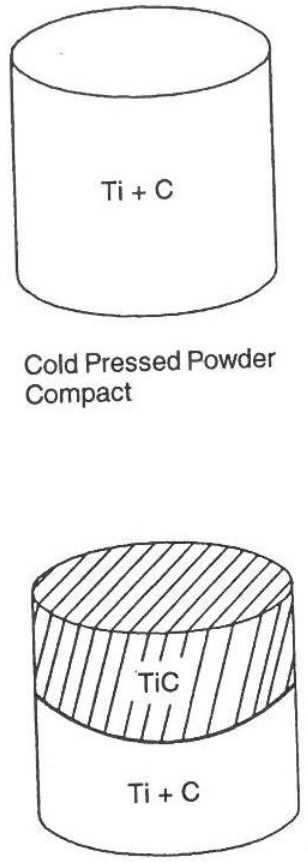

Combustion Reaction Passes Through Sample
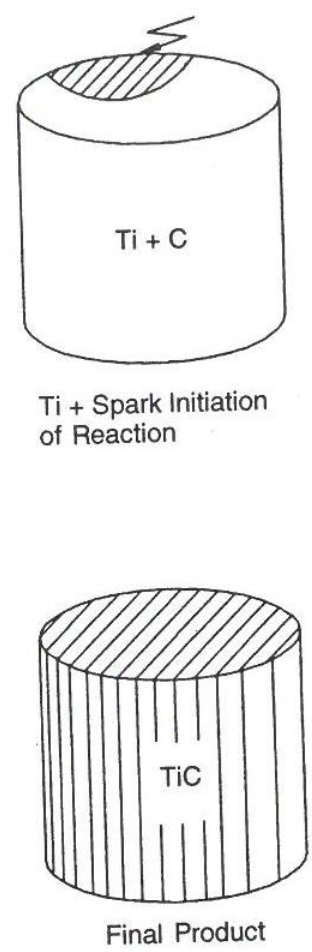

Figure 0.13 Schematic of solid-solid combustion synthesis using Ti-C as a model. ${ }^{85}$

$\mathrm{SiC}, \mathrm{WC}, \mathrm{W}_{2} \mathrm{C}, \mathrm{Mo}_{2} \mathrm{C}, \mathrm{TaC}, \mathrm{NbC}$, and $\mathrm{ZrC}^{89}$ can also be prepared via SHS processes as well as carbide composites and solid solutions, e.g. TiC- $\mathrm{Al}_{2} \mathrm{O}_{3}, \mathrm{SiC}-\mathrm{Al}_{2} \mathrm{O}_{3}$.

\subsubsection{Gas Phase Synthesis Processes}

Gas phase synthesis produce films and fine carbide powders of high purity. These processes are also high yield and fast using thermal aerosol, ${ }^{90}$ laser ${ }^{91}$ or plasma reactor types. ${ }^{92}$ In general gaseous reactants are fed into a heated reactor. Solid products are collected via filtration, electrostatic precipitation or cyclones. The morphology, yield and crystallinity of the carbides are highly dependent on reaction temperature and residence time.

Reactants for this synthesis route are gaseous metal hydrides, such as silane $\left(\mathrm{SiH}_{4}\right)$ for the production of $\mathrm{SiC}$, or gaseous metal halides. Hydrocarbon gases serve as the source of carbon. 


\subsection{Molten Salt Technology}

Molten salts used as chemical reaction media in a wide range of applications are referred to as salt melts, fused salts and salt fluxes. Their excellent properties offer potential for many uses. Molten salt media are used industrial for preparing carbide, nitride, boride and oxide surface coatings for tools. Several texts cover their chemistry and applications. ${ }^{93-95}$ Other applications of molten salt technology include processing of chemical and nuclear waste, ${ }^{96}$ metallurgical extraction and processing (new processes for electro-winning and electrolysis of aluminum from Molten Salts Chemistry and Tech), preparation of ceramics composites and generation of power. Electrochemical energy storage which was realized in the Andasol solar power station which utilizes tanks of a liquid mixture of $60 \%$ sodium nitrate and $40 \%$ potassium nitrate for thermal energy storage which allows the continued generation of electricity when there is no sunlight. ${ }^{97}$

Molten salts have a wide thermal stability range, low vapor pressures, the ability to dissolve solid compounds such as oxides, carbides and nitrides, which are insoluble in low temperature. As such salt melts are useful in solvents for solid state synthesis. ${ }^{94,98-101}$ In addition, their wide electrochemical window allows the electro-winning of electropositive metals or the synthesis of highly electronegative elements. The following sections will discuss on molten salts for reaction media for solid-state synthesis with a focus on previous work that has been done with carbide materials to put our molten salt syntheses into proper context.

\subsubsection{Salt Melt Synthesis (SMS)}

It is necessary to briefly review the field of molten salt synthesis so that we may put our carbide molten salt exploratory experiments in the proper context. Molten salt synthesis is referred to in the literature as salt melt synthesis (SMS), salt flux synthesis, fused salt synthesis or high temperature solutions ${ }^{98,100,101}$. Note that here we differentiate molten salt from ionic 
liquids (ILs) as reaction media comprised of simple inorganic compounds (i.e. halide salts, metal oxides, metal hydroxides etc.) which melt at temperatures in excess of $100^{\circ} \mathrm{C}$. By contrast, ILs are defined most often in the literature as salts which melt at or below $100^{\circ} \mathrm{C}$ and are composed of a charged organic cation and a weakly coordinating inorganic anion. ${ }^{102,103}$ Henceforth, we will use Liu et al. 's terminology for molten salt reactions: salt melt synthesis (SMS).

Considered by some researchers to be of limited application, this area has received less attention that it deserves, especially in the wake of research in ILs. With the rise of ILs study of molten salts was thrust into relative obscurity, but they are once again gaining attention.

\subsubsection{Studies of Salt-like Carbides in High Salt Melts}

Interest in the chemistry of $\mathrm{CaC}_{2}$ in melts was driven by carbide applications in metallurgical processes such as the use of carbide slags for desulphurization and dephosphorization. Even so there are relatively few reports investigating calcium carbide in melts and molten salt systems. Calcium carbide forms eutectics with $\mathrm{CaO}$ and $\mathrm{CaCN}_{2}$. Barber and Sloan ${ }^{104}$ investigated the solubility of $\mathrm{CaC}_{2}$ in alkali and alkaline earth salt melts. Carbide composition of cooled solid mixture was determined by precipitation of the carbide as copper acetylide, and copper concentration was determined colormetrically. The results of their study are displayed in Table 1.6 below. Incidental to this work, it was noted that the salts $\mathrm{ZnCl}_{2}, \mathrm{PbCl}_{2}$ and $\mathrm{CdCl}_{2}$ were investigated, but the carbide was reduced by the metals in these salt melts. ${ }^{105}$

\begin{tabular}{lll}
\hline Solvent & Temperature $(\mathrm{K})$ & Mole\% calcium carbide \\
\hline $\mathrm{LiF}$ & 1273 & 45.0 \\
$\mathrm{LiCl}$ & 1093 & 10.0 \\
$\mathrm{LiBr}$ & 1093 & 8.0 \\
$\mathrm{CaF}_{2}$ & 1673 & 20.0 \\
$\mathrm{CaCl}_{2}$ & 1093 & 10.4 \\
$\mathrm{BaCl}_{2}$ & 1273 & 4.3 \\
\hline
\end{tabular}

Table 0.6 Solubility of calcium carbide in different salt melts ${ }^{106}$ 


\subsubsection{Electrochemical Studies of Calcium Carbide}

Bonomi and colleagues ${ }^{107}$ studied galvanic cells comprised of calcium carbide and lithium nitride solutions in molten salts in order to demonstrate the feasibility of free energy and activity measurements of these materials in the molten state. In the case of the calcium carbide, the cell was heated under argon from temperatures between $873-973^{\circ} \mathrm{C}$. The electrolyte was a eutectic mixture of $\mathrm{LiCl}$ and $\mathrm{CaCl}_{2}$. An iron crucible was used as the anode and the $\mathrm{Li}-\mathrm{Ca}$ alloy electrode was made by cathodic deposition onto an iron microelectrode. The authors claimed different behavior from technical grade calcium carbide compared with pure calcium carbide. The pure $\mathrm{CaC}_{2}$ showed two anodic waves due the oxidation of calcium and the oxidation of the carbon anion. The technical grade carbide showed only one anodic wave attributed to the oxidation of the carbon anion alone. This difference was explained by the authors' belief that the pure $\mathrm{CaC}_{2}$ has a higher calcium content than technical grade $\mathrm{CaC}_{2}$. The dependence of the emf values of the carbide cell on the logarithm of the ratio of the concentration of calcium carbide to the saturation of the cell is shown. In addition, the authors calculate a standard potential value for $\mathrm{CaC}_{2}\left(E^{0}=\sim 0.425 \mathrm{~V}\right)$ from free energy of formation values found in the literature. No additional detail is provided on how this value was determined.

The 1974 publication by White and Morris ${ }^{108}$ presents a review of electrochemical studies performed in molten halide salts. The solubility of calcium carbide in multiple halide salts is tabulated, and the authors note that, excluding magnesium carbide, the alkaline-earth carbides are typically soluble in molten halide salts of their parent alkaline-earth metal. Thus, most of the studies focus on $\mathrm{CaC}_{2}-\mathrm{CaCl}_{2}$ systems. Graphite electrodes were developed which could respond to the activity of carbon in solids or melts. The behavior in these molten systems is complex and different from that of solution chemistry. The authors believe that the transfer of the alkali metal from the anode to the cathode is accomplished through a non-faradaic process which was 
hypothesized by Hesson, Foster and Shimotake ${ }^{108}$. This process was called self-discharge and is attributed to the equilibrium of dissolved alkali metal, electrons and alkali metal ions. The resulting current due to self-discharge is equal to the current density of the flux of the alkali metal as well as the electrons. The potential measurements included in this review list a measured value for $\mathrm{E}^{\mathrm{o}} \mathrm{CaC} 2$ at $815^{\circ} \mathrm{C}$ as $350 \pm 40 \mathrm{mV}$. It also contains an anodic linear scan voltammogram, termed by the authors $\mathrm{iV}$ curve, of a $810^{\circ} \mathrm{C} \mathrm{CaC}_{2}-\mathrm{CaCl}_{2}$ melt at a graphite electrode. The half wave potential of this LSV was determined to be $0.100 \mathrm{~V}$ with respect to the unpolarized graphite electrode.

\subsubsection{Salt Melt Synthesis of Metal Carbides}

Use of salt melts for solid-state synthesis is enjoying renewed attention, this includes the use of salt melts for the preparation of carbide phases. Leonard and coworkers ${ }^{109}$ recently synthesized the chromium carbide phases $\mathrm{CrC}, \mathrm{Cr}_{2} \mathrm{C}, \mathrm{Cr}_{23} \mathrm{C}_{6}, \mathrm{Cr}_{3} \mathrm{C}_{2}$ and $\mathrm{Cr}_{7} \mathrm{C}_{3}$ via salt melt syntheses, termed salt flux synthesis in their publication. The chromium carbides were prepared from chromium metal powder and multi-walled carbon nanotubes (MWCNTs) in eutectic molten salt mixtures. The eutectic mixture used for preparing $\mathrm{Cr}_{3} \mathrm{C}_{2}$ was $67 \mathrm{wt} \%$ lithium chloride and 33 wt $\%$ lithium fluoride. The eutectic for preparing the other carbides was $58 \mathrm{wt} \%$ lithium chloride, $40 \mathrm{wt} \%$ potassium chloride and $2 \mathrm{wt} \%$ potassium fluoride. The use of low temperature eutectic salt fluxes enabled the synthesis of the rarely observed, meta-stable phases $\mathrm{Cr}_{2} \mathrm{C}$ and $\mathrm{CrC}$.

\subsection{Electrochemical Studies of Carbides}

Most electrochemical studies of metal carbides are corrosion studies of alloys, coatings and composites of which the metal carbide is one of several phases. For context we will review the electrochemical studies pertaining to the carbide phases studied in this work: $\mathrm{SiC}, \mathrm{WC}, \mathrm{Cr}_{3} \mathrm{C}_{2}$ and $\mathrm{Cr}_{23} \mathrm{C}_{6}$.

Xiang, Sujuan and $\operatorname{Han}^{110}$ developed a stripping method for the determination of $\mathrm{M}_{6} \mathrm{C}$, $\mathrm{M}_{23} \mathrm{C}_{6}$ and $\mathrm{MC}$ of metals $\mathrm{Fe}, \mathrm{Cr}, \mathrm{W}, \mathrm{V}$ and $\mathrm{Co}$ in high-speed steels as an alternative to 
determination by X-ray diffraction. A conventional three electrode set-up was used in conjunction with a potentiostat. The reference electrode was a saturated calomel electrode and a cylindrical sample of high-speed steel served as the working electrode. Stripping voltammetry results in $10 \%$ $\mathrm{NaOH}+2 \%$ tartaric acid at $0.83 \mathrm{mV} / \mathrm{s}$ showed that samples containing $\mathrm{M}_{6} \mathrm{C}$ had a peak potential at $-200 \mathrm{mV}$, samples containing $\mathrm{M}_{23} \mathrm{C}_{6}$ had an anodic peak potential at $200 \mathrm{mV}$ and samples containing $\mathrm{MC}, \mathrm{M}_{23} \mathrm{C}_{6}$ and $\mathrm{M}_{7} \mathrm{C}_{3}$ had an anodic peak potential at $400 \mathrm{mV}$. They determined that M6C was etched while $\mathrm{MC}$ remained insoluble. Differential etching of $\mathrm{M}_{6} \mathrm{C}+\mathrm{M}_{3} \mathrm{C}$ and $\mathrm{MC}$ was achieved in a $1 \% \mathrm{H}_{2} \mathrm{Cr}_{2} \mathrm{O}_{7}$ electrolyte, anodic peak current for the oxidation and dissolution of $\mathrm{MC}$ was observed at $1400 \mathrm{mV}$ (v. SCE). The presence of $\mathrm{M}_{7} \mathrm{C}_{3}$ and $\mathrm{M}_{23} \mathrm{C}_{6}$ does not interfere with the analysis of MC.

Chromizing is a metallurgical technique used to create coatings of metals that offer high temperature surface protection and resistance to corrosion and wear. Tsai et al. ${ }^{111}$ have characterized the dual phase Fe-24\%Mn-8.3\% Al-5\%Cr-0.38\%Si-0.34\%Mo-0.45\%C alloy coating. The coating was prepared by pack cementation at $100^{\circ} \mathrm{C}$ for $1-16$ hours. The surface morphology of the coating was characterized by SEM. These SEM studies revealed aluminum and manganese oxide particles that, although rare, were believed to negatively impact corrosion resistance. XRD analysis identified the dominant phases in layers of the coating. The surface to 5 microns beneath the surface had $\mathrm{Cr}_{23} \mathrm{C}_{6}$ and the $(\mathrm{Cr}, \mathrm{Fe})_{2} \mathrm{~N}_{1-\mathrm{x}}$ alloy as the primary phase followed by an intermediate layer of $\mathrm{Cr}_{7} \mathrm{C}_{3}$. Samples coated with the alloy had greater corrosion resistance than uncoated samples and a high surface hardness of 2015 to 2485 HK. This improvement in chemical and mechanical properties is attributed to the presence of the chromium carbide surface layers. 
WC has drawn recent attention for its promising application as an electrocatalyst in fuel cells and photoelectrochemical cells. Chen et al. ${ }^{112}$ presented a comprehensive study on the electrochemical stability of WC and $\mathrm{W}$ for comparison over a wide $\mathrm{pH}$ and potential range. They utilized cyclic and linear voltammetry (CV and LSV), chronoamperometric and chronopotentiometric titration techniques and XRD, SEM and XPS to investigate the oxide species formed on the WC surface under different conditions. Electrochemical measurements were performed in a 3-electrode cell. Pt mesh was the counter electrode, saturated calomel electrode (SCE) was the reference electrode and W or WC served as the working electrodes. Chronoamperometric titrations indicated that the oxidation behavior of $\mathrm{W}$ and $\mathrm{WC}$ at different $\mathrm{pH}$ values are similar. However, WC has a larger passivation region than $\mathrm{W}$ that extends to higher $\mathrm{pH}$ values and more positive potentials. Ex-situ characterization with XPS confirmed that the oxide formed on the surface were stable in acidic solution but dissolved in basic conditions.

Roman-Leshkov et al. ${ }^{113}$ have investigated the effect of alloying tungsten carbide (WC) and tantalum with the aim of increasing the electrochemical stability of WC while maintaining its catalytic properties. The bimetallic carbide nanoparticles, $\mathrm{Ta}_{\mathrm{x}} \mathrm{W}_{1-\mathrm{x}} \mathrm{C}$, were synthesized via a reverse microemulsion technique which allows for the synthesis of nonsintered metal-terminated carbide particles and enables tailoring of size and phase. Linear scan voltammetric (LSV) analyses show that the incorporation of Ta into WC increases the nanoparticles' resistance to oxidation while preserving WC's catalytic activity for the HER. Measurements with X-ray absorption nearedge structure (XANES), X-ray photoelectron spectroscopy (XPS) and extended X-ray absorption fine structure (EXAFS) suggest that the increased electrochemical stability of the Ta0.3W0.7C nanoparticles is due to the presence of passivating $\mathrm{TaO}_{\mathrm{x}}$ surface layer and the well-mixed nature of the alloy. It is interesting to note that the LSVs showing the electrochemical stability of $\beta$-WC 
nanoparticles exhibited two oxidation peaks at $\sim+0.4 \mathrm{~V}$ and $+0.7 \mathrm{~V}$ and onset of passivation occurs at $+0.2 \mathrm{~V}$. The authors attribute the presence of two oxidation peaks to the difference in electrochemical stability between the two crystal planes, (111) and (200) of $\beta$-WC. The alloying of WC with Ta changes this behavior significantly. For the alloyed nanoparticles, onset of passivation occurs at $+0.45 \mathrm{~V}$ and there is only one oxidation peak at $+0.75 \mathrm{~V}$. The follow up work of Ledendecker et al. ${ }^{114}$ is discussed in more detail and compared to our VMP results of WC in

\section{Chapter 6.}

Silicon carbide, $\mathrm{SiC}$, is electrically insulating unless doped to bring about semi-conducting properties. Thus, $\mathrm{SiC}$ is more "ceramic" in regards its properties and classification. Most ceramic materials have a high degree of thermal and electrochemical resistance. Thus, ceramics are used in highly corrosive environments. Nevertheless, ceramics can corrode under these aggressive conditions, albeit very slowly. Therefore, it is important to investigate corrosion of ceramics in order to understand their corrosion behavior and the implications this behavior has for their applications. Traditional procedure in the literature for measuring corrosion in ceramics involves immersing a sample in the corrosive medium and measuring mass loss, corrosion layer depth, surface morphological changes and ion concentration in corrosion media. Historically, direct electrochemical methods have not found as much use because most ceramics are poor electronic conductors. These methods enable the investigation of the electrochemical stability window of the material and the determination of the corrosion mechanism. However, over time electrode and sample preparation techniques have been developed for the electrochemical analysis of insulating solid materials. Andrews et al. ${ }^{115}$ report on the corrosion behavior of solid phase sintered SiC ( $\mathrm{SSiC}$ ) and liquid phase sintered $\mathrm{SiC}$ (LPS SiC). $\mathrm{SSiC}$ is prepared in the solid phase at $2200^{\circ} \mathrm{C}$ with small amounts of boron, carbon and aluminum additives to aid in densification. When 
alumina, yttria, or AlN are used as additives a liquid phase is formed with the trace $\mathrm{SiO}_{2}$ surface layers lowering the sintering temperatures to $<2000^{\circ} \mathrm{C}$. This procedure is used to prepare LPS SiC.

Polarization measurements and Tafel analyses and suggest $\mathrm{SiC}$ corrosion in acidic media proceeds via oxidation of the $\mathrm{SiC}$ to produce elemental carbon and a passivating $\mathrm{SiO}_{2}$ surface layer. Corrosion in basic electrolyte proceeds via oxidation of $\mathrm{SiC}$ to produce elemental carbon and dissolved $\mathrm{SO}_{3}{ }^{2-}$ species. SEM images confirm that the corrosion preferentially occurs at grain boundaries in the LPS SSiC due to the presence of alumina and yttria. The corrosion current densities of the LPS SiC materials were much lower than those for the SSiC samples. The authors attribute this difference in current density to the oxidation and dissolution of the alumina and ytrria at $\mathrm{SiC}$ grain boundaries. This reaction is a hydrolysis reaction in which no electrons are exchanged, therefore no contribution to measured current. This explanation is supported by ICP-OES analyses of dissolved $\mathrm{Al}, \mathrm{Si}$ and $\mathrm{Y}$ ions in electrolyte solutions post corrosion testing. The corrosion potential measurements for the LPS SiC samples were not reproducible. This irreducibility was attributed to the heterogeneity of the chemical composition due to the presence of the alumina an ytrria additives.

Corrosion potentials and corrosion current densities were obtained from polarization curves and Tafel analyses. Potential scan rates was $1 \mathrm{mV} / \mathrm{s}$ from $-200 \mathrm{mV}$ to $1000 \mathrm{mV}$. A platinum wire served as the counter electrode and the reference electrode was a saturated calomel electrode (SCE). The measured current corrosion densities ranged from $0.04 \mu \mathrm{A} / \mathrm{cm}^{2}$ to $40 \mu \mathrm{A} / \mathrm{cm}^{2}$ for the $\mathrm{SSiC}$ samples in various media and 0.6 to $1.8 \mu \mathrm{A} / \mathrm{cm}^{2}$. These faradaic currents are very low and difficult to distinguish from charging current when using voltammetric methods typical for the analysis of ions in solution. 


\subsection{Relevance of This Research}

This dissertation reports on explorations of the oxidation of calcium carbide in late transition metal halide salt melts first reported by Barber and Sloane. ${ }^{104} \mathrm{We}$ expand on this work by reporting the characterization and analysis of the carbon produced from this reaction. Moreover, we have also investigated the oxidation of aluminum carbide in tin chloride melts and described the characterization and analyses of the reaction products. To the best of our knowledge, this is the first report on the salt melt synthesis of carbon material from aluminum carbide.

We also describe explorations of the oxidation of ionic carbides by metal cations in solution via galvanic reaction and controlled potential electrolysis between a calcium carbide cell in an ethanol solution of saturated calcium chloride and a zinc cell in an ethanol solution of saturated zinc chloride. Results on a controlled potential electrolysis experiment are also reported. Although results from solution state experiments indicated that calcium carbide had been oxidized to elemental carbon, many questions remained unanswered and problems originating from experimental design remained unresolved.

There were several unknown variables in these experiments that hindered more meaningful measurements. These variables include the parasitic reaction of calcium carbide with ethanol and the corrosion of the stainless-steel electrode that housed the carbide. Although separation of the two half-reactions allowed us to measure current exchanged, the corrosion products from the stainless steel and the products from the reaction of the ethanol and the carbide may have resulted in unknown interactions in these experiments. In order to measure the potential for the carbide half-reaction with thermodynamic meaning, a methodology for the electrochemical study of solid carbide microparticles was adapted. The results showed the electrochemical stability of tungsten carbide (WC), two chromium carbide phases $\left(\mathrm{Cr}_{3} \mathrm{C}_{2}\right.$ and $\left.\mathrm{Cr}_{23} \mathrm{C}_{6}\right)$, silicon carbide ( $\left.\mathrm{SiC}\right)$ in sulfuric 
acid electrolytes and the electrochemical stability of aluminum carbide and calcium carbide in nonaqueous electrolytes. The best of this author's knowledge this is the first report on the electrochemical stability of microparticles of chromium carbides, aluminum carbide and calcium carbide in a liquid electrolyte.

\section{References}

1. Kosolapova, T. J. Carbides. (Plenum Pr, 1971).

2. $\quad$ Robert, F. The Physics and Chemistry of Carbides, Nitrides and Borides. (1990). doi:10.1007/978-94-009-2101-6

3. Levy, R. . B. . \& Boudart, M. . Platinum-Like Behavior of Tungsten Carbide in Surface Catalysis Author ( s ): R . B . Levy and M . Boudart Published by: American Association for the Advancement of Science Stable URL : http://www.jstor.org/stable/1736506 Platinum-Like Behavior of Tungst. Science (80-. ). 181, 547-549 (1973).

4. Li, Y. et al. The electronic, mechanical properties and theoretical hardness of chromium carbides by first-principles calculations. J. Alloys Compd. 509, 5242-5249 (2011).

5. Cotrell, A. Chemical Bonding in Transition Metal Carbides. (The University Press Cambridge, 1995).

6. Barsoum, M. W. MAX Phases: Properties of Machinable Ternary Carbides and Nitrides. (Wiley-VCH, 2013).

7. Radovic, B. M. \& Barsoum, M. W. MAX phases : Bridging. Am. Ceram. Soc. Bull. 92, 20-27 (2013).

8. Wang, J. \& Zhou, Y. Recent Progress in Theoretical Prediction, Preparation, and Characterization of Layered Ternary Transition-Metal Carbides. Annual Review of Materials Research 39, (2009).

9. Oyama, S. T. The Chemistry of Transition Metal Carbides and Nitrides. (Blackie Academic \& Professional, 1996).

10. Lapauw, T., Swarnakar, A. K., Tunca, B., Lambrinou, K. \& Vleugels, J. Nanolaminated ternary carbide (MAX phase) materials for high temperature applications. Int. J. Refract. Met. Hard Mater. 72, 51-55 (2018).

11. Nowotny, H. Crystal Chemistry of Complex Carbides and Related Compounds. Angew. Chemie Int. Ed. English 11, 906-915 (1972).

12. Barsoum, M. W. The MAX Phases : A New Class of Solids. Prog. Solid State Chem. 28, 201-281 (2000).

13. Oyama, S. T. in Kirk-Othmer Encyclopedia of Chemical Technology (ed. Seidel, A.) 1-11 (Wiley, 2015). 
14. Duncan, T. M. The Distribution of Carbon in Boron Carbide : A 13C Nuclear Magnetic Resonance Study. J. Am. Chem. Soc. 106, 2270-2275 (1984).

15. Greenwood, N. N. \& Earnshaw, A. Chemistry of the Elements. (Pergamon Press, 1984).

16. Domnich, V., Reynaud, S., Haber, R. A. \& Chhowalla, M. Boron carbide: Structure, properties, and stability under stress. J. Am. Ceram. Soc. 94, 3605-3628 (2011).

17. Wijesundara, M. B. J. \& Azevedo, R. Silicon Carbide Microsystems for Harsh Environments. 22, (2011).

18. Kitagawa, H., Kado, N. \& Noda, Y. Preparation of N-type Silicon Carbide-Based Thermoelectric Materials by Spark Plasma Sintering. Mater. Trans. 43, 3239-3241 (2002).

19. Pearson's Handbook of Cyrstallographic Data for Intermetallic Phases. (ASM).

20. Lengauer, W. Handbook of Ceramic Hard Materials, Vol 1. (Wiley-VCH, 2000).

21. Lengauer, W. \& Eder, A. in Ecyclopedia of Inorganic Chemistry (ed. King, R. B.) 674690 (John Wiley \& Sons, 2005).

22. Stoll, W. M. in Kirk-Othmer Encyclopedia of Chemical Technology2 (ed. Seidel, A.) 4, (Wiley, 2003).

23. Kumar, E. R. et al. Preliminary design of Indian Test Blanket Module for ITER. Fusion Eng. Des. 83, 1169-1172 (2008).

24. Karen, P. \& Fjellvag, H. Hydrolysis and structure of carbides related to propadiene. $J$. Alloys Compd. 178, 285-295 (1992).

25. Palenik, G. J. \& Warf, J. C. The Hydrolysis of Lanthanum and Cerium Carbides. Inorg. Chem. 1, 345-349 (1962).

26. Durand-Charre, M. Engineering Materials And Processes: Microstructure of Steels and Cast Irons. (Springer-Verlag Berlin Heidelberg, 2004).

27. Loubike, S. \& Bonino, J. P. ELABORATION, MICROSTBUCTUBE AND BEACTIYITY OF Cr,C, POWDERS OF DIFFERENT MORPHOLOGY. 30, 1535-1546 (1995).

28. Ebert, L. B. Intercalation compounds of graphite. Annu. Rev. Mater. Sci. 6, 181-211 (1976).

29. Fredenhagen, K. \& Cadenbach, G. Combination of potassium with carbon. Zeitschrift fur Anorg. und Allg. Chemie 158, 249- (1926).

30. Liu, Y., Merinov, B. V. \& Goddard, W. A. Origin of low sodium capacity in graphite and generally weak substrate binding of $\mathrm{Na}$ and $\mathrm{Mg}$ among alkali and alkaline earth metals. Proc. Natl. Acad. Sci. 113, 3735-3739 (2016).

31. Emery, N., Hérold, C., Marêché, J.-F. \& Lagrange, P. Synthesis and superconducting properties of CaC 6. Sci. Technol. Adv. Mater. 9, 044102 (2008). 
32. Ohzuku, T. Formation of Lithium-Graphite Intercalation Compounds in Nonaqueous Electrolytes and Their Application as a Negative Electrode for a Lithium Ion (Shuttlecock) Cell. J. Electrochem. Soc. 140, 2490 (1993).

33. Ottmers, D. M. \& Rase, H. F. Potassium graphites prepared by mixed-reaction technique. Carbon N. Y. 4, 125-127 (1966).

34. Nitta, N., Wu, F., Lee, J. T. \& Yushin, G. Li-ion battery materials: Present and future. Mater. Today 18, 252-264 (2015).

35. Goriparti, S. et al. Review on recent progress of nanostructured anode materials for Li-ion batteries. J. Power Sources 257, 421-443 (2014).

36. WEI, S., GUO, B. C., PURNELL, J., BUZZA, S. \& CASTLEMAN, A. W. Metallocarbohedrenes As a Class of Stable Neutral Clusters - Formation Mechanism of M8C12 (M = Ti and V). J. Phys. Chem. 96, 4166-4168 (1992).

37. Guo, B. C. et al. Generation of metal-carbon and metal-nitrogen clusters with a laser induced plasma technique. J. Chem. Phys. 97, 5243-5245 (1992).

38. Brock, L. R. \& Duncan, M. A. Near-threshold photoionization to probe neutral 'met-car' clusters. J. Phys. Chem. 100, 5654-5659 (1996).

39. Sakurai, H. \& Castleman, A. W. Ionization potentials for the titanium, zirconium, and the mixed metal met-cars. J. Phys. Chem. A 102, 10486-10492 (1998).

40. Rohmer, M. M., Bénard, M. \& Poblet, J. M. Structure, Reactivity, and Growth Pathways of Metallocarbohedrenes M8C12and Transition Metal/Carbon Clusters and Nanocrystals: A Challenge to Computational Chemistry. Chem. Rev. 100, 495-542 (2000).

41. Guo, B. C., Kerns, K. P. \& Castleman, A. W. Ti8C12+ - Metallo-Carbohedrenes: A New Class of Molecular Clusters? 255, 1411-1413 (1992).

42. Pilgrim, J. S. \& Duncan, M. A. Metallo-carbohedrenes: chromium, iron, and molybdenum analogs. 6958-6961 (1993).

43. Ganji, M. D., Sohbatzadeh, Z. \& Khosravi, A. Spin-dependent transport characteristics of Fe met-cars. Struct. Chem. 25, 551-559 (2014).

44. Ganji, M. D., Fereidoon, A., Khosravi, A., Ahmadian, N. \& Mohammad Zadeh, S. Adsorption of hydrogen molecules onto Li-decorated titanium met-car cluster: A firstprinciples study. Phys. E Low-Dimensional Syst. Nanostructures 46, 193-197 (2012).

45. Cartier, S. F., Chen, Z. Y., Walder, G. J., Sleppy, C. R. \& Castleman, A. W. Production of Metallo-Carbohedrenes in the Solid State Author ( s ): S . F . Cartier , Z . Y . Chen , G . J . Walder, C . R . Sleppy, A . W . Castleman and Jr . Published by : American Association for the Advancement of Science Stable URL : http://www.j. 260, 195-196 (2018).

46. Naguib, M. et al. Two-dimensional nanocrystals produced by exfoliation of Ti3AlC2. Adv. Mater. 23, 4248-4253 (2011).

47. Naguib, M. et al. Two-dimensional transition metal carbides. ACS Nano 6, 1322-1331 (2012). 
48. Naguib, M. et al. New Two - Dimensional Niobium and Vanadium Carbides as Promising Materials for Li - Ion Batteries Partners. 1-2 (2016). doi:10.1021/ja405735d

49. Emmerlich, J. et al. Thermal stability of Ti3SiC2thin films. Acta Mater. 55, 1479-1488 (2007).

50. Presser, V., Heon, M. \& Gogotsi, Y. Carbide-Derived Carbons - From Porous Networks to Nanotubes and Graphene. Adv. Funct. Mater. 21, 810-833 (2011).

51. Naguib, M., Mochalin, V. N., Barsoum, M. W. \& Gogotsi, Y. 25th anniversary article: MXenes: A new family of two-dimensional materials. Adv. Mater. 26, 992-1005 (2014).

52. Xie, X., Chen, S., Ding, W., Nie, Y.\& Wei, Z. An extraordinarily stable catalyst: Pt NPs supported on two-dimensional Ti3C2X2 $(\mathrm{X}=\mathrm{OH}, \mathrm{F})$ nanosheets for oxygen reduction reaction. Chem. Commun. 49, 10112 (2013).

53. Naguib, M. et al. MXene: A promising transition metal carbide anode for lithium-ion batteries. Electrochem. commun. 16, 61-64 (2012).

54. Yang, J., Chen, B., Song, H., Tang, H. \& Li, C. Synthesis, characterization, and tribological properties of two-dimensional Ti3C2. Cryst. Res. Technol. 49, 926-932 (2014).

55. Staritzky, E. Diberylilum carbide, Be2C. 2, 5885 (1956).

56. Li, Y., Liao, Y. \& Chen, Z. Be2C monolayer with quasi-planar hexacoordinate carbons: A global minimum structure. Angew. Chemie - Int. Ed. 53, 7248-7252 (2014).

57. Groen, W. A., Kraan, M. J., van Hal, P. F. \& De Veirman, A. E. M. A new diamondrelated compound in the system Al2O3-Al4C3-AlN. J. Solid State Chem. 120, 211-215 (1995).

58. Gilman, P. S. \& Benjamin, J. S. Mechanical Alloying. Annu. Rev. Mater. Sci. 13, 279-300 (1983).

59. Peng, L. M. \& Zhu, S. J. Creep of metal matrix composites reinforced by combining nanosized dispersoids with micro-sized ceramic particulates or whiskers (review). Int. J. Mater. Prod. Technol. 18, 215-254 (2003).

60. Yang, M. \& Scott, V. D. Carbide formation in a carbon fibre reinforced aluminum composite. 1Carbon 29, 877-879 (1991).

61. Petrusha, I. A., Smirnova, T. I., Osipov, A. S. \& Britun, V. F. Crystallization of diamond on the surface of cBN ceramics at high pressures and temperatures. Diam. Relat. Mater. 13, 666-670 (2004).

62. Solozhenko, V. L. \& Kurakevych, O. O. Equation of state of aluminum carbide Al4C3. Solid State Commun. 133, 385-388 (2005).

63. Gesing, T. M. \& Jeitschko, W. Crystal Structure and Chemical Properties of U2Al3C4 and Structure Refinement of Al4C3. Zeitschrift fur Naturforsch. B 50, 196-200 (1995).

64. Foster, L. M., Long, G. \& Hunter, M. S. Reactions between aluminum oxide and carbon 
the Al2O3-Al4C3 phase diagram. J. Am. Ceram. Soc. 39, 1-11 (1956).

65. Wright, S. G. \& Fowler, R. M. Method for the Production of Aluminum Carbide. (1960).

66. in CRC Handbook of Chemistry and Physics (ed. Rumble, J. R.) (CRC Press, 2013).

67. King, R. C. \& Armstrong, G. T. Heat of Combustion and Heat of Formation of Aluminum Carbide. J. Res. Natl. Bur. Stand. (1934). 68A, 661-667 (1964).

68. Elliot, J. \& Cleiser, M. Thermochemistry for Steelmaking. (Addison-Wesley Publishing Company Inc., 1960).

69. Chase, M. W. NIST-JANAF Thermochemical Tables. J Phys Chem Ref Data, Monograph 9 1-1951 (1998).

70. Choudary, U. V. \& Belton, G. R. Activities in Carbon-Saturdated Fe-Al Alloys and the Stability of Al4C3 at 1873K. Met. Trans. B 8B, 531-534 (1977).

71. King, W. R. \& Dorward, R. C. Electrical Resistivity of Aluminum Carbide at 990-1240K. 1Journal Electrochem. Soc. 132, 388-389 (984).

72. Atoji, M. Neutron diffraction studies of CaC2, YC2, LaC2, CeC2, TbC2, YbC2, LuC2, and UC2. J. Chem. Phys. 35, 1950-1960 (1961).

73. Mathews, J. A. \& Watters, L. L. The carbide of gold. J. Am. Chem. Soc. 22, 108-111 (1900).

74. Bredig, M. A. Polymorphism of calcium carbide. J. Phys. Chem. 46, 801-819 (1942).

75. Cameron, W. in Kirk-Othmer Encyclopedia of Chemical Technology (ed. Seidel, A.) 1-55 (Wiley, 2010).

76. Gel'd, P. V \& Kologreeva, A. G. Electric conductivity of solid technical calcium carbide. Zhurnal Prikl. Khimii 21, 599-610 (1948).

77. Schlumberger, E. Technical Calcium Carbide. Angew. Chemie 39, 213-220 (1925).

78. Lin, Y., Strobel, T. A. \& Cohen, R. E. Structural diversity in lithium carbides. Phys. Rev. B - Condens. Matter Mater. Phys. 92, (2015).

79. Novak, J. Zur Kenntnis Der Magnesiumcarbide. Zeitschrift fur Phys. Chemie 73, 513 (1911).

80. Fjellvag, H. \& Karen, P. Crystal Structure of Magnesium Sesquicarbide. Inorg. Chem. 31, 3260-3263 (1992).

81. Shimp, L. A. \& Lagow, R. J. Reaction of Carbon Vapor with Lithium Atoms. A Direct Synthesis of Polylithium Compounds. J. Am. Chem. Soc. 95, 1343-1344 (1973).

82. Shimp, L. A., Morrison, J. A., Gurak, J. A., Jr, J. W. C. \& Lagow, R. J. Observations on the nature of polylithium organic compounds and their rearrangements. 327, 5951-5953 (1981).

83. Pöttgen, R. \& Jeitschko, W. Sc3C4, a Carbide with C3 Units Derived from Propadiene. 
Inorg. Chem. 30, 427-431 (1991).

84. Hoffmann, R. Electronic structure of two novel carbides, calcium chloride carbide (Ca3Cl2C3) and scandium carbide (Sc3C4), containing $\mathrm{C} 3$ units. Zeitschrift fur Anorg. und Allg. Chemie 607, 57- (1992).

85. Carbide, Nitride and Boride Materials Synthesis and Processing. (Chapman \& Hall, 1997).

86. Mckenna, P. Hard Intermetallic Compounds for New Metal Cutting Tools. Met. Progr. 36, 152 (1939).

87. Nersisyan, H. H. et al. Combustion synthesis of zero-, one-, two- and three-dimensional nanostructures: Current trends and future perspectives. Prog. Energy Combust. Sci. 63, 79-118 (2017).

88. Pampuch, R. \& Stobierski, L. Solid combustion synthesis of refractory carbides: (A review). Ceram. Int. 17, 69-77 (1991).

89. Won, H. Il, Hayk, N., Won, C. W. \& Lee, H. H. Simple synthesis of nano-sized refractory metal carbides by combustion process. J. Mater. Sci. 46, 6000-6006 (2011).

90. Girshick, S. L. Aerosol processing for nanomanufacturing. J. Nanoparticle Res. 10, 935945 (2008).

91. Shi, W. et al. Laser Ablation Synthesis and Optical Characterization of Silicon Carbide Nanowires. Society 80, 3228-3230 (2000).

92. Rao, N., Girshick, S. \& Heberlein, J. Nanoparticle formation using a plasma expansion process. Plasma Chem. Plasma Process. 15, 581 - 606 (1995).

93. Inman, D. \& Lovering, D. G. Electrochemistry in Molten Salts. Compr. Treatise Electrochem. 593 (1972).

94. Molten Salt Technology. (Plenum Press, 1982).

95. Molten Salts Chemistry and Technology. (John Wiley \& Sons, 2014).

96. Salanne, M., Simon, C., Turq, P. \& Madden, P. A. Calculation of activities of ions in molten salts with potential application to the pyroprocessing of nuclear waste. J. Phys. Chem. B 112, 1177-1183 (2008).

97. Dunn, R. I., Hearps, P. J. \& Wright, M. N. Molten-salt power towers: Newly commercial concentrating solar storage. Proc. IEEE 100, 504-515 (2012).

98. Sundermeyer, W. Fused Salts and their Use as Reaction Media. Angew. Chemie - Int. Ed. 4, 222 (1965).

99. Kerridge, D. H. Recent Advances in Molten Salts as Reaction Media. 1Pure Appl. Chem 41, 355 (975).

100. Bugaris, D. E. \& Zur Loye, H. C. Materials discovery by flux crystal growth: Quaternary and higher order oxides. Angew. Chemie - Int. Ed. 51, 3780-3811 (2012). 
101. Liu, X., Fechler, N. \& Antonietti, M. Salt melt synthesis of ceramics, semiconductors and carbon nanostructures. Chem. Soc. Rev. 42, 8237 (2013).

102. Welton, T. Room-Temperature Ionic Liquids. Solvents for Synthesis and Catalysis. Chem. Rev. 99, 2071-2084 (1999).

103. Dupont, J. From molten salts to ionic liquids: A 'nano' journey. Acc. Chem. Res. 44, 1223-1231 (2011).

104. Barber, W. A. \& Sloan, C. L. Solubility of Calcium Carbide in Fused Salt Systems. J. Phys. Chem. 65, 2026-2028 (1961).

105. White, S. H. \& Morris, D. R. Chemistry of solutions of alkaline-earth carbides in molten salts. Phys. Chem. Process Metall. 195-205 (1974).

106. White, S. H. \& Morris, D. R. Chemistry of solutions of alkaline-earth carbides in molten salts. Phys. Chem. Process Metall. 195-205 (1974).

107. Bonomi, A., Hadate, M. \& Gentaz, C. Galvanic Cell Studies on Ionic Carbide and Nitride Solutions in Molten Salts. J. Electrochem. Soc. 124, 982 (1977).

108. Morris, D. R., Aksaranan, C., Waldron, B. S. \& White, S. H. Galvanic Cell Studies Involving Calcium Carbide Solutions. J. Electrochem. Soc. 120, 570 (1973).

109. Schmuecker, S. M., Clouser, D., Kraus, T. J. \& Leonard, B. M. Synthesis of metastable chromium carbide nanomaterials and their electrocatalytic activity for the hydrogen evolution reaction. Dalt. Trans. 46, 13524-13530 (2017).

110. Xiang, M. A. Determination of M6C and MC in P/M High-speed Steel by Etching Method. Chin. J. Met. Sci. Technol. 4, 228-231 (1988).

111. Lee, J., Duh, J. \& Tsai, S. Corrosion resistance and microstructural evaluation of the chromized coating process in a dual phase $\mathrm{Fe}-\mathrm{Mn}-\mathrm{Al}-\mathrm{Cr}$ alloy $\square$. Surf. Coatings Technol. 153, 59-66 (2002).

112. Weidman, M. C., Esposito, D. V., Hsu, I. J. \& Chen, J. G. Electrochemical Stability of Tungsten and Tungsten Monocarbide (WC) Over Wide $\mathrm{pH}$ and Potential Ranges. $J$. Electrochem. Soc. 157, F179 (2010).

113. Hunt, S. T., Kokumai, T. M., Zanchet, D. \& Román-Leshkov, Y. Alloying tungsten carbide nanoparticles with tantalum: Impact on electrochemical oxidation resistance and hydrogen evolution activity. J. Phys. Chem. C 119, 13691-13699 (2015).

114. Göhl, D. et al. Electrochemical stability of hexagonal tungsten carbide in the potential window of fuel cells and water electrolyzers investigated in a half-cell configuration. Electrochim. Acta 270, 70-76 (2018).

115. Andrews, A., Herrmann, M., Sephton, M., Machio, C. \& Michaelis, A. Electrochemical corrosion of solid and liquid phase sintered silicon carbide in acidic and alkaline environments. J. Eur. Ceram. Soc. 27, 2127-2135 (2007). 


\section{Chapter 2: Experimental Methods}

This chapter describes the experimental methods for the investigation of ionic carbide reactions with post transition metal salts in the molten and solution state. The methodology for the study of the electrochemistry of carbide micro particles at a solid electrode is also presented. The objectives of the molten salt experiments were to determine whether the metallic cation in the molten state would oxidize the carbide to elemental carbon and to determine the form of carbon produced. The objectives of the solution state experiments were to determine: 1) if the metallic cation in solution state would oxidize the carbide to elemental carbon, 2) the form of the carbon produced, and 3) measure the current exchanged during the redox process. The goal of the voltammetry of microparticles (VMP) experiments were to study the electrochemical behavior of metal carbides isolated and immobilized on an inert, solid electrode. Specifically, the objectives

of these experiments were: 1) to examine the electroactivity of carbide microparticles, 2) measure the potentials at which the carbide microparticles are oxidized or reduced and 3) determine whether this behavior is reversible.

\subsection{Molten Salt Reactions}

This research reports on investigations of the reactions between calcium carbide and molten zinc chloride (Nasco Scientific, Lab grade) (R 2.1) and aluminum carbide and tin chloride (Acros Organics, 98\%) (R 2.2). The reactants were prepared under an argon atmosphere. In each case, powdered carbide and anhydrous salt were mixed together in a mortar and pestle. The amount of salt used was always in $100 \%$ stoichiometric excess. In the case of calcium carbide (Fisher Scientific, $75-80 \%$ ), it was usually ground to 20 mesh particle size to increase the carbide surface area. The aluminum carbide (Alfa Aesar, 99\%) is only available in in one particle size, $~ 325$ mesh or $\sim 45$ microns.

$$
\mathrm{CaC}_{2}+\mathrm{ZnCl}_{2} \rightarrow 2 \mathrm{C}+\mathrm{CaCl}_{2}+\mathrm{Zn}^{0}
$$




$$
\mathrm{Al}_{4} \mathrm{C}_{3}+6 \mathrm{SnCl}_{2} \rightarrow 3 \mathrm{C}+4 \mathrm{AlCl}_{3}+6 \mathrm{Sn}^{0}
$$

The mixed reactants were loaded into a glass ampoule. The neck of the glass ampoule was cut and then loaded into a pipe bomb reactor and sealed. Figure 2.1 shows the pipe bomb reactor and glass ampoules.

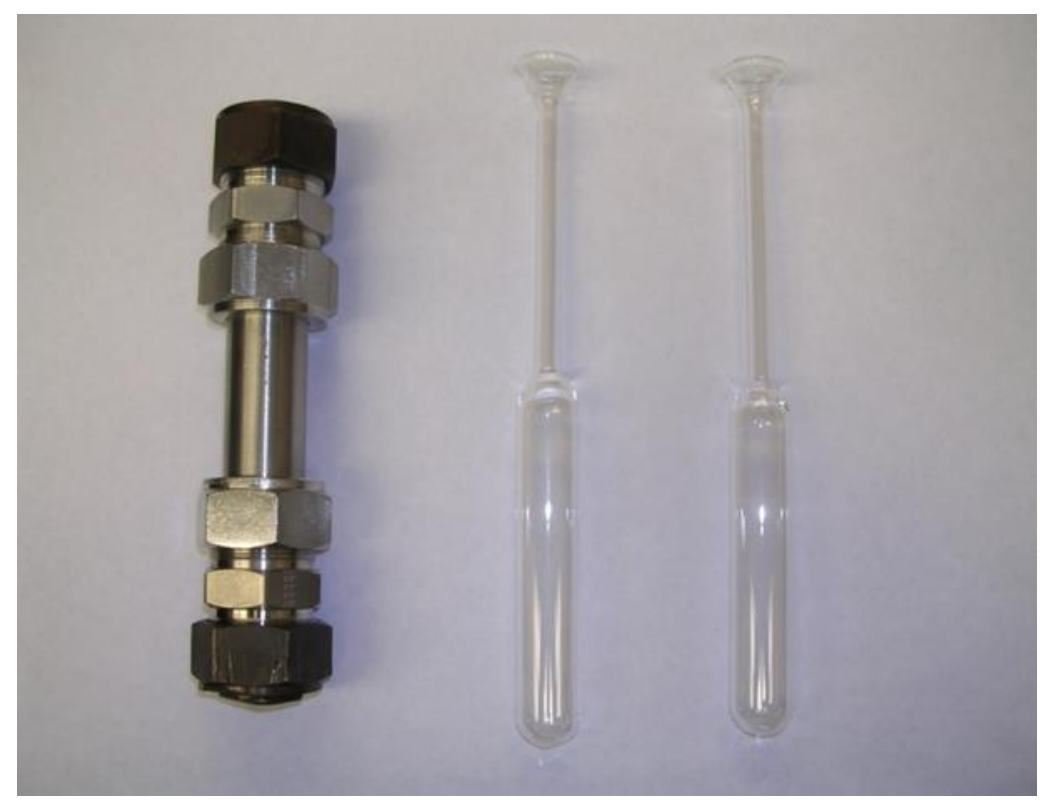

Figure 0.1 Pipe bomb reactor and glass ampoules for molten salt reactions

The temperature necessary for reaction had to be high enough to melt the salt but not high enough to boil. Table 2.1 presents the liquid range of the metal chloride salts used in this research. In experiments with calcium carbide and zinc chloride, the reaction was heated to $302^{\circ} \mathrm{C}$ for a residence time of 72 hours. Experiments with aluminum carbide and tin chloride the reaction temperature was $257^{\circ} \mathrm{C}$ and the residence time was 72 hours.

\begin{tabular}{llll}
\hline Metal Chloride Salt & Melting Point $\left({ }^{\circ} \mathrm{C}\right)$ & Boiling Point $\left({ }^{\circ} \mathrm{C}\right)$ & $\begin{array}{l}\mathrm{E}^{0} \text { of metallic cation } \\
(\mathrm{V})\end{array}$ \\
\hline $\mathrm{SnCl}_{2}$ & 247 & 632 & -0.13 \\
$\mathrm{ZnCl}_{2}$ & 290 & 732 & -0.76 \\
\hline
\end{tabular}

Table 0.1 Selected properties of metal chloride salts used in this research. Note: $E^{0}$ are standard state potentials. 
The physical form of the raw products for each reaction was a heterogeneous, solid mixture of metal salts, unreacted carbide, carbon, elemental metal and metal oxides and hydroxides. This mixture was characterized via SEM studies prior to chemical separation of the products. ${ }^{1-3}$ Tin oxides $\left(\mathrm{SnO}, \mathrm{SnO}_{2}\right)$, zinc oxide $(\mathrm{ZnO})$, aluminum hydroxide $\left(\mathrm{Al}(\mathrm{OH})_{3}\right)$ and calcium hydroxide $\left(\mathrm{Ca}(\mathrm{OH})_{2}\right)$ are amphoteric and insoluble in water. Therefore, these oxide and hydroxide products and byproducts were separated chemically via reaction and dissolution with $6 \mathrm{M}$ hydrochloric acid $(\mathrm{HCl})$. The chemical reactions involved in the separation process with dilute hydrochloric acid are shown below.

$$
\begin{array}{cc}
\mathrm{CaC}_{2}+\mathrm{HCl} \rightarrow \mathrm{C}_{2} \mathrm{H}_{2}+\mathrm{CaCl}_{2} & \mathbf{R ~ 0 . 3} \\
\mathrm{Al}_{4} \mathrm{C}_{3}+12 \mathrm{HCl} \rightarrow 4 \mathrm{AlCl}_{3}+3 \mathrm{CH}_{4} & \mathbf{R ~ 0 . 4} \\
\mathrm{Zn}+2 \mathrm{HCl} \rightarrow \mathrm{ZnCl}_{2}+\mathrm{H}_{2} & \mathbf{R ~ 0 . 5} \\
\mathrm{Sn}+2 \mathrm{HCl} \rightarrow \mathrm{SnCl}_{2}+\mathrm{H}_{2} & \mathbf{R ~ 0 . 6} \\
\mathrm{CaC}_{2}+\mathrm{H}_{2} \mathrm{O} \rightarrow \mathrm{C}_{2} \mathrm{H}_{2}+\mathrm{Ca}(\mathrm{OH})_{2} & \mathbf{R ~ 0 . 7} \\
\mathrm{Al}_{4} \mathrm{C}_{3}+12 \mathrm{H}_{2} \mathrm{O} \rightarrow 4 \mathrm{Al}(\mathrm{OH})_{3}+3 \mathrm{CH}_{4} & \mathbf{R ~ 0 . 8} \\
\mathrm{ZnO}+2 \mathrm{HCl} \rightarrow \mathrm{ZnCl}_{2}+\mathrm{H}_{2} \mathrm{O} & \mathbf{R ~ 0 . 9} \\
\mathrm{CaO}+\mathrm{H}_{2} \mathrm{O} \rightarrow \mathrm{Ca}(\mathrm{OH})_{2} & \mathbf{R ~ 0 . 1 0} \\
\mathrm{Ca}(\mathrm{OH})_{2}+2 \mathrm{HCl} \rightarrow \mathrm{CaCl}_{2}+2 \mathrm{H}_{2} \mathrm{O} & \mathbf{R ~ 0 . 1 1} \\
\mathrm{Al}(\mathrm{OH})_{3}+3 \mathrm{HCl} \rightarrow \mathrm{AlCl}_{3}+3 \mathrm{H}_{2} \mathrm{O} & \mathbf{R ~ 0 . 1 2} \\
\mathrm{SnCl} & +\mathrm{H}_{2} \mathrm{O} \rightarrow \mathrm{Sn}(\mathrm{OH}) \mathrm{Cl}+\mathrm{HCl}
\end{array}
$$

The remaining carbon material was isolated via vacuum filtration, washed with distilled water and methanol and dried in an oven to evaporate off residual methanol.

The process of chemical separation of the carbon product from the byproducts was often laborious. The metal oxides and hydroxides, particularly $\mathrm{Al}(\mathrm{OH})_{3}$, often precipitated in a gel that blinded the filters. This situation necessitated further treatment with acid or base to shift the 
equilibria to the soluble aluminum complex. Additionally, treatment with dilute acids proved sufficient in isolating the carbon products in all cases with the exception of tin oxides, which can form due to moisture and oxygen impurities. $\mathrm{SnO}_{2}$ is insoluble in water and not as readily reactive with hydrochloric acid. Therefore, reactions with tin chloride required a further chemical separation step with hot, concentrated potassium hydroxide, which yields a soluble potassium stannate complex (R 2.14).

$$
\mathrm{SnO}_{2}+\mathrm{KOH} \rightarrow \mathrm{K}_{2}\left[\mathrm{Sn}(\mathrm{OH})_{6}\right]
$$

\section{R 0.14}

\subsection{Solution State Reactions}

We hypothesized that reactions R 2.1 and R 2.2 would proceed at lower temperatures in the solution state. The primary reason these reactions are spontaneous in the molten state is the fact that the ionic salts in the liquid state completely dissociate into their constituent ions. ${ }^{4}$ Thus, mass transport of the metal ions is much higher allowing the oxidation of the carbide to occur at much higher rates. Dissolution of the same salts in nonaqueous solvents should also increase the rate of mass transport. Additionally, the lower temperatures and milder environment allowed for the construction of reaction vessels with stirring that further increased the rate of mass transfer. Moreover, separation of the two half-reactions in a two-compartment reaction cell accomplished two things: 1) enabled monitoring of the current exchanged during the redox reaction and 2) easier isolation of carbon produced during the reaction.

Preliminary experiments with aluminum carbide and salts dissolved in anhydrous, nonaqueous solvents indicated that aluminum carbide was not reactive with late transition metal salts in the solution state. ${ }^{2}$ Thus, only the reaction of calcium carbide and zinc chloride was investigated. This reaction can be separated into two half-reactions:

$$
\mathrm{CaC}_{2} \rightarrow \mathrm{Ca}^{2+}+2 e^{-}+2 \mathrm{C}
$$




$$
Z n^{2+}+2 e^{-} \rightarrow Z n
$$

R 0.16

R 2.15 is the oxidation of the carbon anion in calcium carbide at the anode, and R. 2.16 is the reduction of zinc ion at the cathode. The chloride anion is a spectator ion and is not included in the half-reactions.

The nonaqueous solvent chosen for these experiments was ethanol $\left(\mathrm{CH}_{3} \mathrm{CH}_{2} \mathrm{OH}\right)$. Although, ethanol does react with calcium carbide this reaction ( $\mathrm{R} 2.17$ ) is slow compared with the oxidation of calcium carbide by dissolved zinc ions.

$$
\mathrm{CaC}_{2}+\mathrm{CH}_{3} \mathrm{CH}_{2} \mathrm{OH} \rightarrow \mathrm{Ca}\left(\mathrm{OCH}_{2} \mathrm{CH}_{3}\right)_{2}+\mathrm{H}_{2} \mathrm{C}_{2}
$$

Additionally, metal chloride salts are insoluble in aprotic solvents because chloride anions require hydrogen bonding for stabilization with the solvent ${ }^{5}$. For example, metal chloride salts are more soluble in methanol, but we found that the parasitic reaction between methanol and calcium carbide was faster than the reaction between calcium carbide and ethanol. Thus, the choice of ethanol as a solvent was a compromise between zinc chloride's solubility and the solvent's reactivity with the carbide. The ethanol (PTI Process Chemicals, denatured) was prepared by distillation and drying with molecular sieves according to standard methods in the literature ${ }^{6}$. Saturated ethanol solutions were prepared by dissolving anhydrous zinc chloride (Nasco Scientific, laboratory grade) and calcium chloride (Nasco Scientific, desiccant grade) in dry ethanol.

Section 2.2.1 details the experimental methods and cell design for the galvanic reactions. Section 2.2.2 describes the experimental methods and cell design for the controlled potential electrolysis experiment. 


\subsubsection{Galvanic Reactions of Calcium Carbide and Zinc Chloride}

Figure 2.2 shows the two-compartment cell used for the galvanic reactions. The anode compartment of the cell was filled with the saturated calcium chloride solution and the cathode compartment was filled with the saturated zinc chloride solution. Each compartment was sealed at frosted joints with glass caps fabricated with nipple openings to permit the insertion of the electrodes. A salt bridge in the form of a glass tube with a glass frit and stopcock valve separated the two compartments.

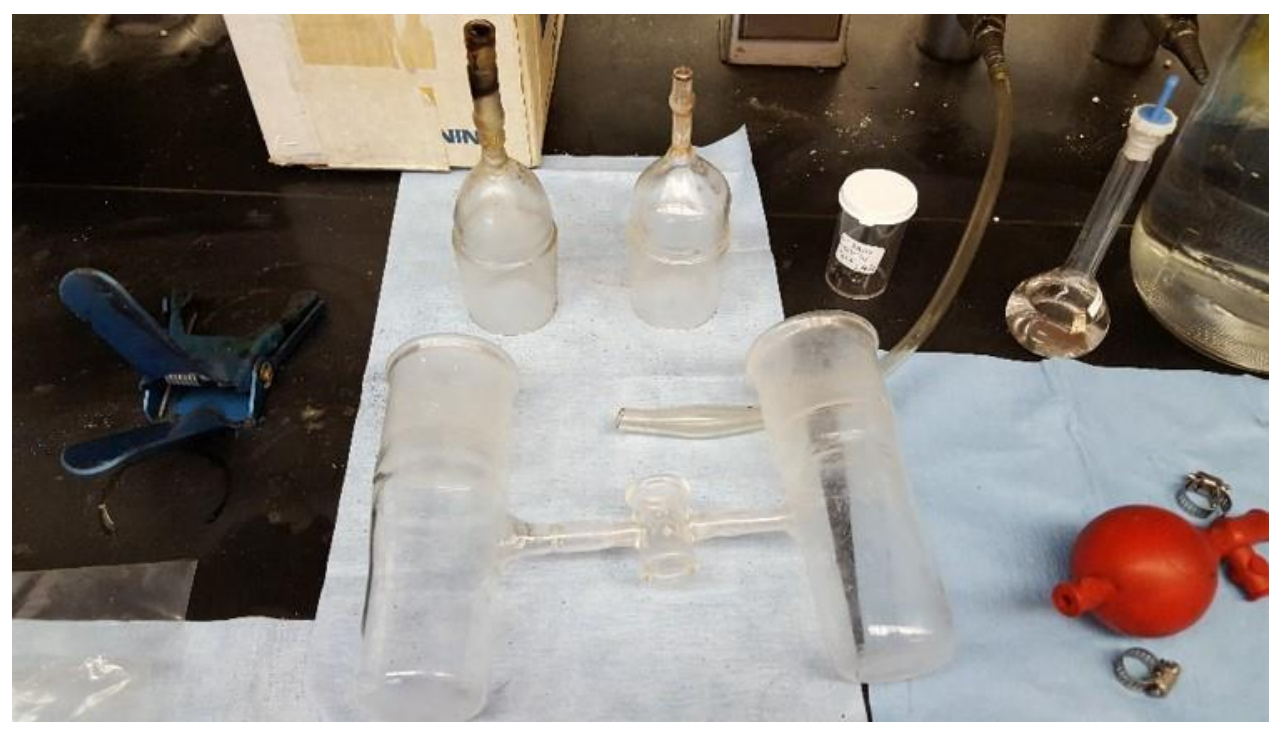

Figure 0.2 Two compartment cell with glass fritted salt bridge for solution reactions

The cathode was a polished zinc rod. The zinc rod was inserted into the nipple openings on the caps and nestled within flexible Tygon tubing also attached to the nipple openings. The cathode compartment was sealed by tightening a hose clamp on the flexible tubing. The anode took the form of a stainless steel, perforated, hollow sphere that could be opened and closed via a rotational mechanism. The stainless-steel sphere was connected to a hollow stainless steel tube. The stainless-steel tube was nestled in flexible Tygon tubing, which connected to a bubbler filled with methanol to prevent moisture from re-entering the cell. A hole drilled in the side of the stainless-steel tube allowed vapors produced during the experiment to escape through the bubbler. 
Calcium carbide pieces were loaded into the anode. An advantage of the stainless-steel anode was that calcium carbide pieces could be tightly loaded within the sphere ensuring good electrical contact during the experiment. A disadvantage was the steel's susceptibility to corrosion in chloride electrolytes.

Electrolyte solutions were prepared, magnetic stir bars were added to each compartment and the cell was assembled under argon atmosphere in a glove box. After sealing the cell by tightening the hose clamps on the flexible tubing around the electrodes, the cell was carefully removed from the glove box to a hood. Each compartment of the cell was placed on a magnetic stirring plate. The cell and bubbler was clamped to a ring stand assembly for stability. The current was monitored with a multimeter connected to the two electrodes in series. The reaction was allowed to proceed for 2 to 4 days.

After 2 to 4 days the cell was disassembled. The contents of the anode were added to $6 \mathrm{M}$ $\mathrm{HCl}$ solution to separate any carbon produced by the reaction from unreacted carbide and calcium oxide and hydroxide. The carbon was isolated by vacuum filtration, washed with DI water and methanol and dried for characterization and further analysis.

\subsubsection{Controlled Potential Electrolysis}

Figure 2.3 shows a diagram of experimental set-up for the controlled potential electrolysis experiment. This experiment utilized the same two-compartment cell, electrolytes, anode and cathode. However, a third reference electrode was added so that the potential could be controlled by a potentiostat. This reference electrode was a double junction $\mathrm{Ag} / \mathrm{AgCl}$ electrode. The reference electrode was connected to the reference lead, the carbide electrode to the working electrode lead and the zinc rod the counter electrode lead of the potentiostat. The poteniostat was a BASi CV-27 
voltammograph connected to a BASi PWR-3 Power Module. A multimeter was also connected in series between the zinc and carbide electrodes.

First, the current at $0 \mathrm{~V}$ was measured. At this point the potential at which calcium carbide oxidizes was still unknown. Therefore, a potential of $+14 \mathrm{~V}$ was applied in an attempt to drive an oxidation at the carbide electrode. The electrolysis was allowed to run for 4 days. During this time, current and observations of visual changes in the cell were recorded. The cell was disassembled, the contents of the anode were added to $6 \mathrm{M} \mathrm{HCl}$ to separate any carbon produced by the reaction from unreacted carbide and calcium oxide and hydroxide. The carbon was isolated by vacuum filtration, washed with DI water and methanol and dried for characterization and further analysis.

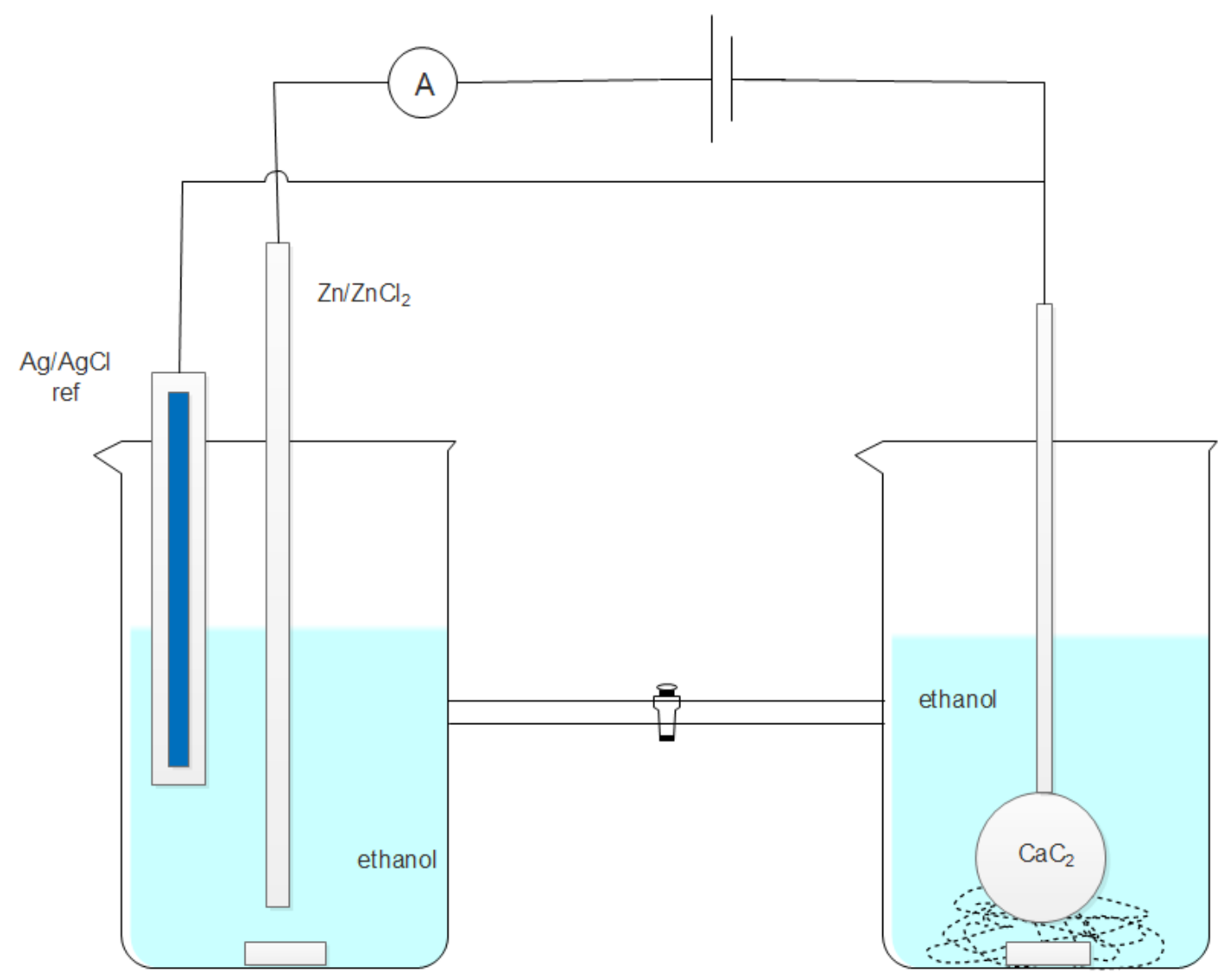

Figure 0.3 Diagram of three-electrode set-up for controlled potential electrolysis experiment in twocompartment cell. 


\subsection{Electrochemical Methods}

The following sections describe the methodology developed and adapted to study the electrochemical behavior of carbide microparticles immobilized on the surface of an inert, solid working electrode.

\subsubsection{General Experimental Considerations for Electrochemical Analyses}

Before electrochemical analyses may be performed, an appropriate experimental system must be designed. The primary parameters to be considered are a suitable electrolyte and supporting electrolyte pairing, an appropriate electrochemical cell configuration and an appropriate working electrode. ${ }^{5,7-10}$

The requirements on a suitable electrolyte are as follows. The electrolyte must be a solvent that is unreactive with the electroactive species under study. The solvent must also have a high dielectric constant for sufficient ionic conductivity and the ability to dissolve appreciable amounts of salts, which support the conductivity of the electrolyte. These salts are termed the supporting electrolyte. Voltammetric studies of ionic carbides, i.e. calcium carbide and aluminum carbide, were performed in nonaqueous, anhydrous electrolytes due to their water reactivity. Therefore, the solvent used was HPLC grade acetonitrile (MeCN, Fisher Scientific) which was dried over molecular sieve by standard methods. ${ }^{6}$ The supporting electrolytes were potassium hexafluorophosphate $\left(\mathrm{KPF}_{6}\right.$, Acros Organics, 99\%), tetrabutylammonium hexafluorophosphate (TBAHFP, TCI, >98\%) or calcium triflate (CaTf, 99.5\%). Voltammetric studies of tungsten carbide (WC, Alfa Aesar 99\%), two chromium carbide phases $\left(\mathrm{Cr}_{3} \mathrm{C}_{2}\right.$ and $\mathrm{Cr}_{23} \mathrm{C}_{6}$, both Alf Aesar, 99.5\%), and silicon carbide were performed in aqueous electrolyte. The supporting electrolyte for aqueous electrolytes was $0.5 \mathrm{M}$ sulfuric acid, prepared with de-ionized water $(18 \mathrm{M} \Omega \cdot \mathrm{cm})$. 
Figure 2.1 shows the configuration of the electrochemical cell used for this research. A three-electrode configuration consisting of a working electrode (WE), reference electrode (RE) and a counter electrode (CE). For measurements in nonaqueous electrolytes, a homemade glassy carbon electrode (GCE) was used as the WE and a platinum wire was used as a pseudo reference electrode. For measurements in aqueous electrolytes, a paraffin impregnated graphite electrode (PIGE) was used as the $\mathrm{WE}$ and a $\mathrm{Ag} / \mathrm{AgCl} 3 \mathrm{M} \mathrm{NaCl}$ reference electrode was used. A textured, platinum wire was used for the CE in all cases. As shown in Figure 2.1, each electrode was contained in a compartment separated by a glass frit to ensure there would be no contamination from products resulting from electrochemical processes at the counter electrode.

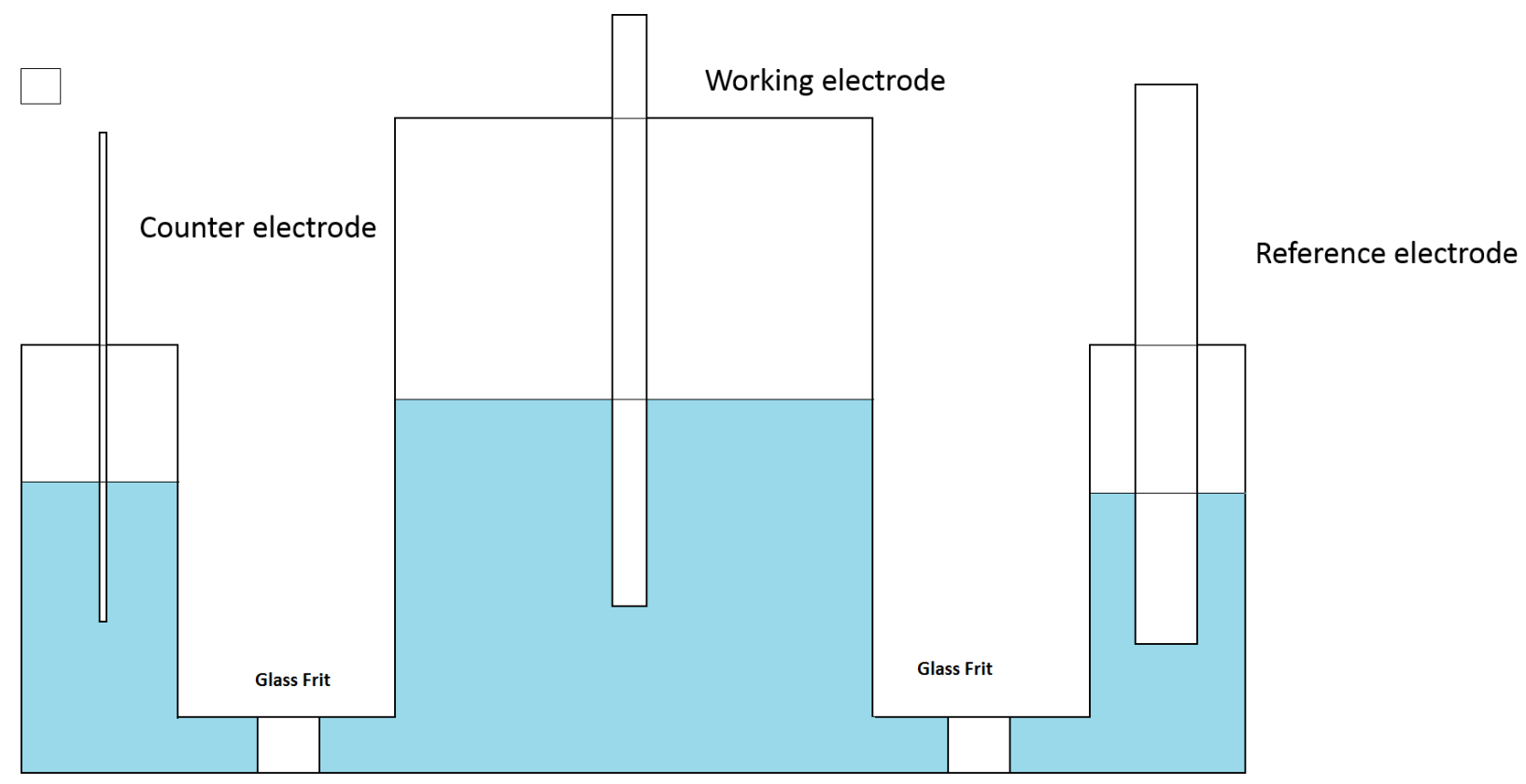

Figure 0.4 Schematic of three compartment electrochemical cell

In addition to a suitable electrochemical cell configuration, an appropriate working electrode (WE) must be chosen. The WE is the transducer in electrochemical analyses, e.g. converting the rates of charge and mass transfer into electric current as in voltammetry. In most cases it is necessary that the WE is a good electronic conductor, presents no chemical interference 
with the electroactive species of interest and is electrochemically inert. Two working electrodes were used for VMP studies: a glassy carbon electrode (GCE) and a paraffin impregnated graphite electrode (PIGE). More detailed discussion of the choice of WE is presented in the following sections. The determination of the inert potential window for specific electrochemical systems is almost impossible ab initio. Therefore, a systematic experimental methodology was employed to establish the inert potential window of each system before analysis of carbide microparticles took place. We followed a method adapted from the recent report of Jaramillo et al. ${ }^{11}$ The results and discussion of the potential window studies are presented in Appendix B.

A PalmSens Emstat Blue 3+ potentiostat, shown in Figure 2.5, was used for voltammetric measurements. Before measurements were initiated, the electrolyte was always sparged with UHP argon for 20 minutes to remove any dissolve oxygen.

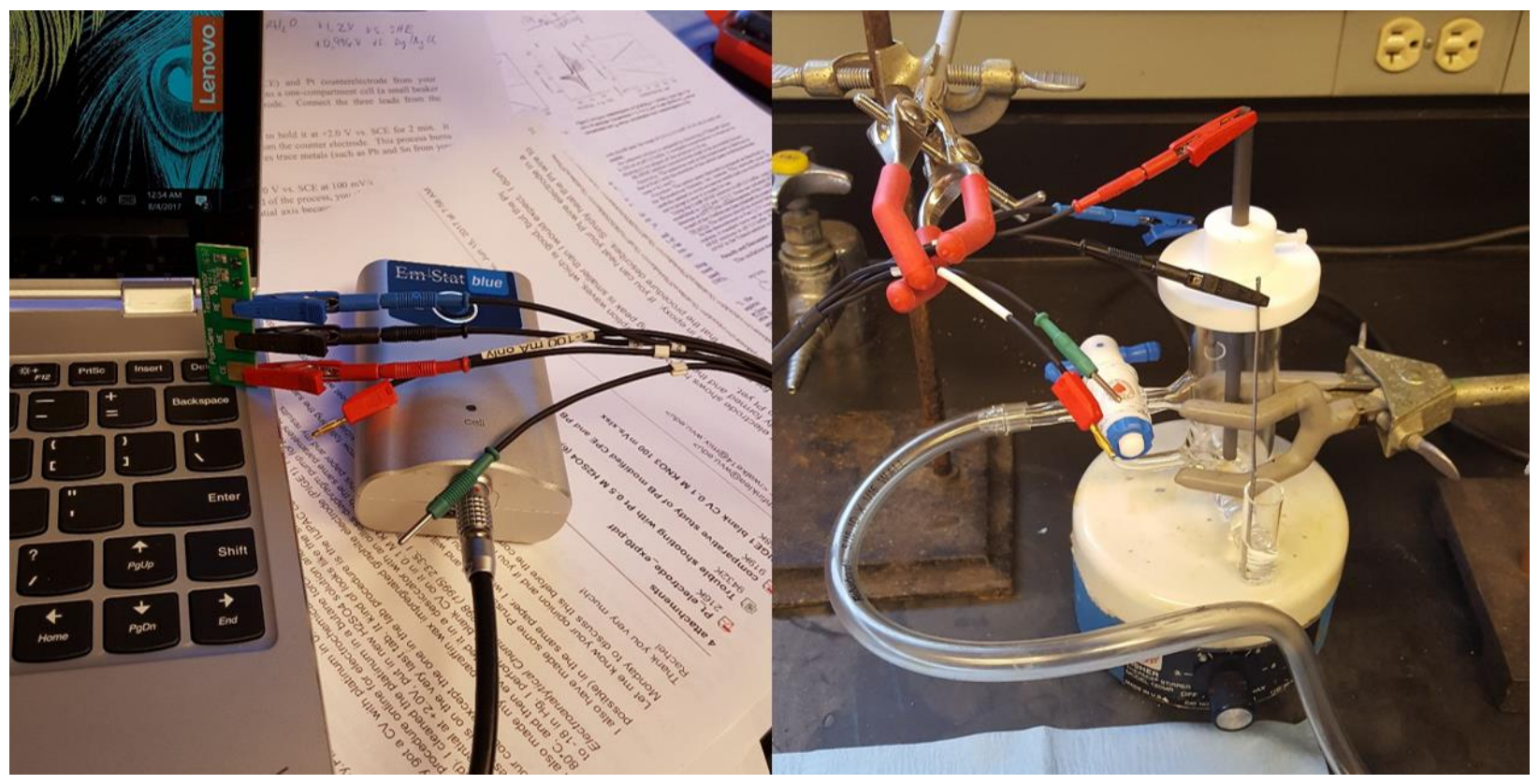

Figure 0.5 PalmSens Potentiostat model Emstat blue 3+ (Left) and electrochemical cell (Right) 


\subsubsection{Open Circuit Potentiometry}

Potentiometric analysis methods involve measuring the potential between two electrodes in the absence of current. One of the electrodes is a reference electrode (RE). The second electrode is called an indicator electrode, rather than working electrode (WE) as in voltammetry. In potentiometry, the potential measured at the indicator electrode is dependent on the activity of a specific ion in the test solution. Examples of indicator electrodes include electrodes selective for metallic cations in solution, fluoride ions and $\mathrm{pH}$ meters. ${ }^{12}$

Open circuit potentiometry (OCP) is a standard measurement to perform prior to voltammetric experiments when one does not know what the standard redox potential or the redox state of the system under study ${ }^{9}$. This may be done in the same electrochemical cell for the voltammetric measurements, using the same RE and the WE as the "indicator electrode." The CE is not electrically connected for OCP measurements. It can be assumed that in the absence of current no significant electrochemical reactions are occurring. Thus, the measured OCP may be used as the initial potential, $E_{i}$, from which voltammetric sweep may be initiated. Initial potentials for the voltammetric studies in this work were determined with OCP.

\subsubsection{Cyclic Voltammetry (CV)}

Voltammetry is a category of electroanalytical techniques in which the current of an electrochemical system is measured in response to an applied potential. If the applied potential is thermodynamically favorable, the species under study can either be oxidized or reduced (R 2.18). The faradaic current response when the species is reduced is called cathodic current and when it is oxidized is anodic current.

$$
O x+e^{-} \leftrightarrow \operatorname{Red}
$$


The Nernst Equation establishes the relationship between the activities of the oxidized (Ox) and reduced species (Red) at equilibrium:

$$
E=E^{0}-\frac{R T}{n F} \ln \frac{a_{R e d}}{a_{O x}}
$$

$E$ is the potential at the working electrode, $E_{0}$ is the standard reduction potential of the $O x /$ Red redox couple, and $a_{\text {Red }}$ and $a_{O x}$ are the activities of $O x$ and Red. It is important to distinguish between the use of $E^{0}$ and $E^{0^{\prime}} . E^{0}$ is the standard reduction potential of a half-cell at standard state measured against the standard hydrogen electrode (SHE) reference cell. $E^{0^{\prime}}$ is the formal potential which is a value measured at conditions deviating from the standard state.

In cyclic voltammetry (CV) an initial potential (Ei) is applied to the working electrode. The potential is chosen such that no redox process can occur. The excitation potential is scanned at a constant scan rate, $v$, from the initial potential $\left(E_{i}\right)$ to a final potential $\left(E_{f}\right)$. An example of this potential waveform is shown in Figure 2.6. The initial potential is selected positive of $E^{0}$, the thermodynamic potential at which the oxidized species $(O x)$ is reduced. At these potentials only nonfaradaic (charging) current flows. As the potential approaches $E^{0^{\prime}}$ reduction starts, and the

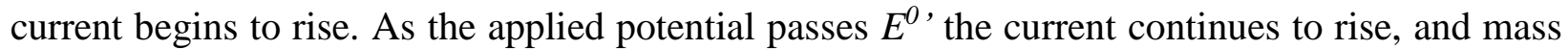
transfer of the $O x$ reaches a maximum rate and the current peaks at $E_{p}{ }^{c}$. The current drops off as the concentration of $O x$ at the WE surface is depleted. ${ }^{7}$ 


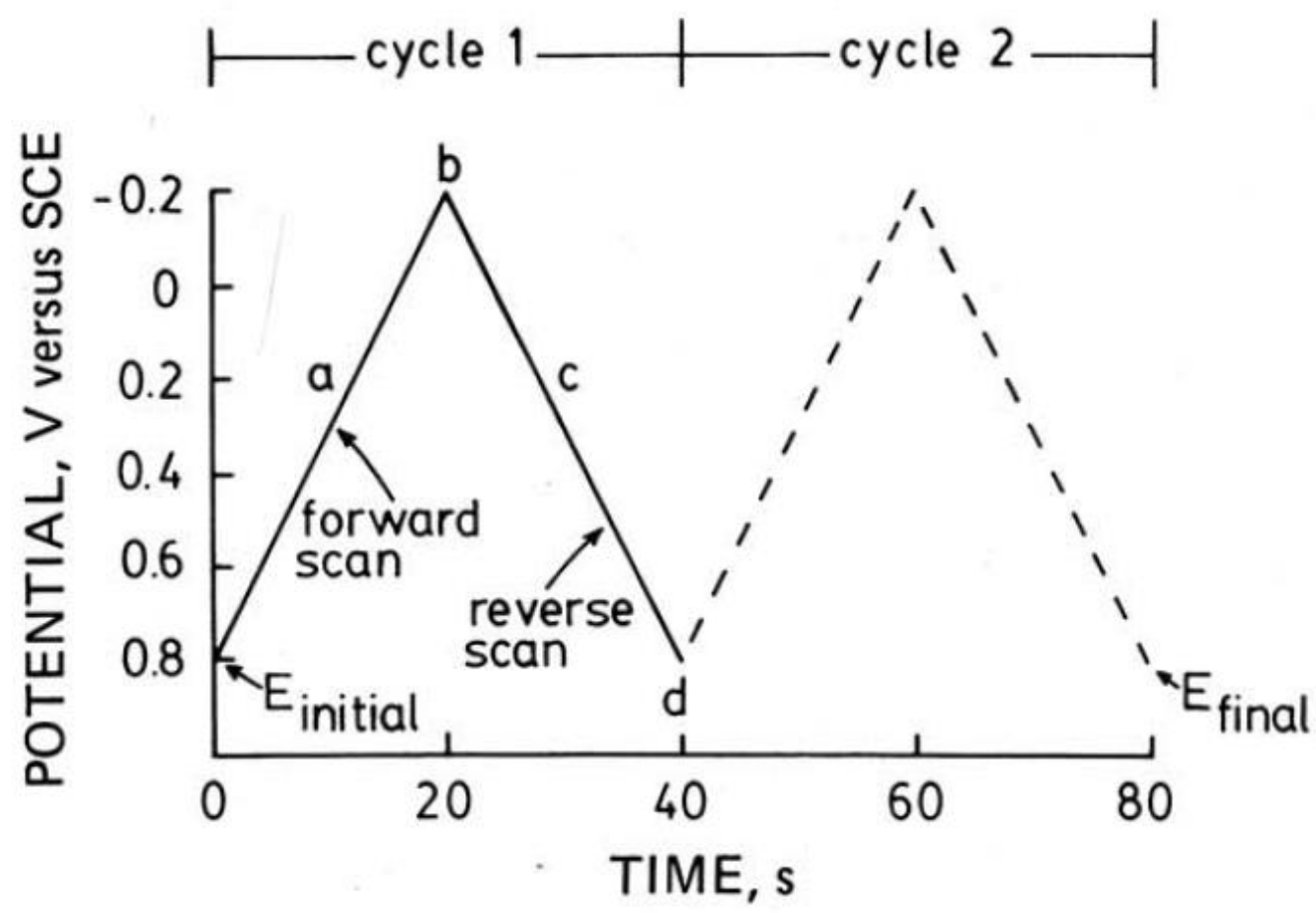

Figure 0.6 Plot showing excitation signal vs. time in CV experiments. below.

The peak currents for a reversible reaction is given by the Randles-Sevcik equation given

$$
i_{p}=\left(2.69 \times 10^{5}\right) n^{3 / 2} A D_{0}^{1 / 2} v^{1 / 2} C_{0}
$$

The peak currents $i_{p}$ depend upon the number of electrons exchanged $(n)$, the area of the WE $(A)$, the diffusion coefficient $\left(D_{0}\right)$, the scan rate $v$ and the bulk electrolyte concentration $\left(C_{0}\right)$. Information such as the number of electrons exchanged or the diffusion coefficient for the system may be extracted if all other variables are known.

The electron transfer kinetics of a system may be examined via CV by varying the scan rate and observing the change in the current peak position. If the electron kinetics are fast the magnitude of the peak current will rise but occur at the same potential. If the current peak positions shifts with increasing scan rates then the electron kinetics are considered slow relative to the scan rate. 
Cyclic voltammetry is similar to LSV. In this case the potential is swept from an initial potential $\left(V_{l}\right)$ to a second potential $\left(V_{2}\right)$, now termed the switching potential, and then reversed at a constant scan rate back to the initial potential. The potential excitation signal versus time and the resulting faradaic current response versus applied potential for an ideal, one electron reversible redox couple is shown in Figure 2.7. A reversible redox system is both thermodynamically reversible as well as kinetically reversible in terms of electron transfer between the redox species and working electrode. This example is presented in the American convention.

The separation $(\Delta \mathrm{E})$ between the anodic $\left(i_{p}{ }^{a}\right)$ and cathodic peak currents $\left(i_{p}{ }^{c}\right)$ of an ideal, reversible redox couple is

$$
\Delta E=E_{p}^{a}-E_{p}^{c}=\frac{59}{n} m V
$$

In practical applications cell resistance may increase the peak separation beyond the ideal value. However, if $\Delta \mathrm{E}$ is less than $100 / n \mathrm{mV}$ and independent of scan rate the redox couple is electrochemically reversible. ${ }^{13}$ Cyclic voltammetry can also yield information on the number of electrons exchanged, the diffusion coefficient, kinetics and the reversibility of the system. Thus, $\mathrm{CV}$ is typically used as the first diagnostic tool to analyze an electrochemical system. 


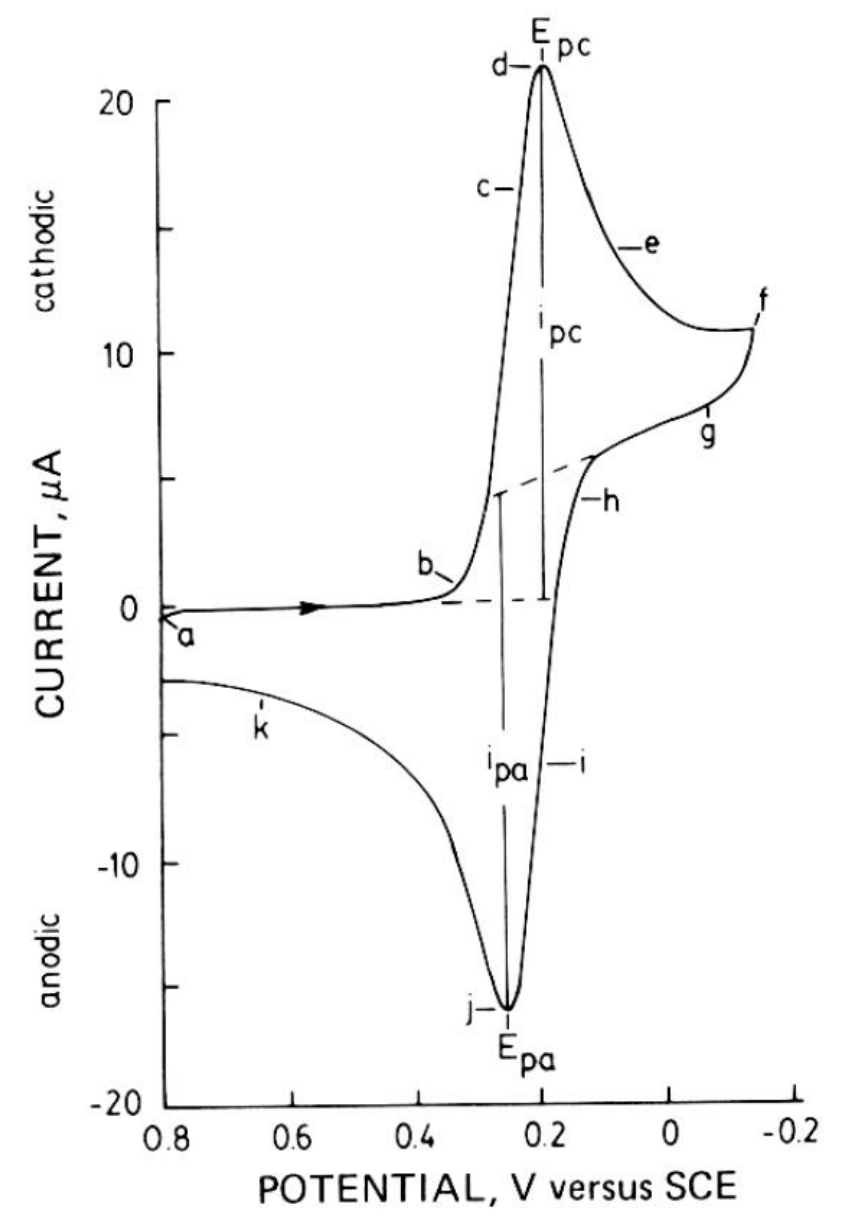

Figure 0.7 Cyclic voltammogram of $6 \mathrm{mM} \mathrm{K}_{3} \mathrm{Fe}(\mathrm{CN})_{6}$ in $1 \mathrm{M} \mathrm{KNO}_{3}$. Scan initiated at $0.8 \mathrm{~V}$ v. SCE in the negative direction at $50 \mathrm{mV} / \mathrm{s}$ at a platinum $\mathrm{WE}$.

\subsubsection{Methods for the Electrochemical Analysis of Solids in Liquid Electrolytes}

This section is a brief review of the different methods for investigating the electrochemical behavior of solid compounds in liquid electrolytes. Furthermore, we explain the reasons we chose the technique voltammetry of microparticles (VMP) for our research.

In a broad sense, the electrochemistry of solids at a liquid electrolyte phase boundary are studied by three methods. These three methods include the use of a working electrode comprised of the solid to be studied, incorporation of the solid into a composite electrode, or by attaching particles of the solid to the surface of an electrode. The first method in which the WE is the solid itself is the historical and primary method used in corrosion studies of the oxidation and dissolution 
metals and metal alloys. ${ }^{14,15}$ This method requires that solid has good electronic conductivity in order to obtain results. Figure 2.8 shows a typical electrochemical cell used for corrosion studies. In this particular study, the WE is a sample of $316 \mathrm{~L}$ stainless steel in artificial bone fluid solution to determine the steels suitability for use in joint implants.

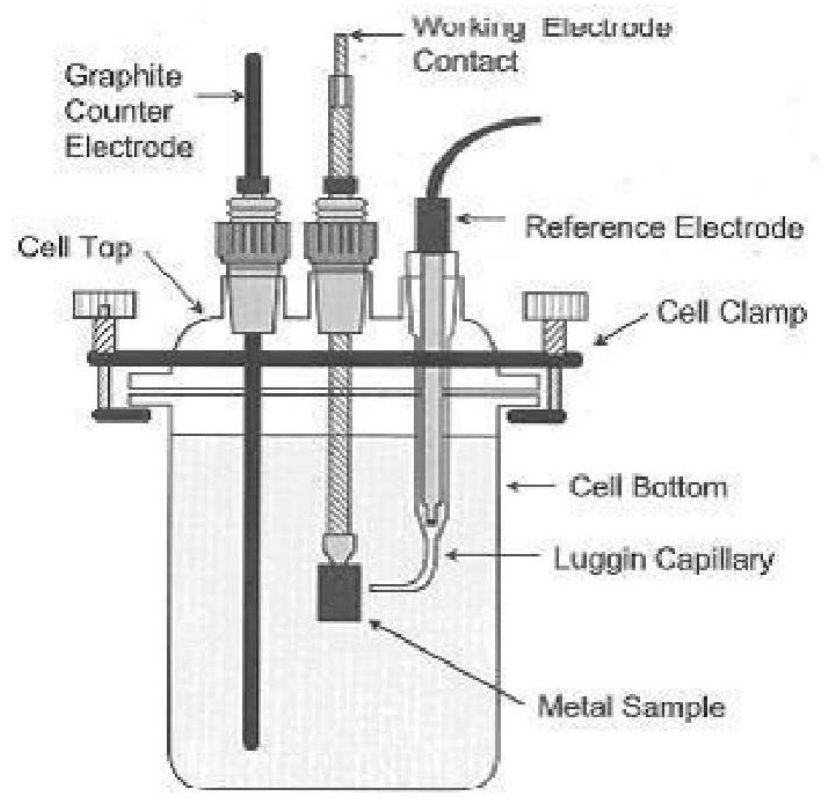

Figure 0.8 The electrochemical cell for a corrosion study of $316 \mathrm{~L}$ stainless steel samples in artificial bone fluid solution. This experimental set up consists of a graphite counter electrode, a sample of steel as the working electrode and a reference electrode with a Luggin capillary to minimize iR drop $^{16}$.

Tallman and Peterson ${ }^{17}$ define a composite electrode as a surface that consists of arrays or ensembles of conductor regions separated from one another by an insulator. Many electrochemical studies of solid materials utilize electrodes that fall within this definition. The second method entails the mixing the solid with conductive powder (usually carbon powder such as carbon black, graphite etc.) to support electronic conductivity and a binder to form a composite electrode. There are many composite electrode variations depending on the type of solid compound under study, the type of information desired and the applications. The earliest example of this is the carbon paste electrode developed by Ralph Adams in $1958 .{ }^{18}$ CPEs are now utilized in many fields for 
biological and analytical applications because of the ease of incorporating chemical modifiers into the paste to improve selectivity for certain analytes. ${ }^{19-21}$ Figure 2.9 shows the specific process and paste recipe for a CPE modified with multi-walled carbon nanotubes (MCNTs) for the selective accumulation and determination of trace amounts of bismuth using differential pulse anodic stripping voltammetry. ${ }^{22}$

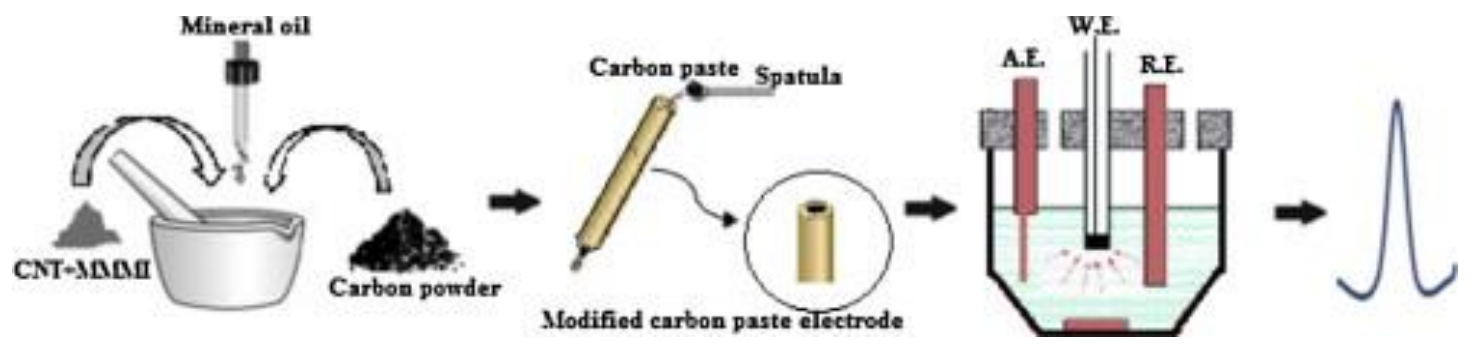

Figure 0.9 Process for fabrication of carbon paste modified with MCNTs for the selective determination of trace bismuth using differential pulse anodic stripping voltammetry. The paste is prepared by mixing carbon powder, mineral oil as a binder and MCNTs together in a mortar and pestle. The paste is packed into an electrode body and inserted into an electrochemical cell for the acquisition of data.

In the study of solids, CPE has proven useful for the analysis of poorly conducting materials such as lead oxides, ${ }^{23}$ silver halides, ${ }^{24}$ and metal chalcogenides. ${ }^{25,26}$ However, most CPE binders are miscible in organic solvents. ${ }^{27,28}$ Thus, the CPE is not compatible with nonaqueous electrolytes.

Researchers in the battery field routinely use composite electrodes to study the electrochemical behavior of electrode materials. In lithium ion battery (LIB) research, battery electrodes are prepared from the electrode material, which has reversible electrochemical behavior (e.g. $\mathrm{LiCoO}_{2}$ ), an additive to support conductivity and a binder. The conductive support is typically carbon powder and the most common binder is polyvinylidene fluoride (PVDF). These components are mixed together in a slurry in a solvent with a high solubility for the binder such as N-methyl-2-pyrrolidone (NMP). The slurry is cast or "doctor bladed" onto a current collector, and the solvent is evaporated off to leave behind a solid, composite electrode for electrochemical analysis. ${ }^{29}$ However, in these composite electrodes, the interfaces between the particles of 
electroactive material and conductive support is often interrupted by pores or the insulating binder, leading to slower charge transfer kinetics. Thus, voltammetric scan rates in the $\mu \mathrm{V} / \mathrm{s}$ range are required to compensate for the slow charge-transfer processes. Fiedler, Besenhard and Fooken demonstrated that the electrochemical characterization of battery electrode materials can be conveniently achieved via VMP at faster scan rates up to $\mathrm{mV} / \mathrm{s}$ range. ${ }^{30}$ By mechanically immobilizing ensembles of particles on the surface of a WE, the process of incorporating the solid particles into a composite electrode is no longer necessary, eliminating the porosity and insulating binder that slows charge transfer kinetics.

\subsubsection{Voltammetry of Microparticles (VMP) for the Electrochemical Analysis of Solids}

Voltammetry of microparticles (VMP) refers to a technique for immobilizing ensembles of solid microparticles or crystals on the surface of a solid electrode (Figure 2.10). Fritz Scholz first reported on this technique in $1989,31,32$ and the abbreviations VIM and VIMP are also used to refer to it. These modified electrodes can be prepared by deposition of solids from a suspension in a volatile solvent, and the solvent is evaporated off. Single crystals have been attached to electrode surfaces using a needle under a microscope. Microparticles from powders may be immobilized on electrode surface by mechanical transfer or abrasion. In this method the electrode surface is rubbed in a sample spot of the powder. This method of sample preparation has been heavily utilized due to its simplicity. In some cases, solid microparticles may be transferred from the polished surfaces of larger, compact solids. ${ }^{33,34}$

Despite the ease of sample transference and electrode modification, this technique has a few disadvantages. The first of these is the lack of control of the amount of sample loaded. Variations in the amount of sample on the electrode leads to variations in peak currents and peak potentials. However, the dependence of peak potential on the activity of the solid can be 
surmounted by employing a calibration curve. ${ }^{35}$ Additionally, the particle size, shape ${ }^{36}$ and distribution on the electrode surface affect the shape of the voltammetric peaks. Voltammetric peaks of ensembles of micrparticles are broader than those obtained from single particles. ${ }^{30}$

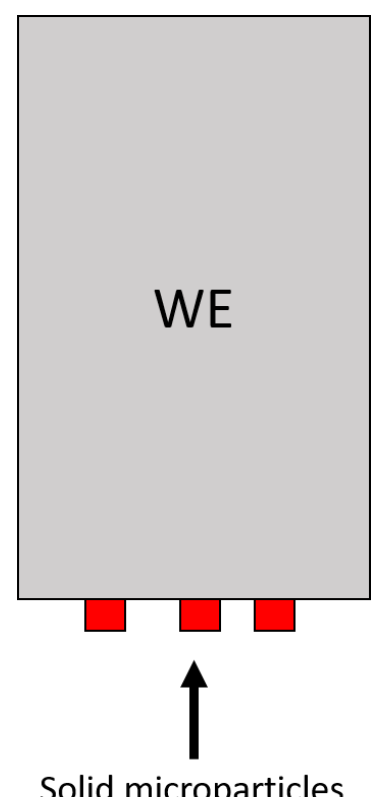

Figure 0.10 Ensembles of solid-microparticles (in red) immobilized on the surface of a solid working electrode (WE)

When it comes to electrochemical analyses there are three types of solid compounds: 1) those which are electrochemically inactive, 2) those which are irreversibly destroyed by oxidation or reduction, 3) those which can undergo reduction and oxidation reversibly ${ }^{8}$. The electrochemical activity of the solid depends on several factors including thermodynamic stability, electronic density of states and charge transfer kinetics at the interfaces of the solid and the ion conductor (electrolyte) and electronic conductor (working electrode). ${ }^{37}$

There is no limitation on the electrochemical analysis of solids with respect to electrical conductivity; the electrochemical analysis of insulating compounds by VMP is well established. ${ }^{34,38,39}$ Solid compounds that undergo reversible reduction and oxidation have the 
ability to exchange electrons with the electrode and ions with the electrolyte. This ability requires that the compound has structural features, such as cavities, channels or interlayers, which can house the ions. Thus, these types of solids have mixed ion and electronic conductivity. ${ }^{40} \mathrm{~A}$ wellstudied example of a solid with reversible redox behavior in aqueous electrolyte is Prussian blue. ${ }^{41-}$ 44

Carbon electrodes are well suited to VMP studies because they are good electronic conductors, inexpensive, and have a wide inert electrochemical window. The hardness of the carbon electrode, and therefore ability to adhere solid particles, is dependent upon the carbon structural phase. As a soft material graphite is appropriate for the mechanical adhesion of hard, inorganic microparticles. Soft organic particles adhere preferentially to harder surfaces such as glassy carbon. However, mechanical adhesion between hard, ceramic particles and harder glassy carbon can be achieved through surface roughening..$^{30,45}$

\subsubsection{Analytical Information Accessible via VMP}

A great deal of qualitative and quantitative information can be obtained from solid-state electrochemical analysis (SSEAC) utilizing VMP. This includes determination of elemental composition, phase composition, structural information, reactivity and mechanistic information, and calculation of thermodynamic data measured potentials.

Scholz and Meyer calculated the standard Gibbs energies of transformations of various sulfosalt minerals ( $\mathrm{R}$ 2.19) based on measurements of the cathodic peak potentials of the reduction and dissolution of microcrystalline samples immobilized on the surface of a graphite electrode.

$$
\mathrm{Ag}_{3} A s S_{3} \text { (xanthoconite) } \rightarrow \mathrm{Ag}_{3} A s S_{3} \text { (proustite) } \quad \text { R } 0.19
$$

Other thermodynamic data that has been obtained by this technique includes the calculation of stability constants for solid lead and mercury dithiocarbamate complexes ${ }^{46}$ redetermination of 
solubility products of insoluble compounds such as $\mathrm{CuSe}^{47}$ and examination of the thermodynamics of mixing of solid solutions and nonstoichiometric compounds. ${ }^{48}$

Although solid-state electrochemistry cannot provide absolute structural data like x-ray diffraction, it is possible to derive reliable structural information from the "fingerprint" electrochemical response of solids similar to many spectroscopic techniques. ${ }^{49}$ Enable identification and differentiation between structural polymorphs which the same chemical composition due to differences in electrochemical responses. For example, Grygar showed that hematite $\left(\alpha-\mathrm{Fe}_{2} \mathrm{O}_{3}\right)$, maghemite $\left(\gamma-\mathrm{Fe}_{2} \mathrm{O}_{3}\right)$, goethite $(\alpha-\mathrm{FeOOH})$, and lepidocrocite $(\gamma-\mathrm{FeOOH})$ undergo reductive dissolution at different rates and different peak potentials. ${ }^{50}$

Additionally, the relative quantification of $\mathrm{Fe}(\mathrm{III}), \mathrm{Fe}(\mathrm{II})^{51}$ and zirconium $^{52}$ has been determined in archaeological ceramics by Doménech's group who have used solid-state electroanalytical chemistry and VMP extensively in archaeometry. ${ }^{33,53-57} \mathrm{The} \mathrm{Fe}(\mathrm{III}) / \mathrm{Fe}(\mathrm{II})$ ratios in ceramic samples were determined from peak area measurents in linear scan voltammograms and from a semi-empirical method based on peak current measurements during CV cycling. Zirconium was determined via a standard addition method using $\mathrm{ZnO}$ as a reference compound.

Unambiguous phase identification and quantitative analysis of minerals covelliteklockmannite $\left(\mathrm{CuS}_{\mathrm{x}} \mathrm{Se}_{\mathrm{x}-1}\right)$ and emplectite-chalcostibite $\left(\mathrm{CuBi}_{\mathrm{x}} \mathrm{Sb}_{1-\mathrm{x}} \mathrm{S}_{2}\right)$ has been demonstrated via VMP abrasive stripping methods. Figure 2.11 a) shows the reduction voltammograms of $\mathrm{CuS}$, $\mathrm{CuSe}$ and nonstoichiometric compound $\mathrm{CuSe}_{0.4} \mathrm{~S}_{0.6}$. Figure 2.11 b) shows the reduction voltammogram of a 1:2 mechanical mixture of $\mathrm{CuS}$ and $\mathrm{CuSe}$. There is one peak for $\mathrm{CuS}$ around $-0.3 \mathrm{~V}$ and a peak for $\mathrm{CuSe}$ around $-0.5 \mathrm{~V}$. The nonstoichiometric compound has one peak at a potential between the peak potential values for pure $\mathrm{CuS}$ and $\mathrm{CuSe}$. However, a sample which is 
just a mechanical mixture of pure phases $\mathrm{CuS}$ and $\mathrm{CuSe}$ yields two separated voltammetric peaks with peak currents corresponding to the relative amounts of sample.
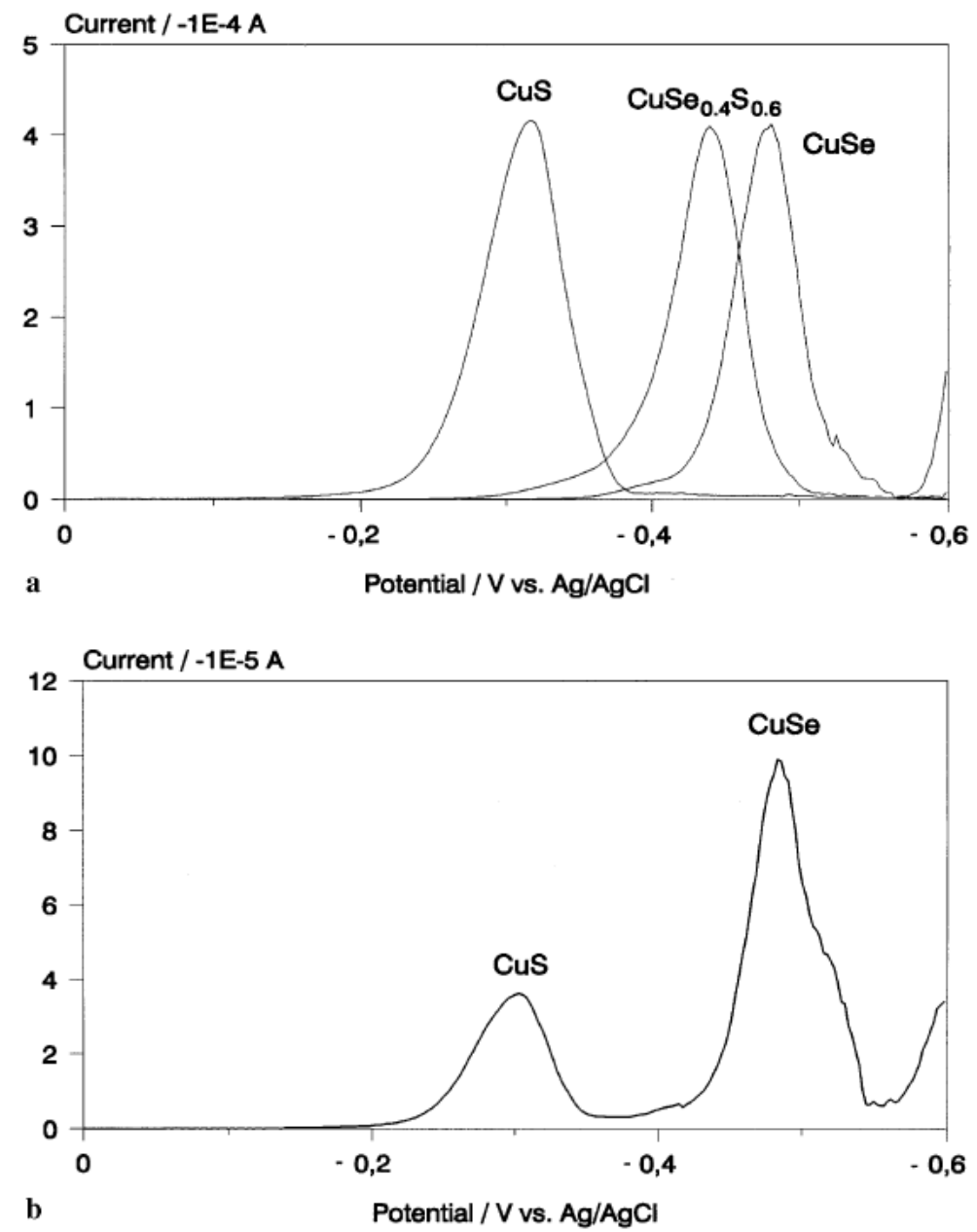

Figure 0.11 Cathodic voltammograms of a) $\mathrm{CuS}, \mathrm{CuSe}$ and $\mathrm{CuS}_{0.6} \mathrm{Se}_{0.4}$ and b) a mechanical mixture of $\mathrm{CuS}$ and $\mathrm{CuSe}(1: 2)$. Electrolyte: $1 \mathrm{M} \mathrm{H}_{2} \mathrm{SO}_{4}$, scan rate: $0.011 \mathrm{~V} / \mathrm{s}^{47}$

Electrochemically driven, topotactic transformations have been observed with VMP coupled with in situ techniques such as $\mathrm{XRD}^{58}$ and atomic force microscopy (AFM). ${ }^{59}$ Figures $2.12 \mathrm{a}$ ), b) and c) present the data from these studies. Figure 2.12 a) displays the reduction voltammogram of tetragonal $\mathrm{PbO}$ (litharge) to cubic $\mathrm{Pb}$. Figure $2.12 \mathrm{~b}$ ) shows the X-ray pairs of reflections collected in real-time as the crystal of $\mathrm{PbO}$ is reduced. Before reduction, only the reflections for $\mathrm{PbO}$ at $2.51 \mathrm{~A}$ is detected. These reflections decrease at the onset of reduction and 
the reflections for $\mathrm{Pb}$ at $2.48 \mathrm{~A}$ simultaneously increase. This instantaneous solid-state transformation from $\mathrm{PbO}$ to crystalline, cubic $\mathrm{Pb}$ was confirmed by in situ AFM results. Figure $2.12 \mathrm{c}$ ) shows an AFM micrograph of a PbO crystal after a 1s reduction, showing the reaction front on the crystal in the midst of its transformation.
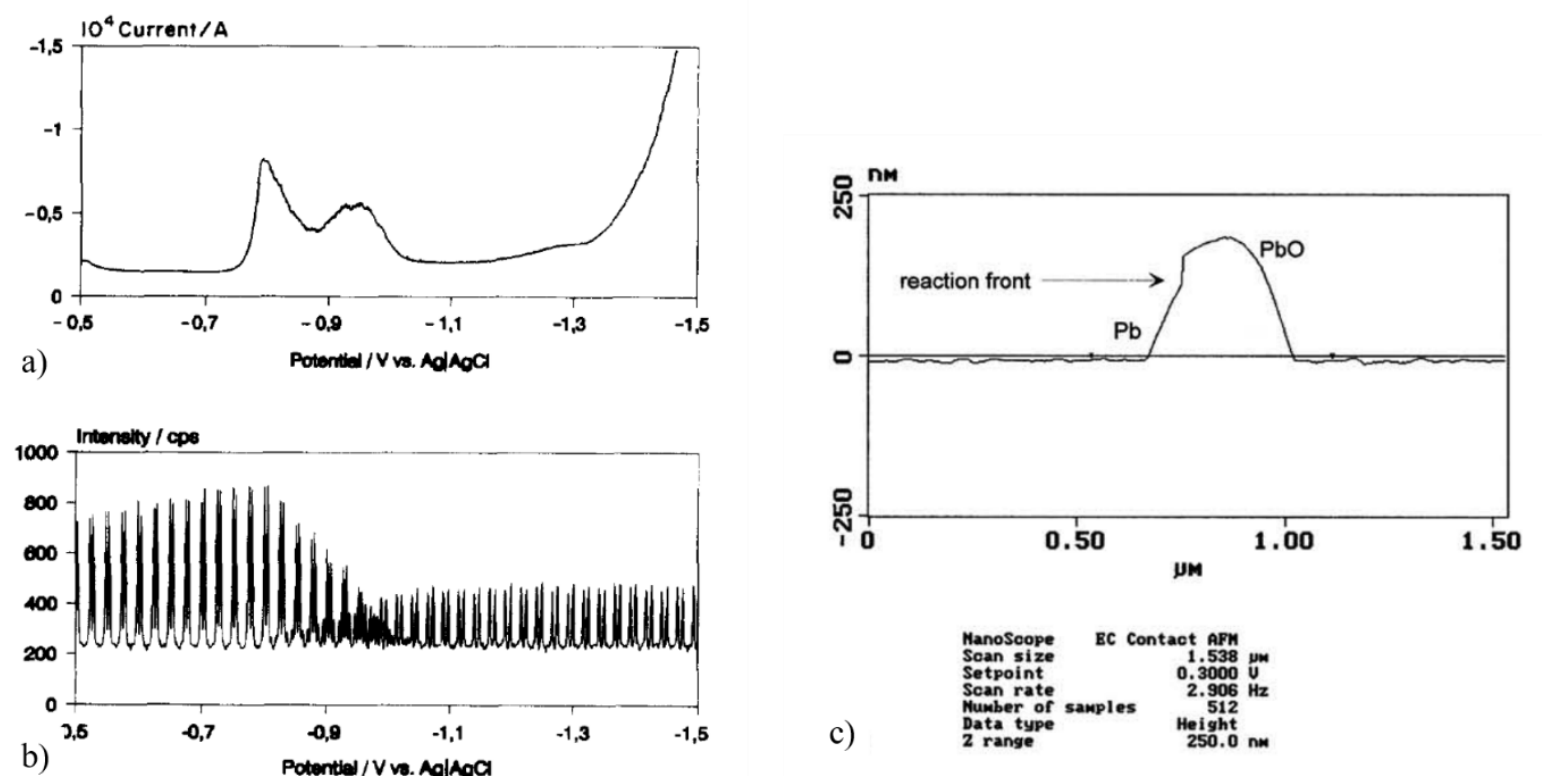

Figure 0.12 Electrochemical reduction of red tetragonal $\mathrm{PbO}$ (litharge) in situ coupled with $\mathrm{X}$-ray diffraction. $\mathrm{PbO}$ was mechanically immobilized on the surface of a paraffin impregnated graphite electrode, electrolyte: $1 \mathrm{M} \mathrm{KCl,} \mathrm{a)} \mathrm{linear} \mathrm{sweep} \mathrm{voltammogram} \mathrm{with} \mathrm{scan} \mathrm{rate} 0.1 \mathrm{mV} / \mathrm{s}$, b) corresponding diffraction pattern showing simultaneous decrease in $\mathrm{PbO}$ reflection and increase in

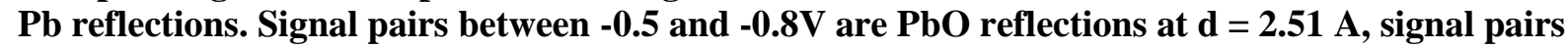

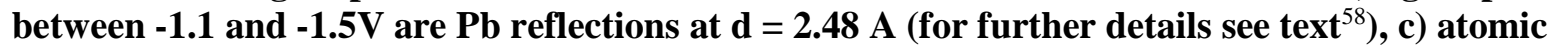
force micrograph of a $\mathrm{PbO}$ crystal on a gold surface in $1 \mathrm{M} \mathrm{KCl}$ after a reduction for 1 showing a step at the reaction front of the $\mathrm{PbO}$ to $\mathrm{Pb}$ transformation. ${ }^{59}$

\subsubsection{Preparation of Paraffin Impregnated Electrode (PIGE)}

PIGE is particularly suited to the mechanical attachment of solid microparticles as graphite is both a good conductor and a soft material. Wax impregnation further improves the electrode performance by increasing the electrodes adhesive properties and decreasing the amount of charging current observed in voltammograms by inhibiting intercalation of the supporting electrolytes into the graphite. The PIGE was prepared from a graphite rod (Alfa Aesar) of high purity of dimensions $6.15 \mathrm{~mm}$ in diameter and $152 \mathrm{~mm}$ in length. Paraffin wax was melted in a 
vacuum oven and the rod was placed in the melt. The oven was then evacuated. After a minimum of four hours the oven was re-pressurized, the rod was removed from the liquid wax and polished gently on paper after cooling.

After this process, solid particles may be mechanically attached by rubbing the polished end of the PIGE into the powdered sample spot dispersed on a glass plate. The PIGE is then inserted into the cell and raised so that the modified surface just touches the electrolyte. Cleaning the solids off the PIGE after experiments involves polishing the PIGE on clean paper until a blank $\mathrm{CV}$ is obtained.
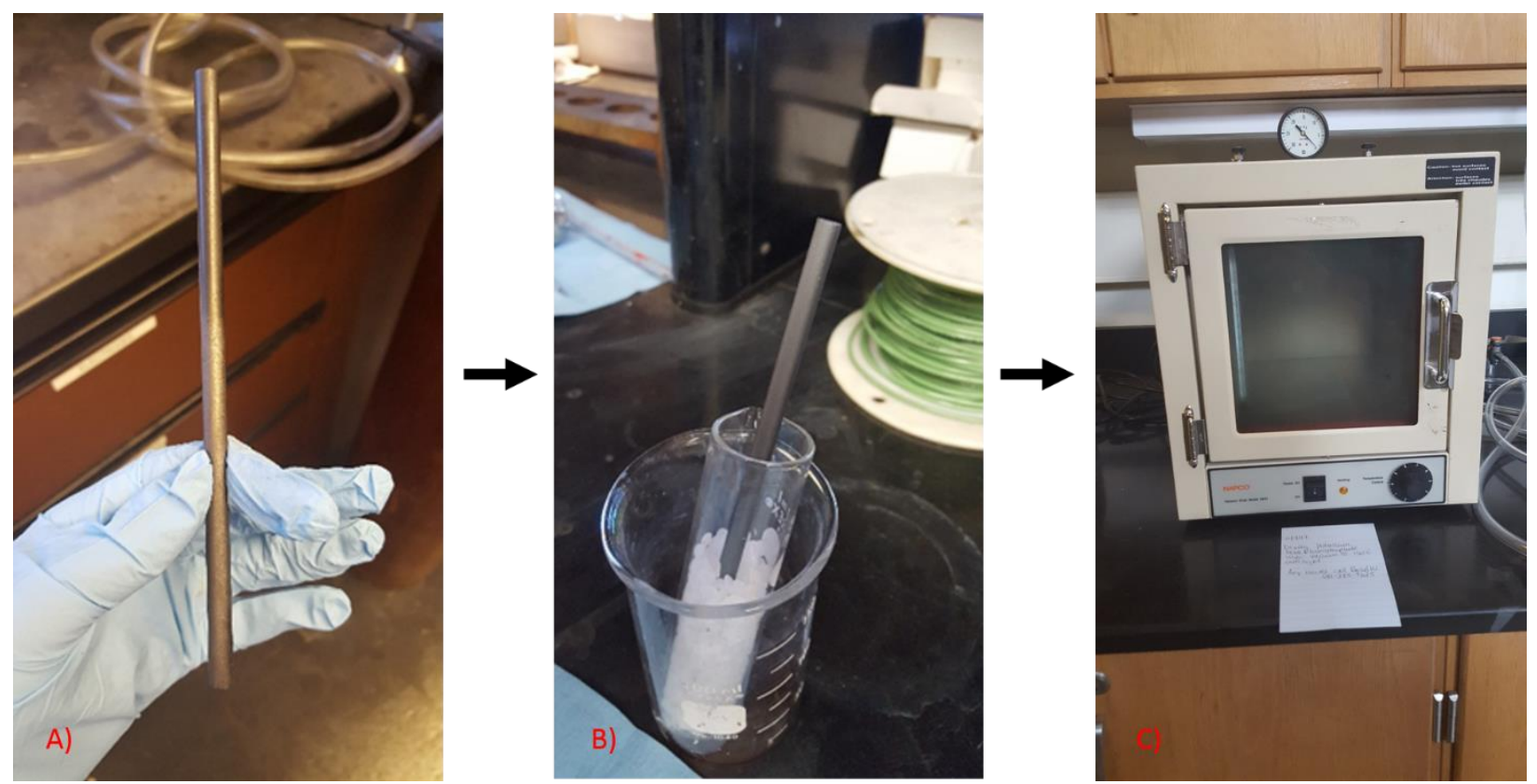

Figure 0.13 Preparationg of PIGE: a) high-purity graphite rod in b) paraffin wax assembly which is placed in c) vacuum oven at $125^{\circ} \mathrm{C}$ for $2-4$ hours.

\subsubsection{Surface Preparation of Glassy Carbon Electrode (GCE)}

A glassy carbon electrode (GCE) was machined from a glassy carbon rod (Alfa Aesar, ash $<100 \mathrm{ppm}$ ) with dimensions $100 \mathrm{~mm}$ in length and $4 \mathrm{~mm}$ in diameter and an aluminum rod. The aluminum rod provided the electrical contact between the potentiostat and the GCE. There was no insulating covering over the body of the GCE. During measurements, the GCE was lifted up and 
secured so that only the circular face of the GCE was touching the electrolyte to maintain a constant electrode area.

Abrasive attachment of carbide particles damages the surface of the GCE. Therefore, GCE surface was rigorously cleaned and polished between every experiment. The GCE was soaked in $3 \mathrm{M} \mathrm{HCl}$ to remove any residual carbide, oxide or hydroxide particles for a half hour and sonicated in DI water. The GCE was then polished successively with medium emery paper, fine emery paper until the surface appeared homogenous under a magnifying glass. Then the electrode was sonicated in DI water to remove dislodged carbon particles from the surface. The GCE was then polished on carbimet emery paper of 1200 grit or 12 microns. Following sonication, the electrode underwent further polishing in slurries of DI water and alumina of particle sizes 1.0, 0.3 and 0.05 microns. The electrode was rinsed with DI water, isopropanol and sonicated in between each polishing step. The GCE was then stored over charged silica in a vacuum desiccator.

\subsubsection{Sample Preparation for VMP experiments}

In all cases, solid carbide particles were attached to the surface of carbon working electrodes via mechanical abrasion. All carbides studied in this research with the exception of calcium carbide are commercially available as powders and were used as received. Small samples of carbide powder were transferred to a clean, smooth glass plate. The circular face of the carbon electrode was carefully rubbed in the sample spot on the plate. Excess powder was removed by gentle tapping of the electrode before insertion into the electrochemical cell.

In the case of calcium carbide, a small calcium carbide piece was selected and roughly crushed with a diamonite (synthetic sapphire) mortar and pestle. Samples of calcium carbide were chosen for analysis from the powder that had originated from within the carbide piece to avoid surface samples with oxide and hydroxide contamination. 


\section{References}

(1) Stiller, A. SEM Characterization of Products Aluminum Carbide and Tin Chloride Reactions, Unpublished Data; Morgantown, WV, 2010.

(2) Hardinger, J. Reactions of Metal Carbides to Produce Carbon, West Virginia University, 2017.

(3) Anderson, D. P. Analysis of Black “Carbon” Powder from West Virginia University; Dayton, OH, 2010.

(4) Sundermeyer, W. Fused Salts and Their Use as Reaction Media. Angew. Chemie - Int. Ed. 1965, 4 (3), 222.

(5) Orbakh, D. Nonaqueous Electrochemistry; CRC Press: New York, 1999.

(6) Williams, D. B. G.; Lawton, M. Drying of Organic Solvents: Quantitative Evaluation of the Efficiency of Several Desiccants. J. Org. Chem. 2010, 75 (24), 8351.

(7) Bard, A. J.; Faulkner, L. R. Electrochemical Methods: Fundamentals and Applications; 1980.

(8) Scholz, F. Electroanalytical Methods -Guide to Experiments and Applications, 2nd ed.; Scholz, F., Ed.; Springer: HeidelBerg, Germany, 2010.

(9) Laboratory Techniques in Electroanalytical Chemistry; Kissinger, P. T., Heinman, W. R., Eds.; Marcel Dekker, Inc.: New York, 1984.

(10) Hamann, C. H.; Hamnett, A.; Vielstich, W. Electrochemistry; Wiley-VCH: Weinheim u.a, 1998.

(11) Benck, J. D.; Pinaud, B. A.; Gorlin, Y.; Jaramillo, T. F. Substrate Selection for Fundamental Studies of Electrocatalysts and Photoelectrodes: Inert Potential Windows in Acidic, Neutral, and Basic Electrolyte. PLoS One 2014, 9 (10).

(12) Skoog, D. A.; Holler, F. J.; Nieman, T. A. Principles of Instrumental Analysis, 5. ed., [N.; Brooks/Cole [u.a]: London u.a., 2003.

(13) Kaufman, E. N. Characterization of Materials. In Vol 1; John Wiley \& Sons Inc: Hoboken, NJ, 2003; pp 580-592.

(14) Jones, D. A. Principles and Prevention of Corrosion, 2nd ed.; Prentice Hall, Inc, 1996.

(15) Mccafferty, E. Introduction to Corrosion Science; 2010.

(16) Paul, S.; Prasad, N. Study of Passivation, Repassivation and Metastable Pitting of 316L Stainless Implant in Bone Solution. Res. Rev. Electrochem. 2013, 4 (1), 7-12.

(17) Tallman, D. E.; Petersen, S. L. Composite Electrodes for Electroanalysis: Principes and Applications. Electroanalysis 1990, 2, 499-510.

(18) Adams, R. N. Carbon Paste Electrodes. Anal. Chem. 1958, 30 (9), 1576.

(19) Kalcher, K.; Svancara, I.; Radovan, M.; Vytras, K.; Walcarius, A. Heterogeneous Carbon Electrochemical Sensors; Grimes, Dickey, Pishko, Eds.; Encyclopedia of Sensors; 
American Scientific Publishers: The Pennsylvania State University, University Park, Pennsylvania, USA, 2006; pp 283-429.

(20) Kalcher, K.; Kauffmann, J. M.; Wang, J.; Svancara, I.; Vytras, K.; Neuhold, C.; Yang, Z. Sensors Based on Carbon-Paste in Electrochemical Analysis - a Review with Particular Emphasis on the Period 1990-1993. Electroanalysis 1995, 7 (1), 5-22.

(21) Švancara, I.; Vytřas, K.; Kalcher, K.; Walcarius, A.; Wang, J. Carbon Paste Electrodes in Facts, Numbers, and Notes: A Review on the Occasion of the 50-Years Jubilee of Carbon Paste in Electrochemistry and Electroanalysis. Electroanalysis 2009, 21 (1), 7-28.

(22) Fathirad, F.; Afzali, D.; Mostafavi, A.; Shamspur, T.; Fozooni, S. Fabrication of a New Carbon Paste Electrode Modified with Multi-Walled Carbon Nanotube for Stripping Voltammetric Determination of Bismuth(III). Electrochim. Acta 2013, 103, 206-210.

(23) Zakharchuk, N.; Meyer, S.; Lange, B.; Scholz, F. A Comparative Study of Lead Oxide Modified Graphite Paste Electrodes and Solid Graphite Electrodes with Mechanically Immobilized Lead Oxides. Croat. Chem. Acta2 2000, 73 (3), 667-704.

(24) Ruby, W. R.; Tremmel, C. G. Some Electrochemical Properties of a Carbon Paste-Silver Halide Electrode. J. Electroanal. Chem. Interfacial Electrochem. 1968, 18 (3), 231-238.

(25) Arce, E. M.; González, I. A Comparative Study of Electrochemical Behavior of Chalcopyrite, Chalcocite and Bornite in Sulfuric Acid Solution. Int. J. Miner. Process. 2002, 67 (1-4), 17-28.

(26) Lamache, M.; Bauer, D. Anodic Oxidation of Cuprous Sulfide and the Preparation of Nonstoichiometric Copper Sulfide. Anal. Chem. 1979, 51 (8), 1320-1322.

(27) Svancara, I.; Zima, J. Possibilities and Limitations of Carbon Paste Electrodes in Organic Electrochemistry. Curr. Org. Chem. 2011, 15, 3043-3058.

(28) Marcoux, Lynn S; Prater, K. B.; Prater, B. G. and Adams, R. N. A Nonaqueous Carbon Paste Electrode Simplified Purification of Acetonitrile for Elecfroanalytical Applications. Anal. Chem. 1965, 37 (11), 1446-1447.

(29) Talaie, E.; Bonnick, P.; Sun, X.; Pang, Q.; Liang, X.; Nazar, L. F. Methods and Protocols for Electrochemical Energy Storage Materials Research. Chem. Mater. 2017, 29 (1), 90105.

(30) Fiedler, D. A.; Besenhard, J. O.; Fooken, M. H. Rapid Electrochemical Characterization of Battery Electrode Materials in the Solid State. J. Power Sources 1997, 69 (1-2), 157160.

(31) Scholz, F.; Nitschke, L.; Henrion, G.; Damaschun, F. A Technique to Study the Electrochemistry of Minerals. Naturwissenschaften 1989, 76 (4), 167-168.

(32) Scholz, F.; Nitschke, L.; Henrion, G. A New Procedure for Fast Electrochemical Analysis of Solid Materials The Effect of N A D H on Different Human and Mouse. 1989, 76, 910 .

(33) Doménech-Carbó, A.; Doménech-Carbó, M. T.; Peiró-Ronda, M. A. "One-Touch” 
Voltammetry of Microparticles for the Identification of Corrosion Products in Archaeological Lead. Electroanalysis 2011, 23 (6), 1391-1400.

(34) Scholz, Fritz and Meyer, B. Electroanalytical Chemistry, Vol. 2; Bard, Allen J. and Rubinstein, I., Ed.; Marcel Dekker, Inc., 1998; pp 60-87.

(35) Meyer, B.; Scholz, F. Redetermination of the Transformation Enthalpies of the Xanthoconite-Proustite, Pyrostilpnite-Pyrargyrite and Trechmannite-Smithite Phase Transitions. Phys. Chem. Miner. 1997, 24 (1), 50-52.

(36) Schröder, U.; Oldham, K. B.; Myland, J. C.; Mahon, P. J.; Scholz, F. Modelling of Solid State Voltammetry of Immobilized Microcrystals Assuming an Initiation of the Electrochemical Reaction at a Three-Phase Junction. J. Solid State Electrochem. 2000, 4 (6), 314-324.

(37) Brainina, K. Z.; Neyman, E. Phase Analysis of Solids. In Electroanalytical Stripping Methods; Winefordner, J. D., Ed.; John Wiley \& Sons, 1993; pp 123-174.

(38) Hermes, M.; Scholz, F. The Electrochemical Oxidation of White Phosphorus at a ThreePhase Junction. Electrochem. commun. 2000, 2 (12), 845-850.

(39) Doménech-Carbó, A.; Labuda, J.; Scholz, F. Electroanalytical Chemistry for the Analysis of Solids: Characterization and Classification (IUPAC Technical Report)*. Pure Appl.

Chem 2013, 85 (3), 609-631.

(40) Gellings, P. J.; Bouwmeester, H. J. M. The CRC Handbook of Solid State Electrochemistry; CRC Press Inc, 1996.

(41) Ellis, D.; Eckhoff, M.; Neff, V. D. Electrochromism in the Mixed-Valence Hexacyanides. 1. Voltammetric and Spectral Studies of the Oxidation and Reduction of Thin Films of Prussian Blue. J. Phys. Chem 1981, 85 (14), 1225-1231.

(42) McCargar, J. W.; Neff, V. D. Thermodynamics of Mixed-Valence Intercalation Reactions: The Electrochemical Reduction of Prussian Blue. J. Phys. Chem. 1988, 92 (12), 35983604.

(43) Dostal, A.; Meyer, B.; Scholz, F.; Schröder, U.; Bond, A. M.; Marken, F.; Shaw, S. J. Electrochemical Study of Microcrystalline Solid Prussian Blue Particles Mechanically Attached to Graphite and Gold Electrodes: Electrochemically Induced Lattice Reconstruction. J. Phys. Chem. 1995, 99 (7), 2096-2103.

(44) Wang, R. Y.; Wessells, C. D.; Huggins, R. A.; Cui, Y. Highly Reversible Open Framework Nanoscale Electrodes for Divalent Ion Batteries. Nano Lett. 2013, 13 (11), 5748-5752.

(45) Lange, B.; Lovri, I. I.; Scholz, F. The Catalytic Action of Adsorbed Thiocyanate Ions and Thiourea in the Electron Transfer from Glassy Carbon to Solid Copper(I) Selenide and Copper (I) Sulfide Particles. J. Electroanal. Chem. 1996, 418, 21-28.

(46) Bond, A. M.; Scholz, F. Calculation of Thermodynamic Data from Voltammetry of Solid Lead and Mercury Dithiocarbamate Complexes Mechanically Attached to a Graphite Electrode. J. Phys. Chem. 1991, 95 (19), 7460-7465. 
(47) Meyer, B.; Zhang, S.; Scholz, F. The Quantitative Analysis of Mixed Crystals CuSxSe1-X with Abrasive Stripping Voltammetry and a Redetermination of the Solubility Product of $\mathrm{CuSe}$ and the Standard Potential of the $\mathrm{Cu} / \mathrm{CuSe}$ Electrode. Fresenius J Anal Chem 1996, $356,267-270$.

(48) Bond, A. M.; Scholz, F. Electrochemical, Thermodynamic, and Mechanistic Data Derived from Voltammetric Studies on Insoluble Metallocenes, Mercury Halide and Sulfide Compounds, Mixed Silver Halide Crystals, and Other Metal Complexes Following Their Mechanical Transfer to a Graphi. Langmuir 1991, 7 (12), 3197-3204.

(49) Doménech-Carbó, A.; Labuda, J.; Scholz, F. Electroanalytical Chemistry for the Analysis of Solids: Characterization and Classification (IUPAC Technical Report). Pure Appl. Chem. 2012, 85 (3), 609-631.

(50) Grygar, T. Electrochemical Dissolution of Iron (III) Hydroxy-Oxides: More Information about the Particles. 1Collect. Czech. Chem. Commun. 1996, 61 (1), 93-.

(51) Doménech Carbó, A.; Sánchez-Ramosa, S.; Doménech-Carbó, M. T.; GimeroAdelantado, J. V.; Bosh-Reig, F.; Yusá-Marco, D. J.; Saurí-Peris, M. . Electrochemical Determination of the Fe ( III )/ Fe ( II ) Ratio in Archaeological Ceramic Materials Using Carbon Paste and Composite Electrodes. Electroanalysis 2002, 14 (10), 685-696.

(52) Doménech-Carbó, A.; Moya-Moreno, M.; Doménech-Carbó, M. T. Standard Addition Method Applied to Solid-State Stripping Voltammetry: Determination of Zirconium in Minerals and Ceramic Materials. Anal. Bioanal. Chem. 2004, 380 (1), 146-156.

Doménech-Carbó, A.; del Hoyo-Meléndez, J. M.; Doménech-Carbó, M. T.; Piquero-Cilla, J. Electrochemical Analysis of the First Polish Coins Using Voltammetry of Immobilized Particles. Microchem. J. 2017, 130, 47-55.

(54) Doménech, A.; Doménech-Carbó, M. T.; De Agredos Pascual, M. L. V. Dehydroindigo: A New Piece into the Maya Blue Puzzle from the Voltammetry of Microparticles Approach. J. Phys. Chem. B 2006, 110 (12), 6027-6039.

Doménech-Carbó, a; Doménech-Carbó, M. T.; Gimeno-Adelantado, J. V; Bosch-Reig, F.; Saurí-Peris, M. C.; Casas-Catalán, M. J. Electrochemical Analysis of the Alterations in Copper Pigments Using Charge Transfer Coefficient/Peak Potential Diagrams. Application to Microsamples of Baroque Wall Paintings Attached to Polymer Film Electrodes. Fresenius. J. Anal. Chem. 2001, 369 (7-8), 576-581.

(56) Doménech, A.; Doménech-Carbó, M. T.; Edwards, H. G. M. Quantitation from Tafel Analysis in Solid-State Voltammetry. Application to the Study of Cobalt and Copper Pigments in Severely Damaged Frescoes. Anal. Chem. 2008, 80 (8), 2704-2716.

(57) Doménech-Carbó, A. Editorial: Electrochemistry for Conservation Science. J. Solid State Electrochem. 2010, 14 (3), 349-351.

(58) Meyer, B.; Ziemer, B.; Scholz, F. In Situ X-Ray Diffraction Study of the Electrochemical Reduction of Tetragonal Lead Oxide and Orthorhombic $\mathrm{Pb}(\mathrm{OH}) \mathrm{Cl}$ Mechanically Immobilized on a Graphite Electrode. J. Electroanal. Chem. 1995, 392, 79-83. Hasse, U.; Scholz, F. In Situ Atomic Force Microscopy of the Reduction of Lead Oxide 
Nanocrystals Immobilised on an Electrode Surface. 2001, 3, 429-434. 


\section{Chapter 3: Characterization Methods}

This chapter briefly reviews the instrumental techniques used for supporting analyses in this research. These analytical techniques were used primarily to characterize the carbon materials produced in molten salt and solution state reactions of ionic carbides with post-transition metal salts. These characterization methods include micro-Raman spectroscopy, scanning electron microscopy (SEM) coupled with electron dispersive spectroscopy (EDS), x-ray photoelectron spectroscopy (XPS) and powder x-ray diffraction (XRD). Additionally, SEM, Raman and XPS were utilized to characterize the carbon electrodes used for VMP studies and investigate the interactions between the carbon electrodes and nonaqueous electrolytes. Thus, reviews of each technique will have a focus on the techniques' applicability to carbon materials' characterization.

\subsection{Micro-Raman Spectroscopy}

The Raman Effect is a phenomenon in which incident light is inelastically scattered by molecular vibrations in a material. It is a heavily used analytical and characterization technique due to its wide applicability in many fields. Most molecular samples - e.g. solids, thin films, gels, liquids, mixtures, etc., yield Raman spectra. The spectra of materials are unique to the chemical compositions of these materials, and are used as chemical "fingerprints" for materials identification in many fields. ${ }^{1-5}$ Quantitative, structural and morphological analyses can also be obtained with specialized Raman spectroscopic methods such as resonance Raman spectroscopy (RRS) ${ }^{6,7}$ surface enhanced Raman spectroscopy (SERS), and polarized Raman spectroscopy. This survey of Raman spectroscopy is not meant to be exhaustive, but a brief review to give context for the analyses presented in this work. Raman spectroscopy was utilized in our research for the characterization of solid materials, especially the carbon materials produced from molten salt and solution reactions with aluminum and calcium carbide. 
Instrumentation for Raman spectroscopy consists of a laser excitation source, a sample illumination system and a spectrometer. ${ }^{8}$ When the sample illumination system coupled to the laser and spectrometer is an optical microscope, micro-Raman spectroscopy can be performed. The intensity of a peak in the Raman spectrum of any compound is inversely proportional to the fourth power of the wavelength of the laser ${ }^{9}$ while the spatial resolution of the incident laser is directly proportional it. The wavelengths at which scattering and spatial resolution is optimal lie in the ultraviolet to near-infrared region. However, UV-Vis wavelengths may suffer from fluorescence interference. This can be mitigated by using NIR wavelength excitation. ${ }^{10}$

A Renishaw InVia Raman Microscope with laser excitation of $532 \mathrm{~nm}$ with a maximum power of $100 \mathrm{~mW}, 1800 \mathrm{l} / \mathrm{m}$ grating was utilized for Raman analyses and characterization. Spectra were taken on the 50x objective typically at $10 \%$ unless otherwise stated. 


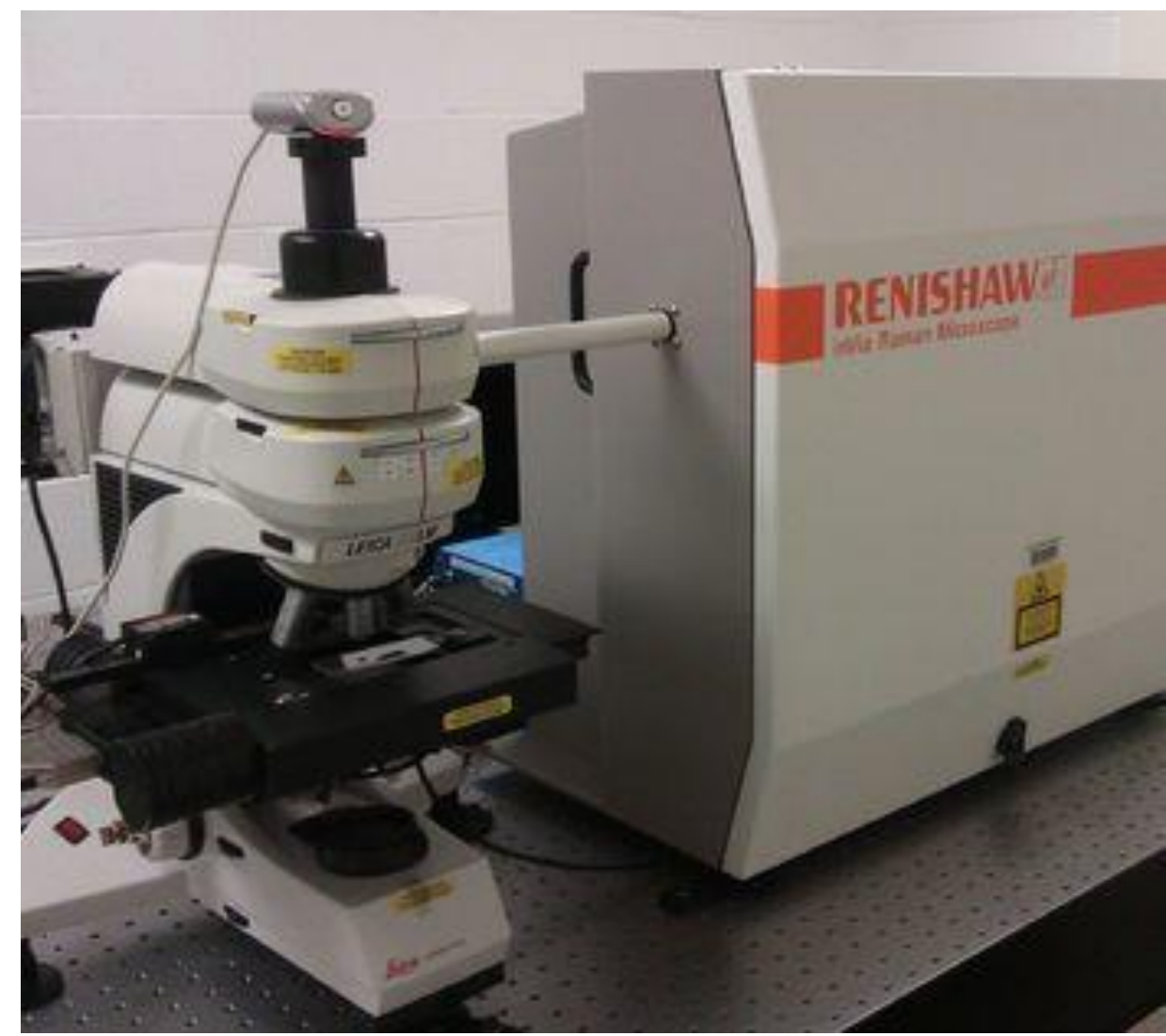

Figure 0.1 Renishaw inVia Raman Microscope

\subsubsection{Raman Spectroscopy of Solids}

The selection rules for Raman spectroscopy of solids differ from those for molecular spectroscopy and require some knowledge of solid-state physics for rigorous interpretation. ${ }^{3,11,12}$ A brief introduction on solid-state Raman spectra is provided in this section. For a more complete review, we refer to references. ${ }^{3,11,13-15}$

In addition to molecular point group symmetry, vibrations within the solid, in which the atomic vibrations are coupled to each other throughout the lattice must be considered. Therefore, both molecular and crystal symmetry must be taken into account. Lattice vibrations, called phonons, are characterized by wave vector, $\boldsymbol{K}$. The length of $\boldsymbol{K}$ is equal to $2 \pi / \lambda$, where $\lambda$ is the wavelength. There are two types of phonons: optical and acoustical. The former may be observed 
by optical spectroscopy, whereas the latter phonon type corresponds to sound waves traveling through solid media.

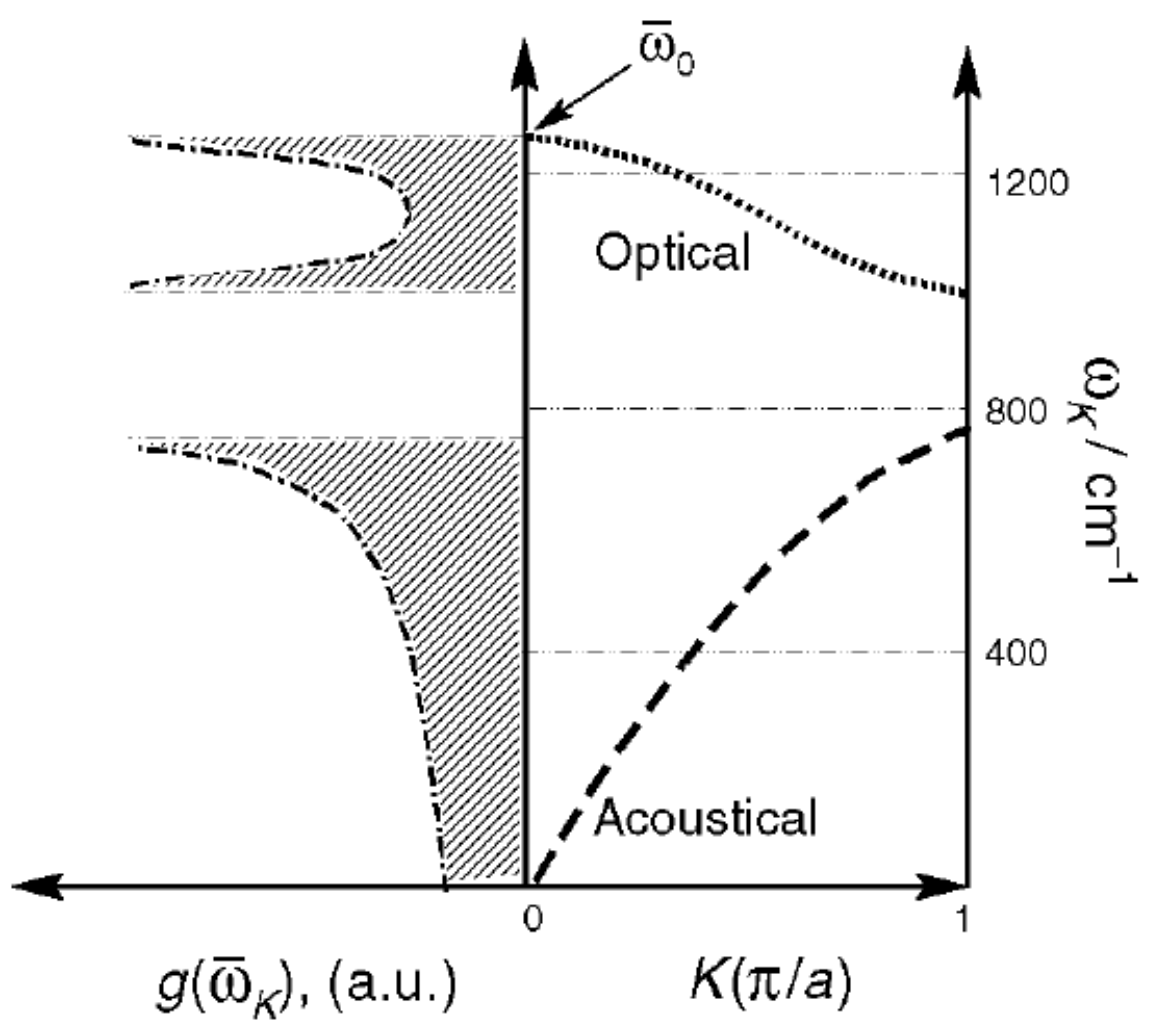

Figure 0.2 The right panel shows the phonon dispersion curve for a lattice with two atoms in a unit cell. The left panel shows the density of states curves for both the optical and acoustical phonon branches. ${ }^{12}$

The phonon frequency, $\bar{\omega}_{\boldsymbol{K}}$, depends on the length and direction of wave vector $\boldsymbol{K}$. Dispersion curves such as the one shown above in Figure 3.2, illustrate the relationship between $\boldsymbol{K}$ and, $\bar{\omega}_{K}$. The range from $-\pi / a \leq \boldsymbol{K} \leq \pi / a$ is called the first Brillouin zone (BZ), which is the zone physically relevant for spectroscopy. Raman scattering requires that energy be conserved

$$
h c \bar{\omega}-h c \bar{\omega}^{\prime}= \pm h c \bar{\omega}_{\boldsymbol{K}}
$$


where $\bar{\omega}, \bar{\omega}^{\prime}$, and $\bar{\omega}_{\boldsymbol{K}}$ are the frequencies for incident light, scattered light and the phonon which is either created (+) or destroyed (-). Thus, the conservation of momentum in terms of wave vectors is

$$
k-k^{\prime}= \pm K
$$

where $\boldsymbol{k}, \boldsymbol{k}^{\prime}$, and $\boldsymbol{K}$ are the wave vectors for the incident light, scattered light and phonon respectively. Taking into account the geometry of the Raman experiment and the wavelength of the laser excitation require that $\boldsymbol{K}=0$ for a Raman process involving one phonon. In the simplified example in Figure 3.2 this corresponds to the phonon frequency, $\bar{\omega}_{0}$ for the optical branch at $\boldsymbol{K}=$ 0. In terms of molecular spectroscopy, this frequency can be considered the fundamental transition and in solid-state physics is termed the first order spectrum.

Second order bands occur in Raman spectroscopy in which a two-phonon process occurs in the phonons propagate in opposite directions and are equal in magnitude, such that the solidstate selection rule $\boldsymbol{K}=0$ is still satisfied. Second order bands are analogous with overtones and combination bands in molecular spectroscopy.

Second order spectra can be interpreted by considering the vibrational density of states shown to the left in Figure 3.2. The density of states, $g\left(\bar{\omega}_{\boldsymbol{K}}\right)$, is inversely proportional to the slope of the dispersion curve:

$$
g\left(\bar{\omega}_{\boldsymbol{K}}\right)=\alpha\left(\frac{d\left(\bar{\omega}_{\boldsymbol{K}}\right)}{d \boldsymbol{K}}\right)^{-1}
$$

Thus, the density of states for the optical phonons are highest at the flat parts of the dispersion curve. In Figure 3.2, this occurs at the zone center, $\boldsymbol{K}=0$, and the zone boundary. In a 
two-phonon process, sampling of phonons is not restricted to the zone center, and all $\boldsymbol{K}$ values are allowed provided that the selection rule $K=0$ is still met. This means that for a two phonon, second order process the two phonons must have wave vectors that are equal in length but opposite in direction. In principle, all phonons on the dispersion curve in a second order process can be observed. Nevertheless, the maximum contributions come from the points at which the density of vibrational states is highest, at the zone center and zone boundary.

The situation again becomes more complex when considering crystal size and semi crystalline and amorphous solid phases. The extreme case of true amorphous materials, e.g. glasses, lack long-range order resulting in the loss of translational symmetry. This wide range of molecular environments leads to broadened peaks and high scattering backgrounds. Semicrystalline phases have some long-range order and their spectral band activity is determined by the symmetry of chains or sites within the crystal. The spectra of semi-crystalline materials have a combination of crystalline and amorphous characteristics. This can be seen clearly in the comparison of spectra of amorphous type carbon materials, such as coke and glassy carbon, with crystalline carbon materials in the following section 3.1.3 Raman Spectroscopy of Carbon

\section{Materials.}

Furthermore, crystal size and lattice defects introduce additional spectral features. For example, point group theory assumes an infinite lattice, so when crystals are sufficiently small, i.e. $10 \mathrm{~nm}$ or less, their symmetry is not accurately defined by the space group. This can lead to the activation of bands that were previously forbidden by theory. A classic example of this, is the activation of the silent $A_{l g}$ mode in small finite graphite crystals now known as the " $\mathrm{D}$ " peak in

the spectra of graphitic materials. ${ }^{16}$ Similarly, lattice defects in sufficient concentrations also disrupt crystal symmetry, which can result in activation of forbidden bands or phonon confinement 
in nanosized materials. Phonon confinement is a consequence of the localization of a phonon in a small region of space. This confinement introduces uncertainty in the phonon's momentum and phase angle due to the uncertainty principle. The uncertainty in the phase angle gives rise to shifts and broadening of Raman bands. Osswald et al. have observed this phenomenon in nanodiamonds, studying the correlation of phonon confinement with both crystal size and lattice defects. ${ }^{17}$

\subsubsection{Artifacts and anomalies in Solid-State Raman Spectroscopy}

The anomalies and artifacts that occur in both solid-state and molecular Raman spectroscopy are similar. "Hot pixels" in CCD array detectors and low-level radiation events such as cosmic rays can cause sharp, irregular spikes to appear in spectra. ${ }^{9}$ Peaks due to cosmic rays appear randomly in the spectra most often at intensities higher than the Raman signals. Hot pixels are sharp and can be lower in intensity. Spectral artifacts due to hot pixels may be recognized by performing a dark noise scan, and they can be removed via software.

\subsubsection{Interpretation of Raman Spectra of Carbon Materials}

Raman spectroscopy is the gold standard for the characterization of carbon materials.

Figure 3.3 shows the structures for a selected number of carbon allotropes. Raman characterization of carbon materials has been reviewed extensively in the literature. ${ }^{5,18-22}$ The Raman spectra of all carbon materials contain similar features, but are also highly sensitive to small structural changes. Here we will review the spectral features of amorphous, graphitic carbons, diamond and graphene, which are the most relevant to the research in this work. For details on the Raman spectra of nanomaterials such as carbon nanotubes ${ }^{5,23}$ and fullerenes ${ }^{24,25}$ the author refers to these reviews. ${ }^{23,25-27}$ 

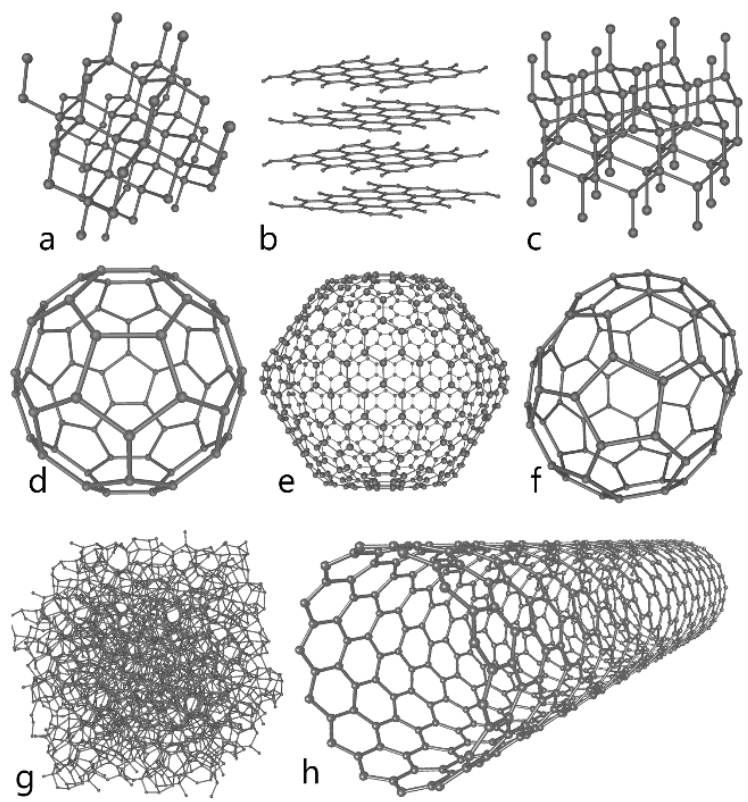

Figure 0.3 Selected allotropes of carbon: a) diamond, b) graphite, c) lonsdaleite, $d-f)$ fullerenes $\left(\mathbf{C}_{60}\right.$, $\left.\mathrm{C}_{450}, \mathrm{C}_{70}\right) ; \mathrm{g}$ ) amorphous carbon, $\mathrm{h}$ ) carbon nanotube. Source:

https://courses.lumenlearning.com/introchem/chapter/allotropes-of-carbon/

\subsubsection{Amorphous Carbons}

As mentioned in an earlier section, the Raman bands associated with glassy and amorphous type carbons are broad due to lack of long-range order and loss of translational symmetry, which results in a broad distribution of states. There are many different types of amorphous carbons and they are typically differentiated by their physical properties and applications. Glassy carbon, a non-graphitizing carbon, combines glassy and ceramic properties with those of graphite such as electrical conductivity and high temperature resistance. The Raman spectra of glassy carbon ${ }^{28}$ has two broad bands at 1340 and $1590 \mathrm{~cm}^{-1}$ shown in Figure 3.4. Acetylene black, another type of amorphous carbon material made from the incomplete combustion of petroleum products has broad bands centered at 1355 and $1575 \mathrm{~cm}^{-1}$ similar to glassy carbon. ${ }^{29}$ The spectra of coals and cokes $^{30,31}$ have broad bands around 1360 and $1600 \mathrm{~cm}^{-1}$. The bandwidths and position can vary with the rank of coal and the degree of order or graphitization in cokes. The Raman spectra of two 
different types of coke are shown in Figure 3.4 for comparison with glassy carbon. Needle coke, so named because the anisotropic microstructure gives it a needle like appearance, has broad bands at 1348 and $1597 \mathrm{~cm}^{-1}$. The spectra of a sample of coke lacking this anisotropic microstructure is shown below it, with broad bands at 1370 and $1599 \mathrm{~cm}^{-1}$. Our results are comparable to the Raman studies on cokes performed by Green et al. ${ }^{31}$

Even though coal is not strictly a pure carbon material, Tsu et al. showed that the Raman spectra of different coals were surprisingly similar to the Raman spectra of polycrystalline graphite in spite of the complexity and mineral deposits present in coal. ${ }^{30}$ The spectra consisted of broad peaks at 1370 and $1606 \mathrm{~cm}^{-1}$. Although the Raman spectra of amorphous carbons look very similar, they do exhibit small differences in intensity and wavenumbers. These differences can be correlated with differences in microstructure, but this is beyond the scope of this overview.

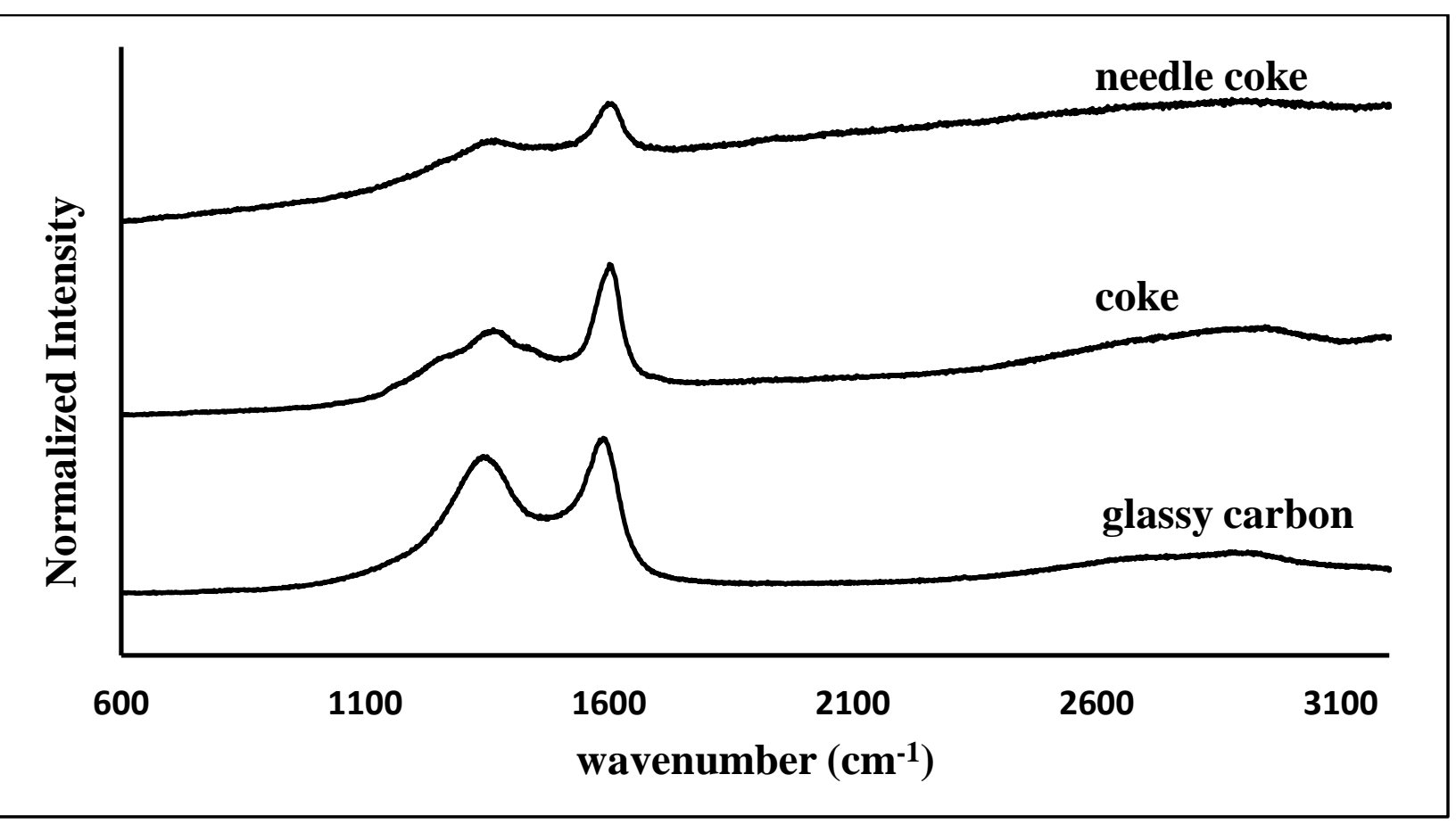

Figure 0.4 Raman spectra of amorphous type carbon materials glassy carbon, coke and needle coke. 


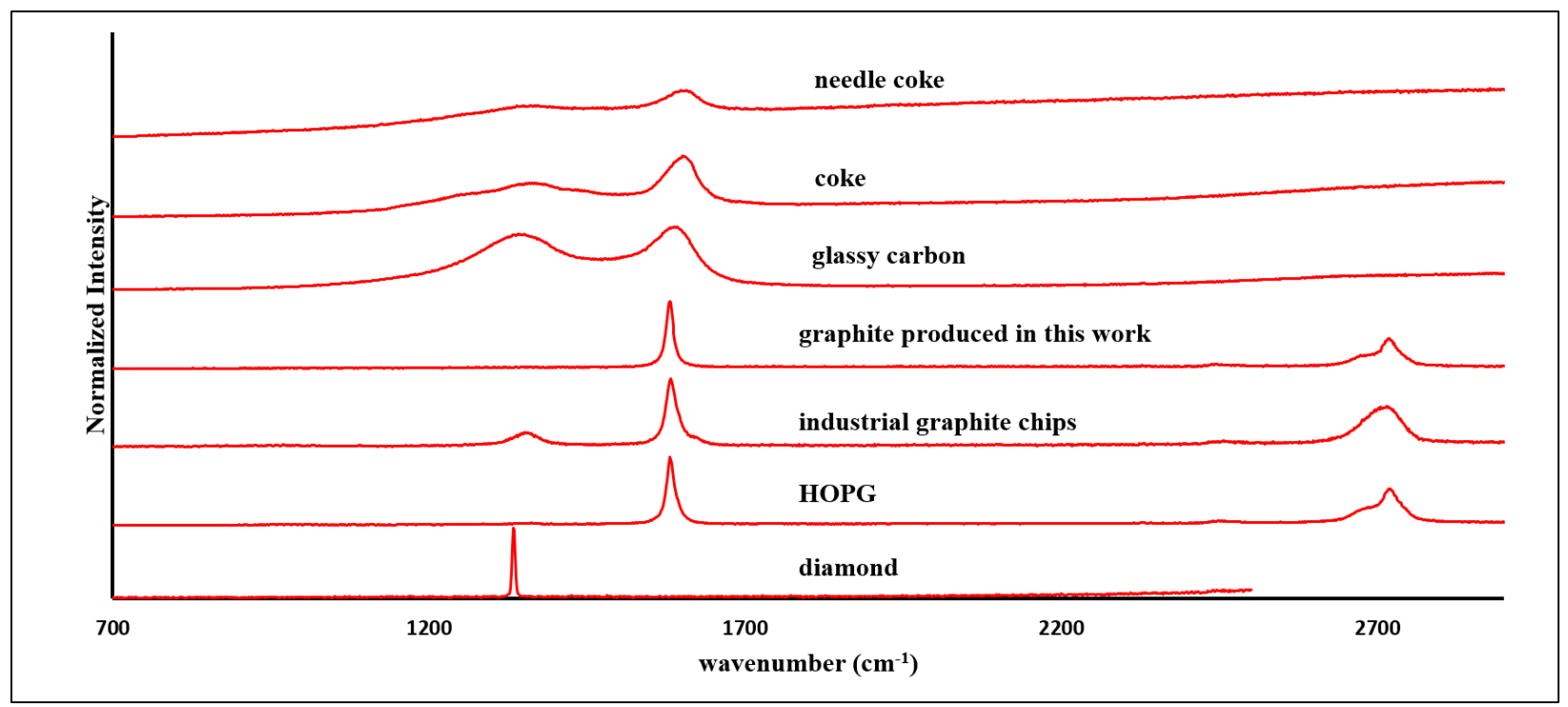

Figure 0.5 Raman spectra of carbon materials ranging from amorphous to highly ordered.

The $\pi$ states in amorphous carbon are more polarizable than $\sigma$ bonds, so $\mathrm{sp}^{2}$ carbon has a larger Raman cross-section. In addition, $\mathrm{sp}^{2}$ bonds are more resonant with visible to near IR light and dominate the spectra compared to $\mathrm{sp}^{3}$ vibrational modes which are resonant with UV light.

\subsubsection{The Raman spectra of diamond}

The first order Raman spectra of single crystal, gem quality diamond has only one sharp peak around $1332 \mathrm{~cm}^{-1}$ which corresponds to the $T_{2 g}$ mode. ${ }^{32}$ 


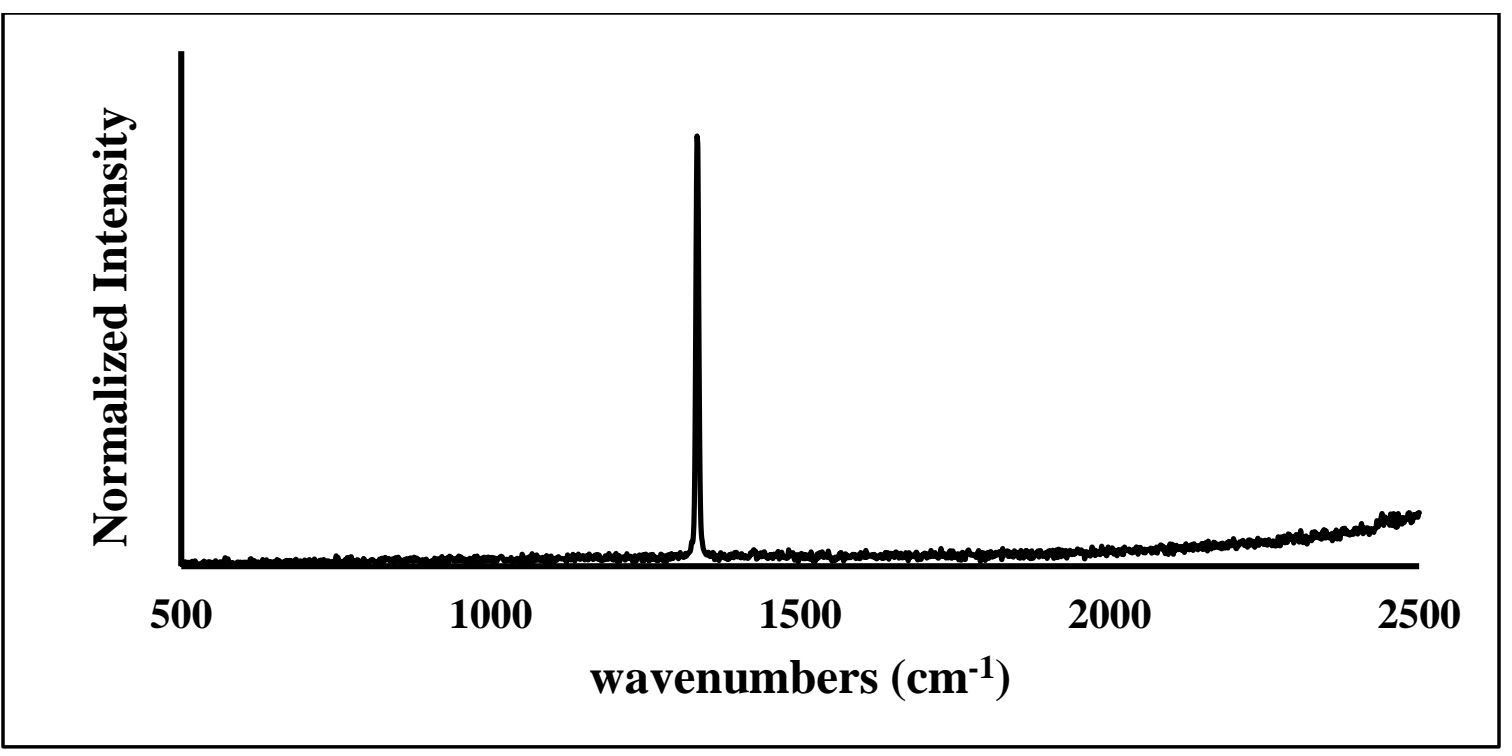

Figure 0.6 Raman spectrum of diamond

A second order peak ${ }^{33}\left(2467 \mathrm{~cm}^{-1}\right)$ and third order peaks ${ }^{34}\left(3300\right.$ and $\left.3825 \mathrm{~cm}^{-1}\right)$ are much less intense by several orders of magnitude and are therefore difficult to observe without specialized instrumentation and heating the sample to high temperatures. Additional peaks have been observed in the spectra of nanodiamonds grown by chemical vapor deposition (CVD). Most CVD diamonds are polycrystalline with amorphous carbon at their grain boundaries. As the crystal size decreases the Raman bands broaden and new peaks can be observed in the Raman spectra due to the breakdown of selection rules. Table 3.1 lists Raman peaks typically observed for nanodiamonds and CVD diamond films.

\begin{tabular}{clc}
\hline Position $\left(\mathbf{c m}^{-\mathbf{1}}\right)$ & \multicolumn{1}{c}{ Assignment } & Reference \\
\hline $1100-1150$ & $\begin{array}{l}\text { Transpolyacetylene at grain } \\
\text { boundaries }\end{array}$ & 34,35 \\
1332 & $\begin{array}{l}\text { First-order Raman peak, due } \\
\text { to sp vibrations } \\
\mathrm{sp}^{2} \text { amorphous carbon }(\mathrm{D} \\
\text { peak) } \\
\text { Transpolyacetylene at grain } \\
\text { boundaries } \\
\text { spe amorphous carbon }(\mathrm{G}\end{array}$ & 36 \\
peak) & 37 \\
\hline
\end{tabular}

Table 0.1 Raman band assignments for diamond and nanodiamond 


\subsubsection{The spectrum of graphite and graphene}

The first Raman spectrum of graphite was measured in 1970 by Tuinstra and Koenig. ${ }^{38}$ The spectrum of pristine, single crystal graphite consisted of one sharp peak at $1575 \mathrm{~cm}^{-1}$. This peak was attributed to the doubly degenerate $\mathrm{E}_{2 \mathrm{~g}}$ mode corresponding to the in plane stretching modes of the $\mathrm{sp}^{2}$ carbon bonds in graphite. This peak was thenceforth dubbed the "G" peak in the literature for carbon materials analysis by Raman spectroscopy. Other graphitic materials showed a second peak at $\sim 1350 \mathrm{~cm}^{-1}$. Tuinstra and Koenig originally attributed this band to an $A_{1 \mathrm{~g}}$ mode associated with in plane "breathing mode" vibrations with symmetry $\mathrm{D}_{\mathrm{h} 3}$. They believed that this mode was activated by crystal size and defects in the graphite lattice. Whereas this mode is inactive for an "infinite," single crystal of graphite because the changes in polarizability cancel, this is not the case for polycrystalline graphite. Thus, activation of this mode was initially attributed to the relaxation of the Raman selection rules as a consequence of small crystal size.

Other peaks in the Raman spectra of defected graphite, single layer and multi-layer graphene and other carbon nanomaterials launched a debate over the Raman solid-state processes in

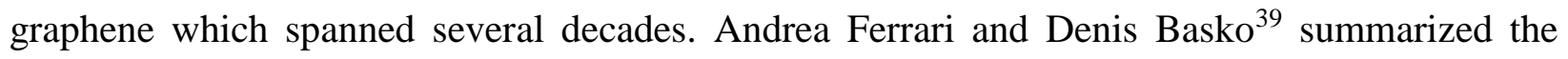
current understanding of these processes and the interpretation of the resulting spectra.

Defect free graphite and graphene both have G peak $\left(\sim 1581 \mathrm{~cm}^{-1}\right)$ and 2D peak $\sim 2700 \mathrm{~cm}^{-1}$. The $G$ peak is the high frequency band of the doubly degenerate $E_{2 g}$ mode of corresponding to the in-plane stretching of the $\mathrm{sp}^{2}$ carbon bonds. The low frequency $\mathrm{E}_{2 \mathrm{~g}}$ band ${ }^{16,40}$ has been observed around $40-50 \mathrm{~cm}^{-1}$ but does not receive as much attention in the literature as the $\mathrm{G}$ band because it is much lower in intensity and frequency. The $\mathrm{D}$ band $\left(\sim 1350 \mathrm{~cm}^{-1}\right)$ which is only observed in polycrystalline or defected graphite is now thought to be due to transverse optical (TO) phonons at the Brillion Zone (BZ) center $\mathbf{K}$. It is activated by double resonance, which requires electronic 
backscattering from the defect. It is dispersive with excitation wavelength due to a Kohn anomaly at $\mathbf{K}$. The 2D band is the second order, overtone of the $\mathrm{D}$ band in which two phonon states are excited which have equal energy but opposite wave vectors.

\begin{tabular}{|c|c|c|}
\hline Position $\left(\mathrm{cm}^{-1}\right)$ & Name & Assignment \\
\hline$\sim 1100$ & D” & One phonon, defect assisted scattering process \\
\hline 1350 & $\mathrm{D}$ & $\begin{array}{l}\text { One phonon, electron-defect assisted scattering } \\
\text { process }\end{array}$ \\
\hline 1570 & G & $\mathrm{E}_{2 \mathrm{~g}}$ mode corresponding to in-plane $\mathrm{sp}^{2}$ stretching \\
\hline 1620 & $\mathrm{D}^{\prime}$ & $\begin{array}{l}\text { One-phonon, electron-defect assisted scattering } \\
\text { process }\end{array}$ \\
\hline 2450 & $\mathrm{D}+\mathrm{D} "$ & $\begin{array}{l}\text { Combination band of the D phonon and the D" } \\
\text { phonon from the LA branch }\end{array}$ \\
\hline$\sim 2700$ & $2 \mathrm{D}$ & $\begin{array}{l}\text { Second order, over tone of } \mathrm{D} \text { band, two phonon } \\
\text { process }\end{array}$ \\
\hline 2950 & D+D' & Combination band of the D and D' phonon \\
\hline 3250 & 2D' & $\begin{array}{l}\text { Second order, overtone of } 2 \mathrm{D} \text { band, two phonon } \\
\text { process }\end{array}$ \\
\hline
\end{tabular}

Table 0.2 Raman band assignments for graphite and graphene

Multi-phonon processes up to 6 phonons can be observed, however this is rarely reported because most Raman spectra are only collected up to $\sim 3300 \mathrm{~cm}^{-1}$.

\subsubsection{Distinguishing between graphene and graphite}

Both graphene and graphite have the $\mathrm{G}$ and $2 \mathrm{D}$ bands in their spectra. Peak $\mathrm{C}$ at $\sim 42 \mathrm{~cm}^{-1}$ is called the shear mode in few layer graphene (FLG) and is attributed to the low-frequency $E_{2 g}$ mode. The position of $\mathrm{C}$ shifts to lower wavenumbers and decreases in intensity with decreasing graphene layers. The $\mathrm{C}$ band should be absent from single layer graphene (SLG) since it involved the out of plane displacements and interaction between two adjacent graphene planes. The $\mathrm{C}$ mode is very low in energy and is below the filter cut-offs of most Raman spectrometers. Detection of the $\mathrm{C}$ band would require a triple spectrometer or a BragGrate notch filter with a single spectrometer like the one was used by Tan et al. ${ }^{41}$ 
Bands attributed to layer-breathing modes $(\mathrm{LBM})$ at $\sim 80-300 \mathrm{~cm}^{-1}$ due to the interlayer vibrational modes in few layer graphene have also been observed. ${ }^{42}$ These bands are very low in intensity. Much of the guidelines found in the literature for differentiating graphite and graphene is qualitative. The two most commonly cited qualitative characteristics are the shape of the $2 \mathrm{D}$ peak the ratio of the intensities of the $2 \mathrm{D}$ peak and G peak. Single layer graphene has a 2D peak which is symmetrical or referred to as Lorentzian. The 2D peak loses its symmetry with increasing number of graphene layers.

Additionally, several empirical methods for determining the number of graphene layers from Raman have been reported in the literature. The number of layers can be determined by peak fitting of the $2 \mathrm{D}$ band. Increasing the number of graphene layers lowers the symmetry of the graphene plane resulting in a splitting of vibrational modes which overlap to form a wider, less symmetric 2D band. ${ }^{43}$ The $\mathrm{G}$ band is also highly sensitive to the number of graphene layers. Therefore, the graphene layer thickness ( $n$ ) may be calculated from the shift in the $\mathrm{G}$ band position (E 3.4). ${ }^{36}$

$$
\omega_{0}=1581.6+11 /\left(1+n^{1.6}\right) \quad \mathbf{E ~} \mathbf{0 . 4}
$$

The number of layers can also be calculated from the shift in the shear mode, $\mathrm{C}$, using the following equation: ${ }^{41}$

$$
\operatorname{Pos}(C)_{n}=\sqrt{\frac{2 \alpha}{\mu}} \sqrt{1+\cos \left(\frac{\pi}{n}\right)}
$$

\section{E 0.5}

where $n$ is the number of layers, $\alpha=12.8 \times 1018 \mathrm{~N} \mathrm{~m}^{-3}$ is the interlayer coupling, and $\mu=7.6 \mathrm{x}$ $10-27 \mathrm{~kg} \dot{\mathrm{A}}^{-2}$ is the graphene mass per unit area.

Lui and Heinz reported an equation for calculating the number of graphene layers from the $\operatorname{LBM}(\mathrm{E} 3.6)$, 


$$
\omega_{N}(n)=\omega_{0} \sin [(N-n) \pi / 2 N] \quad \text { E } 0.6
$$

where $\omega_{0}=132.3 \mathrm{~cm}^{-1}$ is the frequency of out of plane optical mode for bulk graphite, $\mathrm{n}$ is the index where $n=1,2, \ldots, N-1$ and $N$ is the number of graphene layers.

\subsection{Scanning Electron Microscopy (SEM)}

A Hitachi S-4700 Scanning Electron Microscope, picture in Figure 3.7, was used for characterization of samples.

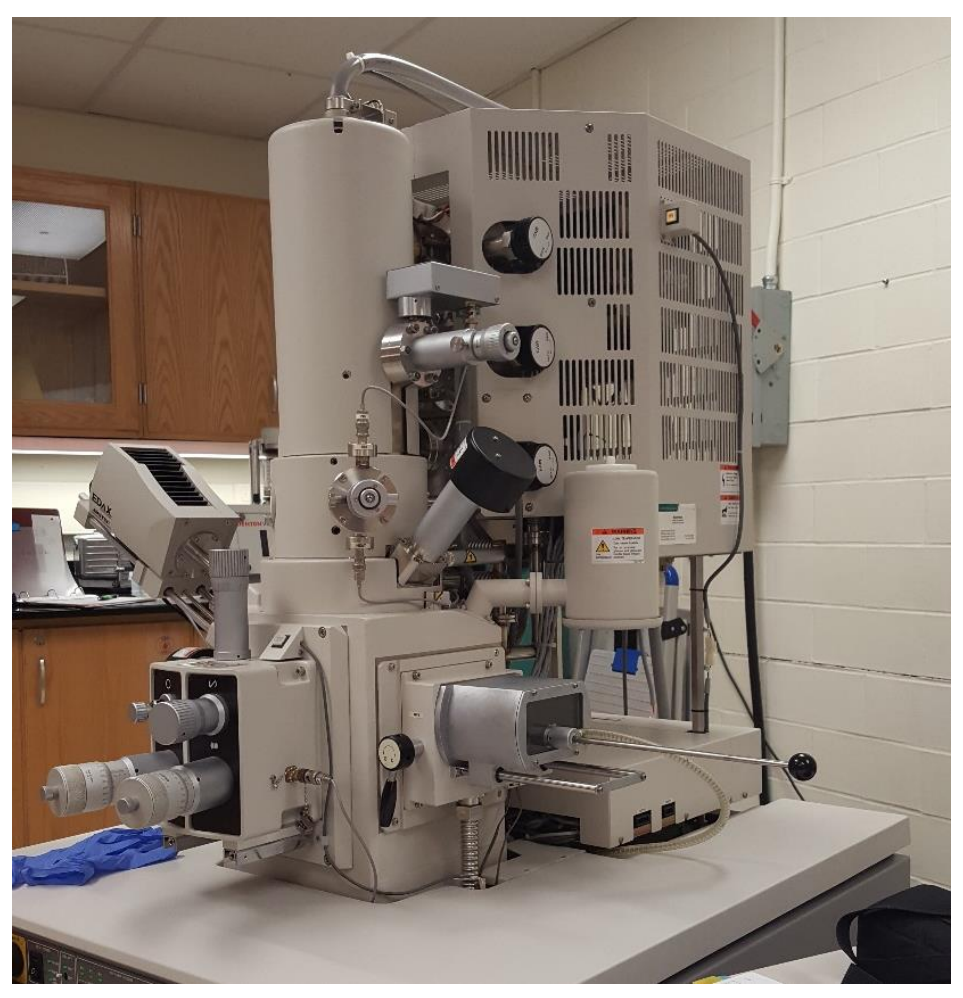

Figure 0.7 Hitachi S-4700 Scanning Electron Microscope

In scanning electron microscopy, an electron beam is scanned across the surface of a specimen in a raster pattern. When the primary electrons, that is the incident beam of electrons, contact the sample, they can interact with the sample in three ways. Secondary electrons may be emitted from the $K$ shell of the sample atoms by inelastic collisions with the primary electrons (Figure 3.8A). Detection of these secondary electrons is the most common imaging mode in SEM. Alternatively, the primary electrons may be elastically scattered by the nuclei of the atoms in the 
sample. These electrons are referred to as back scattered electrons (Figure 3.8B). The larger the nuclei the more backscattering of the primary electron beam occurs. Images generated from the detection of BSE can provide information on the distribution of elements in a specimen. When a primary electron pushes out a secondary electron from an inner shell, a higher energy electron drops down to take its place, releasing energy in the form of a characteristic X-ray (Figure 3.8C). Collection of these characteristic $\mathrm{x}$-rays provide information on the elemental composition of the sample. This mode of detection is referred to as energy dispersive X-ray spectroscopy EDAX or $\operatorname{EDS}^{20}$.

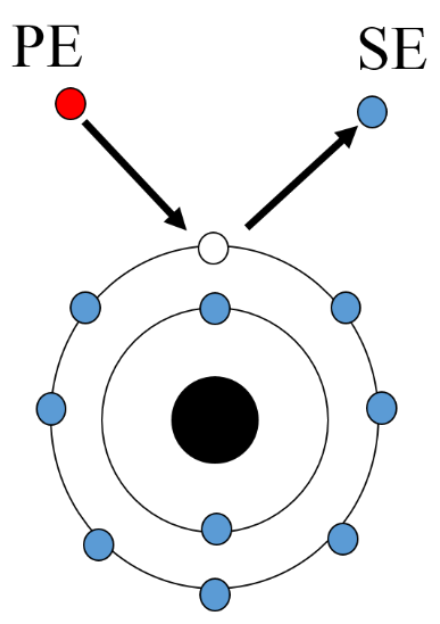

A

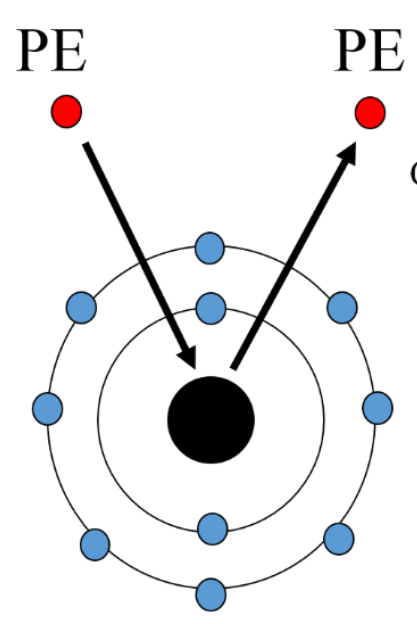

B

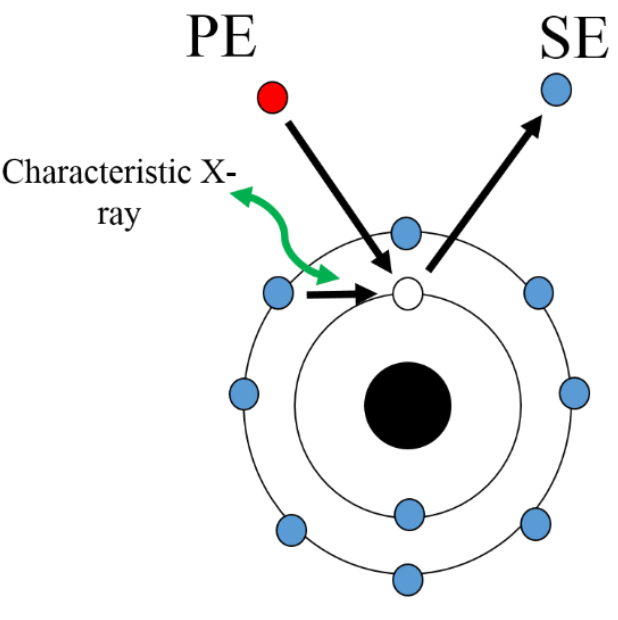

$\mathrm{C}$

\section{Figure 0.8 Mechanisms in SEM}

SEM is frequently used for characterization of carbon materials ${ }^{44-47}$ For example, Kagi et $a l .{ }^{47}$ investigated graphite inclusions within and coated on diamond in ultrahigh-pressure metamorphic minerals. Figure 3.9 shows SEM images of various morphologies observed in one of these samples. Large, well-formed single crystals of graphite are depicted in Figure 3.9 (a), (b) and (e). 

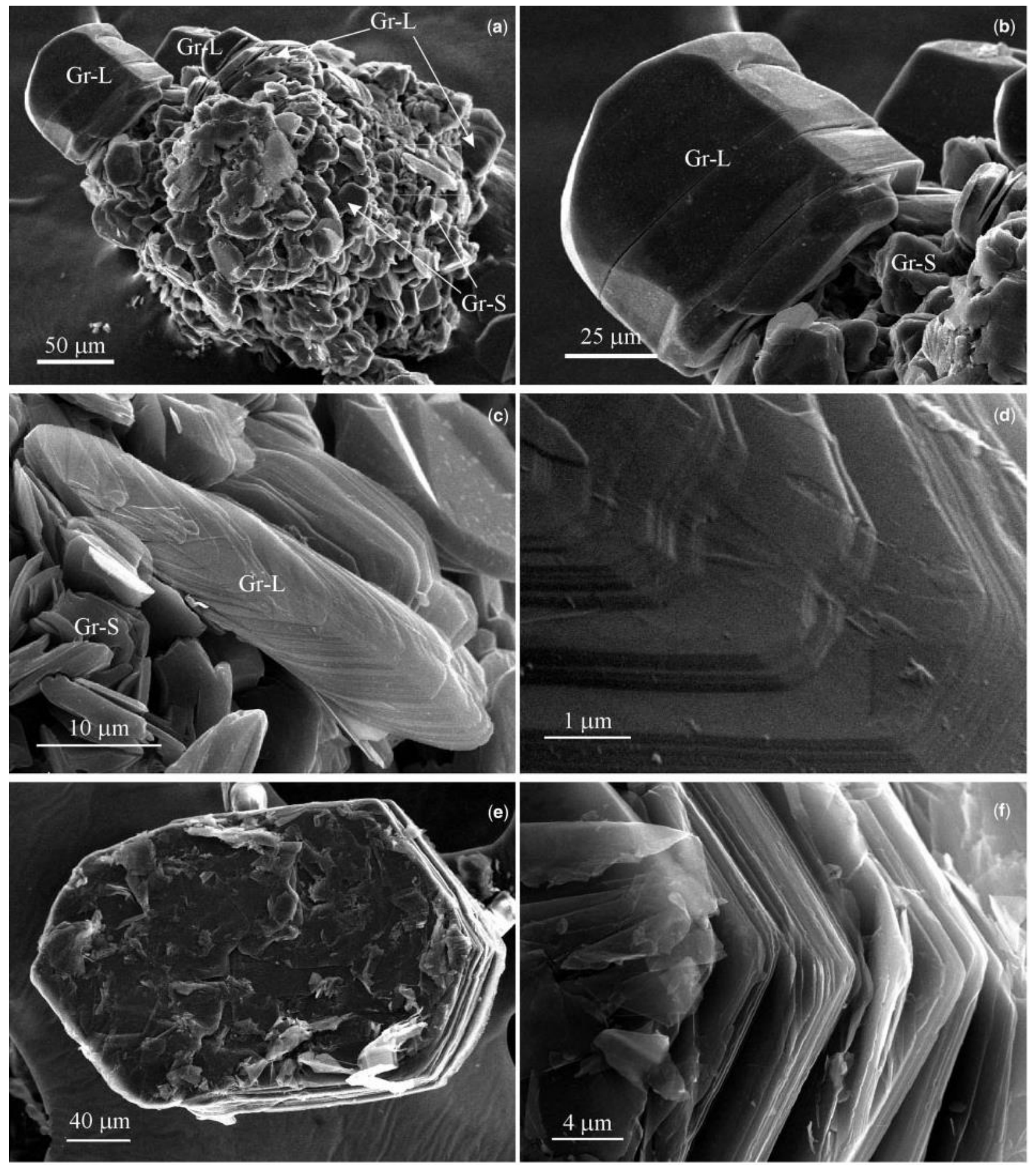

Figure 0.9 SEM images of different morphological types of graphite inclusions observed in ultrahigh-pressure metamorphic minerals. (a-d) Detailed morphology of graphite coatings; (e, f) single graphite crystals; (b), (d) and (f) are enlargements of (a), (c) and (e), respectively. Gr-L denote large graphite crystals; Gr-S denote small graphite crystals. 


\subsection{X-ray Photoelectron Spectroscopy (XPS)}

In 1887 Heinrich Hertz observed that metals emit electrons when irradiated with photons of sufficient energy. This was later explained by Albert Einstein in 1905 and termed the photoelectric effect. These discoveries finally culminated in the development of Electron Spectroscopy for Chemical Analysis (ESCA). ESCA can be split into two types of analysis: ultraviolet photoelectron spectroscopy (UPS) and X-ray photoelectron spectroscopy (XPS). ${ }^{48,49}$ Excitation by UV light causes the emission of valence electrons, and irradiation by higher energy X-rays result in the emission of core electrons.

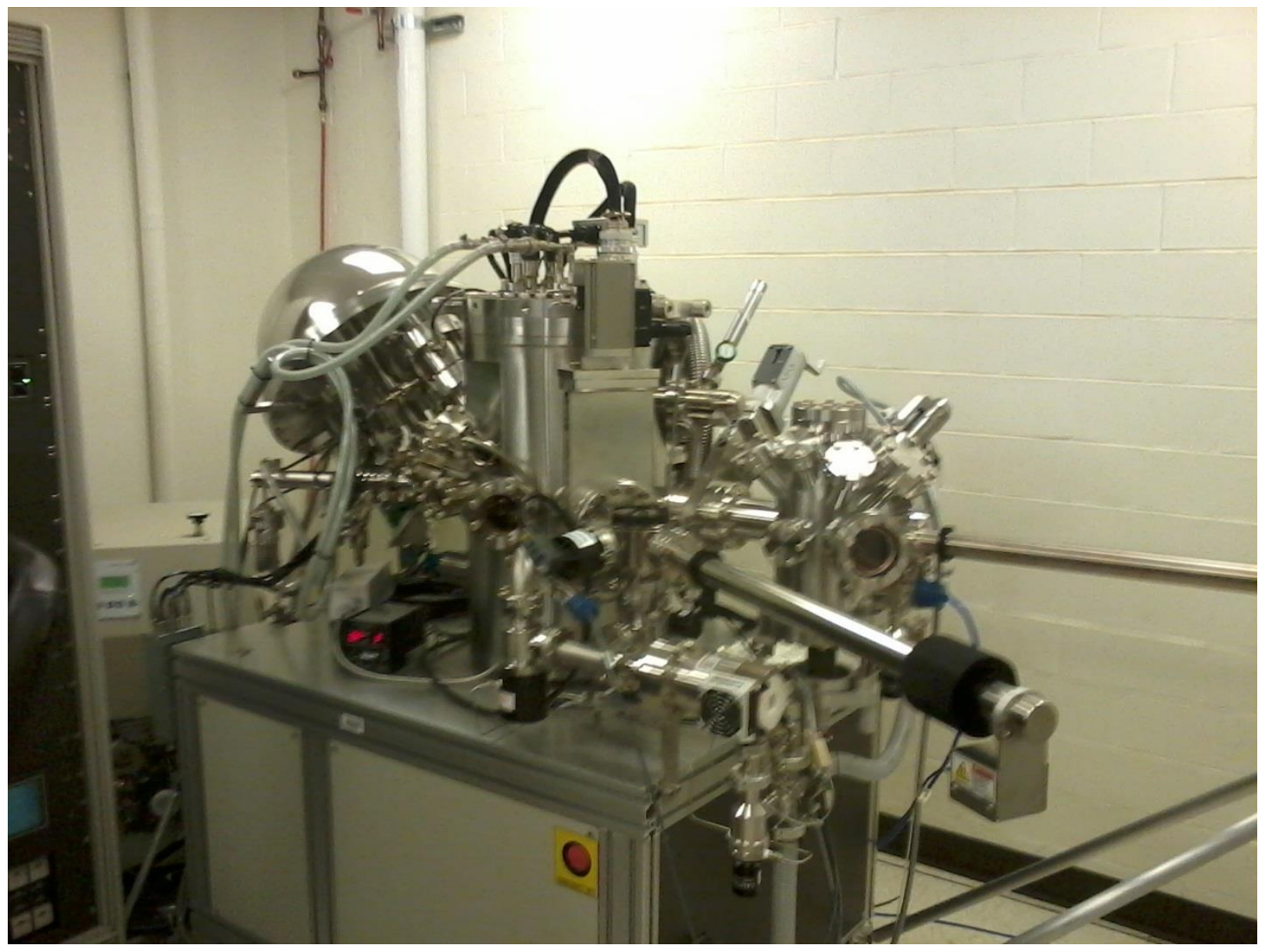

Figure 0.10 PHI 5000 VersaProbe X-ray Photoelectron Spectrometer

Incident radiation of energy, $h v$, must exceed the minimum amount of energy required to remove an electron from a solid to a point in vacuum in order to induce the emission of a 
photoelectron. This energy minimum is termed the work function $\left(W_{f}\right.$ or $\left.\varphi\right)$ and is material dependent. The emitted photoelectron will travel from the surface of the solid with a certain kinetic energy $\left(E_{k i n}\right)$ which will be equal to the energy of the incident x-rays minus the work function of the material and the binding energy of the electron $\left(E_{b}\right)$. This process is shown below in Figure 3.11 .

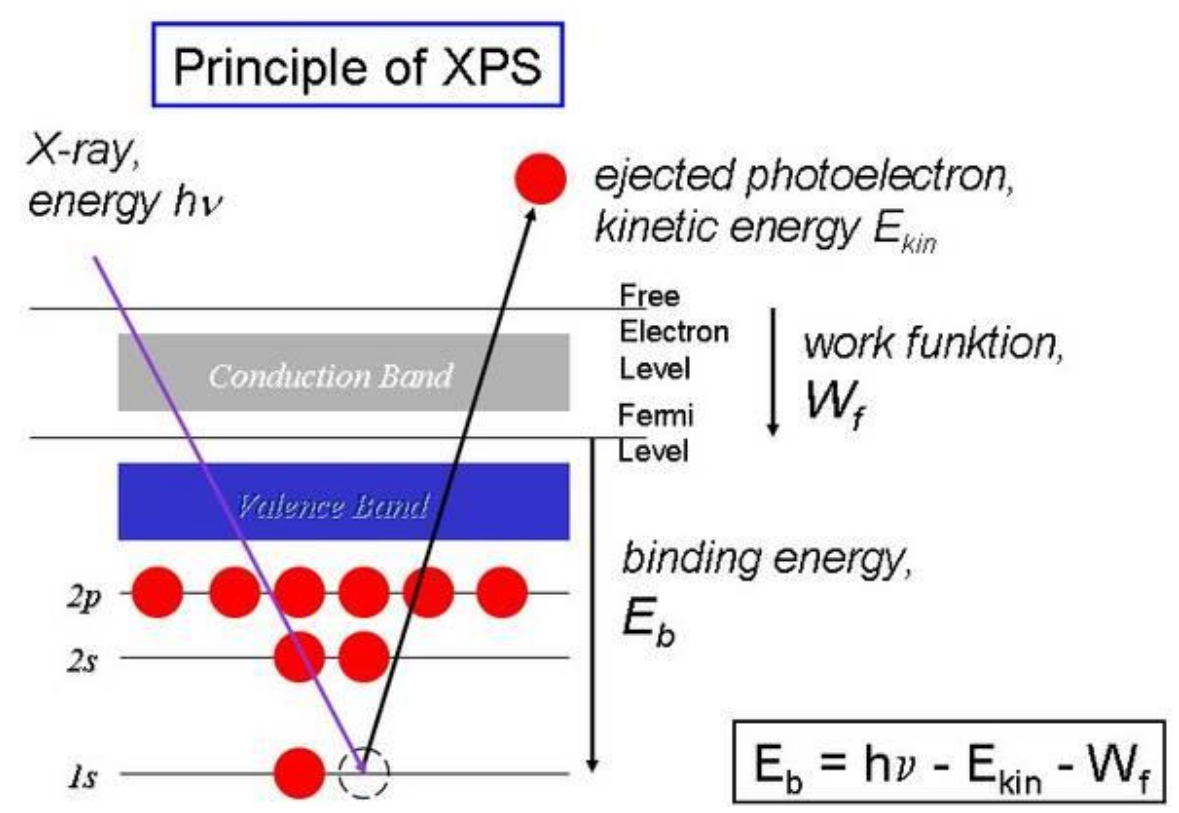

Figure 0.11 Mechanism of XPS, Image Source: https://www.ifw-dresden.de/de/institute/institutfuer-komplexe-materialien/abteilungen/mikro-und-nanostrukturen/available-methods/xps/

The value of the binding energy is dependent upon the energy level or orbital from which the photoelectron was emitted. Changes in the local bonding environment changes the energies of the orbitals in the solid, and these changes are reflected in changes in binding energies in the XPS spectra. These shifts in binding energy are termed chemical shifts. They provide information on the chemical state of the material. Therefore, XPS provides information on the elemental composition and chemical states of materials. XPS is not to be confused with energy dispersive Xray spectroscopy or EDS. In EDS the excitation source can be an x-ray or electron beam and will eject an electron out just like XPS. However, when the electron is ejected another electron falls in 
energy and emits X-rays to fill the hole left by the ejected electron. It is the emitted $\mathrm{x}$-rays from this secondary process, which is the detected signal in EDS. As such, EDS can provide elemental composition but no structural information.

XPS is a widely used tool for studying the surface chemistry of carbon materials ${ }^{50-52}$ and the intercalation mechanisms in graphite anodes for lithium batteries. ${ }^{53-56}$ XPS can differentiate between different carbon allotropes due to the energy differences the $\mathrm{C}-\mathrm{C}$ bonding environments. However, caution must be used in detailed interpretations of XPS spectra because of the technique's high sensitivity to structural defects and charging effects. In an example pertinent to our research, Sato et al. recently resolved the controversial assignments of the C1s peak of diamond and graphite ${ }^{57}$ Reports in the literature prior to the work of Sato $e t$ al. for the assignments of binding energies for the $\mathrm{C} 1 \mathrm{~s}$ peak for photoelectrons from $\mathrm{sp}^{3}$ and $\mathrm{sp}^{2} \mathrm{C}-\mathrm{C}$ bonds were conflicting, some works assigning one higher or lower than the other.

Compare the conflicting $\mathrm{C} 1 \mathrm{~s}$ peaks for diamond and graphite in the spectra from a commonly used XPS reference website, xpssimplified.com with spectra obtained in our lab (Figure 3.12). In our spectrum (Figure 3.12 a)) the $\mathrm{C} 1 \mathrm{~s}$ peak for diamond occurs at a higher binding energy than the $\mathrm{C} 1 \mathrm{~s}$ peak for graphite. An argon ion gun was used to compensate for the charging effect of the CVD diamonds. Although both spectra have the shoulder peak, known as the shake-up feature, the peaks for diamond and graphite occur at different binding energies. Therefore, Table 3.3 presents assignments for the C1s peak suggested by Sato et al. 

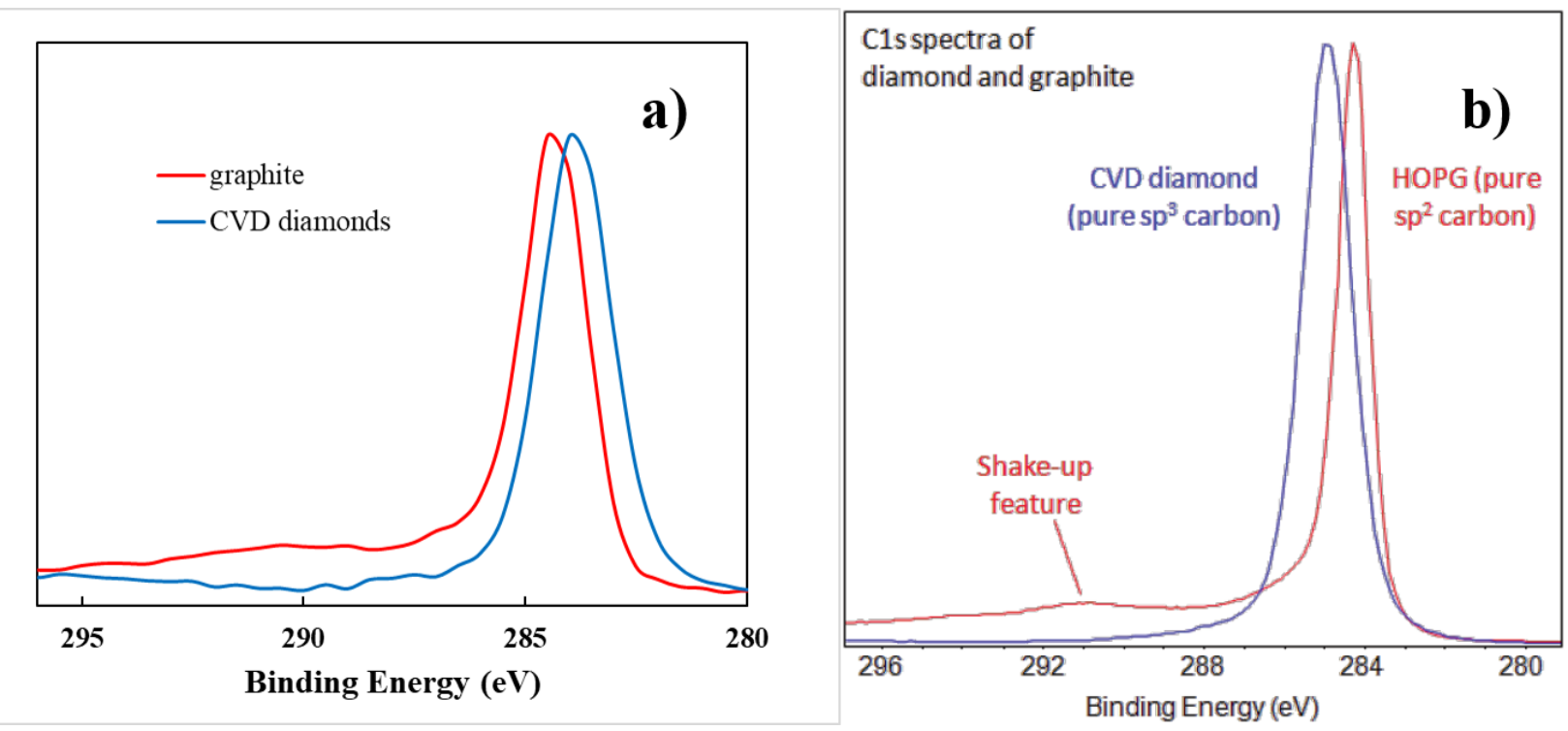

Figure 0.12 a) C1s peak of graphite and diamond from XPS spectra obtained in our lab and b) C1s spectra of diamond and HOPG on XPS reference website: https://xpssimplified.com/elements/carbon.php

\begin{tabular}{cc}
\hline Chemical State & C1s Binding Energy (eV) \\
\hline $\mathrm{C}-\mathrm{C}, \mathrm{sp}^{3}$ & 283.4 \\
$\mathrm{C}-\mathrm{C}, \mathrm{sp}^{2}$ & 283.8 \\
$\mathrm{sp}^{3} \mathrm{C}-\mathrm{O}-\mathrm{sp}^{3} \mathrm{C}$, epoxy & 284.1 \\
$\mathrm{sp}^{3} \mathrm{C}-\mathrm{O}-\mathrm{sp}^{3} \mathrm{C}$, ether & 284.3 \\
$\mathrm{sp}^{2} \mathrm{C}=\mathrm{O}$ & 284.7 \\
$\mathrm{sp}^{2} \mathrm{C}-\mathrm{O}-\mathrm{sp}^{2} \mathrm{C}$, epoxy & 284.9 \\
$\mathrm{sp}^{3} \mathrm{C}=\mathrm{O}$ & 285.1 \\
\hline
\end{tabular}

Table 0.3 Suggested C1s peak assignments for the interpretation of XPS spectra in carbon ${ }^{57}$

A PHI 5000 VersaProbe XPS was used in this research surface characterization of carbon materials produced by reactions of calcium carbide with zinc chloride in the molten or solution state. XPS was used for study the degree of oxidation and chemical state of the surface of these carbon products. Additionally, this technique was utilized to study nonaqueous electrolyte interactions with the carbon electrodes used in the VMP experiments. However, as noted earlier, detailed interpretation is not trivial and is beyond the scope of this work.

\subsection{X-ray Powder Diffraction (XRD)}

The theory of single crystal x-ray diffraction and crystallography has been described in detail elsewhere. ${ }^{8,58-60}$ This research utilized powder XRD for supporting analyses 
and characterization. Powder XRD has several advantages over single-crystal XRD, which are beneficial to our research. ${ }^{61,62}$ In powder XRD diffraction, data may be obtained without the necessity of a large $(\sim 100 \mu \mathrm{m})$ single crystal. In addition, phase and structure identification can be accomplished quickly by comparing the diffraction patter to a database of known materials and mixtures of two or more crystalline phases can be accurately identified. Moreover, powder diffraction may be applied to bulk materials, thin films, and polycrystalline samples. ${ }^{61}$ This technique is useful for characterizing structural changes in poorly crystalline and amorphous materials.

For example, Rosalind Franklin ${ }^{63,64}$ demonstrated the applicability of x-ray crystallography to amorphous materials through her work on the study of structural changes in coal, graphite and non-graphitizing carbons. Figure 3.13 below shows diffraction data obtained of an amorphous, non-graphitizing carbon produced from pyrolysis of the polymer polyvinylidene chloride, $\left(\mathrm{C}_{2} \mathrm{H}_{2} \mathrm{Cl}_{2}\right)_{\text {n. }}$. Curve $\mathrm{I}$ is the diffraction curve corrected for absorption, polarization and angle variance, where the diffraction peaks for the (002) and (hk0) reflections are noted. Franklin used Fourier integral analysis and Warren's equations for diffraction of random-layer lattices ${ }^{65}$ to interpret the data. Her findings indicated that $65 \%$ of the carbon consists of perfect graphite crystallite layers with an average diameter of $16 \mathrm{~A}$, and 35\% has no long-range structure. Roughly $55 \%$ of the graphite crystallites are structured in layers with an interlayer distance of $3.7 \mathrm{~A}$, while $45 \%$ of the remaining layers have no definite orientation with respect to each other. This work is considered the first reliable description of the structure of a char, which is a solid material important in combustion, carburization, charring and pyrolysis ${ }^{66}$. 


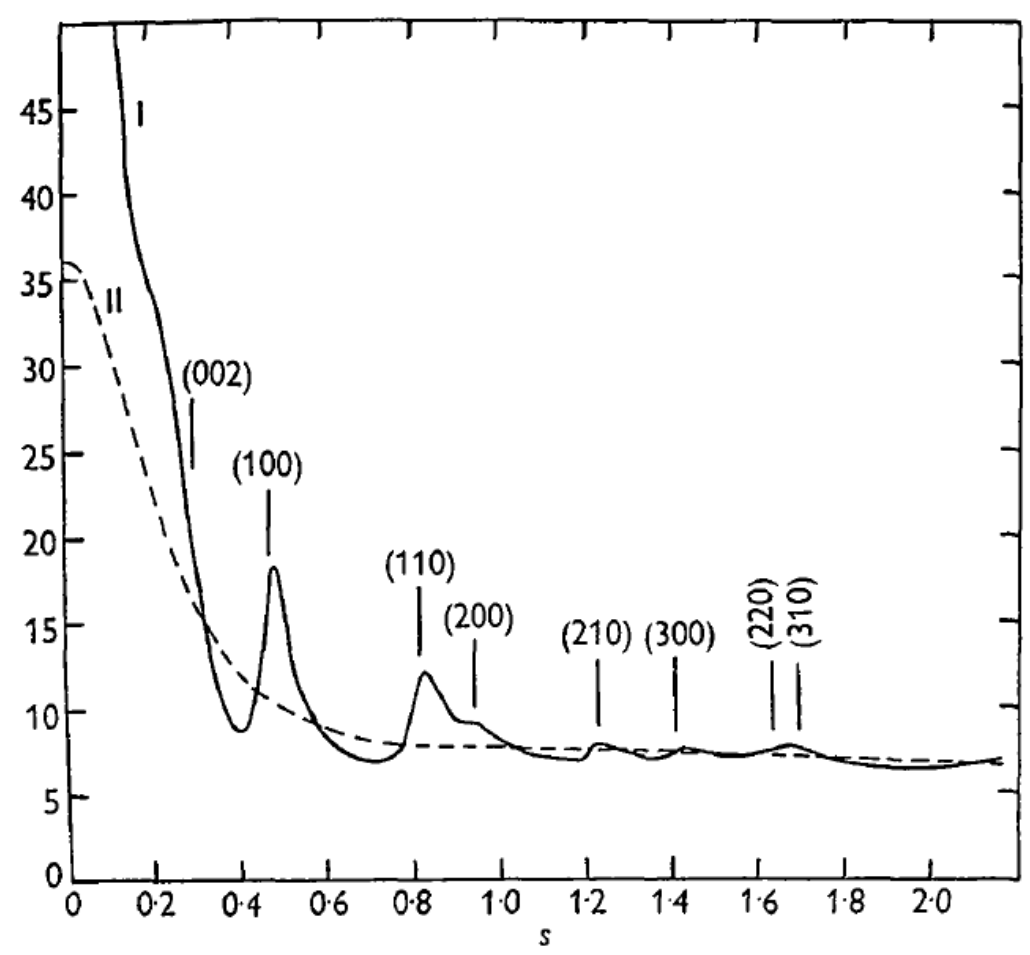

Figure 0.13 Diffraction data for powder analysis of non-graphitizing carbon produced by pyrolysis of $\left(\mathrm{C}_{2} \mathrm{H}_{2} \mathrm{Cl}_{2}\right)_{\mathrm{n}}$. Curve I, corrected intensity curve. Curve II, independent scattering curve. Where intensity is plotted against $s=2 \sin \theta / \lambda$

The instrument utilized in this work was a PANalytical X'Pert Pro X-ray Diffractometer. This XRD had a Cu-ka1 $8047.2 \mathrm{eV}$ x-ray source and an angular range of $0^{\circ}<2 \theta<100^{\circ}$. Powder XRD was used to characterize the structure and phase of carbon material produced from carbide reactions in molten salts. 


\section{References}

(1) Brodersen, S.; Weber, A. Raman spectroscopy; Springer: Berlin, 1979; Vol. 11.

(2) Kereszutry, G. In The Handbook of Vibrational Spectroscopy, Vol 1; Chalmers, J. M., Griffiths, P. R., Eds.; John Wiley \& Sons Inc, 2002; pp 71-87.

(3) Everall, N. J. In Handbook of Vibrational Spectroscopy Vol 1; Chalmers, J. M., Griffiths, P. R., Eds.; John Wiley \& Sons Inc, 2002; pp 141-149.

(4) Nakashima, S.; Harima, H. In Handbook of Vibrational Spectroscopy Vol. 4; Chalmers, J. M., Griffiths, P. R., Eds.; John Wiley \& Sons, 2002.

(5) Hodkiewicz, J.; Scientific, T. F. Prog. Mater. Sci. 2005, 50, 929-961.

(6) Ludwig, M.; Asher, S. A. Appl. Spectrosc. 1988, 42 (8), 1458-1466.

(7) McHale, J. L. In The Handbook of Vibrational Spectroscopy, Vol 1; Chalmers, J. M., Griffiths, P. R., Eds.; John Wiley \& Sons Inc, 2002; pp 534-556.

(8) Skoog, D. A.; Holler, F. J.; Nieman, T. A. Principles of instrumental analysis, 5. ed., [N.; Brooks/Cole [u.a]: London u.a., 2003.

(9) Bowie, B. T.; B., C. D.; Lewis, I. R.; Griffiths, P. R. In Handbook of Vibrational Spectroscopy; Griffiths, P. R., Chalmers, Eds.; John Wiley \& Sons, 2002; pp 2356-2378.

(10) Yvon, H. J. Fluoresc. 01 2014, 2-3.

(11) Tuschel, D. 2.

(12) Nielsen, O. F.; Shabanova, E.; Nissum, M. J. Chem. Educ. 2000, 77 (5), 633-null.

(13) Kittel, C. Introduction to Solid State Physics, 8th ed.; John Wiley \& Sons: Danvers, MA, 2005.

(14) Opel, M.; Venturini, F. Eur. Pharm. Rev. 2002, 7 (3), 76-82.

(15) Gouadec, G.; Colomban, P. Prog. Cryst. Growth Charact. Mater. 2007, 53 (1), 1-56.

(16) Ferrari, A. C.; Basko, D. M. Nat. Nanotechnol. 2013, 8 (4), 235-246.

(17) Osswald, S.; Mochalin, V. N.; Havel, M.; Yushin, G.; Gogotsi, Y. Phys. Rev. B - Condens. Matter Mater. Phys. 2009, 80 (7).

(18) Cuesta, A.; Dhamelincourt, P.; Laureyns, J.; Martinez-Alonso, A.; Tascon, J. M. D. Carbon N. Y. 1994, 32 (8), 1523-1532.

(19) Hodkievicz, J. Characterizing Carbon Materials with Raman Spectroscopy; 2010.

(20) Kaufman, E. N. In Vol 1; John Wiley \& Sons Inc: Hoboken, NJ, 2003; pp 580-592.

(21) McKenzi, D. R. Reports Prog. Phys. 1996, 59, 1611-1664.

(22) Pierson, H. O. Handb. Carbon, Graph. Diam. Fullerenes 1993, 25-69.

(23) Saito, R.; Hofmann, M.; Dresselhaus, G.; Jorio, A.; Dresselhaus, M. S. Adv. Phys. 2011, 60 (3), 413-550. 
(24) Dresselhaus, M.S., Dresselhaus, G., Eklund, P. C. J. Phys. Chem. 1996, 27 (October 1995), 351-371.

(25) Lu, X.; Chen, Z. Chem. Rev. 2005, 105 (10), 3643-3696.

(26) Dresselhaus, M. S.; Dresselhaus, G.; Saito, R.; Jorio, A. Phys. Rep. 2005, 409 (2), 47-99.

(27) O’Brien, P.; Craighead, H.; Kroto, H.; Amer, M. S. Raman Spectroscopy, Fullerenes and Nanotechnology; Royal Society of Chemistry, 2010.

(28) Nathan, M. I. J. Appl. Phys. 1974, 45 (5), 2370.

(29) Sadezky, A.; Muckenhuber, H.; Grothe, H.; Niessner, R.; Pöschl, U. Carbon N. Y. 2005, $43(8), 1731-1742$.

(30) Tsu, R.; Gonzalez, J. H.; Hernandes, I. C.; Luengo, C. A. Solid State Commun. 1977, 24 (12), 809-812.

(31) Green, P. D.; Johnson, C. A.; Thomas, K. M. Fuel 1983.

(32) Filik, J. Spectrosc. Eur. 2005, 17 (5).

(33) Herchen, H.; Capelli, M. A. Phys Rev B 1994, 49 (5), 3213.

(34) Prawer, S.; Nemanich, R. J. Philos. Trans. R. Soc. A Math. Phys. Eng. Sci. 2004, 362 (1824), 2537-2565.

(35) Ferrari, A. C.; Robertson, J. Philos. Trans. R. Soc. A Math. Phys. Eng. Sci. 2004, 362 (1824), 2477-2512.

(36) Wall, M. Thermo Sci. 2011, 5.

(37) Ferrari, A. C.; Robertson, J. Philos. Trans. Math. Phys. Eng. Sci. 2004, 362 (1824), 24772512.

(38) Tuinstra, F.; Koenig, J. L. J. Chem. Phys. 1969, 53 (2), 1126-1130.

(39) Ferrari, A. C.; Basko, D. M. Nat. Nanotechnol. 2013, 8 (4), 235-246.

(40) Nemanich, R. J.; Solin, S. A. Am. Phys. Soc. 1979, 20 (2), 392-401.

(41) Tan, P. H.; Han, W. P.; Zhao, W. J.; Wu, Z. H.; Chang, K.; Wang, H.; Wang, Y. F.; Bonini, N.; Marzari, N.; Pugno, N.; Savini, G.; Lombardo, A.; Ferrari, A. C. Nat. Mater. 2012, 11 (4), 294-300.

(42) Lui, C. H.; Heinz, T. F. Phys. Rev. B - Condens. Matter Mater. Phys. 2013, 87 (12), 1-7.

(43) Ferrari, A. C.; Meyer, J. C.; Scardaci, V.; Casiraghi, C.; Lazzeri, M.; Mauri, F.; Piscanec, S.; Jiang, D.; Novoselov, K. S.; Roth, S.; Geim, A. K. Phys. Rev. Lett. 2006, 97 (18), 187401.

(44) Sevilla, M.; Fuertes, A. B. Carbon N. Y. 2009, 47 (9), 2281-2289.

(45) Palyanov, Y.; Kupriyanov, I.; Borzdov, Y.; Nechaev, D.; Bataleva, Y. Crystals 2017, 7 (5), 119. 
(46) Kim, T. W.; Ryoo, R.; Gierszal, K. P.; Jaroniec, M.; Solovyov, L. A.; Sakamoto, Y.; Terasaki, O. J. Mater. Chem. 2005, 15 (15), 1560-1571.

(47) Korsakov, A. V.; Perraki, M.; Zedgenizov, D. A.; Bindi, L.; Vandenabeele, P.; Suzuki, A.; Kagi, H. J. Petrol. 2010, 51 (3), 763-783.

(48) Weimer, J. J. In Characterization of Materials Vol 2; Kaufman, E. N., Ed.; John Wiley \& Sons Inc: Hoboken, NJ, 2003; pp 970-1006.

(49) Ratner, B. D.; Castner, D. G. In Surface Analysis: The Principle Techniques; Vickerman, J. C., Gilmore, I. S., Eds.; John Wiley \& Sons Inc, 2009; pp 47-109.

(50) Retzko, I.; Unger, W. E. S. Adv. Eng. Mater. 2003, 5 (7), 519-522.

(51) Brender, P.; Gadiou, R.; Rietsch, J.-C.; Fioux, P.; Dentzer, J.; Ponche, A.; Vix-Guterl, C. Anal. Chem. 2012, 84 (5), 2147-2153.

(52) Park, S.-J.; Kim, K.-S. Microsc. Sci. Technol. Appl. Educ. 2010, 1905-1916.

(53) Edström, K.; Herstedt, M.; Abraham, D. P. J. Power Sources 2006, 153 (2), 380-384.

(54) Verma, P.; Maire, P.; Novák, P. Electrochim. Acta 2010, 55 (22), 6332-6341.

(55) Lapteva, L. L.; Fedoseeva, Y. V.; Gevko, P. N.; Smirnov, D. A.; Gusel'nikov, A. V.; Bulusheva, L. G.; Okotrub, A. V. J. Struct. Chem. 2017, 58 (6), 1173-1179.

(56) Andersson, A. M.; Edström, K. J. Electrochem. Soc. 2001, 148 (10), A1100.

(57) Fujimoto, A.; Yamada, Y.; Koinuma, M.; Sato, S. Anal. Chem. 2016, 88 (12), 6110-6114.

(58) Massa, W. Crystal Structure Determination, 1st ed.; Springer-Verlag: HeidelBerg, Germany, 2004.

(59) Lipson, H.; Cochran, W. Determination of Crystal Structure; Cornell Univ Press, 1966.

(60) Stout, G. H.; Jensen, L. H. X-ray Structure Determination: A Practical Guide, 2nd ed.; Wiley-Interscience, 1989.

(61) Stephens, P. In Characterization of Materials Vol 2; Kafmann, E. N., Ed.; John Wiley \& Sons Inc: Hoboken, NJ, 2003; pp 835-849.

(62) Percharsky, V. K.; Zavalij, P. Y. Fundamentals of Powder Diffraction and Structure Characterization of Materials, 2nd ed.; Springer: New York, 2009.

(63) Franklin, R. E. Proc. R. Soc. London 1951, 209.

(64) Franklin, R. E. Acta Cryst. 1950, 3, 107-.

(65) Warren, B. E. J. Chem. Phys. 1934, 2 (9), 551-555.

(66) Harris, P. J. F. Interdiscip. Sci. Rev. 2001, 26 (3), 204-210. 


\section{Chapter 4: Molten Salt Reactions of Salt-like Carbides}

This chapter describes the results of the molten salt reactions between two ionic carbides, aluminum carbide $\left(\mathrm{Al}_{4} \mathrm{C}_{3}\right)$ and calcium carbide $\left(\mathrm{CaC}_{2}\right)$, and late transition metal salts. The objectives of the molten salt experiments were to determine whether the metallic cation in the molten state would oxidize the carbide to elemental carbon and to determine the form of carbon produced. Previous exploratory work indicated that the covalent carbide, silicon carbide ( $\mathrm{SiC}$ ) was unreactive with molten, late transition metal halide salts, specifically tin chloride and tin fluoride. ${ }^{1}$

The results of reactions of aluminum carbide and tin chloride ( $\mathrm{R} 4.1$ ), calcium carbide and tin chloride (R 4.2) and calcium carbide and zinc chloride (R 4.3) are reported in this chapter.

$$
\begin{array}{rlrl}
\mathrm{Al}_{4} \mathrm{C}_{3}+\mathrm{SnCl}_{2} & \rightarrow 3 \mathrm{AlCl}_{3}+\mathrm{Sn}^{0}+3 \mathrm{C} & & \mathbf{R ~ 0 . 1} \\
\mathrm{CaC}_{2}+\mathrm{SnCl}_{2} & \rightarrow \mathrm{CaCl}_{2}+\mathrm{Sn}^{0}+2 \mathrm{C} & \mathbf{R ~ 0 . 2} \\
\mathrm{CaC}_{2}+\mathrm{ZnCl}_{2} & \rightarrow \mathrm{CaCl}_{2}+\mathrm{Zn}^{0}+2 \mathrm{C} & & \mathbf{R ~ 0 . 3}
\end{array}
$$

The results indicate the carbide was oxidized by the transition metal cation in the molten state to produce elemental carbon. The oxidation of calcium carbide by molten, late transition metal salts was first noted by Barber and Sloane. ${ }^{2}$ However, no analysis or characterization of the carbon product was provided. Therefore, the following sections present the analysis and characterization of the carbon produced and isolated from these reactions.

\subsection{Reaction of Aluminum Carbide with Tin Chloride}

Salt melt syntheses were carried out between aluminum carbide ( $\sim 325$ mesh, $99.5 \%$ purity) and anhydrous tin chloride by the methodology as described in Chapter 2 Experimental Methods. The carbon remaining after separation of the raw products was characterized via powder X-ray 
diffraction (XRD), scanning electron microscopy (SEM) and energy dispersive X-ray spectroscopy (EDS).

Figure 4.1 shows the third party XRD analysis of the carbon material carried out by David Anderson. ${ }^{3}$ Peaks in the spectrum were identified through software which matches peaks with materials in the Joint Committee of Powder Diffraction Standards (JCPDS) database. The only identifiable peaks are the (002) reflection for graphite at $26^{\circ}$ and the (111) reflection for diamond at $44^{\circ}$. The (101) peak for graphite also occurs at this angle, however, it is unlikely to occur without the (100) graphitic peak at $42^{\circ}$. Therefore, the most likely assignment for this peak is the (111) reflection for diamond. This supports the presence of diamond or diamond related material. However, the unidentified peaks are not typical of pure diamond material. Additionally, the high degree of background scattering suggests that the predominant carbon phase is amorphous. Anderson's SEM and EDS analyses also indicated the presence of metal (potassium, tin) and mineral impurities (mostly $\mathrm{SnO}_{2}$ ).

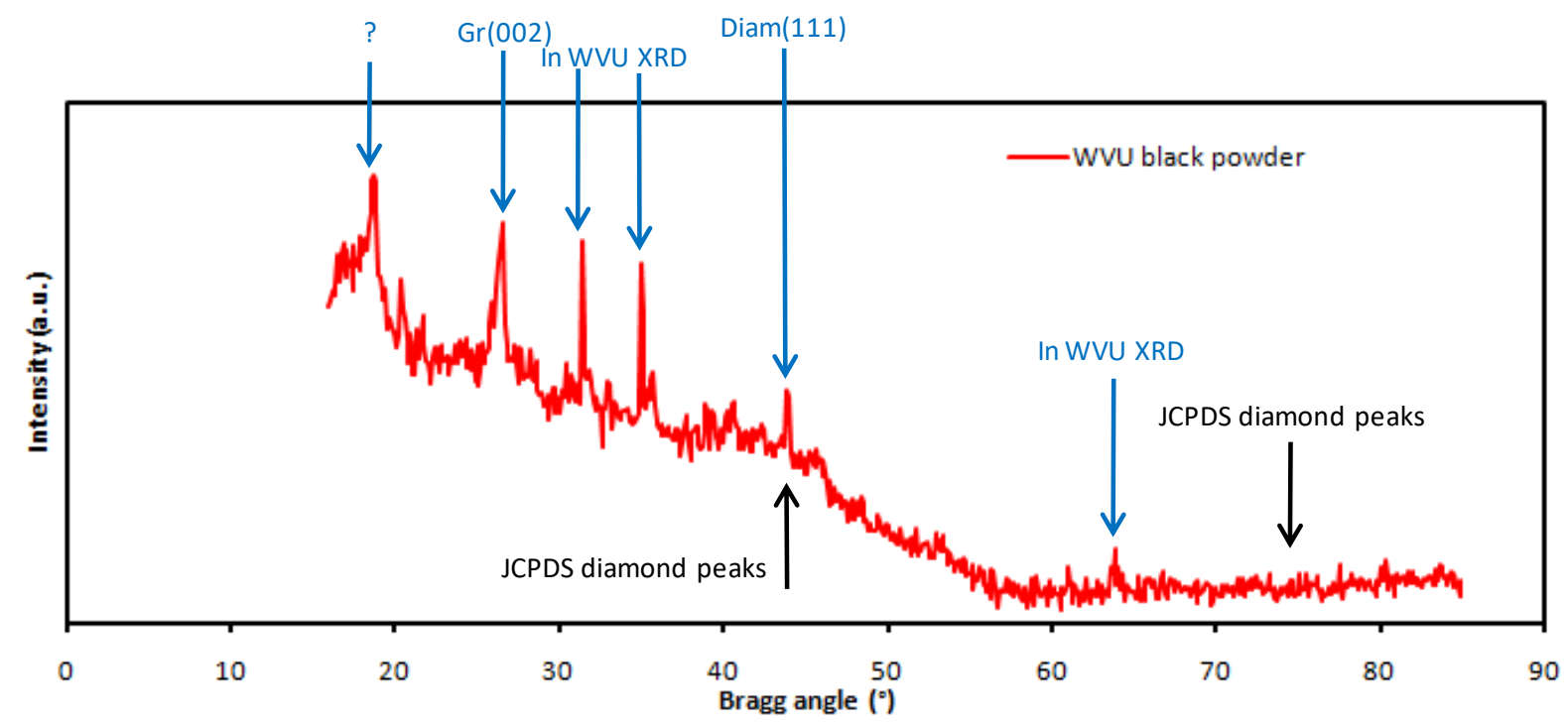

Figure 0.1 XRD pattern of carbon material from aluminum carbide and tin chloride reaction, called "WVU black powder," from Anderson's report ${ }^{3}$. 
Figure 4.2 displays SEM images of typical morphologies observed in the analysis of reaction products from aluminum carbide and tin chloride. Figure 4.2 a) shows a metallic sphere of tin about 55 microns in diameter. Beads of reduced tin metal were commonly observed. The reduction of the tin cation to tin metal confirms the oxidation of the carbon anion in the aluminum carbide. The reason there are beads of tin as byproducts because the reaction temperature is above the melting point of tin. Reduction of the tin occurs in the liquid state and the molten metal forms beads due to surface tension. When the reaction products are cooled the tin is prevented from crystalizing and this preserves the spherical morphology. ${ }^{4}$

Figure $4.2 \mathrm{~b}$ ) displays SEM image of a thin film from the same sample with a surface morphology which appears to be comprised of many small platelets. Figure 4.3 shows EDS spectrum corresponding to this SEM image indicating the majority composition of this film is carbon. Figures $4.2 \mathrm{c}$ ) and d) show morphologies of products from another aluminum carbide and tin chloride reaction. ${ }^{1}$ The mass of the products remaining after chemical separation indicated a $70 \%$ yield for this reaction. Figure $4.2 \mathrm{c}$ ) shows an SEM image at higher magnification illustrating the features of a large area of the sample. This image shows large crystalline specimens that appear to be larger than the initial size of the aluminum carbide, 44 microns. Figure $4.2 \mathrm{~d}$ ) shows a close up of one of these crystals, corresponding EDS (not shown) indicates that these crystals are composed of carbon. The morphology in this image is crystalline with sharp edges and smooth, planar faces. However, there is no layering which is indicative of graphite. 


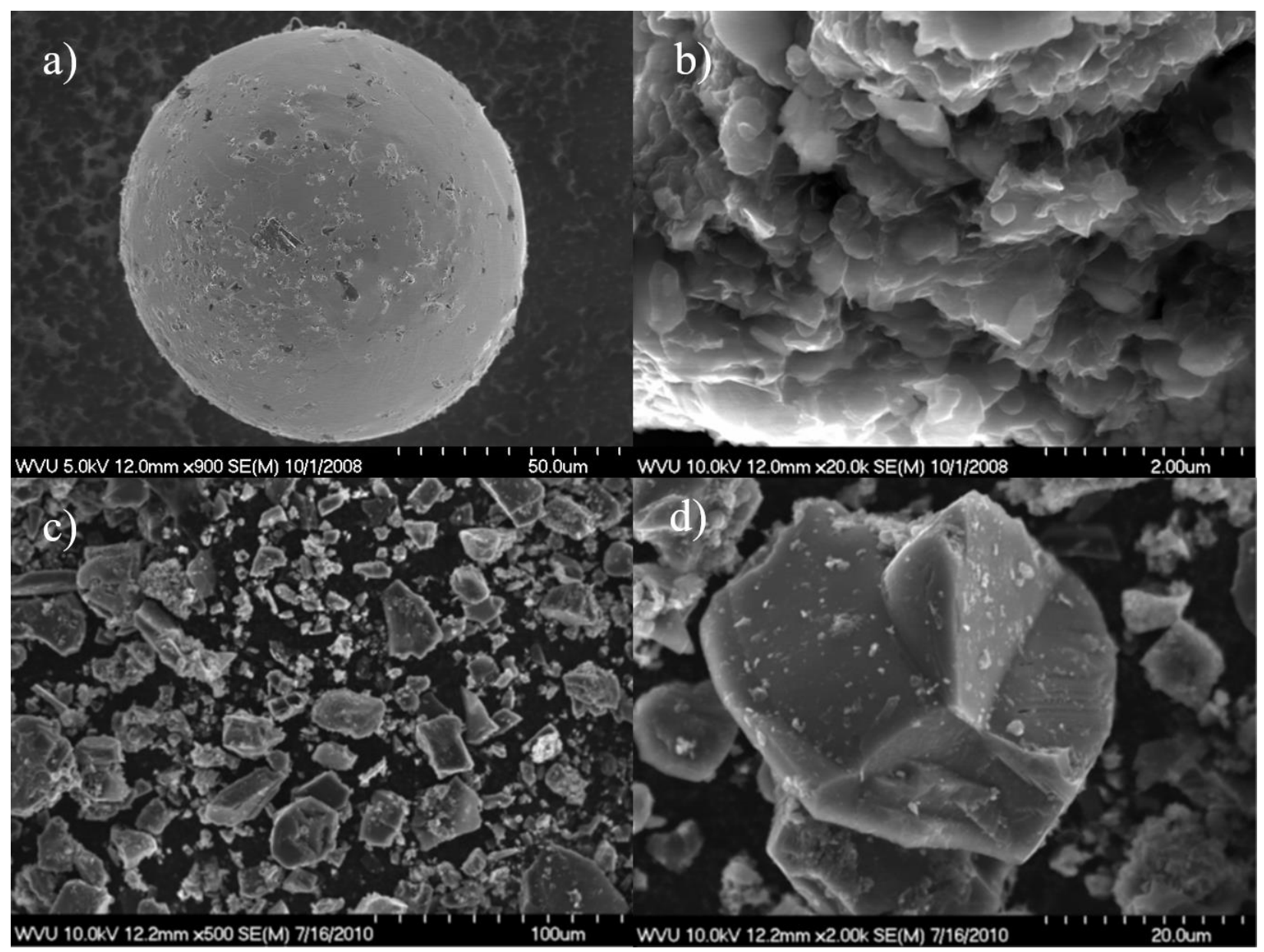

Figure 0.2 SEM images of reaction products typical of aluminum carbide and tin chloride, a) a bead of reduced tin metal, b) thin film of aggregates of carbon platelets, c) image of bulk sample at higher magnification, d) close-up of a carbon crystal. 


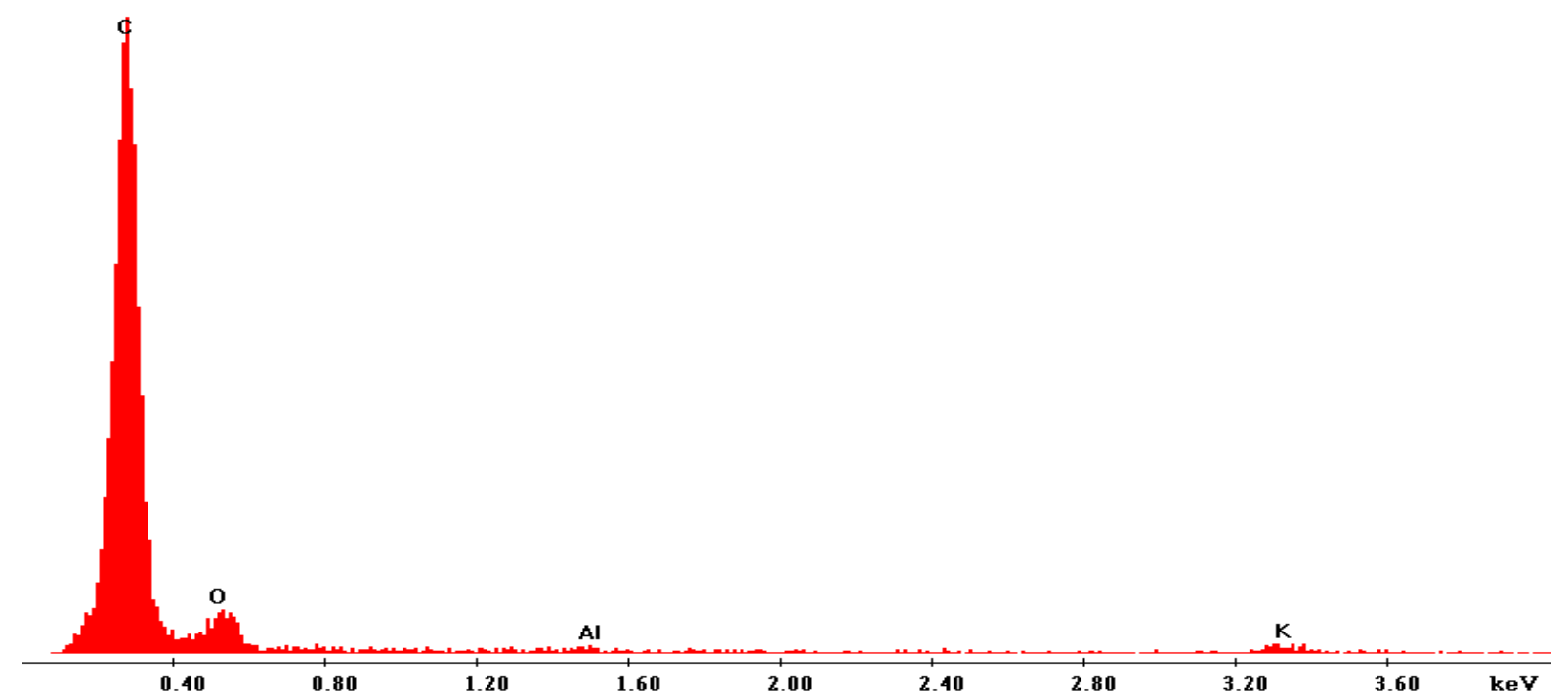

Figure 0.3 EDS spectrum corresponding to thin film of carbon platelet aggregates in Figure 4.2 b)

There have been relatively few studies on producing carbon materials from aluminum carbide. One example is the recent work of Walton et al. investigating the production of carbidederived carbons (CDCs) from aluminum carbide shows promise for synthesizing activated carbons with tunable pore size. Etching of the carbide by chlorination at varying temperatures enabled control of the crystallinity, surface area and residual aluminum content ( $\mathrm{R} 4.4, \mathrm{R} 4.5)$. Etching temperatures ranged from 300 to 900 and reaction time was $1 \mathrm{hr}$. Higher etching temperatures produced carbon that is more ordered and graphitic ${ }^{5}$ The ratio of formation of the monomer and dimer of aluminum chloride is also temperature dependent.

$$
\begin{aligned}
& \mathrm{Al}_{4} \mathrm{C}_{3}+6 \mathrm{Cl}_{2} \rightarrow 4 \mathrm{AlCl}_{3}+3 \mathrm{C} \\
& \mathrm{Al}_{4} \mathrm{C}_{3}+6 \mathrm{Cl}_{2} \rightarrow 2 \mathrm{Al}_{2} \mathrm{Cl}_{6}+3 \mathrm{C}
\end{aligned}
$$$$
\text { R } 0.4
$$

Although Walton et al.'s synthesis route led to graphitic and amorphous carbons, the characterization data of products from salt melt synthesis with tin chloride indicate the presence of amorphous carbon and diamond-related material. It is possible that the carbon produced via reaction $\mathrm{R} 4.1$ is diamond-like carbon (DLC), a type of amorphous carbon with properties similar 
to that of diamond due to the high content $\mathrm{sp}^{3}$ hybridization..$^{6-9}$ The work of Hayashi et al. supports this hypothesis. Hayashi and cohorts prepared carbon nano-onions ${ }^{10,11}$ from diamond nanoparticles through high temperature annealing 9 . Initial XRD patterns of the diamond nano-particles contain broadened peaks for the (111), (220) (322) and (400) diamond reflections, and a small satellite peak for (002) reflection of graphite. The XRD patterns showing the evolution of the diamond nano-particles to carbon onions show the decrease of the (111) diamond reflection and the increase of the (002) graphite reflection. These results demonstrate the transformation of predominantly $\mathrm{sp}^{3}$ type bonding material to $\mathrm{sp}^{2}$ type.

There are very few studies on diamond-related materials involving aluminum carbide, and all of them have been performed at high temperatures and pressures. Britun et al. studied the crystallization of diamond assisted by aluminum carbide formation at temperatures and pressures of 2270-2470 K and 8GPa. Their experiments were performed in a recessed-anvil toroid-type highpressure apparatus. The carbon source was high purity graphite sandwiched between aluminum foil and a cBN substrate. Characterization by TEM indicated that a diamond layer crystallizes via two routes. First of these is the incongruent melting of aluminum carbide (R 4.6), and the second is the recrystallization from graphite within the aluminum-carbide melt. The authors believed the difference in solubility between metastable graphite and stable diamond under high temperatures and pressures drives this second process. ${ }^{12}$

$$
\mathrm{Al}_{4} \mathrm{C}_{3} \rightarrow L(A l, C)+C(\text { diamond }) \quad \text { R } 0.6
$$

At this point assignment of the carbon product produced to a single carbon allotrope would be premature. Many interesting and varied carbon morphologies have been observed, and it is still unclear which is the dominant morphology. 


\subsection{Reaction of Calcium Carbide with Tin Chloride}

Salt melt syntheses were carried out between calcium carbide $\left(\mathrm{CaC}_{2}, 72-82 \%\right)$ and anhydrous tin chloride (R 4.2) by the methodology as described in Chapter 2 Experimental Methods. The carbon remaining after separation of the raw products was characterized via scanning electron microscopy (SEM) and energy dispersive X-ray spectroscopy (EDS).

Figure 4.4 displays SEM images of typical morphologies observed in the analysis of reaction products from calcium carbide and tin chloride ${ }^{4}$. Figure 4.4 a) shows metallic spheres of tin sitting on a bed of amorphous material. Again, the reduction of the tin cation to tin metal confirms the oxidation of the carbon anion took place in the calcium carbide as well. In addition to the amorphous material, other morphologies were observed such as aggregates of thin films and stacks of plates of carbon as shown in Figure 4.4 b). Corresponding EDS spectrum is shown in Figure $4.4 \mathrm{c})$.

Stacks of planar carbon sheets are characteristic of graphitic carbons. Moreover, graphite is the carbon phase most likely to be produced by oxidation of calcium carbide considering the anisotropy of the acetylide anions within the carbide's structure which form a near hexagonal arrangement. The amorphous carbon may originate from the elemental carbon impurities in calcium carbide from unreacted coke as discussed in Appendix A. It is unclear if and how this amorphous carbon influences the reaction pathway of R 4.2. Barber and Sloane's report ${ }^{2}$ only referred to the reduction of $\mathrm{ZnCl}_{2}, \mathrm{PbCl}_{2}$ and $\mathrm{CdCl}_{2}$ molten salts by calcium carbide; thus, the research presented here would be the first report of a similar reaction in a $\mathrm{SnCl}_{2}$ melt. 

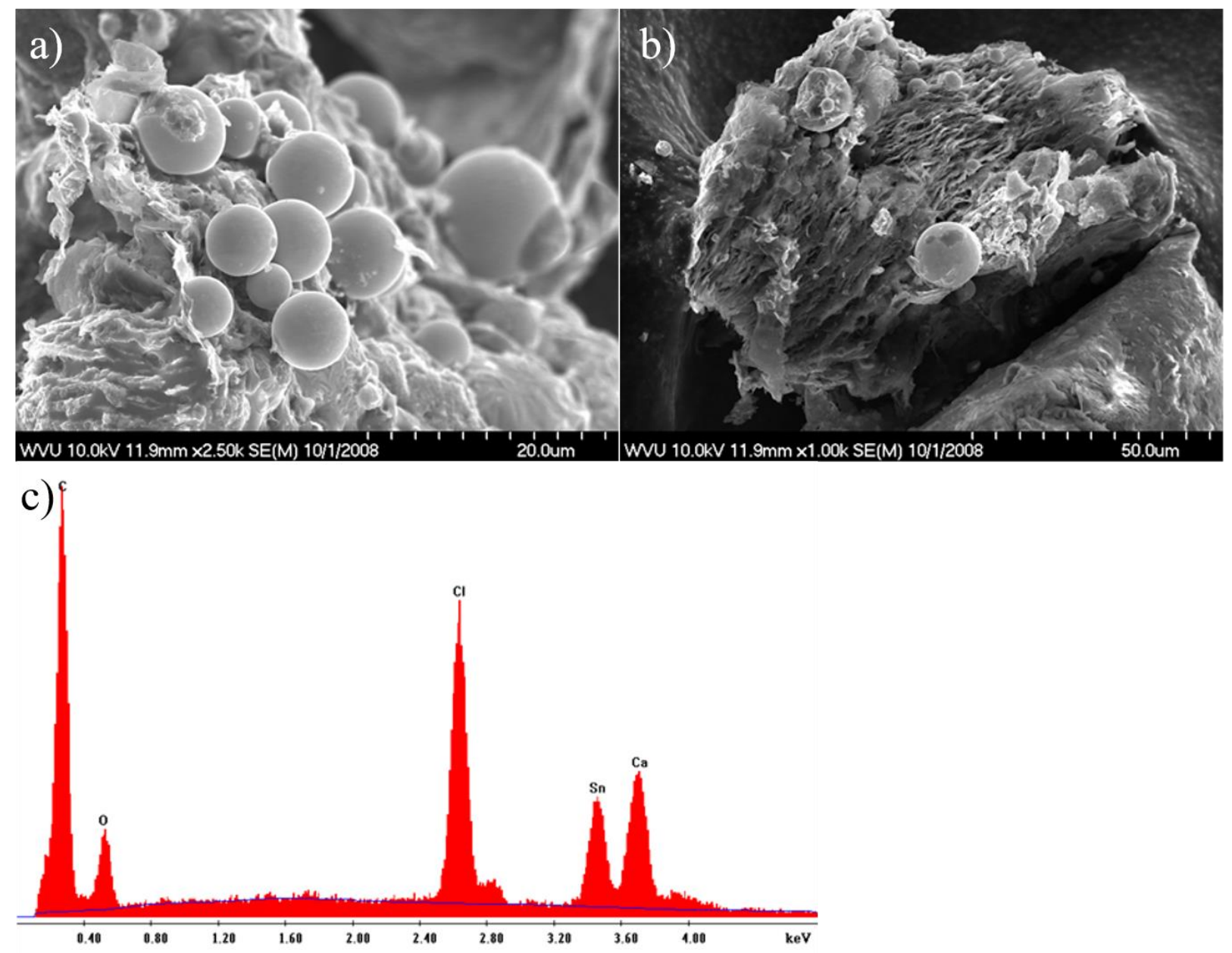

Figure 0.4 SEM images of reaction products typical of calcium carbide and tin chloride, a) tin beads resting on a bed of amorphous material, b) stacks of planar sheets of carbon with spheres of tin on their surface, $c$ ) EDS spectrum of $b$ ).

\subsection{Reaction of Calcium Carbide with Zinc Chloride}

Salt melt syntheses were carried out between calcium carbide $\left(\mathrm{CaC}_{2}, 72-82 \%\right)$ and anhydrous zinc chloride ( $\mathrm{R}$ 4.2) by the methodology as described in Chapter 2 Experimental Methods. The carbon remaining after separation of the raw products was characterized via scanning electron microscopy (SEM) and energy dispersive X-ray spectroscopy (EDS), microRaman spectroscopy, and X-ray photoelectron spectroscopy (XPS).

Results of characterization and analyses indicated that the zinc cation in the molten state had oxidized the calcium carbide to produce graphite and amorphous carbon of varying 
morphologies. Large, pristine single crystals of graphite were often observed in the products of these reactions. In the optical microscope viewing field specimens which are flat, reflective and angular are easily recognized as graphitic crystals. Figures 4.5 and 4.6 c) and d) show SEM and optical microscope images which display large, euhedral graphite crystals some of which are isolated single crystals and some of which are polycrystalline aggregates. However, there were also amorphous carbon microstructures such as the sphere of thin carbon in Figure 4.6 a) and the aggregate of amorphous structures in Figure 4.6 b). Observation of these samples via optical microscopy and SEM indicated that graphite crystals often obscured by amorphous carbon, which is dark, non-reflective, and out of focus.

Results of preliminary experiments suggested that a hydrogen peroxide/trifluoroacetic acid $\left(\mathrm{H}_{2} \mathrm{O}_{2}\right.$ /TFA) treatment used for oxidizing coal ${ }^{13}$ may be a route to separating the amorphous carbon from the graphite, as large, hexagonal single crystals were easier to find in samples post-oxidation treatment. First reported by Deno, ${ }^{14}$ it has been proposed that the oxidative degradation and dissolution of coal proceeds by the carboxylation of alkyl bridges between aromatic groups, which is followed by cleavage into smaller groups. We have initiated experiments exploring $\mathrm{H}_{2} \mathrm{O}_{2} / \mathrm{TFA}$ as a route for the chemical separation of graphitic and amorphous carbon. Figures $4.6 \mathrm{c}$ ) and d) show single crystals in samples that had undergone the oxidative treatment with $\mathrm{H}_{2} \mathrm{O}_{2} / \mathrm{TFA}$. The absence of amorphous material on and around the graphitic crystals suggest that this may be a promising method for further purification to a single carbon phase.

Note that no beads of zinc metal were observed in analyses. The reason zinc metal is absent in analyses is because the temperature of the zinc chloride melt was below the melting temperature of zinc. Therefore, when the metal cations are reduced in the melt the are likely reduced to fine 
nanoparticles of zinc which are quickly reacted away in the chemical separation step with hydrochloric acid.

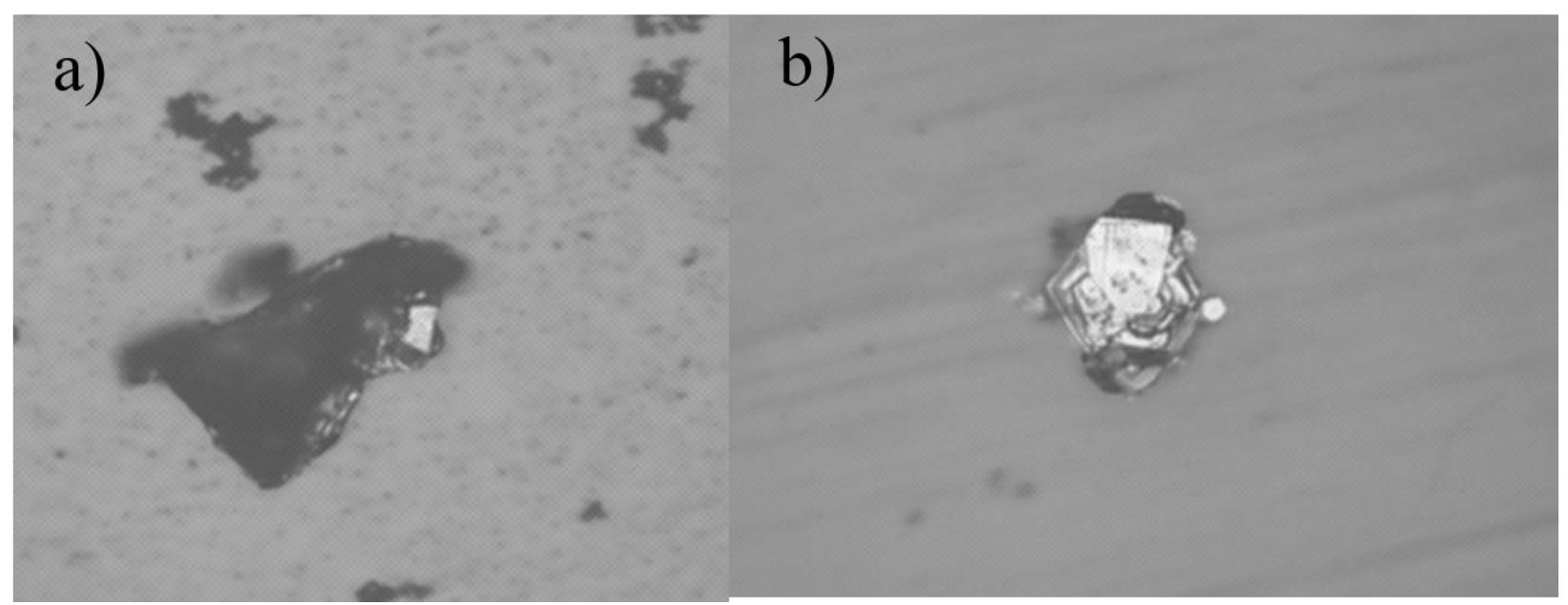

Figure 0.5 Optical microscope of a) carbon product from reaction of calcium carbide and zinc chloride before oxdiation treatment with $\mathrm{H}_{2} \mathrm{O}_{2}$ /TFA and b) after oxidation treatment. 


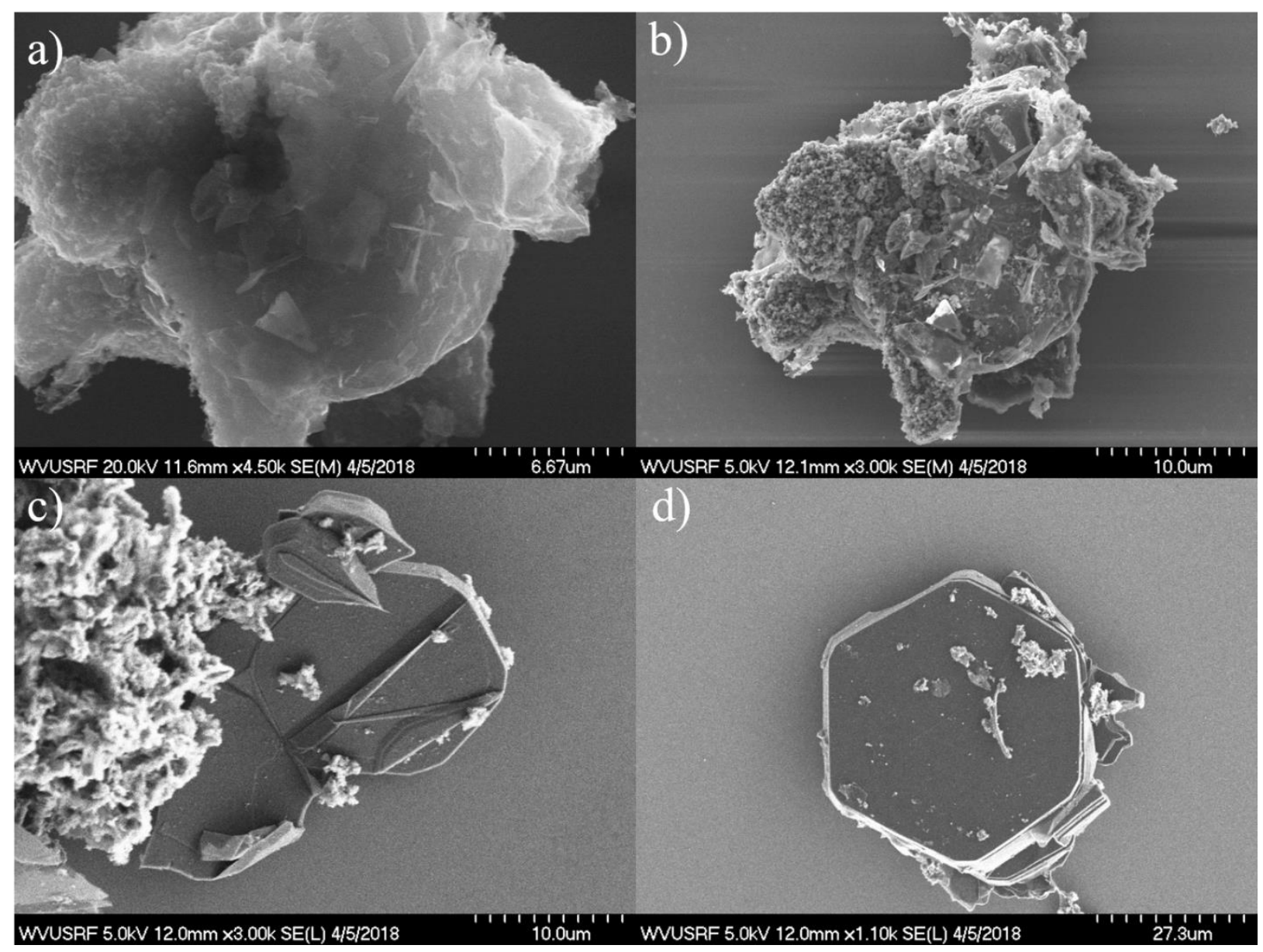

Figure 0.6 SEM images of a) and b) carbon product from reaction of calcium carbide and zinc chloride before oxidation treatment. Image in a) displays spherical structure of thin carbon film and b) shows aggregates of amorphous carbon. SEM images in c) and d) show hexagonal, single crystals of graphite after oxidation treatment.

Raman spectra were collected of the hexagonal crystals confirming the identification of graphite. Figure 4.7 shows the Raman spectrum of one of these crystals. The most intense peak in the spectrum occurs at $1570 \mathrm{~cm}^{-1}$ and corresponds to the $\mathrm{G}$ band $\mathrm{sp}^{2}$ vibrations in graphite. The second most intense peak is the $2 \mathrm{D}$ band at $\sim 2700 \mathrm{~cm}^{-1}$. There is a small, satellite peak at $\sim 2450$ $\mathrm{cm}^{-1}$ which is known as the $\mathrm{D}+\mathrm{D}$ ”. It is important to note the absence of the $\mathrm{D}$ band at $1350 \mathrm{~cm}^{-1}$. The $\mathrm{D}$ band is a one phonon, electron scattering process which is only activated in the presence of defects or in polycrystalline samples of very small crystal grains. ${ }^{15}$ Thus, D band is absent for this crystal due to its large size and pristine structure. 


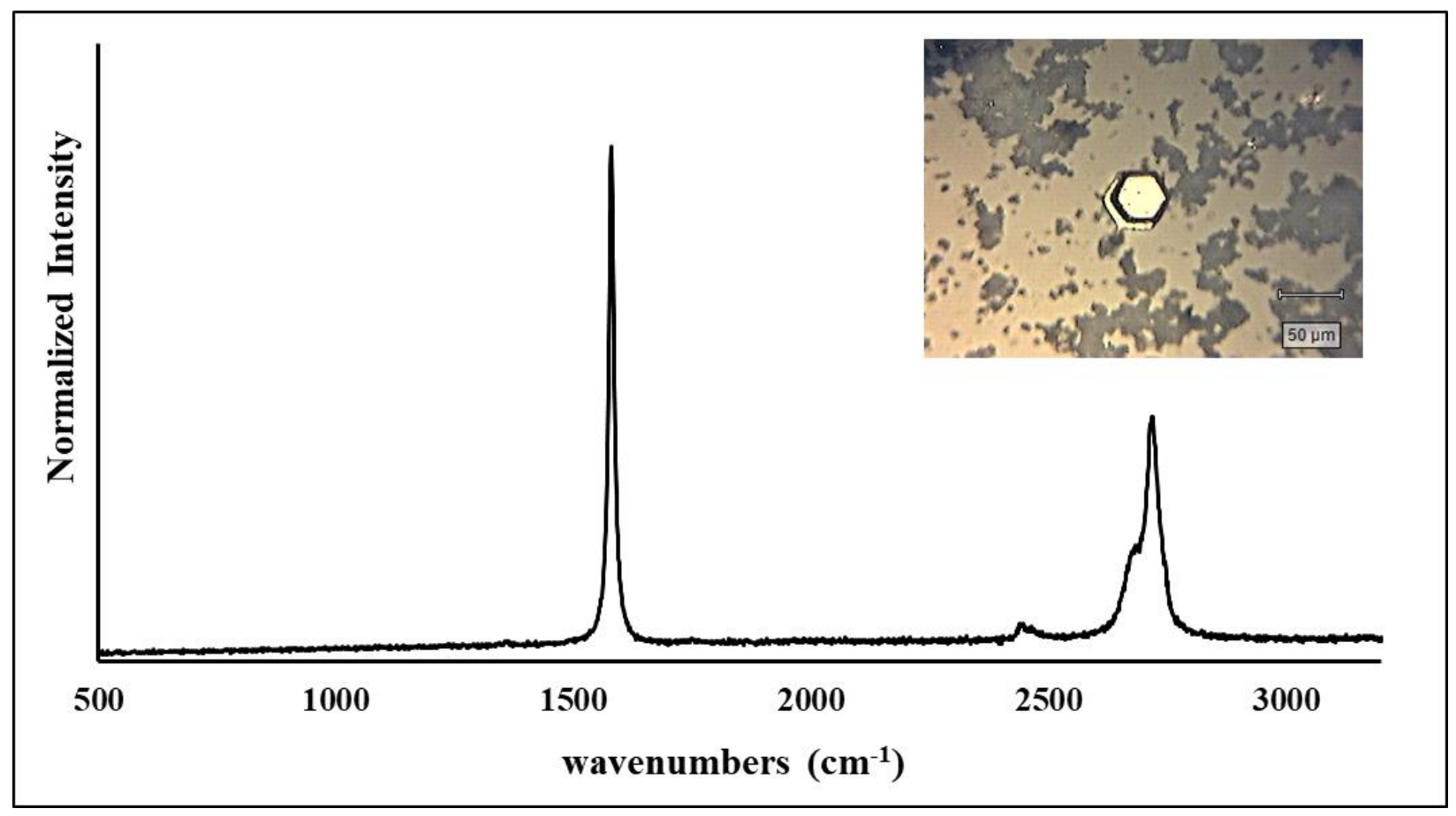

Figure 0.7 Raman spectrum of single crystal of graphite shown in inset optical microscope image in right hand corner. Laser wavelength $532 \mathrm{~nm}, 50 x$ objective, $10 \%$ of $100 \mathrm{~mW}$.

Figure 4.8 shows an XPS spectrum presenting the surface characterization of the carbon material produced in reaction $\mathrm{R}$ 4.3. The most intense peak is the $\mathrm{C} 1 \mathrm{~s}$ band in agreement with the composition of the sample. The presence of the $\mathrm{O} 1 \mathrm{~s}$ and $\mathrm{O} 2 \mathrm{~s}$ peaks can be attributed to epoxy and hydroxy surface groups. The $\mathrm{Cl} 2 \mathrm{~s}$ and $\mathrm{Cl} 2 \mathrm{p}$ peaks indicate the presence of residual chloride from the reaction, and the $\mathrm{Si} 2 \mathrm{~s}$ and $\mathrm{Si} 2 \mathrm{p}$ peaks are likely due to $\mathrm{SiO}_{2}$ or $\mathrm{SiC}$ impurities. 


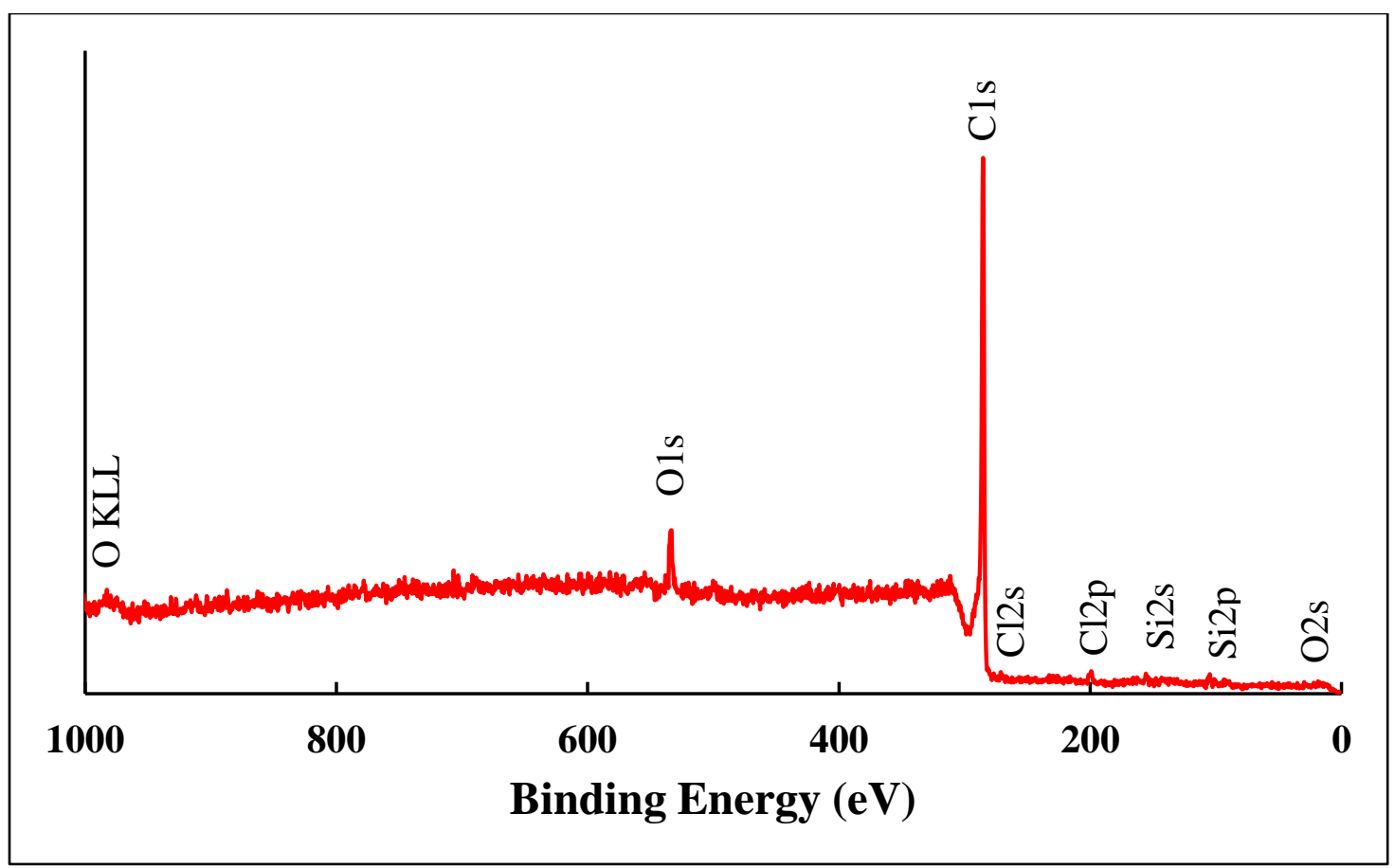

Figure 0.8 XPS spectrum of carbon material produced from reaction of calcium carbide and molten zinc chloride.

To the best of our knowledge there are no studies characterizing the carbon products from the salt melt syntheses in reactions R 4.1, R 4.2 and R 4.3. As mentioned earlier Barber and Sloane noted that metals in $\mathrm{ZnCl}_{2}, \mathrm{CdCl}_{2}$ and $\mathrm{PbCl}_{2}$ melts were reduced by calcium carbide, but they did not pursue this further.

\section{References}

(1) Hardinger, J. Reactions of Metal Carbides to Produce Carbon, West Virginia University, 2017.

(2) Barber, W. A.; Sloan, C. L. J. Phys. Chem. 1961, 65 (11), 2026-2028.

(3) Anderson, D. P. Analysis of Black "Carbon" Powder from West Virginia University; Dayton, OH, 2010.

(4) Stiller, A. SEM Characterization of Products Aluminum Carbide and Tin Chloride Reactions, Unpublished Data; Morgantown, WV, 2010.

(5) Moran, C. M.; Marti, R. M.; Hayes, S. E.; Walton, K. S. Carbon N. Y. 2017, 114, 482495.

(6) Robertson, J. Mater. Sci. Eng. R Reports 2002, 37 (4-6), 129-281.

(7) Kester, D.; Bray, D. Diam. Relat. Mater. 1998, 7, 468-471. 
(8) Roy, R. K.; Deb, B.; Bhattacharjee, B.; Pal, A. K. Thin Solid Films 2002, 422 (1-2), 9297.

(9) Tomita, S.; Burian, A.; Dore, J. C.; Lebolloch, D.; Fujii, M.; Hayashi, S. Carbon N. Y. 2002, 40, 1469-1474.

(10) Rao, C. N. R.; Seshadri, R.; Govindaraj, A.; Sen, R. Mater. Sci. Eng. R 1995, 15 (6), 209262.

(11) Zeiger, M.; Jäckel, N.; Mochalin, V. N.; Presser, V. J. Mater. Chem. A 2016, 4 (9), 31723196.

(12) Petrusha, I. A.; Smirnova, T. I.; Osipov, A. S.; Britun, V. F. Diam. Relat. Mater. 2004, 13 (4-8), 666-670.

(13) Choudhury, D.; Sanyal, P. K.; Banerjee, A. K. Fuel 1988, 67 (2), 177-181.

(14) Deno N C, Greigger B A, S. S. O. Fuel 1978, 57 (8), 455-459.

(15) Ferrari, A. C.; Basko, D. M. Nat. Nanotechnol. 2013, 8 (4), 235-246. 


\section{Chapter 5: Solution State Syntheses}

\subsection{Reactions of Ionic Carbides with Metal Chloride Salts in the Solution State}

Results presented in Chapter 4 showed that metallic cation in salt melt reactions had oxidized the carbon anion in calcium and aluminum carbide and produced elemental carbon ( $\mathrm{R}$ 5.1. R 5.2 and R 5.3). Reactions show again for convenience:

$$
\begin{array}{rlr}
\mathrm{Al}_{4} \mathrm{C}_{3}+\mathrm{SnCl}_{2} \rightarrow 3 \mathrm{AlCl}_{3}+\mathrm{Sn}^{0}+3 \mathrm{C} & \mathbf{R ~ 0 . 1} \\
\mathrm{CaC}_{2}+\mathrm{SnCl}_{2} \rightarrow \mathrm{CaCl}_{2}+\mathrm{Sn}^{0}+2 \mathrm{C} & \mathbf{R ~ 0 . 2} \\
\mathrm{CaC}_{2}+\mathrm{ZnCl}_{2} \rightarrow \mathrm{CaCl}_{2}+\mathrm{Zn}^{0}+2 \mathrm{C} & \mathbf{R ~ 0 . 3}
\end{array}
$$

The carbon material produced in reactions with calcium carbide ranged from graphitic to amorphous in structure. Results suggested that the oxidation of aluminum carbide by tin chloride melts was amorphous with diamond related structure.

We wished to determine whether this reaction would proceed at room temperature with the metal chloride salts dissolved in anhydrous solvents. Preliminary experiments with aluminum carbide and salts dissolved in anhydrous ethanol indicated that aluminum carbide was not reactive with late transition metal salts in the solution state, and similar experiments with calcium carbide and tin chloride were inconclusive. ${ }^{1}$ Thus, only the results from calcium carbide reactions with zinc chloride dissolved in ethanol is presented. These results support the hypothesis that the zinc cation in solution oxidizes the carbon anion in the calcium carbide. This reaction can be separated into two half-reactions (shown again for convenience):

$$
\begin{gathered}
\mathrm{CaC}_{2} \rightarrow \mathrm{Ca}^{2+}+2 e^{-}+2 \mathrm{C} \\
\mathrm{Zn}^{2+}+2 e^{-} \rightarrow Z n
\end{gathered}
$$

Section 5.1 presents the results of the solution state galvanic reactions of calcium carbide and zinc chloride. Section 5.2 presents the results of a controlled potential electrolysis experiments 
in which we have attempted to drive the reactions $R 2.15$ and $R 2.16$ by applying a potential with a poteniostat.

\subsection{Solution State Galvanic Reactions}

Solution state galvanic reactions were carried out between calcium carbide and zinc chloride dissolved in anhydrous ethanol via the methodology described in Chapter 2 Experimental Methods. The zinc electrode and the carbide electrode were connected electrically, and the current was monitored with a multimeter. A nonzero current was immediately noted implying that electrons were flowing through the external circuit between the electrodes and charged species $\left(\mathrm{Cl}^{-}\right)$were flowing through the salt bridge between the two cells. Additionally, closing the stop cock in the salt bridge resulted in zero current further supporting this interpretation. Over time the precipitated zinc chloride in the saturated zinc half-cell disappeared, implying that the zinc cation had been consumed. The average current measured between the half-cells fluctuated between 0.5 and 2.0 over the course of 2 to 4 days $^{2}$.

The carbon material remaining after chemical separation of the raw products was characterized by scanning electron microscopy (SEM), energy dispersive X-ray spectroscopy (EDS), X-ray photoelectron spectroscopy (XPS) and micro-Raman spectroscopy.

Figure 5.1 shows SEM images representative of carbon morphologies observed in the analysis of products from the galvanic, solution reactions of calcium carbide and zinc chloride. Figures 5.1 a), c) and d) display either large single crystals of graphite or polycrystalline aggregates comprised of smaller, well formed crystal grains. The graphite crystals in Figures 5.1 c) and d) appear to be covered in a fine film and amorphous material. Figure 5.1 b) displays a carbon microstructure with morphology that is not characteristic of graphite. This sphere of carbon has a 40 micron diameter and is likely amorphous. These results indicate oxidation of the calcium 
carbide by the zinc cation in the solution state did occur to some degree. The images and EDS spectra show that the remaining carbon material has a mixture of graphitic and amorphous morphologies.

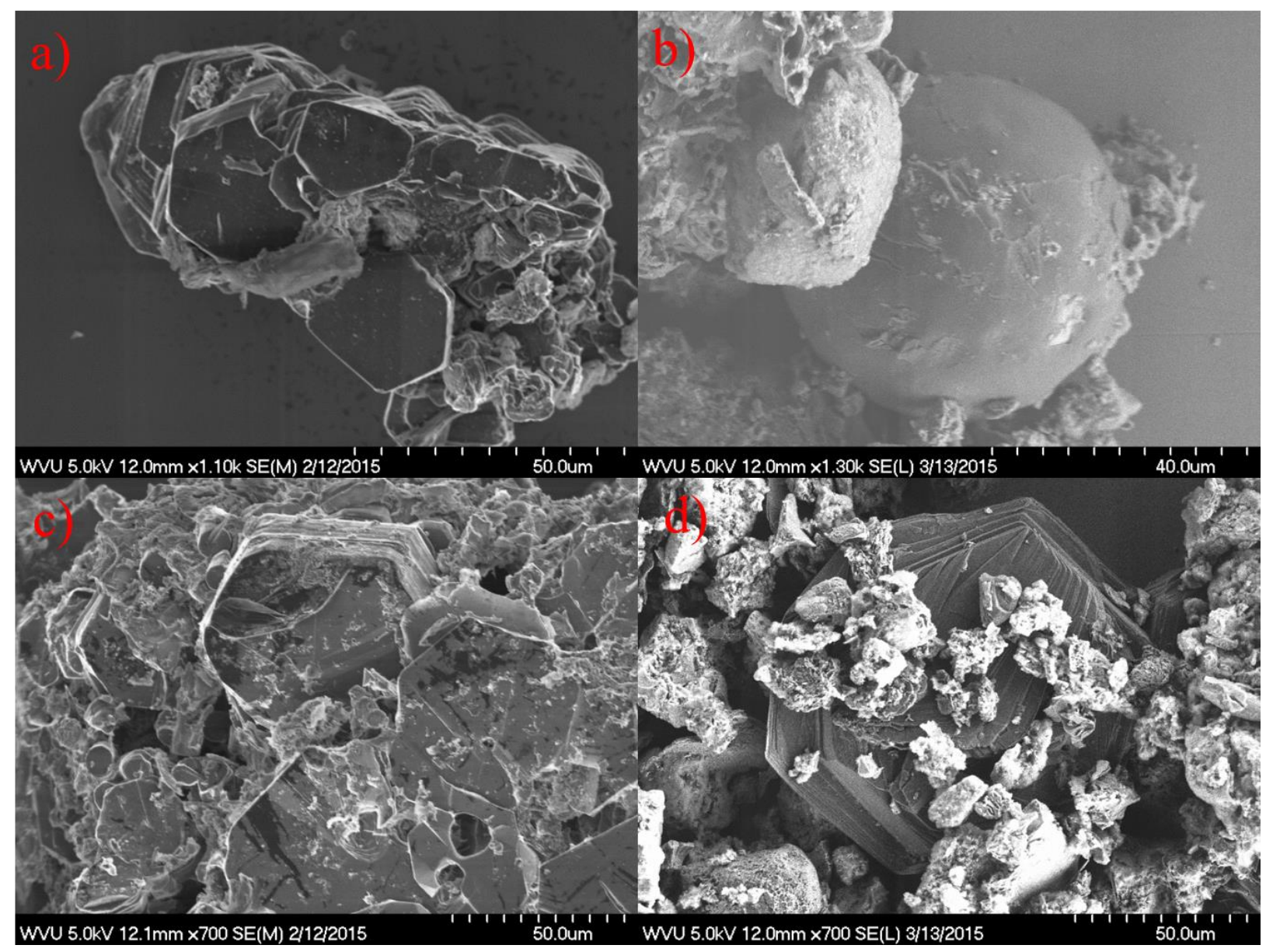

Figure 0.1 SEM images of products typical of galvanic, solution calcium carbide and zinc chloride reactions: a) polycrystalline aggregates of small, hexagonal grains, b) a carbon crystal with spherical morphology, c) aggregates of single crystals of graphite which appear to be covered in a film, d) crystals of graphite covered in amorphous material.

Raman spectra from different areas in the same sample support this interpretation. Figure 5.2 a) - c) show optical microscope images of the viewing field of the Raman microscope from which the spectra in Figure 5.2 were collected. The Raman laser was always focused in the middle of the microscope's viewing field. Figures 5.2 a) and b) show specimens dispersed on the slide that are too small to bring into focus in the microscope. However, there is a small, highly reflective 
crystal to the right in Figure 5.2 b). Figures 5.2 c) and d) display larger specimens which have morphology indicative of graphitic crystalline material. These crystals are not euhedral, single crystals, but they are reflective, with flat faces and sharp edges. These specimens are likely aggregates of polycrystalline graphite.

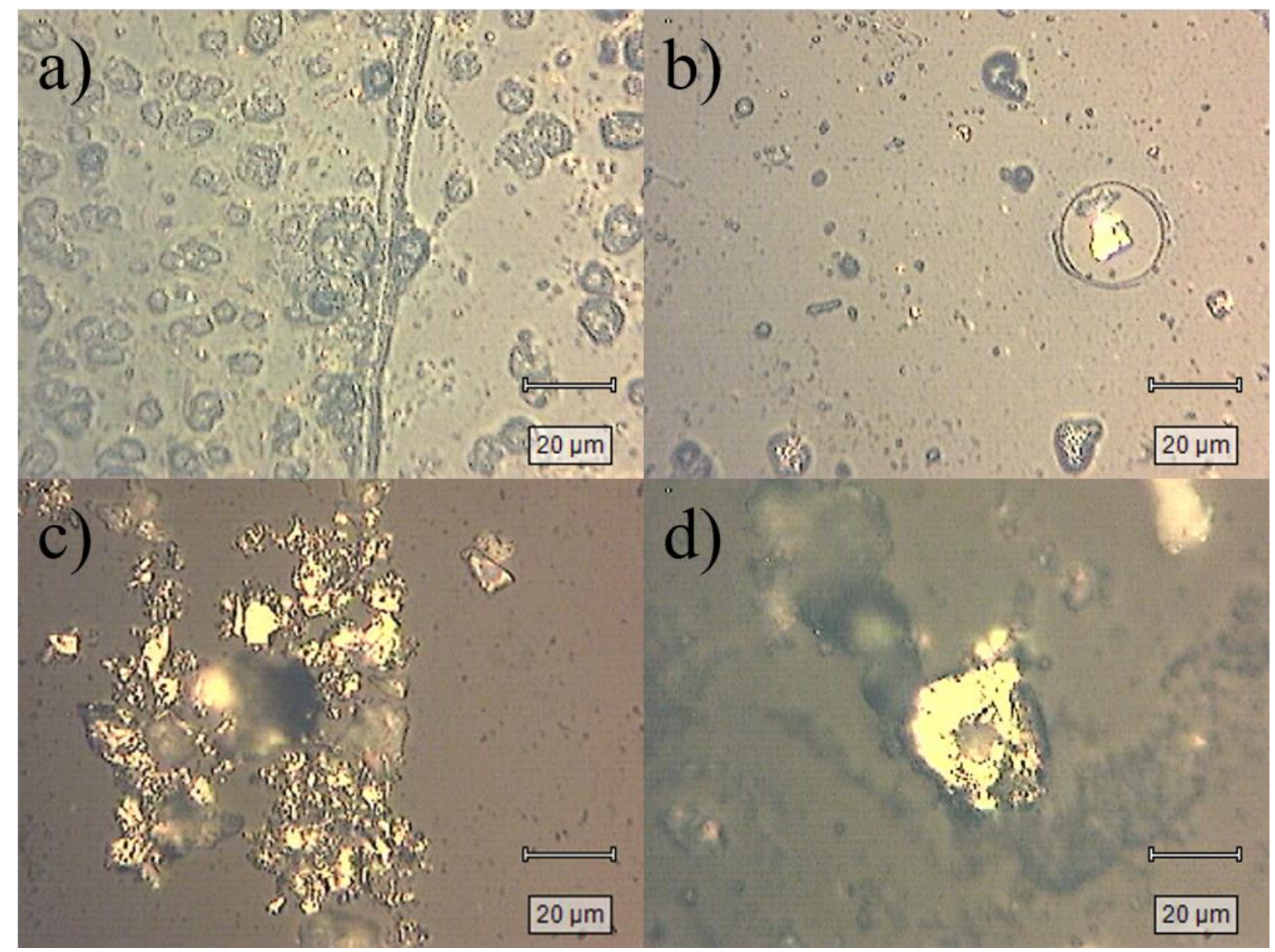

Figure 0.2 Optical microscope images displaying morphologies of the specimens yielding the Raman spectra in Figure 5.3. Image a) corresponds to the red spectrum, b) corresponds to the black spectrum, c) corresponds to the green spectrum and d) corresponds to the blue spectrum.

Figure 5.2 displays the Raman spectra corresponding to the optical microscope images in

Figure 5.2. The red spectrum was collected from the sample area in Figure 5.2 a) and the black spectrum from the sample area in b). The broad, merged D and G peaks in both spectra as well as the high background scattering indicate the amorphous nature of the material in these images. The 
green Raman spectrum of the crystals in Figure $5.2 \mathrm{c}$ ) and the blue Raman spectrum of the large crystal in Figure $5.2 \mathrm{~d}$ ) show a narrowing of the D, G and 2D bands and a decrease in background scattering. This is consistent with the increasing size of the crystals and increasing crystallinity. The Raman spectrum of the specimen in Figure 5.2 d) indicates that this specimen is graphite. However, the presence of the D peak suggests that it is polycrystalline.

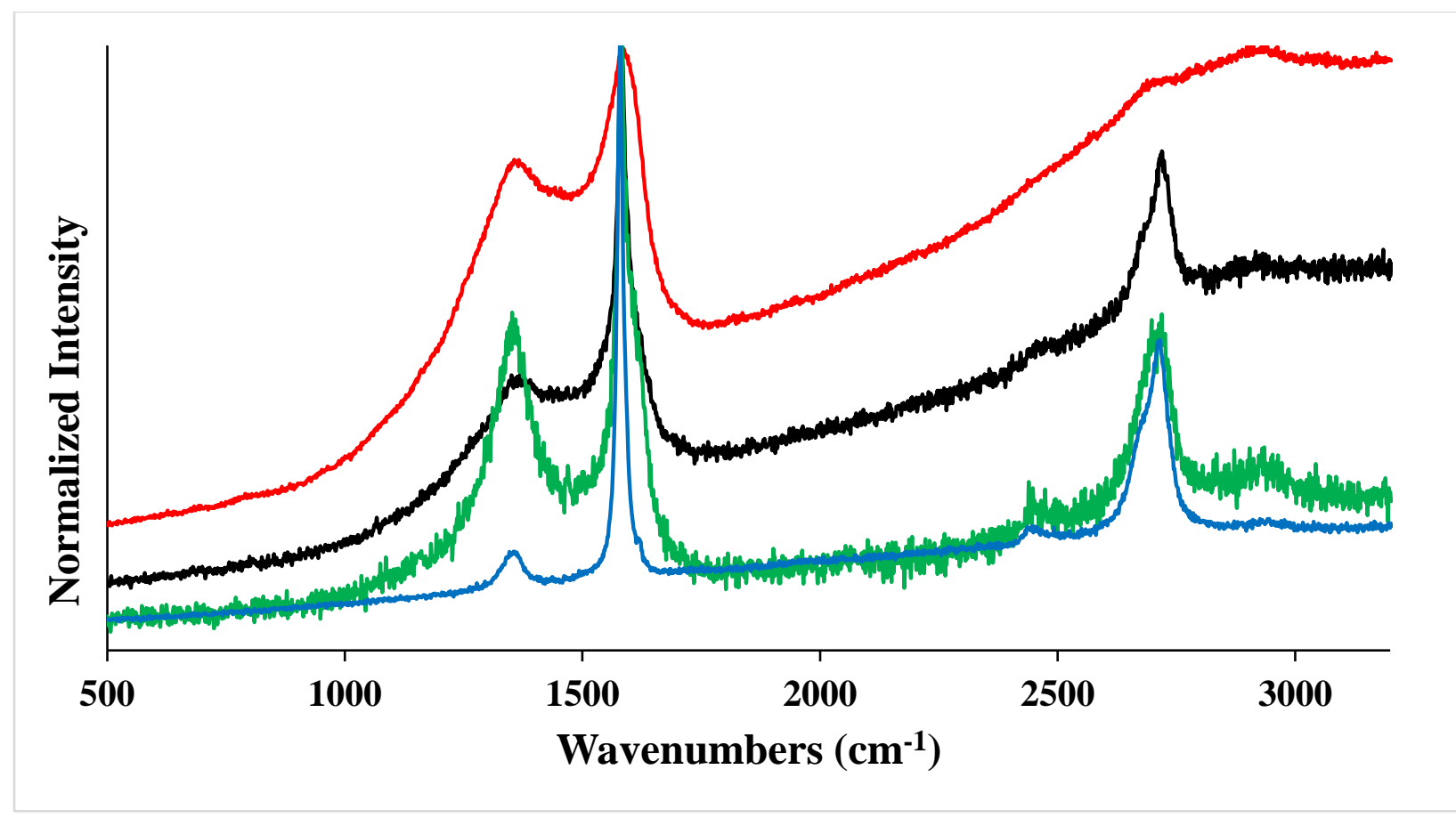

Figure 0.3 Raman spectra of different areas of the same sample from galvanic, solution reactions of calcium carbide and zinc chloride. Laser wavelength $532 \mathrm{~nm}, 50 x$ objective, $10 \%$ of $100 \mathrm{~mW}$.

Figures 5.4 and 5.5 shows XPS spectra of different carbon with large particle size and small particle size. These samples were roughly separated by particle size by the settling rate method. In Figure 5.4, the most intense peak is the C1s, however, in the spectrum of the smaller particle size the O1s peak is the most intense. This increase in intensity of the O1s band is in agreement with the increase in epoxy and hydroxyl groups due to increased surface area. The Cl2s and $\mathrm{Cl} 2 \mathrm{p}$ peaks indicate the presence of residual chloride from the reaction, and the Si2s and Si2p peaks are likely due to $\mathrm{SiO}_{2}$ or $\mathrm{SiC}$ impurities. The Ar2p band is likely from implanted $\mathrm{Ar}$ ions from the Ar gun. 


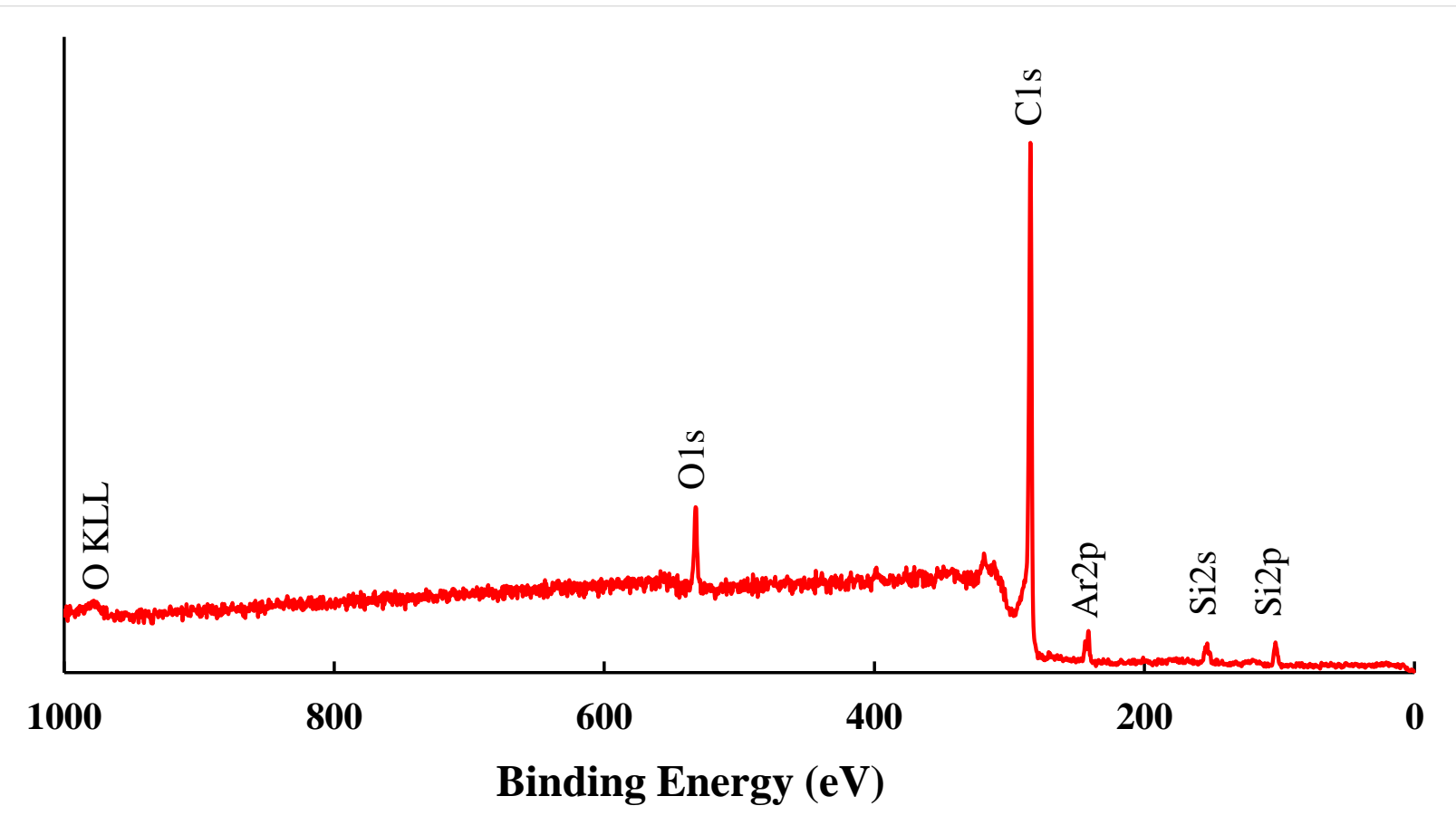

Figure 0.4 XPS spectrum of large particle size carbon material produced from reaction of calcium carbide and zinc chloride.

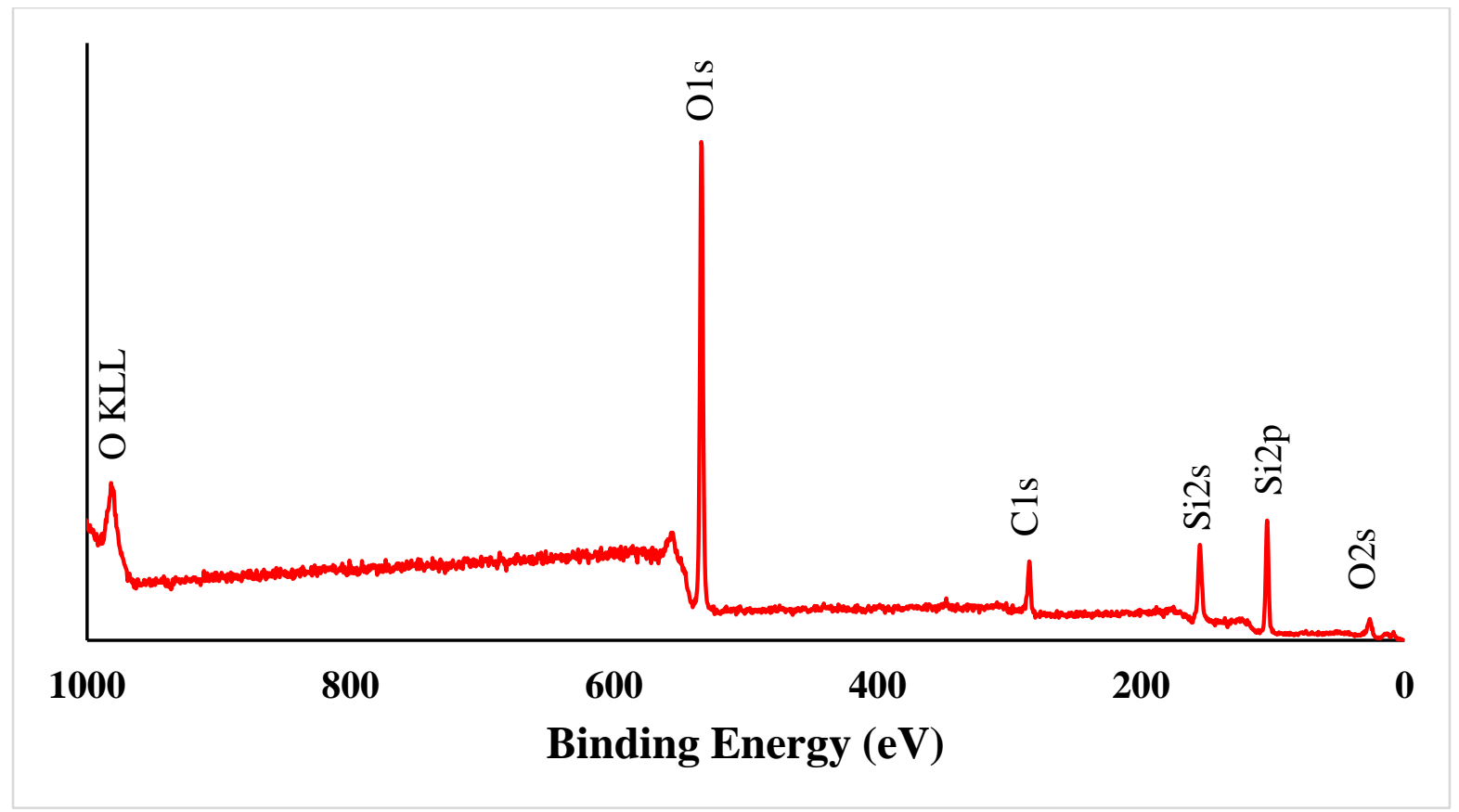

Figure 0.5 XPS spectrum of small particle size carbon material produced from reaction of calcium carbide and zinc chloride. 


\subsection{Solution State Controlled Potential Electrolysis}

A controlled potential electrolysis experiment was conductive in an attempt to drive the reactions R 2.15 and R 2.16 following the methodology described in Chapter 2 Experimental Methods. When a potential of $0 \mathrm{~V}$ was applied a current of $5 \mu \mathrm{A}$ was measured. The applied voltage was increased to $+14 \mathrm{~V}$ to drive an oxidation at the carbide electrode. With this increase in applied potential and increase in current from $5 \mu \mathrm{A}$ to $100 \mu \mathrm{A}$ was observed. This significant increase in current implies an increase in the overall reaction rate upon application of $+14 \mathrm{~V}$. Over time the precipitated zinc chloride in the saturated zinc half-cell dissolved, indicating that the zinc cation in solution had been consumed. More zinc chloride was added to the zinc half-cell until saturation was reached. The current reached a maximum of $200 \mu \mathrm{A}$ over the course of 4 days. On the fourth day, both cells were opaque white implying the production of calcium chloride in the carbide halfcell to the point of over saturation. The white precipitate in the zinc cell is likely due to zinc oxide and hydroxide formation from reaction with oxygen and moisture impurities.

The carbon material remaining after chemical separation of the raw products was characterized by scanning electron microscopy (SEM), energy dispersive X-ray spectroscopy (EDS) and micro-Raman spectroscopy. Figure 5.6 presents SEM images of various morphologies observed in the carbon collected after the controlled potential electrolysis of calcium carbide and zinc chloride. Figure 5.6 a) shows an image of the bulk material in which flat, stacks of graphite crystals in many different orientations are sitting on the surface of amorphous. The fibers are silica fibers from the glass fiber filters used to isolate the carbon after treatment with hydrochloric acid. The cross-sections of the crystals were not constant, and the sizes were highly variable (Figure 5.6 b)); however, this sample had a high number of graphitic crystals. The image in Figure $5.6 \mathrm{c}$ ) depicts graphitic crystals, which are less well formed and seem to have a higher degree of disorientation. Figure 5.6 c) displays a very unusual structure which had that had never been 
observed before. This structure was a network of porous amorphous carbon according to elemental analysis via EDS. Also depicted in Figure $5.6 \mathrm{c}$ ) is one of the glass fibers from the filtration process.

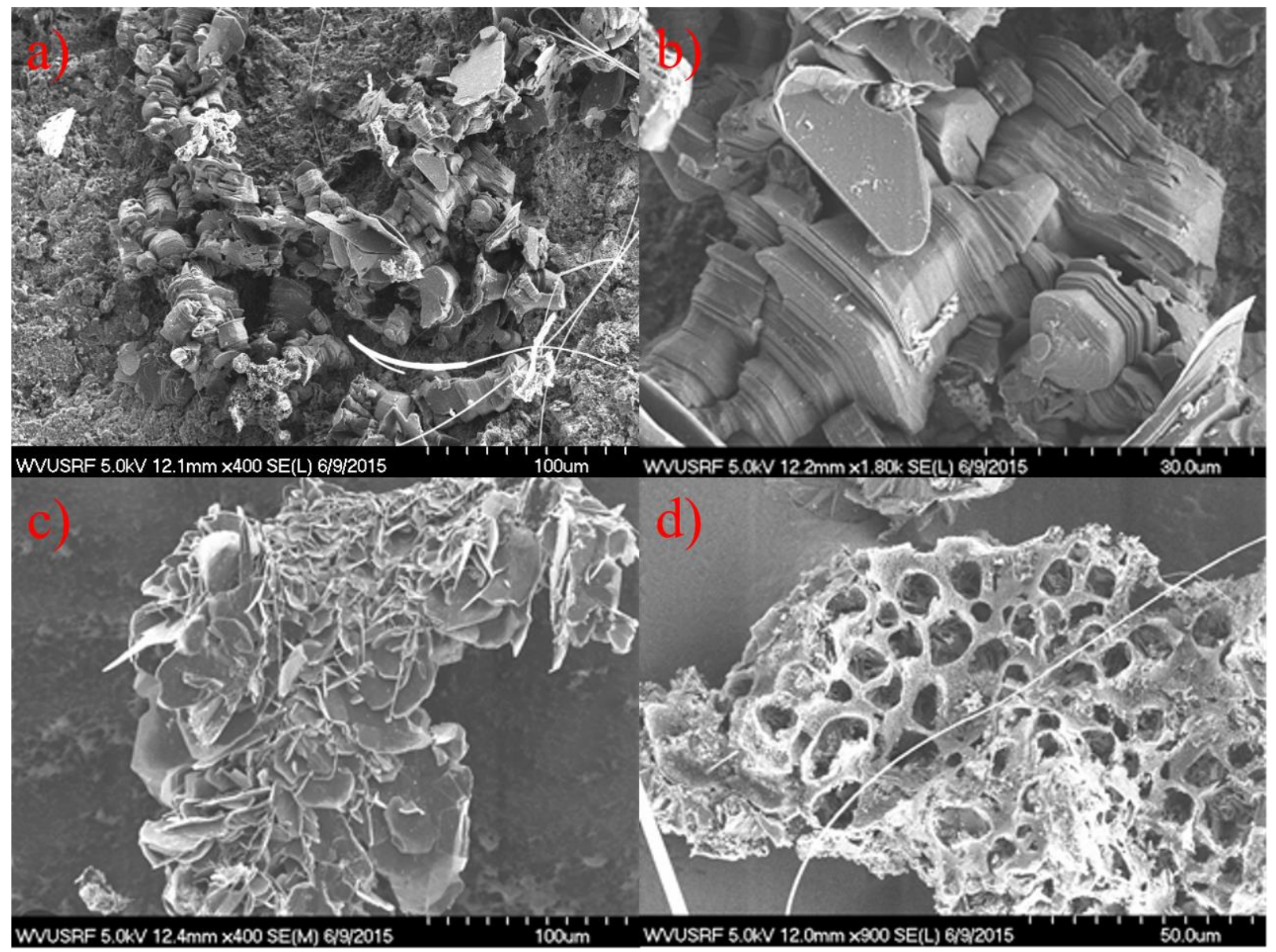

Figure 0.6 SEM images of various morphologies observed in the products from the controlled potential electrolysis of calcium carbide and zinc chloride: a) image polycrystalline aggregates of small, hexagonal grains sitting on amorphous carbon, b) close-up of the stacks of graphite crystals in a), looser, more disoriented aggregates of graphite crystals c) aggregates of single crystals of graphite which appear to be covered in a film, d) porous, amorphous structure that was identified as carbon by EDS and a fiber from the glass fiber filter used for isolation of the carbon.

Figure 5.7 shows Raman spectra collected from various areas of the carbon material produced from the controlled potential electrolysis experiment of calcium carbide and zinc chloride. The spectra indicate that the material is highly graphitic. However, variability in intensities and breadth of the bands, particularly the $\mathrm{D}$ and 2D peaks, also suggest significant 
differences in defects and crystallinity within the sample. The green spectrum which was collected from the specimen shown in the inset photo of Figure 5.7 has the highest scattering background. The large background scattering in this spectrum may be due to the high degree of disorder in the area from which it was collected.

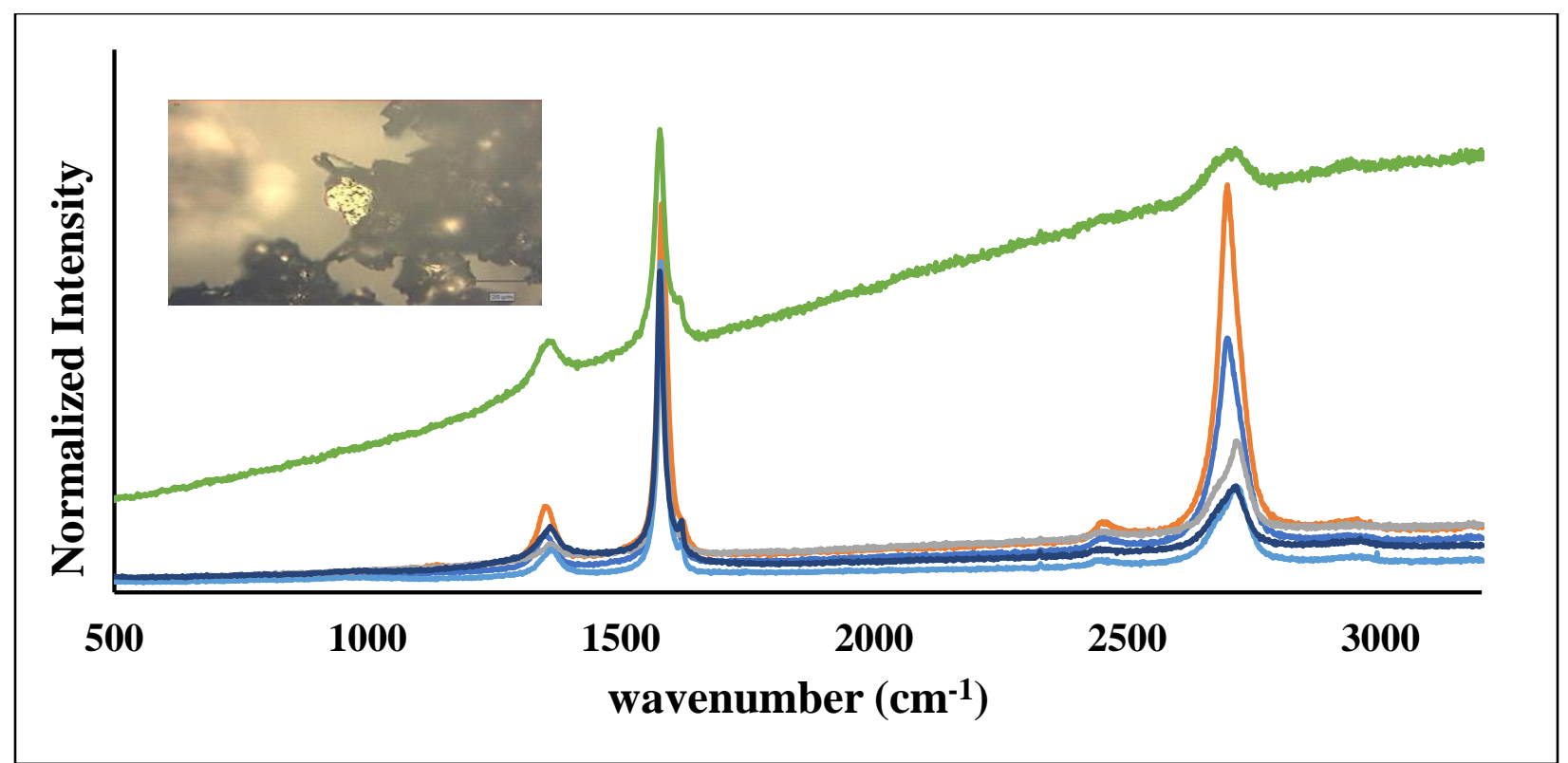

Figure 0.7 Raman spectra of different areas of the same sample from the controlled potential electrolysis reaction of calcium carbide and zinc chloride. Inset photo is optical microscope image of the specimen from which the green spectrum was collected. Laser wavelength $532 \mathrm{~nm}, 50 x$ objective, $10 \%$ of $100 \mathrm{~mW}$.

Recently, Li et al. ${ }^{3}$ reported on the preparation of mesoporous carbon materials through mechanochemical reaction of calcium carbide with anhydrous, transition metal chlorides $\left(\mathrm{ZnCl}_{2}\right.$, $\mathrm{FeCl}_{3}$ and $\mathrm{CuCl}$ ). A comparison of our results with those of $\mathrm{Li}$ et al. may be instructive. The mechanochemical reaction was carried out by ballmilling 100 mesh $\mathrm{CaC}_{2}$ (75 wt\%) with anhydrous metal chloride $\left(\mathrm{MCl}_{\mathrm{n}}\right)$ at ambient temperature. The ball mill was evacuated, and reactants were milled for 3 hours at different milling speeds, from 600 to $150 \mathrm{rpm}$. No reaction occurs at speeds below $150 \mathrm{rpm}$. Afterwards the reaction products were treated with dilute nitric acid to remove metals, salts and any unreacted carbide. The carbon material was then washed with distilled water and filtered. 
The authors propose a reaction mechanism, which proceeds in a stepwise manner. As an example, the first step of the reaction between calcium carbide and iron (III) chloride involves an interfacial, metathesis reaction, forming calcium chloride and a complex iron carbide (R 5.6). This complex iron carbide decomposes to a metastable carbide, $\mathrm{FeC}_{\mathrm{x}}$, and carbon in $\mathrm{R}$ 5.7. $\mathrm{FeC}_{\mathrm{x}}$ decomposes further into elemental iron and carbon ( $\mathrm{R}$ 5.8). To support this reaction mechanism the raw reaction products were washed only with ethanol to remove calcium chloride and other salts. The XRD results of the products post-ethanol treatment show peaks for $\mathrm{FeC}_{15.1}$, graphite (102) and Fe. Only $\mathrm{Zn}$ and $\mathrm{Cu}$ were detected in XRD results from the products of reactions with the zinc and chloride salts after washing with ethanol. This is consistent with the well-known instability of the carbides of zinc and copper.

$$
\begin{array}{rlr}
\mathrm{CaC}_{2}+\mathrm{FeCl}_{3} \rightarrow \mathrm{Fe}_{2}\left(C_{2}\right)_{3}+\mathrm{CaCl}_{2} & \text { R 0.6 } \\
\mathrm{Fe}_{2}\left(C_{2}\right)_{3} \rightarrow \mathrm{Fe} C_{x}+\mathrm{C} & \text { R 0.7 } \\
\mathrm{Fe} C_{x} \rightarrow \mathrm{Fe}+x \mathrm{C} & \text { R 0.8 }
\end{array}
$$

The morphology of carbon materials resulting from these reactions was considerably different from the morphology observed in the carbon products from our molten salt and solution reactions. XRD patterns of the carbon products from all three reactions had two peaks corresponding to the (002) and (101) planes of graphite. Carbon from reactions with $\mathrm{FeCl}_{3}, \mathrm{CDC}$ $\mathrm{Fe}$, had sharper peaks than $\mathrm{CDC}-\mathrm{Zn}$ and $\mathrm{CDC}-\mathrm{Cu}$, indicating higher crystallinity. Figure 5.8 displays TEM and SEM images of the carbon materials (referred in to in the text ${ }^{3}$ as carbide derived carbon $\mathrm{CDC}$ ) produced by mechanochemical reaction with $\mathrm{ZnCl}_{2}, \mathrm{FeCl}_{3}$ and $\mathrm{CuCl}$. The carbon products from all three reactions are composed of aggregated nanoparticles of varying size. CDC-Zn had a looser structure and CDC-Fe had small spheres dispersed throughout the sample. 
The authors believe these spheres may be an $\mathrm{Fe}-\mathrm{C}$ alloy. The higher $\mathrm{Fe}$ content in the accompanying elemental analysis supports this suggestion.
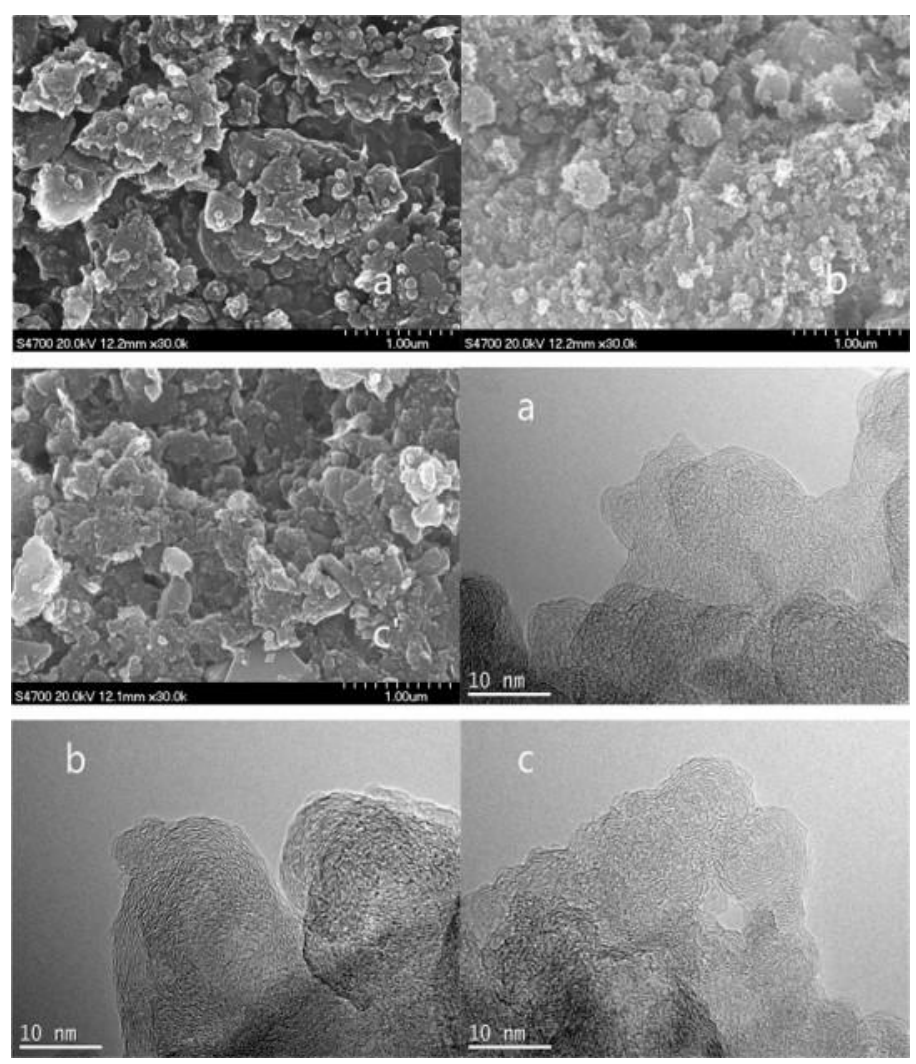

Figure 0.8 SEM and TEM images of the CMs. SEM: (a') CDC-Fe, (b') CDC-Zn, (c') CDC-Cu. TEM: (a) CDC-Fe, (b) CDC-Zn, (c) CDC-Cu. ${ }^{3}$

Figure 5.9 presents the Raman spectra of the carbon materials from all three reactions. All three spectra contain the D peak at $\sim 1330 \mathrm{~cm}^{-1}$ and the $\mathrm{G}$ peak at $\sim 1580 \mathrm{~cm}^{-1}$ characteristic of carbon materials. Only the CDC-Cu and CDC-Fe have the 2D peak at $\sim 2700 \mathrm{~cm}^{-1}$. The poor separation of the $\mathrm{D}$ and $\mathrm{G}$ peaks and peak intensity ratio $\left(\mathrm{I}_{\mathrm{D}} / \mathrm{I}_{\mathrm{G}}\right)$ of 2.0 indicate in all three spectra suggest high degree of amorphous character. This contrasts with our observations of carbon materials ranging from amorphous to highly graphitic in structure. The authors of this study attribute the disorder of their carbon products to the damage induced by intense mechanical stress due to the mechanochemical reaction conditions. Moreover, the authors believe that the metal 
aggregates and transition metal carbide intermediates formed during reaction disrupt the polymerization and rearrangement of the $\mathrm{C}-\mathrm{C}$ bonds inhibiting a more ordered, layered structure.

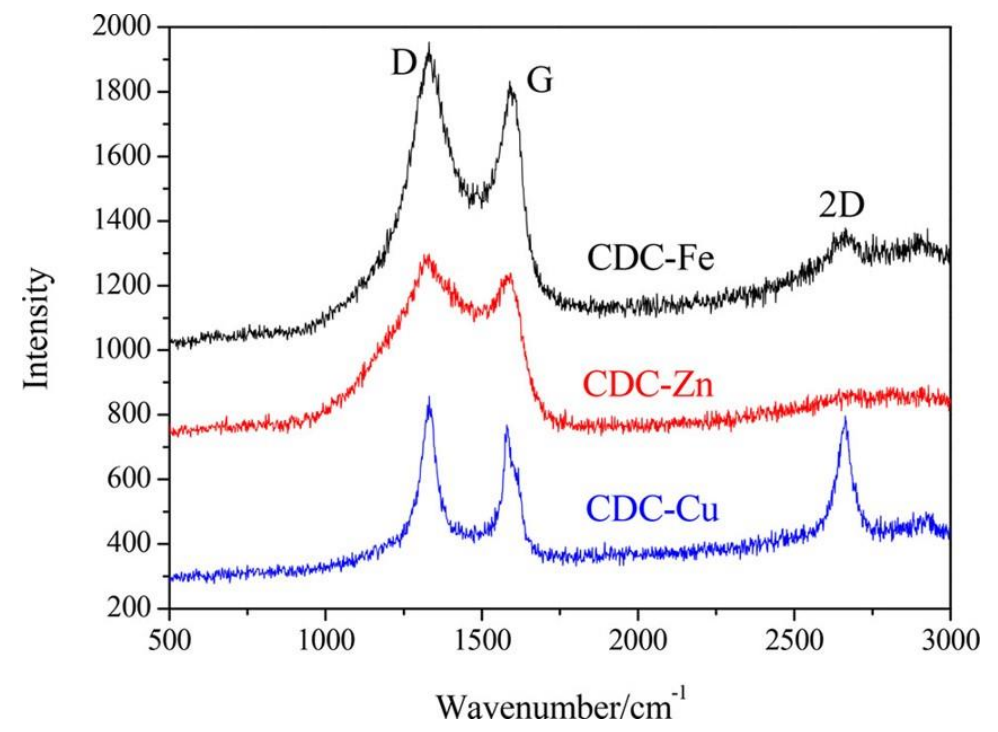

Figure 0.9 Raman spectra of carbon materials (CDC) produced from mechano-chemical reaction of calcium carbide with $\mathrm{FeCl}_{3}$ (black), $\mathbf{Z n C l}_{2}$ (red) and $\mathrm{CuCl}$ (blue). ${ }^{3}$

There were no mechanical stressors in the molten salt or in the solution reactions to induce damage during carbon crystal growth. Secondly, the mechanochemical reaction described by Li et al. is a solid-solid phase reaction. The reactions described in this dissertation are heterogeneous reactions occurring between a solid carbide and a transition metal ion either in the liquid or solution state. The transition metal ion is reduced to elemental, metal nanoparticles (or liquid metal in the case of molten reactions with tin). Simultaneously the carbon anion in the carbide is oxidized and a calcium cation must leach out of the solid to maintain charge balance within the solid. Therefore, there is no formation of intermediate transition metal carbides and aggregates of metal nanoparticles have less opportunity for disrupting crystal growth. These milder reaction conditions may preserve the anisotropic arrangement of the acetylide anions in the tetragonal crystal structure of calcium carbide and allow for C-C polymerization to graphite. 


\section{References}

(1) Hardinger, J. Reactions of Metal Carbides to Produce Carbon, West Virginia University, 2017.

(2) Yurchick, C. The Carbon Project: Statement of Work Report; Morgantown, WV, 2016.

(3) Zhang, K.; Tao, S.; Xu, X.; Meng, H.; Lu, Y.; Li, C. Preparation of Mesoporous Carbon Materials Through Mechanochemical Reaction of Calcium Carbide and Transition Metal Chlorides. Ind. Eng. Chem. Res. 2018, acs.iecr.8b00323. 


\section{Chapter 6: Voltammetry of Carbide Microparticles at a Solid Electrode}

This chapter describes the full characterization of paraffin impregnated graphite electrodes (PIGE), the preparation of which is communicated in Chapter 2 Experimental Methods. Also described are results indicating the PIGE's incompatibility with nonaqueous electrolytes. Additionally, this chapter reports on results of VMP experiments of covalent and transition metal carbides at a PIGE in $0.5 \mathrm{M} \mathrm{H}_{2} \mathrm{SO}_{4}$ and results of VMP experiments on aluminum carbide and calcium carbide at a glassy carbon electrode (GCE) in various nonaqueous electrolytes.

\subsection{Preparation and Characterization of a Paraffin Impregnated Graphite Electrode}

Characterization of the graphite before and after wax impregnation was carried out with Raman spectroscopy and scanning electron microscopy (SEM). The Raman spectra in Figure 6.1 A) of bare graphite and PIGE are very similar confirming that the wax fills the pores of the graphite without significant effects on the chemical bonding of the graphite. Figure $6.1 \mathrm{~B}$ ) and $6.1 \mathrm{C}$ ) compare the morphology of the bare graphite and PIGE. The rough microstructure may be due to polishing of the electrodes with emery paper that is too rough.

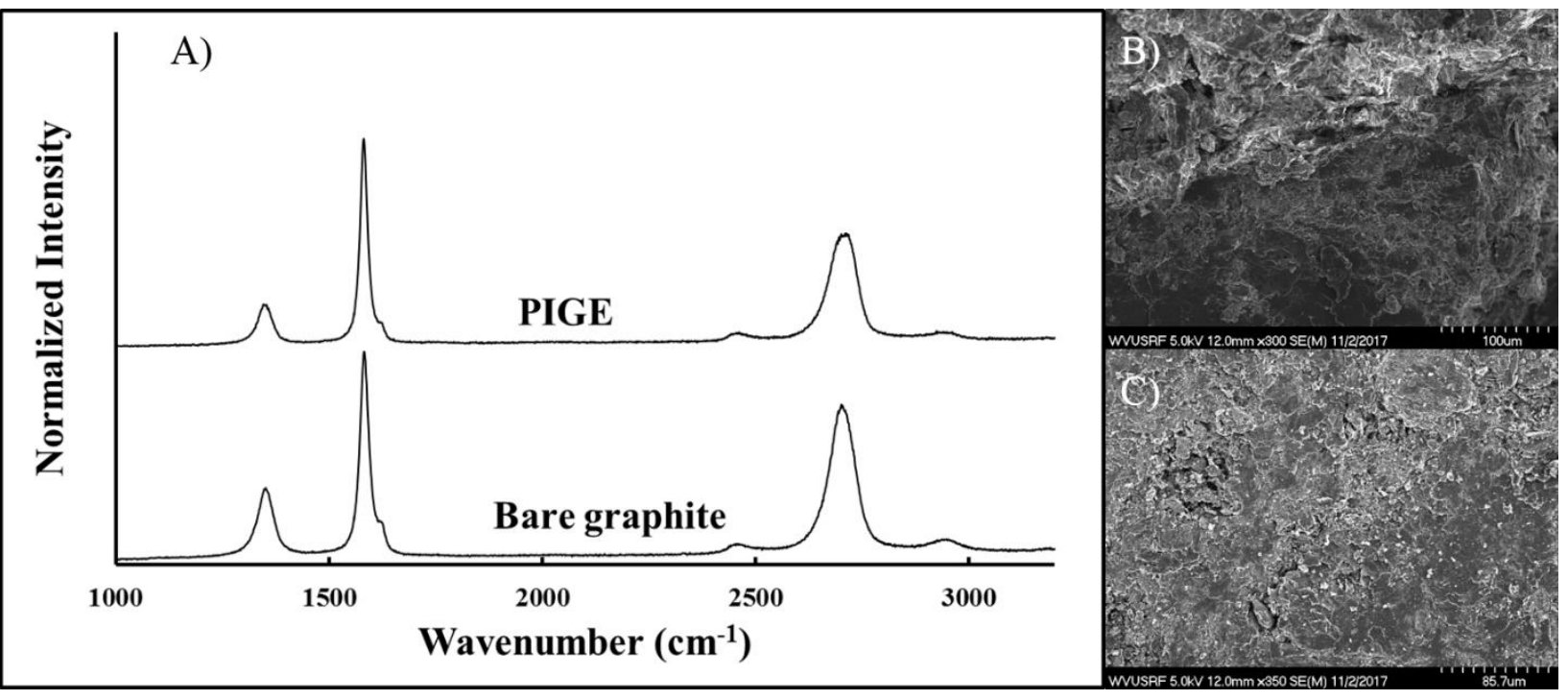

Figure 6.1 Panel A) compares the Raman spectra of the bare graphite rod before and after wax impregnation. SEM images show the coarse surface microstructure of B) bare graphite and C) PIGE after polishing with emery paper. 
CV scan rate studies with ferrocene were performed to compare the electrode behavior of graphite before and after wax impregnation (Figure 6.2). Ferrocene is commonly used as a redox standard because it is a compound which displays ideal, reversible oxidation and reduction with fast kinetics. Scan rate studies were also performed with a gold working electrode for comparison. The results are presented in Table 6.1. The gold working electrode was a thin gold wire that displayed microelectrode behavior ${ }^{1}$ at scan rates $<0.25 \mathrm{~V} / \mathrm{s}$. However, at faster scan rates the separation between the anodic and cathodic peak potentials was relatively constant at $80-85 \mathrm{mV}$, indicating fast charge transfer kinetics. For the graphite electrode and the PIGE, the peak splitting between the anodic $\left(i_{p a}\right)$ and cathodic $\left(i_{p c}\right)$ peak currents increased with increasing scan rate. This indicates that the electron kinetics of ferrocene is slower with the PIGE than at metal working electrodes like gold.

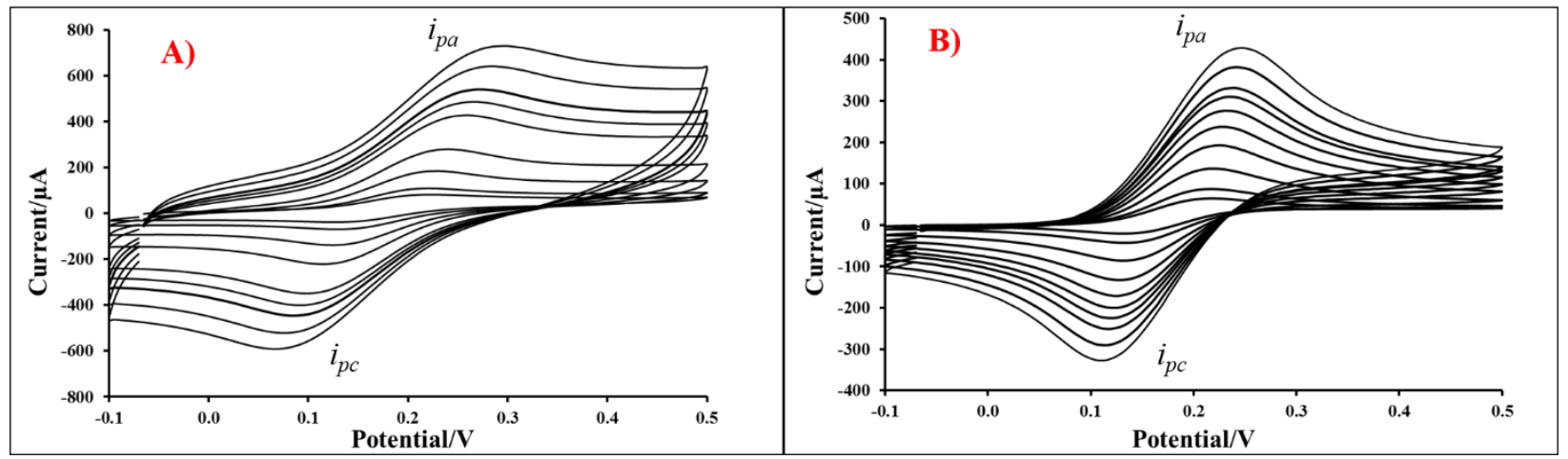

Figure 6.2 CV scan rate studies, scan rates ranging from 0.01 to $0.50 \mathrm{~V} / \mathrm{s}$, of ferrocene in $0.1 \mathrm{M}$ $\mathrm{KPF}_{6} / \mathrm{MeCN}$ at $\mathrm{A}$ ) a graphite electrode before wax imregnation and $\mathrm{B}$ ) after wax impregnation (PIGE). The diameter of the PIGE and graphite is $6.15 \mathrm{~mm}$. 


\begin{tabular}{ll|llll}
\hline Gold & & Graphite & & PIGE & \\
$\mathbf{v}(\mathbf{V} / \mathbf{s})$ & $\boldsymbol{\Delta} \mathbf{E}_{\mathbf{p}}(\mathbf{V})$ & $\boldsymbol{v}(\mathbf{V} / \mathbf{s})$ & $\boldsymbol{\Delta} \mathbf{E}_{\mathbf{p}}(\mathbf{V})$ & $\boldsymbol{v}(\mathbf{V} / \mathbf{s})$ & $\boldsymbol{\Delta} \mathbf{E}_{\mathbf{p}}(\mathbf{V})$ \\
\hline 0.01 & & & & & \\
0.02 & 0.550 & 0.01 & 0.100 & 0.01 & 0.090 \\
0.05 & 0.380 & 0.02 & 0.090 & 0.02 & 0.080 \\
0.10 & 0.442 & 0.05 & 0.105 & 0.05 & 0.090 \\
0.20 & 0.330 & 0.10 & 0.125 & 0.10 & 0.095 \\
0.25 & 0.255 & 0.20 & 0.160 & 0.20 & 0.105 \\
0.30 & 0.090 & 0.25 & 0.175 & 0.25 & 0.110 \\
0.40 & 0.085 & 0.30 & 0.185 & 0.30 & 0.125 \\
0.50 & 0.085 & 0.40 & 0.210 & 0.40 & 0.125 \\
\hline
\end{tabular}

Table 6.1 Scan rates $(v)$ and peak potential splitting $(\Delta \mathrm{E})$ for ferrocene scan rate studies at gold, graphite and PIGE working electrodes.

We believe these results indicate that the PIGE behaves as a microelectrode array with many small, conductive sites fixed on an insulating surface. This is consistent with the Tallman and Petersen's definition for composite electrodes. ${ }^{2}$ Additionally, the CVs show that the wax impregnation inhibits intercalation of the supporting electrolyte, thus significantly decreasing the charging current that distorts and obscures the peak currents in the bare graphite CV. ${ }^{3}$

\subsection{PIGE and Nonaqueous Electrolyte Compatibility}

When initial experiments were performed with PIGE in $0.1 \mathrm{M} \mathrm{KPF} / \mathrm{MeCN}$ to establish the potential window of the system, i.e. the potential interval in which only minimal charging current is observed, faradaic peaks at $\sim 1.5 \mathrm{~V}$ and $-0.6 \mathrm{~V}$ were observed (Figure 6.3). Comparison of CVs performed with bare graphite under the same conditions showed similar redox behavior. These peaks were likely due to the anodic oxidation ( $\mathrm{R}$ 6.1) and cathodic reduction ( $\mathrm{R}$ 6.2) of the graphite and subsequent intercalation of the supporting electrolyte ions. ${ }^{4}$

$$
\begin{array}{cc}
C_{n}+P F_{6}^{-} \leftrightarrow C_{n} P F_{6}+e^{-} & \text {R 0.1 } \\
C_{n}+K^{+}+e^{-} \leftrightarrow K C_{n} & \text { R 0.2 }
\end{array}
$$


This was surprising because the PIGE literature indicates that the wax impregnation prevents the intercalation of the supporting electrolyte into the graphite without significant compromise of electrical conductivity.

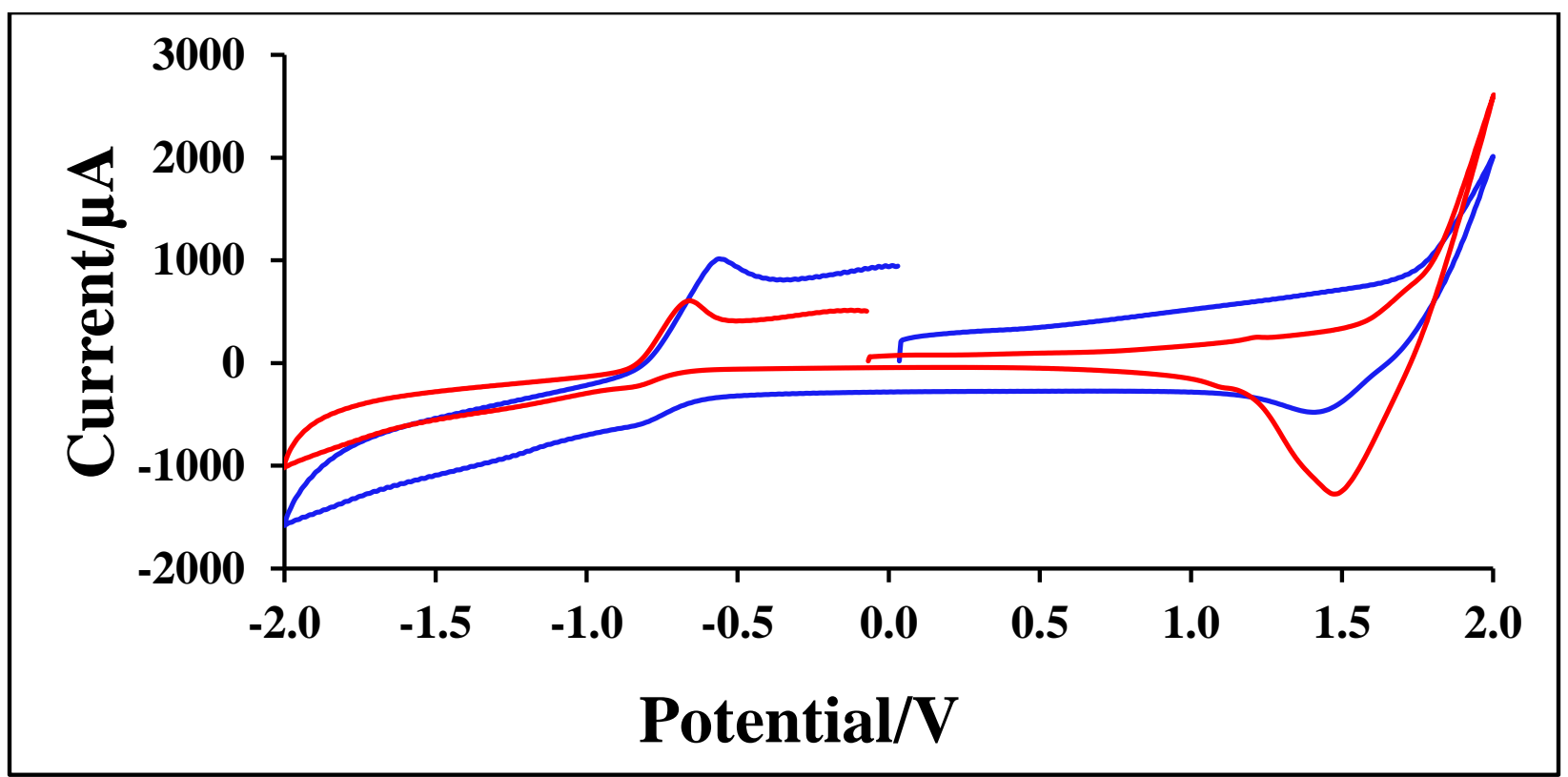

Figure 6.3 CVs in $0.1 \mathrm{M} \mathrm{KPF} 6 / \mathrm{MeCN}$ at scan rates $0.1 \mathrm{~V} / \mathrm{s}$. Both scans were initiated in the positive direction. The red $\mathrm{CV}$ was obtained using the PIGE and the blue CV obtained using bare graphite

We performed XPS studies to investigate this phenomenon in the PIGE. Figures 6.4 A) and 6.4 B) show the XPS spectra of bare graphite and PIGE before CV experiments in $0.1 \mathrm{M}$ $\mathrm{KPF}_{6} / \mathrm{MeCN}$. The graphite spectrum has a $\mathrm{C} 1 \mathrm{~s}$ peak and a small O1s peak likely due to hydroxyl and epoxy surface groups. Interestingly, after wax impregnation, i.e. in the PIGE sample, no surface oxygen was detected. 

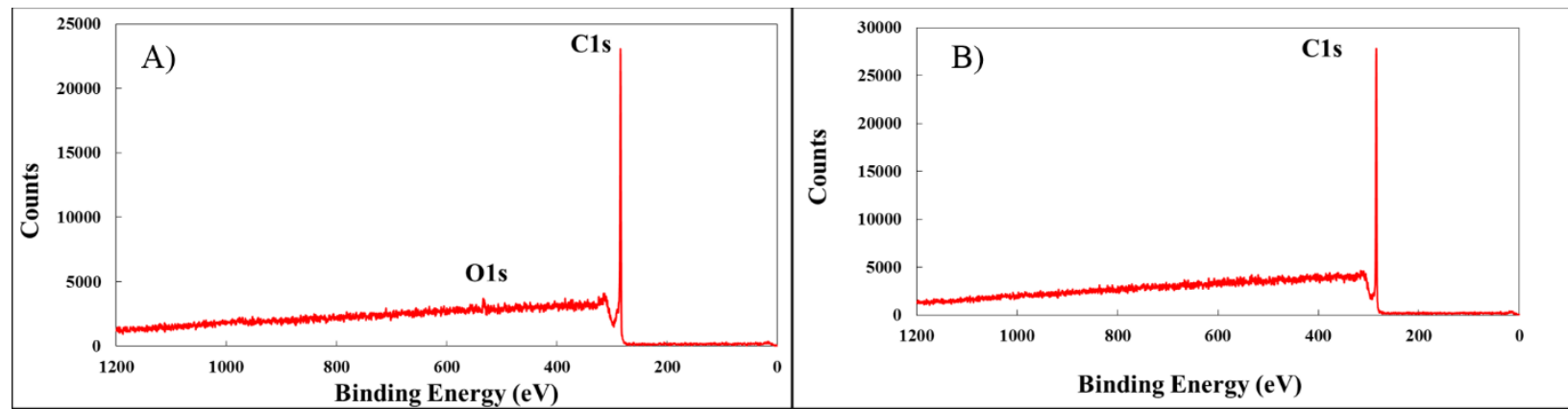

Figure 6.4 XPS spectra of a sample of A) a bare graphite electrode and B) a PIGE before CV studies in $0.1 \mathrm{M} \mathrm{KPF}_{6} / \mathrm{MeCN}$

Figures 6.5 A) and B) show XPS spectra of graphite and PIGE after CV experiments. The graphite spectrum has strong potassium, fluorine and phosphorous signatures and the PIGE shows only a weak potassium signal. XPS spectra were collected again on the same samples after removal of $20 \mathrm{~nm}$ of the surface by sputtering. The potassium, fluorine and phosphorous peaks in the graphite spectrum were still strong, while the weak potassium peak in the PIGE spectrum completely vanished (spectra not shown). This implies that the intercalation into the PIGE is a surface sensitive process. 

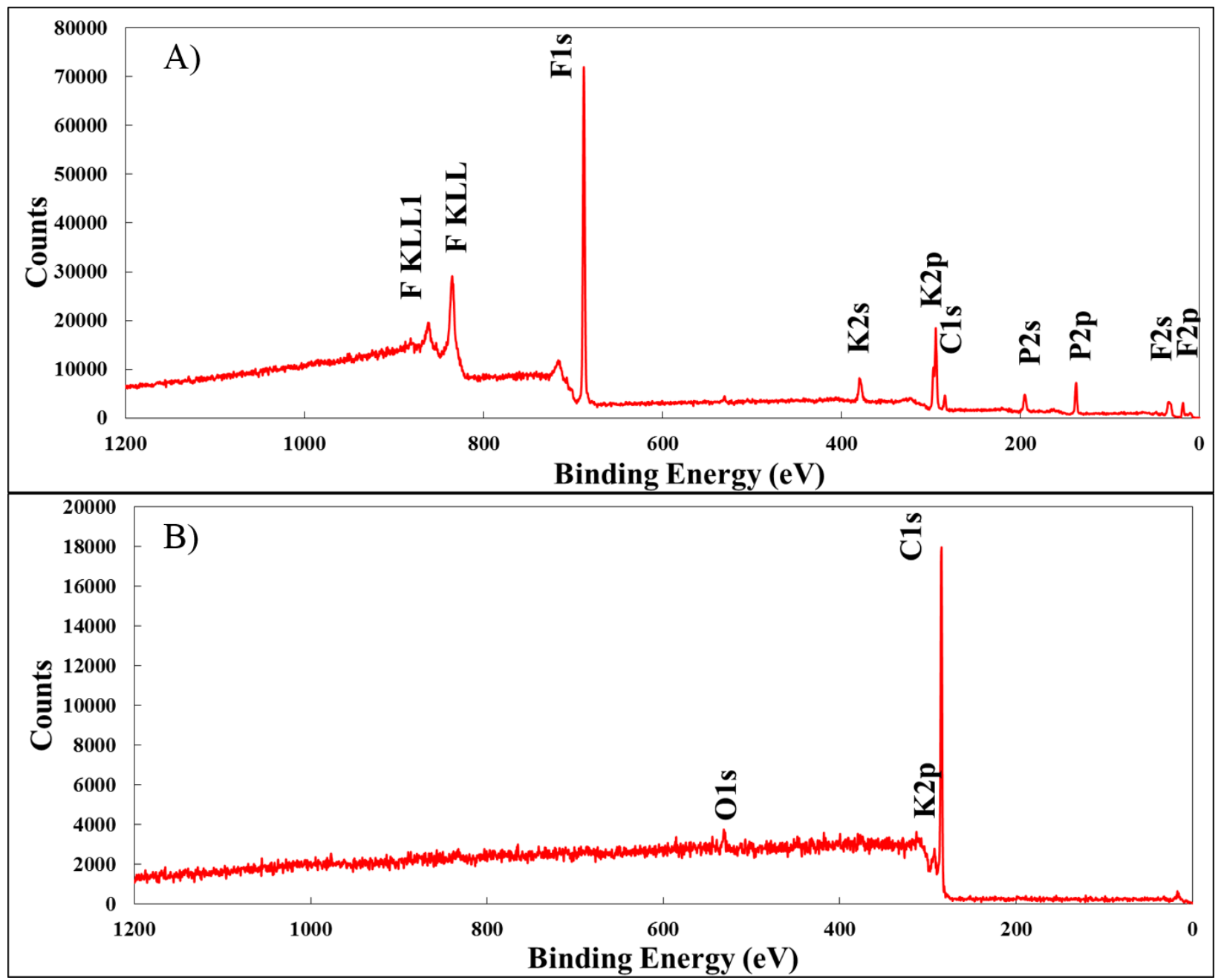

Figure 6.5 XPS spectra of samples of A) the bare graphite electrode and B) the PIGE after CV studies in $0.1 \mathrm{M} \mathrm{KPF}_{6} / \mathrm{MeCN}$

Experiments in which we attempted to eliminate the intercalation phenomenon yielded mixed results. These attempts included using a supporting electrolyte with larger cations that would inhibit the intercalation effect, such as tetrabutylammonium hexafluorphosphate (TBAHFP) and polishing the PIGE with smooth paper rather than rougher emery paper so that the wax would not be disturbed. Results from these experiments were inconclusive. Thus, it appeared that the PIGE was not suitable for analyses in nonaqueous electrolytes. 


\subsection{Analyses of various Metal Carbide Particles Immobilized on a Solid Electrode}

The fundamental electrochemistry of ionic carbides has received little attention in the literature, with only a few reports investigating calcium carbide in molten salts ${ }^{5,6}$. The electrochemical analysis of ionic carbides presents two main challenges: 1) they are water reactive, and 2) they are insoluble solids which are electrically semiconducting at best. The first challenge means that experiments must be conducted in a nonaqueous electrolyte and care must be taken to maintain a moisture free system. To address the second problem we have employed the method of voltammetry of micro particles (VMP) at a paraffin wax impregnated graphite electrode (PIGE) developed by Fritz Scholz. ${ }^{3}$

The electrochemistry of covalent and transition metal carbides microparticles were also explored via the VMP technique for comparison to results on ionic carbides and the results of other researchers using other techniques. Covalent carbides and transition metal carbides do not hydrolyze as readily as salt-like carbides, so their analyses were carried out in $0.5 \mathrm{M} \mathrm{H}_{2} \mathrm{SO}_{4}$ at a PIGE. VMP experiments on aluminum carbide and calcium carbide were carried out in various nonaqueous electrolytes at GCE due to the PIGE's incompatibility with nonaqueous electrolytes. The results of these studies are presented in the following sections.

\subsubsection{Analysis of $\mathrm{SiC}$ in $0.5 \mathrm{M} \mathrm{H} \mathrm{H}_{2} \mathrm{SO} 4$ immobilized on a PIGE}

The first non-ionic carbide tested was silicon carbide ( $\mathrm{SiC}$ ), a covalent carbide. The $\mathrm{SiC}$ was in the form of a fine green powder, mesh size 200-450 (74-38 microns), is $\alpha$-phase, hexagonal, subclass, $6 \mathrm{H}$ polytype.

The SiC particles were attached to the face of a polished PIGE by gently polishing the electrode face into the powdered sample on a clean glass plate. Excess, poorly adhered particles were removed by gentle tapping of the PIGE. Inspection of the surface under a magnifying glass showed that $\mathrm{SiC}$ particles were adhered, but the mechanical abrasion also had caused significant 
damage to the surface. The OCP was measured for five minutes beforehand and remained relatively constant. Five CVs of the SiC crystals were collected at $10 \mathrm{mV} / \mathrm{s}$ in $0.5 \mathrm{M} \mathrm{H}_{2} \mathrm{SO}_{4}$ and compared with the CV blank (see Figure 6.6 below). There are no faradaic peaks due to the oxidation or reduction of the $\mathrm{SiC}$ in the voltammograms. However, the first scan (red trace, Scan 1) shows increased background current compared with the blank CV collected before modification with $\mathrm{SiC}$. Subsequent scans show that the background current decreases to the level measured in the blank $\mathrm{CV}$, indicating passivation and possibly some $\mathrm{SiO}_{2}$ formation. This experiment was repeated several times initiating the scans in the positive and negative direction with the same results.

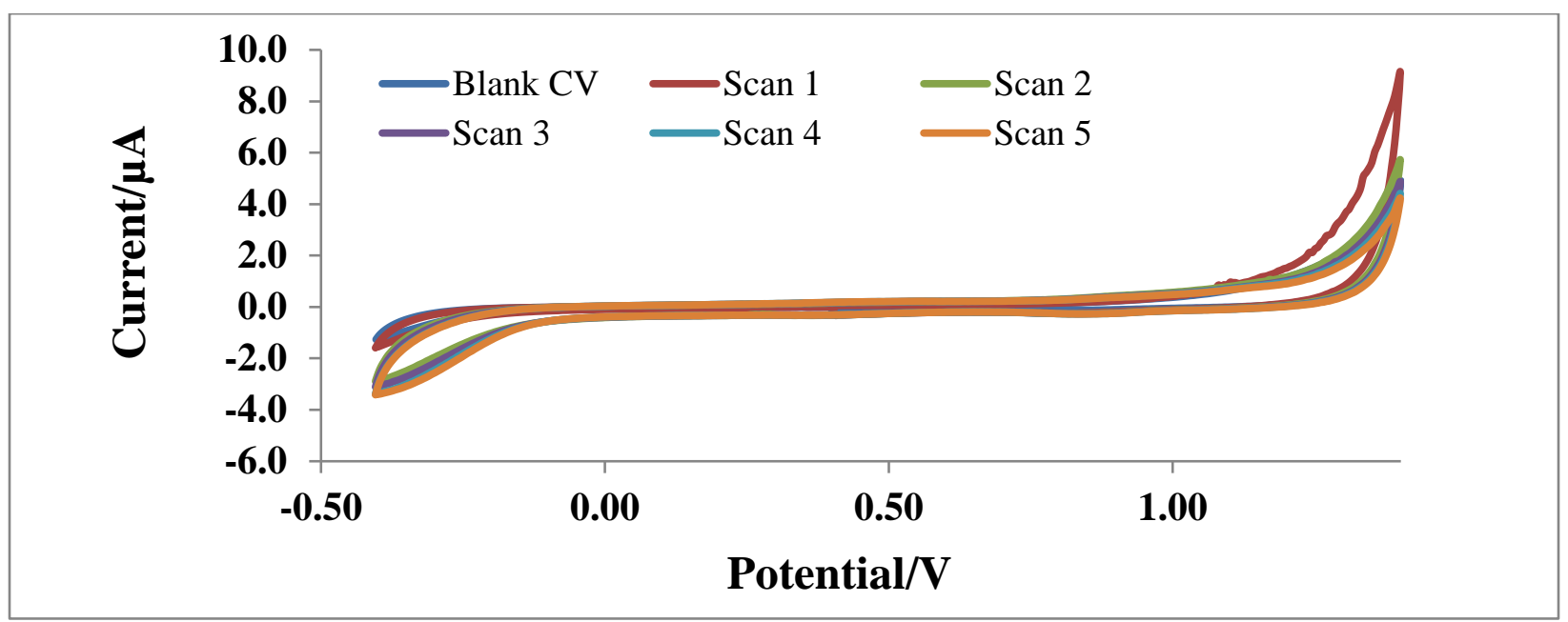

Figure 6.6 CVs of SiC + PIGE compared with Blank CV of PIGE (blue) in $0.5 \mathrm{M} \mathrm{H}_{2} \mathrm{SO}_{4}, 10 \mathrm{mV} / \mathrm{s}$, initiated from the $\mathrm{OCP}$ vs. $\mathrm{Ag} / \mathrm{AgCl} 3 \mathrm{M} \mathrm{NaCl}$

There are no VMP analyses of $\mathrm{SiC}$ in the literature. However, $\mathrm{SiC}$ is known as a corrosion resistant ceramic, so there are few electrochemical studies in the literature. For example, Michaelis et al. reported on the electrochemical corrosion of silicon carbide. The $\mathrm{SiC}$ in their study was a commercially available, $\alpha$-phase, sintered $\mathrm{SiC}$, embedded in an epoxy resin to form a composite electrode. This composite electrode was used as the working electrode in their electrochemical 
system. Their corrosion studies were performed in several aqueous electrolytes $0.5 \mathrm{M} \mathrm{H}_{2} \mathrm{SO}_{4}, 1 \mathrm{M}$ $\mathrm{NaOH}$ and $1 \mathrm{M} \mathrm{HCl}$.

CVs of $\mathrm{SiC}$ corrosion in both $0.5 \mathrm{M} \mathrm{H}_{2} \mathrm{SO}_{4}$ and $1 \mathrm{M} \mathrm{NaOH}$ at $10 \mathrm{mV} / \mathrm{s}$ scan rates are displayed where the oxidation of the $\mathrm{SiC}$ samples are denoted with an arrow (Figure $6.6 \mathrm{a}$ ) and b) below). This arrow is necessary because the potential range in the CVs was scanned to oxidative and cathodic break down of the electrolyte. Therefore, the oxidation peak for the SiC in both electrolytes is not visible because the peaks for the oxygen and hydrogen evolution completely out scale it ${ }^{7}$. The corrosion potential and corrosion current density of the sintered SiC samples were determined by linear scan voltammetry (LSV) at a scan rate of $0.5 \mathrm{mV} / \mathrm{s}$. In $0.5 \mathrm{M} \mathrm{H} 2 \mathrm{SO} 4$ the corrosion potential was $-0.131 \mathrm{vs}$. SCE and the current density was $0.133 \mu \mathrm{A} / \mathrm{cm}^{2}$. Analysis of $\mathrm{SiC}$ samples after corrosion experiments show pitted areas along $\mathrm{SiC}$ grain boundaries with $\mathrm{SiO}_{2}$ inclusions. 

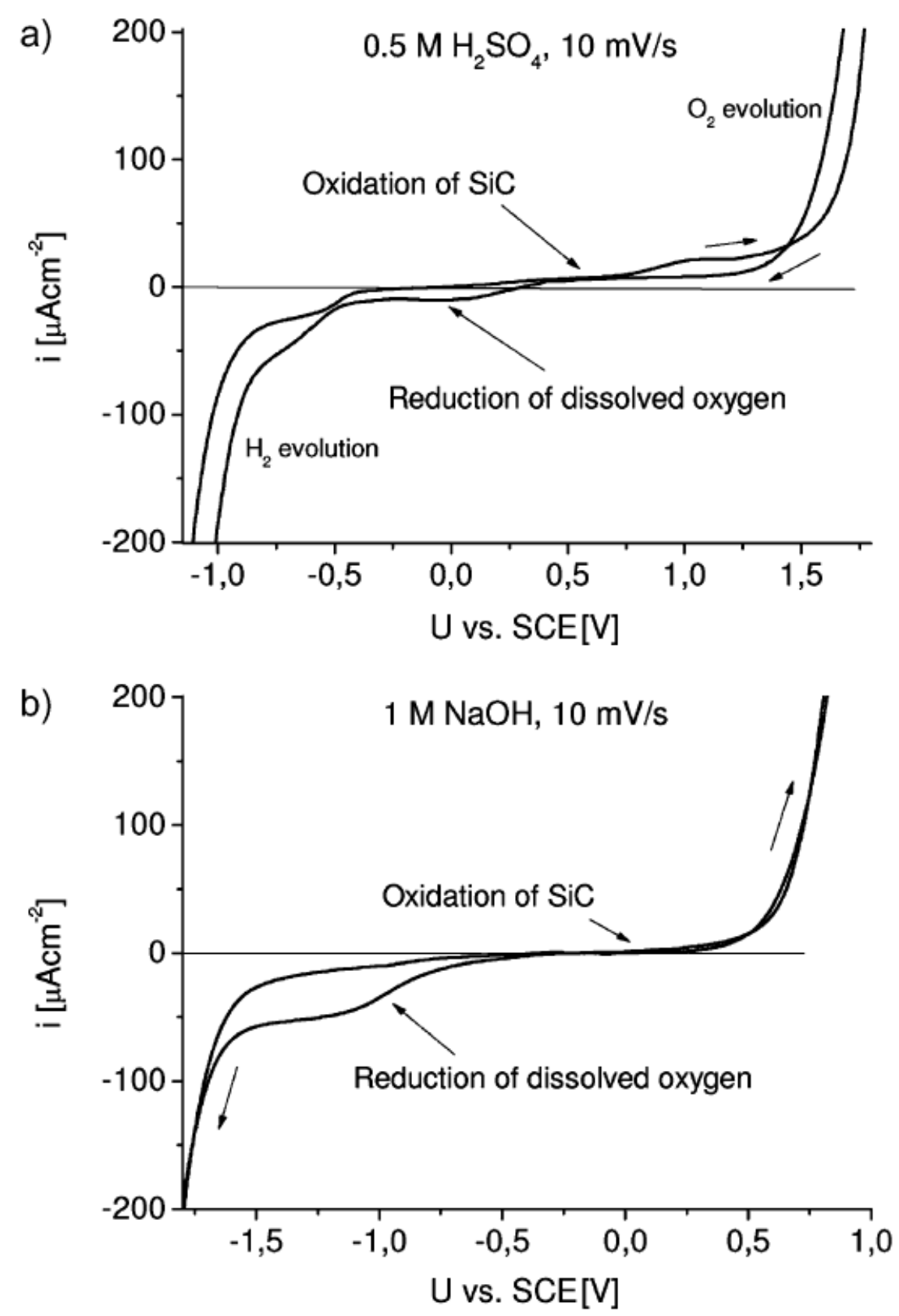

Figure 6.7 CVs of SSiC-1 in $0.5 \mathrm{M} \mathrm{H}_{2} \mathrm{SO}_{4}\left(\right.$ a) and $1 \mathrm{M} \mathrm{NaOH}(\mathrm{b})$, scan rate $=10 \mathrm{mV} / \mathrm{s}^{8}$

The following schemes for the oxidation of $\mathrm{SiC}$ in acidic media are given below:

$$
\begin{array}{cr}
\mathrm{SiO}_{2}+4 \mathrm{H}^{+}+4 e^{-} \leftrightarrow \mathrm{Si}+2 \mathrm{H}_{2} \mathrm{O} & \text { R 0.3 } \\
\mathrm{SiO}_{2}+\mathrm{C}+4 \mathrm{H}^{+}+4 e^{-} \leftrightarrow \mathrm{SiC}+2 \mathrm{H}_{2} \mathrm{O} & \text { R 0.4 } \\
\mathrm{SiO}_{2}+6 \mathrm{H}^{+}+\mathrm{CO}+6 e^{-} \leftrightarrow \mathrm{SiC}+3 \mathrm{H}_{2} \mathrm{O} & \text { R 0.5 }
\end{array}
$$




$$
\begin{array}{cc}
\mathrm{SiO}_{2}+8 \mathrm{H}^{+}+\mathrm{CO}_{2}+8 e^{-} \leftrightarrow \mathrm{SiC}+4 \mathrm{H}_{2} \mathrm{O} & \text { R 0.6 } \\
\mathrm{CO}_{2}+4 \mathrm{H}^{+}+4 e^{-} \leftrightarrow \mathrm{C}+2 \mathrm{H}_{2} \mathrm{O} & \text { R 0.7 }
\end{array}
$$

The results of our VMP analyses of $\mathrm{SiC}$ are not in agreement with those of Michaelis et al. However, there are 250 known polymorphs of $\mathrm{SiC}^{9}$, and although their $\mathrm{SiC}$ sample was also $\alpha$ phase, they did not specify the polytype. In addition, the SiC sample was sintered and contained aluminum and boron additives which dramatically increased the electrical conductivity. The corrosion response of $\mathrm{SiC}$ is strongly dependent on both factors.

\subsubsection{Analyses of $\mathrm{WC}$ in $0.5 \mathrm{M} \mathrm{H}_{2} \mathrm{SO}_{4}$ immobilized on a PIGE}

A binary transition metal carbide, tungsten carbide (WC), was also analyzed at a PIGE in

$0.5 \mathrm{M} \mathrm{H}_{2} \mathrm{SO}_{4}$. The WC was in the form of a dull, dark gray powder, 100-270 mesh (53-140 microns), $99.5 \%$ pure. Modification of the PIGE with the WC particles was achieved in the same manner as before. The OCP was measured at zero current and changed by more than $10 \mathrm{mV}$ over the span of five minutes. This instability in the OCP may indicate that they system had not yet achieved equilibrium.

Five CVs of the WC crystals were collected at $10 \mathrm{mV} / \mathrm{s}$ in $0.5 \mathrm{M} \mathrm{H}_{2} \mathrm{SO}_{4}$ and compared with the CV blanks (see Figure 6.8 below). All scans were initiated in the positive direction. During the first scan after WC attachment there is a large peak at $\sim 1.18 \mathrm{~V}$ due to an irreversible, oxidative process (orange trace, Scan 1). There are no peaks corresponding to a reduction process on the return positive scan, although the currents are higher than those observed in the blank CVs. This may be due to the surface roughening that occurs as a result of the abrasive attachment of the carbide powder. The second scan in light blue shows the same oxidative process but with a much lower peak current. The following three scans show that the peak current due to this oxidation has reduced to near background levels. 


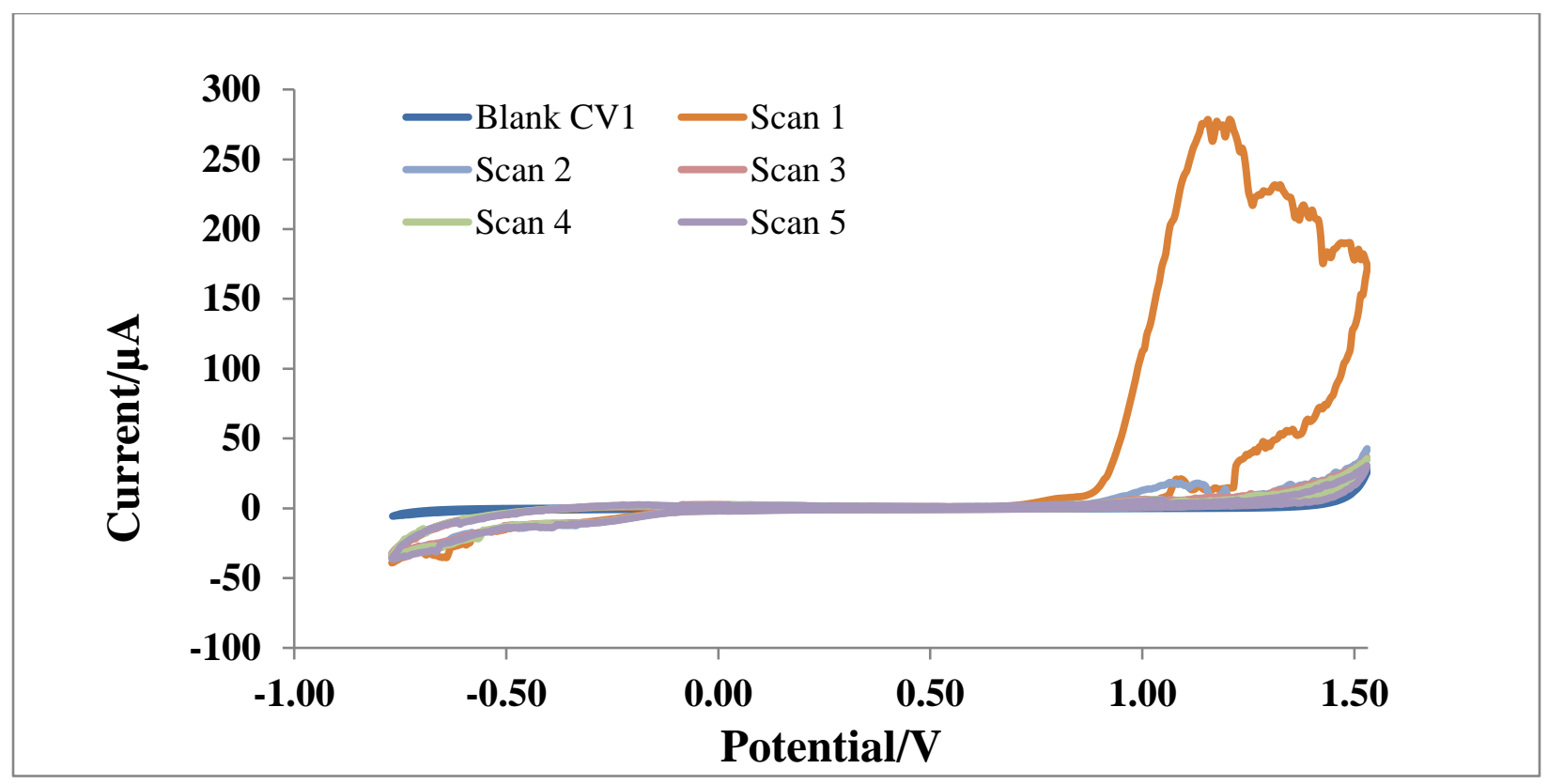

Figure 6.8 CVs of WC + PIGE compared with five blank CVs of PIGE in $0.5 \mathrm{M} \mathrm{H}_{2} \mathrm{SO}_{4}, 10 \mathrm{mV} / \mathrm{s}$, initiated in the positive direction from the $\mathrm{OCP}=0.398 \mathrm{~V}$ vs. $\mathrm{Ag} / \mathrm{AgCl} 3 \mathrm{M} \mathrm{NaCl}$

The Figure 6.9 shows five CVs of WC attached to the PIGE compared with a blank CV. In this experiment, all scans were initiated in the negative direction to drive a reduction. The orange trace is the first scan of $\mathrm{WC}$ and a large reduction appears at $\sim-0.77 \mathrm{~V}$ with a peak current of 1.5 $\mathrm{mA}$. This is likely the reduction the hydrogen evolution reaction (HER, R 6.8) catalyzed by the WC.

$$
2 H^{+}+2 e^{-} \rightarrow H_{2}
$$

R 0.8

The scan in the positive direction shows the same oxidative process seen in the CVs that were initiated in the positive direction. The following cycles show a dramatic decrease in in the reduction process attributed to HER to near background levels. The current peaks for the oxidation process seen in the first cycle decreases with each subsequent scan. These results indicate that the WC is oxidized and irreversibly destroyed, almost completely, in the first scan. ${ }^{10-12}$

$$
W C+5 \mathrm{H}_{2} \mathrm{O} \rightarrow \mathrm{WO}_{3}+\mathrm{CO}_{2}+10 \mathrm{H}^{+}+10 e^{-}
$$




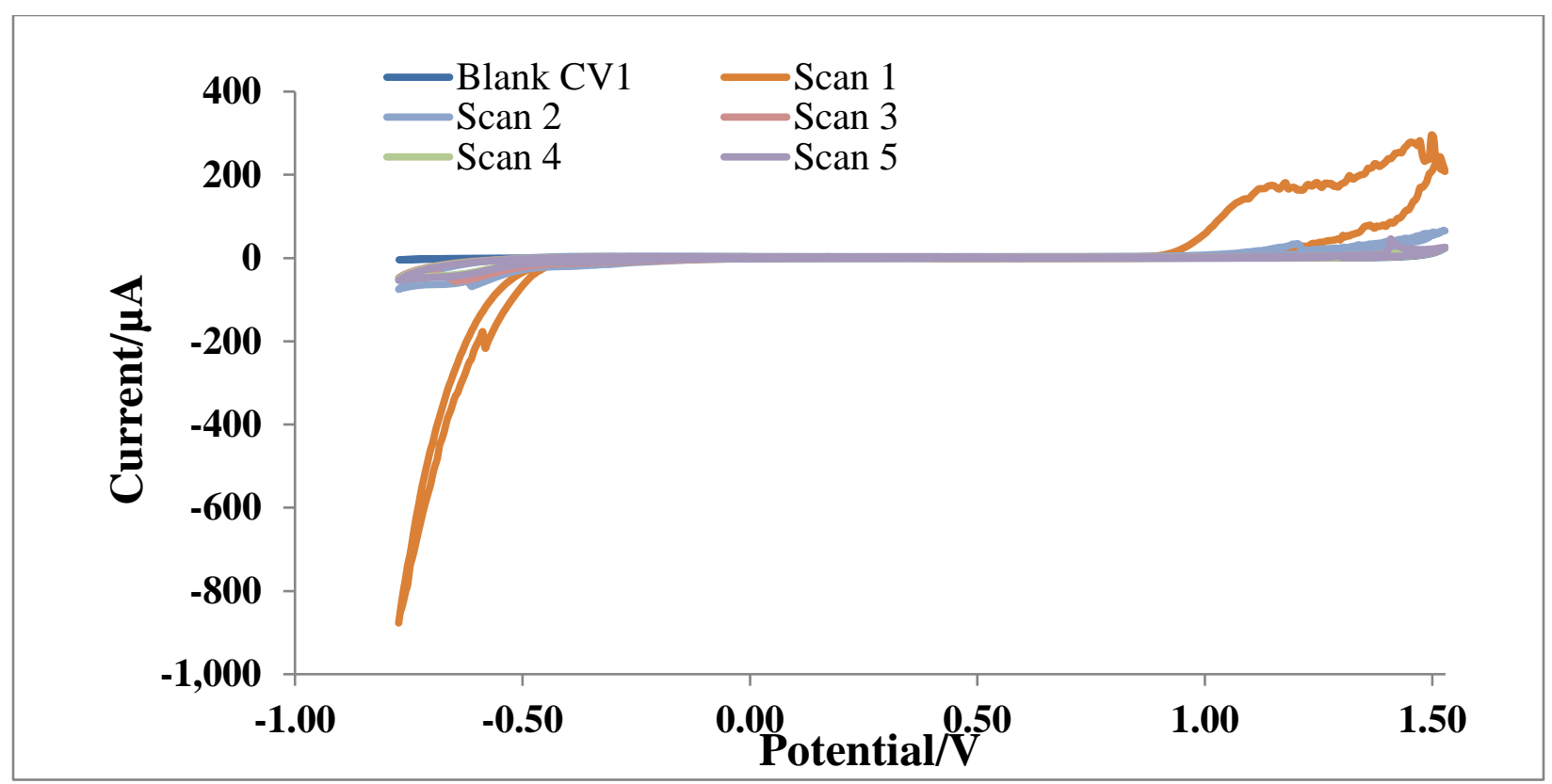

Figure 6.9 CVs of WC + PIGE compared with 5 blank CVs of PIGE in $0.5 \mathrm{M} \mathrm{H}_{2} \mathrm{SO}_{4}, 10 \mathrm{mV} / \mathrm{s}$, initiated in the negative direction from the OCP vs. Ag/AgCl 3M NaCl.

The recent results on WC's electrochemical stability at positive potentials by Ledendecker et al. confirm this interpretation. ${ }^{12}$ Ledendecker modified a glassy carbon (GC) electrode with WC by casting an aliquot of WC suspended in ultrapure water, $5 \mathrm{wt} \%$ Nafion solution in isopropanol onto the GC surface. Electrochemical measurements were performed in a scanning flow cell coupled to an inductively coupled mass spectrometer (SFC-ICP-MS) to monitor the dissolution of $\mathrm{WC}, \mathrm{W}$ and $\mathrm{WO}_{3}$ rate over time. $\mathrm{W}$ concentration in the electrolyte was monitored via the ${ }^{184} \mathrm{~W}$ isotope to determine dissolution rates upon cycling at different oxidative potentials. The electrolyte was $0.1 \mathrm{M} \mathrm{HClO}_{4}$, a graphite rode served as the counter electrode and all potentials were reported vs the RHE. The CVs from Ledendecker et al.'s study are shown in Figure 6.10 below. 


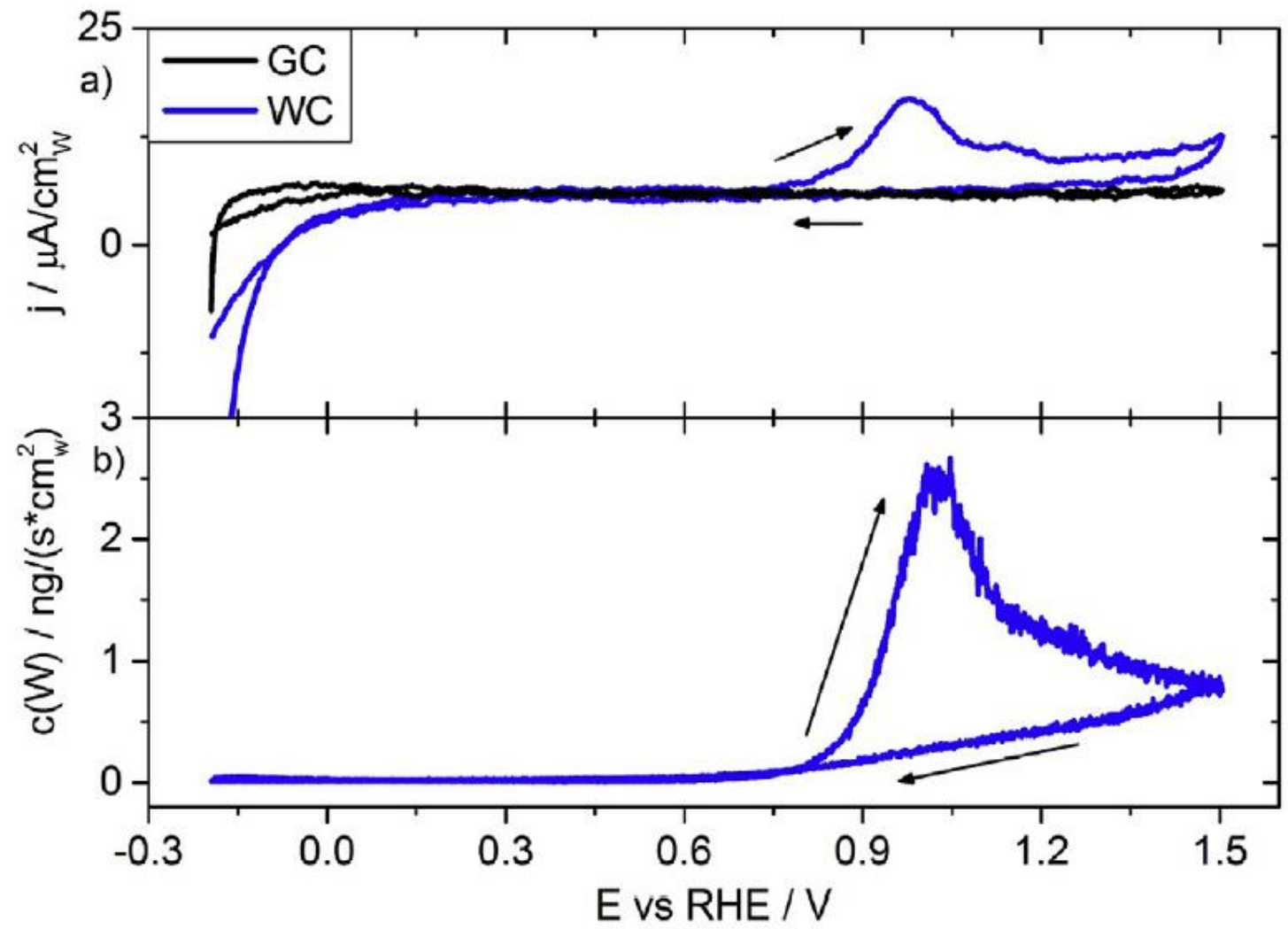

Figure 6.10 a) $\mathrm{CV}$ of $1 \mathrm{ug}$ spot of $\mathrm{WC}$ pretreated with $\mathrm{NaOH}$ and the corresponding background $\mathrm{CV}$ of a glassy carbon plate (GC) at $2 \mathrm{mV} / \mathrm{s}$ in $0.1 \mathrm{M} \mathrm{HClO4,} \mathrm{b)} \mathrm{the} \mathrm{corresponding} \mathrm{dissolution} \mathrm{rate}$ profile of $\mathrm{WC}^{12}$.

Figure 6.10 a) shows two irreversible oxidation peaks at $\sim 1.1 \mathrm{~V}$ and $\sim 0.97 \mathrm{~V}$ which are attributed to oxidation at two different crystal planes of WC. Comparison with our results in Figure 6.8 shows an irreversible oxidation peak is shifted to potentials that are more positive. The reason for this shift is likely the differences in particle size. The WC microparticles in our study are much larger than those in the studied by Ledendecker et al., e.g. 53 microns vs $190 \mathrm{~nm}$. Samples of larger particle size have lower surface energy and thus have higher corrosion resistance. Otherwise our results appear to be in good agreement. 


\subsubsection{Analysis of $\mathrm{Cr}_{3} \mathrm{C}_{2}$ in $0.5 \mathrm{H}_{2} \mathrm{SO}_{4}$ immobilized on a PIGE}

Two chromium carbides were examined as representatives of the intermediate transition metal carbide group. The two carbide phases were $\mathrm{Cr}_{3} \mathrm{C}_{2}$ and $\mathrm{Cr}_{23} \mathrm{C}_{6}$. The first chromium carbide, $\mathrm{Cr}_{3} \mathrm{C}_{2}$, was in the form of a dull, light gray powder, 325 mesh ( 44 microns), 99.5\% pure. Microparticles of the carbide were attached to the PIGE surface in the same way as previously described.

$\mathrm{CV}$ results with $\mathrm{Cr}_{3} \mathrm{C}_{2}$ were qualitatively similar to WC. Figure 6.11 shows five blank $\mathrm{CV}$ scans collected with the unmodified PIGE prior to carbide attachment. The CVs show the same features discussed in Appendix B. Electrochemical Window Experiments. The peak current at the positive limit due to oxygen evolution reaction (OER) is no larger than $25 \mu \mathrm{A}$ and the peak current at the negative limit before the onset of the hydrogen evolution reaction is no larger than $-5 \mu \mathrm{A}$. The presence of the reductive shoulder from -0.270 to $-0.770 \mathrm{~V}$ is attributed to reduction of oxide groups on the surface of the electrode or proton intercalation. ${ }^{13}$

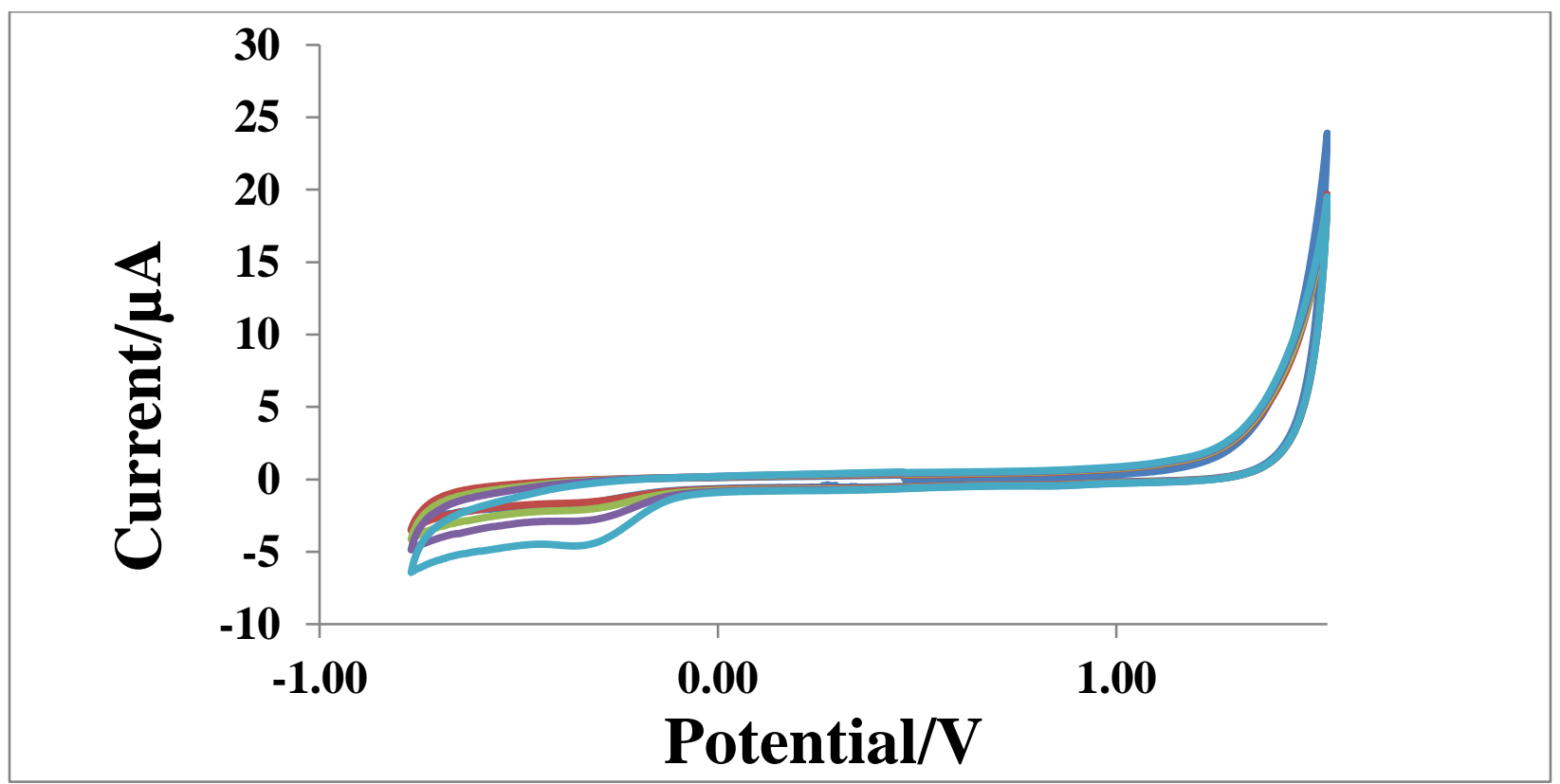

Figure 6.11 Five CVs of unmodified PIGE initiated in positive direction from the $\mathrm{OCP}=\mathbf{- 0 . 3 8 2 \mathrm { V } \text { to }}$ $+1.528 \mathrm{~V}$ to $-\mathbf{0 . 7 8 6} \mathrm{V}$ at $10 \mathrm{mV} / \mathrm{s}$. 
Initiation of potential scans in the positive direction from the open circuit potential (OCP), resulted in large oxidative currents (Figure 6.12). This is indicated by the blue scans, "Scan 1", in both Figures 6.12 and 6.13. However, the anodic peak potentials occurred at more positive potentials $(\sim 1.5 \mathrm{~V})$ than the oxidation of $\mathrm{WC}$ and the peak currents were more than ten times larger than those observed with WC. The increased oxidative current could be a result of variations in absolute amount of sample immobilized on the electrode and smaller overall particle size or due to the differences in electrical conductivity of the two carbides. $\mathrm{Cr}_{3} \mathrm{C}_{2}$ has a bulk resistivity of 75 $\mu \Omega$ - $\mathrm{cm}^{14,15}$ while resistivities of WC are between $250-535 \mu \Omega-\mathrm{cm} .{ }^{16}$

Initiation in the positive direction destroyed most of the $\mathrm{Cr}_{3} \mathrm{C}_{2}$ in the first scan, although the higher peak current at the positive limit in the first scan and the smaller, but still distinguishable anodic peak currents in the second scan (red, Scan 2) indicate that a significant amount of $\mathrm{Cr}_{3} \mathrm{C}_{2}$ remained after the first scan. The current levels for subsequent scans decreased to near background levels indicating that all the carbide had been consumed. 


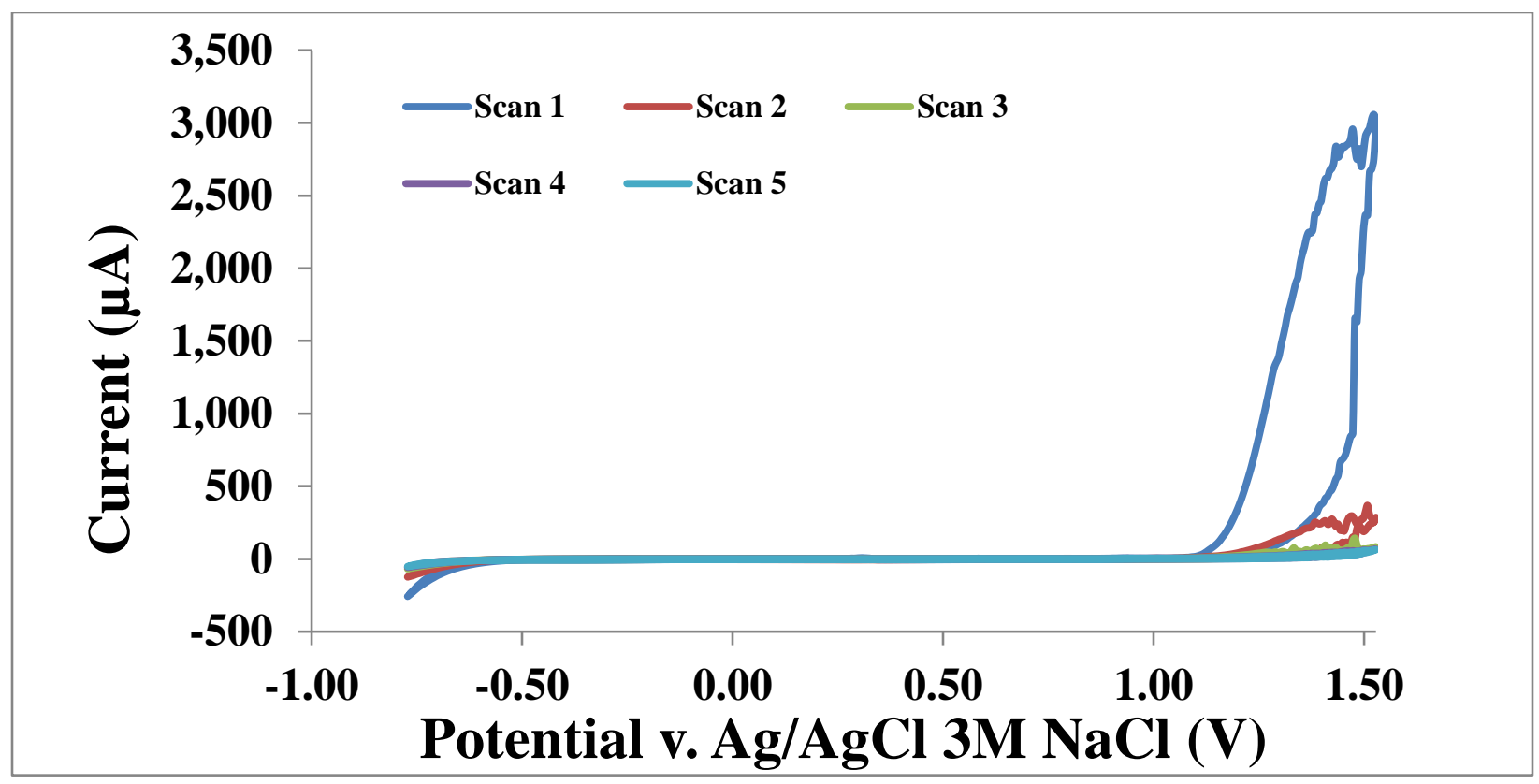

Figure 6.12 CVs of $\mathrm{Cr}_{3} \mathrm{C}_{2}+$ PIGE compared with five blank CVs of PIGE in $0.5 \mathrm{M} \mathrm{H}_{2} \mathrm{SO}_{4}, 10 \mathrm{mV} / \mathrm{s}$, initiated in the positive direction from the OCP vs. Ag/AgCl $3 \mathrm{M} \mathrm{NaCl}$.

The Figure 6.13 below shows $\mathrm{CV}$ scans of $\mathrm{Cr}_{3} \mathrm{C}_{2}$ initiated in the negative direction compared with a blank $\mathrm{CV}$. The current at the positive potential limit is highest in the first scan (blue, Scan 1) at a peak current of $\sim-0.55 \mathrm{~mA}$. The literature indicates that this dramatic increase in current at the positive limit is the HER, ${ }^{17,18}$ catalyzed by $\mathrm{Cr}_{3} \mathrm{C}_{2}$. When the potential is scanned in the positive direction, the carbide is oxidized and a large quantity of it destroyed. Thus, on the second cycle (red, Scan 2) the current at the negative limit for the HER catalysis decreases significantly as does the anodic peak current for the oxidation of the carbide. The peak current for both processes continues to decrease in subsequent scans to near background levels. 


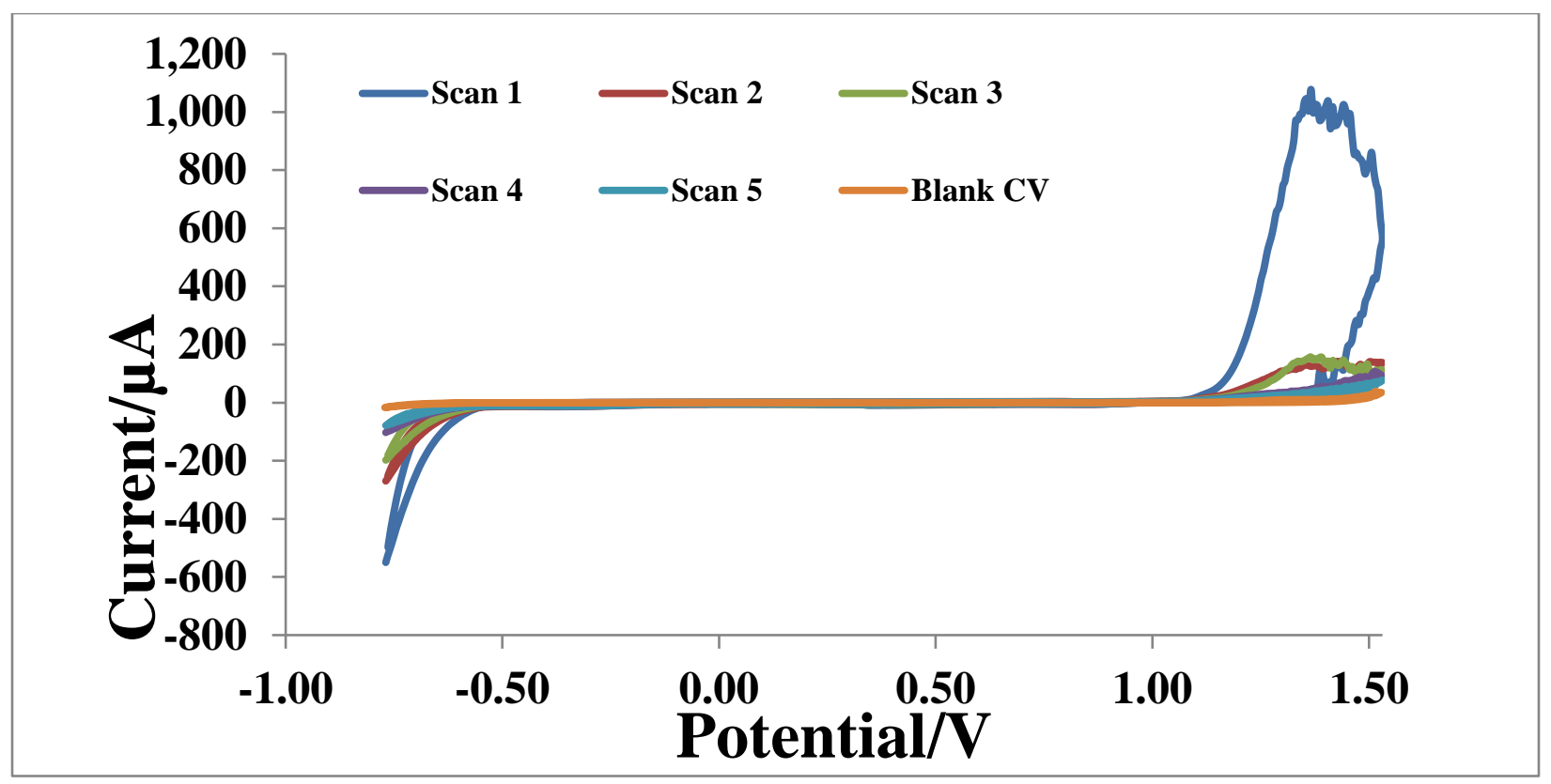

Figure 6.13 CVs of $\mathrm{Cr}_{3} \mathrm{C}_{2}+$ PIGE compared with five blank CVs of PIGE in $0.5 \mathrm{M} \mathrm{H}_{2} \mathrm{SO}_{4}, 10 \mathrm{mV} / \mathrm{s}$, initiated in the negative direction from the $\mathrm{OCP}=\mathbf{- 0 . 0 3 9 V}$.

As mentioned previously, Leonard et al. have recently reported on the catalytic activity of various chromium carbide phases for the HER.$^{17,18}$ Most electrochemical studies are corrosion studies of chromium carbide coatings, ${ }^{19,20}$ alloys $^{21,22}$ and composites..$^{23,24}$ To the best of our knowledge, there are no similar studies in the literature that examine the electrochemical stability window of $\mathrm{Cr}_{3} \mathrm{C}_{2}$. However, Tyurin has reported on thermodynamic electrochemical equilibria of the $\mathrm{Cr}-\mathrm{C} / \mathrm{H}_{2} \mathrm{O}$ system. ${ }^{25}$ According to this reference, the following equilibria may be involved with the oxidation and dissolution of $\mathrm{Cr}_{3} \mathrm{C}_{2}$ :

$$
\begin{array}{cc}
2 \mathrm{Cr}_{3} \mathrm{C}_{2}+9 \mathrm{H}_{2} \mathrm{O} \rightarrow 4 \mathrm{C}(\mathrm{gr} .)+3 \mathrm{Cr}_{2} \mathrm{O}_{3}+18 \mathrm{H}^{+}+18 e^{-} & \mathbf{R ~ 0 . 1 0} \\
\mathrm{Cr}_{2} \mathrm{O}_{3}+6 \mathrm{H}^{+}+2 e^{-} \rightarrow 2 \mathrm{Cr}^{2+}+3 \mathrm{H}_{2} \mathrm{O} & \mathbf{R ~ 0 . 1 1} \\
\mathrm{Cr}_{2} \mathrm{O}_{3}+6 \mathrm{H}^{+} \rightarrow 2 \mathrm{Cr}^{2+}+3 \mathrm{H}_{2} \mathrm{O} & \mathbf{R ~ 0 . 1 2}
\end{array}
$$




\subsubsection{Analysis of $\mathrm{Cr}_{23} \mathrm{C}_{6}$ in $0.5 \mathrm{M} \mathrm{H}_{2} \mathrm{SO}_{4}$ immobilized on a PIGE}

The second chromium carbide investigated was the $\mathrm{Cr}_{23} \mathrm{C}_{6}$ phase. $\mathrm{The} \mathrm{Cr}_{23} \mathrm{C}_{6}$ was in the form of a light gray powder, 99.5\% pure, $\sim 325$ mesh ( 44 microns). After the collection of CV scans of the unmodified PIGE, microparticles of the carbide were attached to the PIGE surface in the same way as previously described.

$\mathrm{CV}$ results for $\mathrm{Cr}_{23} \mathrm{C}_{6}$ were similar to $\mathrm{WC}$ and $\mathrm{Cr}_{3} \mathrm{C}_{2}$. Initiation of potential scans in the positive direction from the open circuit potential (OCP), resulted in large oxidative currents (Figure 6.14). However, the anodic peak potentials occurred at more positive potentials $(\sim 1.4 \mathrm{~V})$ than the oxidation of WC but shifted by $-0.1 \mathrm{~V}$ compared to the oxidation potential of $\mathrm{Cr}_{3} \mathrm{C}_{2}$. This is consistent with Tyurin's thermodynamic calculations predicting the higher stability of the $\mathrm{Cr}_{3} \mathrm{C}_{2}$ phase. ${ }^{25}$ The current peaks are similar in magnitude with those observed in the $\mathrm{CVs}$ of $\mathrm{Cr}_{3} \mathrm{C}_{2}$. Initiation in the positive direction destroyed most of the carbide in the first scan (orange trace, Scan 1). The current levels for subsequent scans decreased to near background levels indicating that all the carbide had been consumed. 


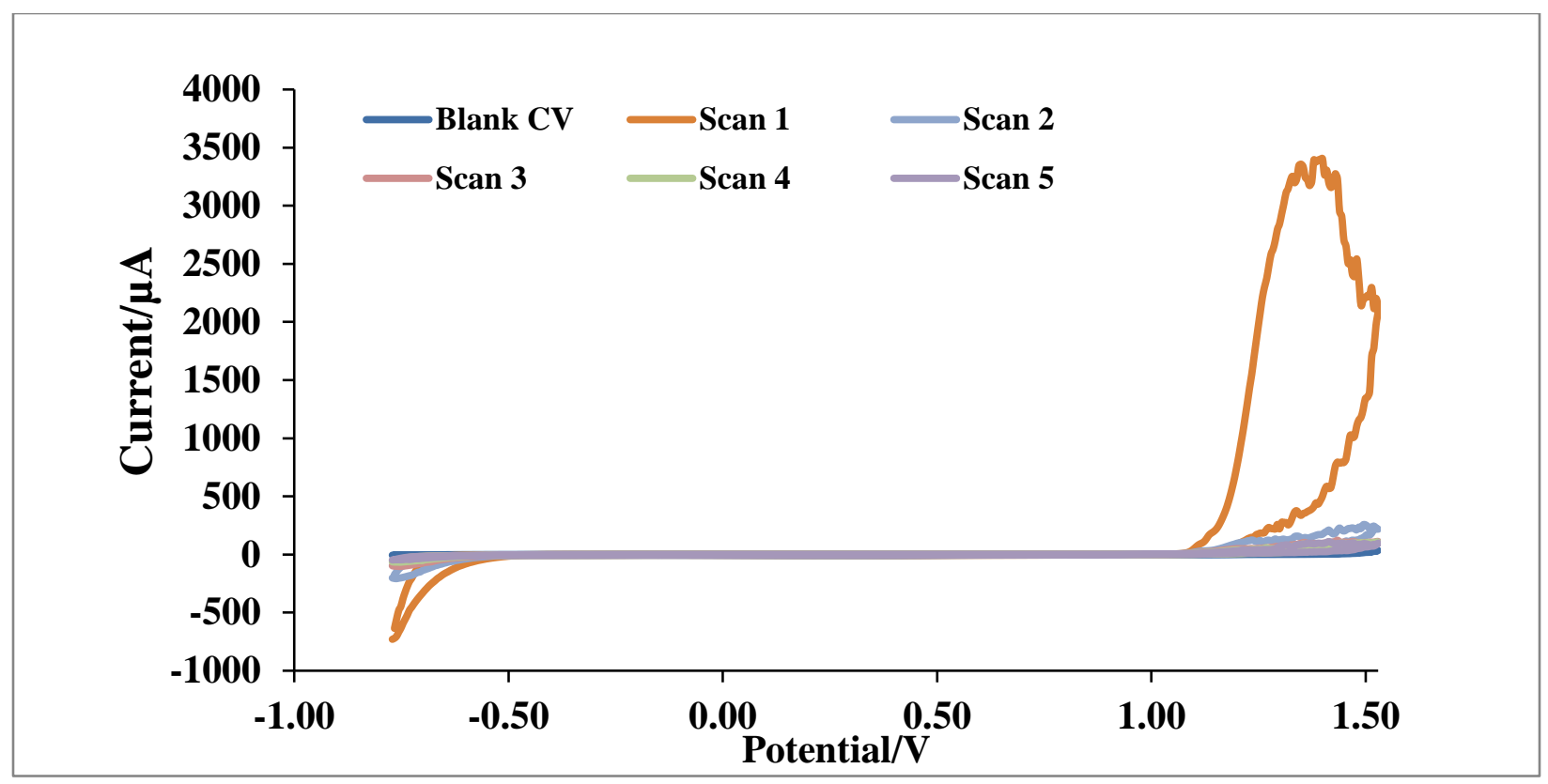

Figure 6.14 CVs of $\mathrm{Cr}_{23} \mathrm{C}_{6}+$ PIGE compared with 5 blank CVs of PIGE in $0.5 \mathrm{M} \mathrm{H}_{2} \mathrm{SO}_{4}, 10 \mathrm{mV} / \mathrm{s}$, initiated in the positive direction from the $\mathrm{OCP}=0.219 \mathrm{~V}$ over a potential range of $1.528 \mathrm{~V}$ to $0.768 \mathrm{~V}$.

Figure 6.15 below shows $\mathrm{CV}$ scans of $\mathrm{Cr}_{23} \mathrm{C}_{6}$ initiated in the negative direction compared with blank CVs. The current at the positive potential limit is highest in the first scan (blue, Scan 1) at a peak current of $\sim-0.75 \mathrm{~mA}$. Again, the literature indicates that this dramatic increase in current at the positive limit is the HER, ${ }^{17,18}$ catalyzed by $\mathrm{Cr}_{23} \mathrm{C}_{6}$. When the potential is scanned in the positive direction, the carbide is oxidized and a large quantity of it destroyed. Thus, on the second cycle (red, Scan 2) the current at the positive limit decreases significantly as does the anodic peak current for the oxidation of the carbide. The peak current for both processes continues to decrease in subsequent scans to near background levels. 


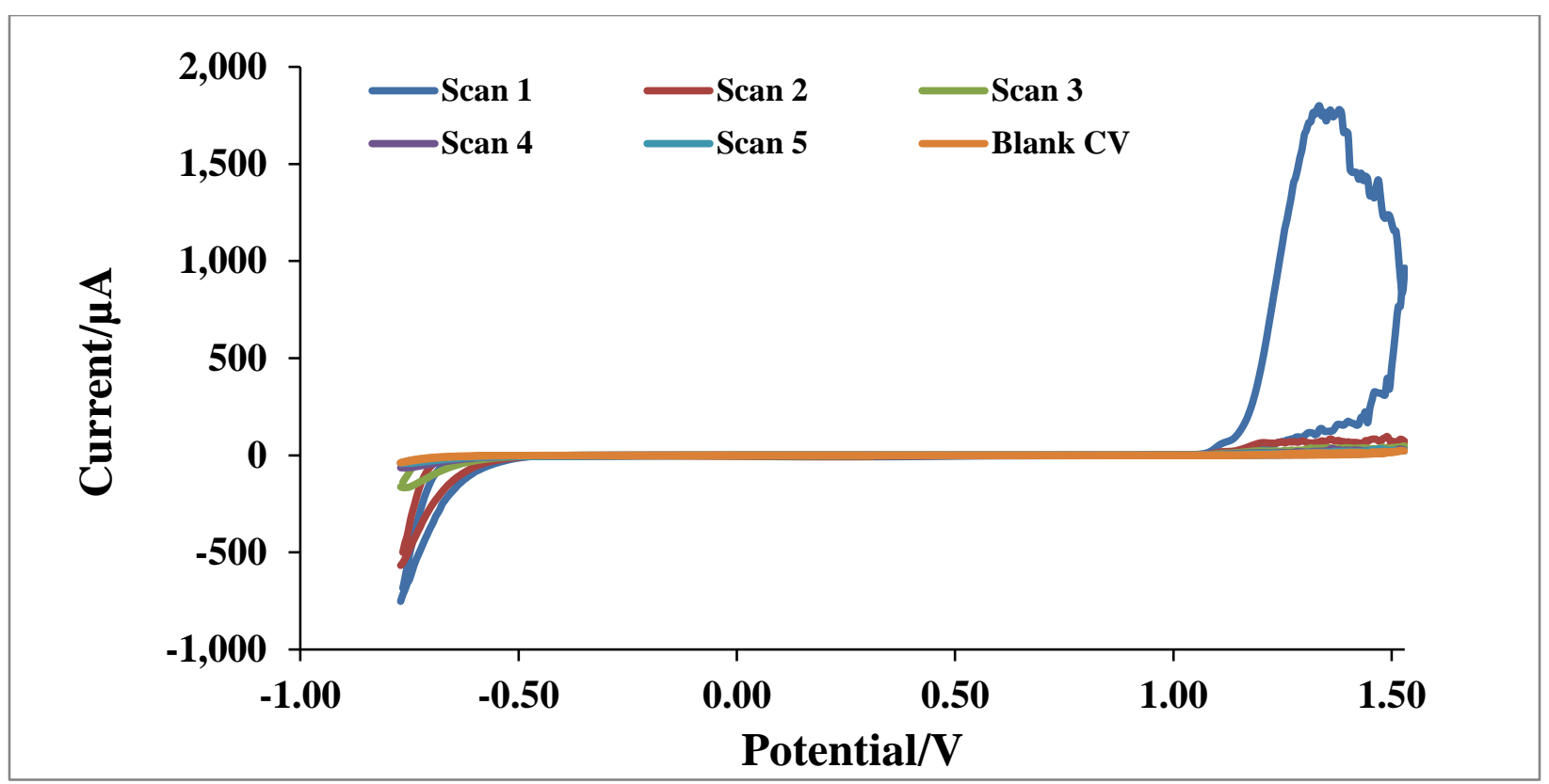

Figure 6.15 CVs of $\mathrm{Cr}_{23} \mathrm{C}_{6}+$ PIGE compared with five blank CVs of PIGE in $0.5 \mathrm{M} \mathrm{H}_{2} \mathrm{SO}_{4}, 10 \mathrm{mV} / \mathrm{s}$, initiated in the negative direction from the $\mathrm{OCP}=0.310 \mathrm{~V}$ to $-\mathbf{0 . 7 6 8 V}$ to $1.528 \mathrm{~V}$.

$\mathrm{Cr}_{23} \mathrm{C}_{6}$ was one of the carbide phases studied by Leonard et al. in their research on the catalytic activity of various transition metal carbides for the HER. ${ }^{17,18}$ Most electrochemical studies involving the analysis of the $\mathrm{Cr}_{23} \mathrm{C}_{6}$ phase are corrosion studies of chromium carbide coatings, ${ }^{26,27}$ alloys ${ }^{28}$ and composites..$^{29,30}$ To the best of our knowledge, there are no similar studies in the literature that examine the electrochemical stability window of $\mathrm{Cr}_{23} \mathrm{C}_{6}$. However, Tyurin's publication on the thermodynamic electrochemical equilibria of the $\mathrm{Cr}-\mathrm{C} / \mathrm{H}_{2} \mathrm{O}$ system indicates that the corrosion of the $\mathrm{Cr}_{23} \mathrm{C}_{6}$ may proceed through a solid-state transformation to chromium carbides of lower chromium content (See Figure 6.16). ${ }^{25}$ 


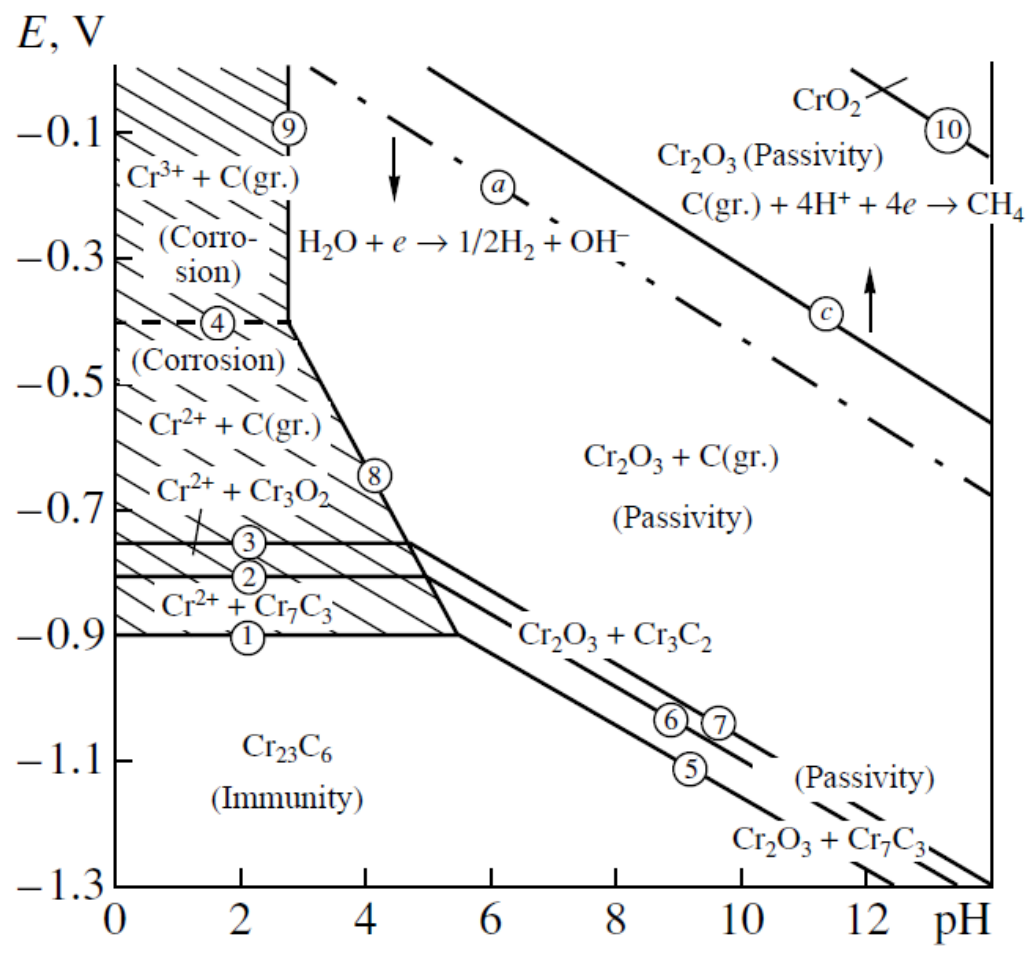

Figure 6.16 The potential-pH value of the $\mathrm{Cr} 23 \mathrm{C6}-\mathrm{H} 2 \mathrm{O}$ system at $25^{\circ} \mathrm{C}, 1 \mathrm{~atm}$ (air), and $\mathrm{a}_{\mathrm{i}}=1 \mathrm{~mol} / \mathrm{l}$ (unhydrated form of oxides) ${ }^{25}$.

Therefore, oxidation and dissolution of the $\mathrm{Cr}_{23} \mathrm{C}_{6}$ phase may proceed by the following equilibria:

$$
\begin{aligned}
& \mathrm{Cr}_{23} \mathrm{C}_{6} \rightarrow 2 \mathrm{Cr}_{7} \mathrm{C}_{3}+9 \mathrm{Cr}^{+}+18 e^{-} \\
& 2 \mathrm{Cr}_{7} C_{3} \rightarrow 3 \mathrm{Cr}_{3} \mathrm{C}_{2}+5 \mathrm{Cr}^{+}+10 e^{-} \\
& \mathrm{Cr}_{3} C_{2} \rightarrow 2 C(g r .)+3 \mathrm{Cr}^{2+}+6 e^{-}
\end{aligned}
$$

\subsubsection{Analysis of $\mathrm{Al}_{4} \mathrm{C}_{3}$ in $0.1 \mathrm{M} \mathrm{KPF6/MeCN}$ immobilized on a GCE}

Aluminum carbide $\left(\mathrm{Al}_{4} \mathrm{C}_{3}\right)$ was one of the two ionic carbides investigated via VMP analysis at a glassy carbon electrode (GCE). The aluminum carbide was in the form of a fine light brown to yellow powder, $\sim 325$ mesh ( $\sim 44$ microns), After the collection of CV scans of the 
unmodified GCE, the electrode was rinsed with dry $\mathrm{MeCN}$ and dried with a kim wipe. As discussed in Appendix B. Electrochemical Window Experiments, cycling the GCE in $0.1 \mathrm{M} \mathrm{KPF} 6 / \mathrm{MeCN}$ reduced the electrochemical signals due to impurities to low levels that were stable and reproducible. Microparticles of the aluminum carbide were attached to the GCE surface by mechanical abrasion as previously described. Inspection of the surface under a magnifying glass showed that $\mathrm{Al}_{4} \mathrm{C}_{3}$ particles were adhered, but the mechanical abrasion also had caused significant damage to the surface.

Figure 6.17 shows five $\mathrm{CV}$ scans of the GCE in $0.1 \mathrm{M} \mathrm{KPF}_{6} / \mathrm{MeCN}$ after modification with aluminum carbide. The scans were initiated from the $\mathrm{OCP}$ in the positive direction in order to drive an oxidation. However, there are no features in the first scan (blue, Scan 1) until the reverse scan in the negative direction. This feature is a broad peak at $\sim-1.74 \mathrm{~V}$ that is ten times in magnitude above the background current due to a reductive process. When the potential is scanned back to the OCP two small, oxidative peaks appear. Upon initiation of the second scan (red, Scan 2) in the positive direction, a second oxidative process is observed, yielding a broad peak at $\sim 0.57 \mathrm{~V}$. The return sweep and subsequent scans yield CVs with the same features as the CVs of the unmodified GCE. 


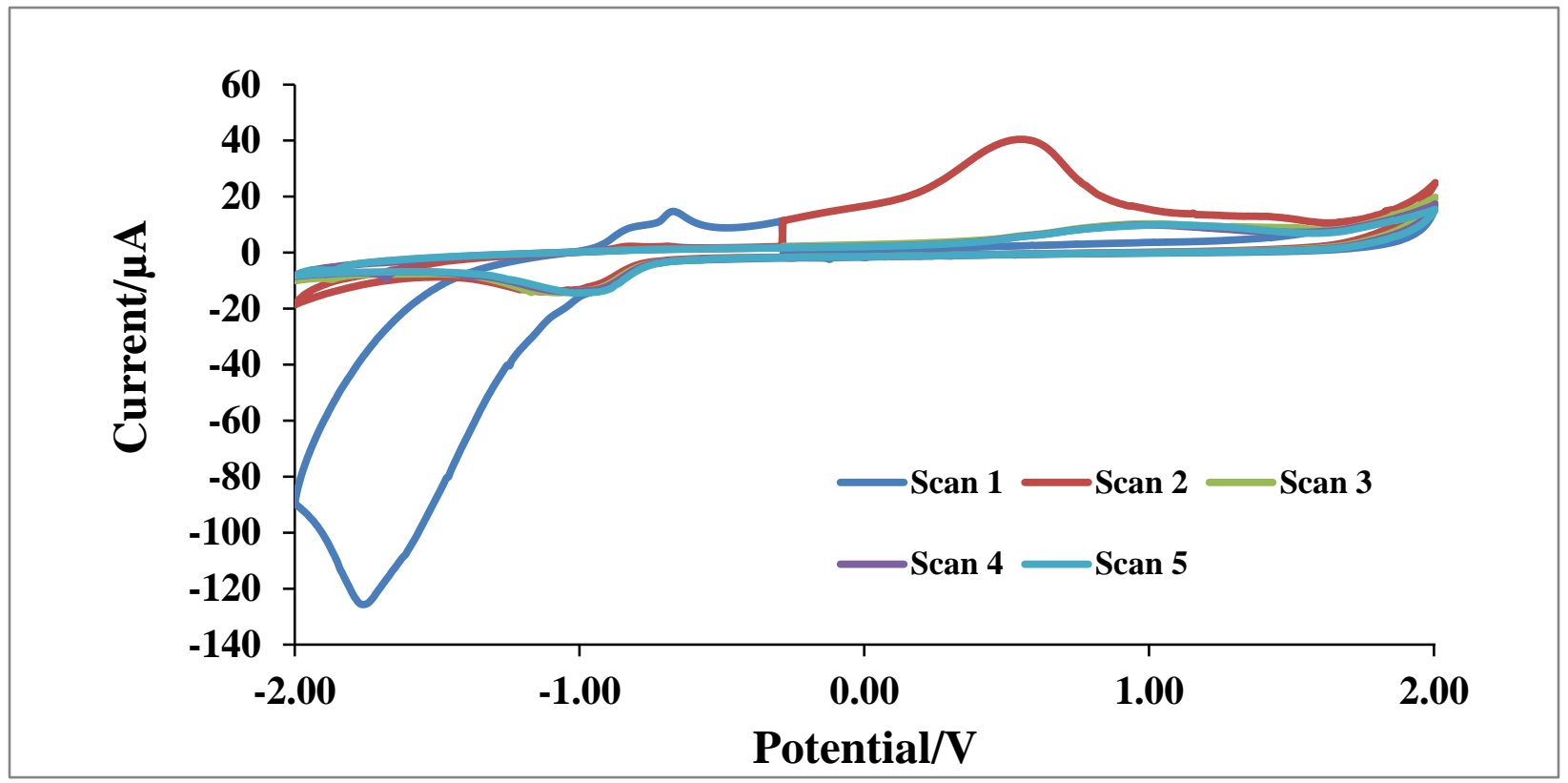

Figure 6.17 CVs of $\mathrm{Al}_{4} \mathrm{C}_{3}+\mathrm{GCE}$ compared in $0.1 \mathrm{M} \mathrm{KPF} / \mathrm{MeCN}$, scan rate $10 \mathrm{mV} / \mathrm{s}$, initiated in the negative direction from the $\mathrm{OCP}=-\mathbf{0 . 2 8 6 \mathrm { V }}$ over the potential range $+2.00 \mathrm{~V}$ to $-\mathbf{2 . 0 0 \mathrm { V }}$.

Scans initiated in the negative direction from the OCP showed similar features. There is a broad peak in the negative region due to a reductive process during the first scan. When the potential was swept in the positive direction a small oxidation peak appeared followed by a broad peak due to a second oxidative process. The electrochemical features in subsequent scans were the same as those in the CVs of the unmodified GCE. The electrochemical features in the first scan of Figure 6.18 have lower peak currents, shifted peak potentials, and broadened shapes compared 
with the current peaks in Figure 6.17. This may be due to the variation in amount of sample loading inherent to the VMP technique.

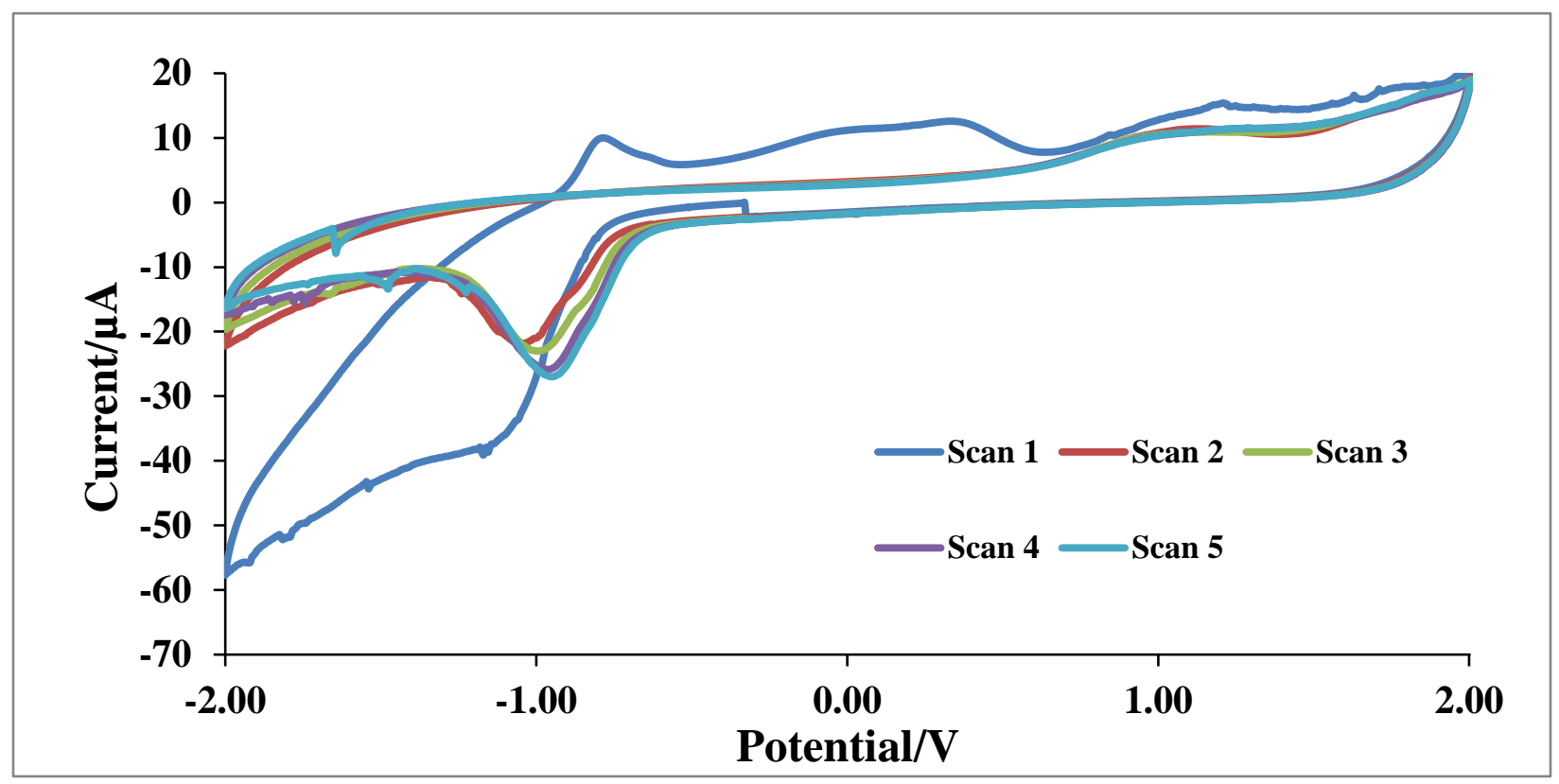

Figure 6.18 CVs of $\mathrm{Al}_{4} \mathrm{C}_{3}+\mathrm{GCE}$ compared in $0.1 \mathrm{M} \mathrm{KPF} / \mathrm{MeCN}$, scan rate $10 \mathrm{mV} / \mathrm{s}$, initiated in the

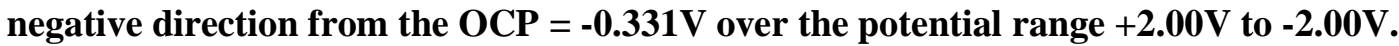

The presence of impurities in the system makes interpretation of these results difficult. However, the fact that the electrochemical features associated with the unmodified GCE are suppressed after introduction of aluminum carbide to the electrode strongly suggests that particle samples are interrupting direct contact with the electrode surface and the electrolyte. Moreover, the new features that are present in the first scans after aluminum carbide introduction and the general reproducibility of these features further indicate that the aluminum carbide particles are electrochemically active. Therefore, we tentatively assign these peak currents to the reduction of aluminum carbide followed by oxidation processes in which the carbide is irreversibly destroyed.

More detailed interpretation will require further analyses, and to the best of this author's knowledge, there are no electrochemical analyses of aluminum carbide in the literature to aid us 
in our interpretation. However, as a starting point we may hypothesize possible half-reactions based upon the structure of aluminum carbide.

$\mathrm{Al}_{4} \mathrm{C}_{3}$ has a rhombohedral structure with alternating layers of $\mathrm{Al}_{2} \mathrm{C}$ and $\mathrm{Al}_{2} \mathrm{C}_{2}$ units stacked in the c-direction. If we assume separation of charge based on this structure the oxidation and reduction pathways may be:

$$
\begin{aligned}
A l_{2} C+6 e^{-} & \rightarrow 2 A l+C^{6-} \\
A l_{2} C_{2}+6 e^{-} & \rightarrow 2 A l+2 C^{3-}
\end{aligned}
$$

Oxidation:

$$
\begin{aligned}
A l_{2} C & \rightarrow 2 A l^{3+}+C+6 e^{-} \\
A l_{2} C_{2} & \rightarrow 2 A l^{3+}+2 C+6 e^{-}
\end{aligned}
$$

It is likely that the above proposed half-reactions are an oversimplification. The carbon anions with such large negative charges would be highly unstable and have never been observed in experiment. Additionally, the closest $\mathrm{C}-\mathrm{C}$ atomic distance in $\mathrm{Al}_{4} \mathrm{C}_{3}$ is $316 \mathrm{pm}$, and it is thought that such a large separation of charge is unlikely to occur over such a great distance. Instead, the electrochemical processes may be more complicated and may involve oxidation and reduction of nonstoichiometric species or the carbide may undergo multiple oxidation and reduction steps due to the chemically different aluminum and carbon species involved.

\subsubsection{Analysis of $\mathrm{CaC}_{2}$ in 0.1M TBAHFP/MeCN immobilized on a GCE}

Due to the quasi-reversible redox feature observed at potentials >-1.1V (discussed in Appendix B), the potential window used for calcium carbide experiments in $0.1 \mathrm{M}$ TBAHFP/MeCN was $-1.069 \mathrm{~V}$ to $1.931 \mathrm{~V}$. The OCP was measured at zero current for five minutes. 
Blank CVs of the unmodified GCE were collected by initiating scans in the positive direction from the OCP to the positive potential limit, then to the negative potential limit and back to the OCP.

After the collection of the blank CVs, the GCE was rinsed in dry MeCN and dried with a kimwipe. The calcium carbide analyzed was in the form of 6.4 to $12.7 \mathrm{~mm}$ granules, Lab grade. The appearance of the calcium carbide pieces were gray to white solids with varying degrees of oxidation and impurities. Some small pieces were completely white indicating the surface was covered with calcium oxide. Other pieces had faces with thin black layers. These layers are likely elemental carbon impurities. A small piece of calcium carbide was selected. This carbide piece was small and gray in appearance and appeared to have less surface oxides. This piece was crushed in a diamonite (synthetic sapphire) mortar and pestle. The resulting powder was coarse and heterogeneous in appearance. The powder was mostly brown with darker, reflective crystals dispersed within it. A small portion of the powder which had come from inside the carbide piece was placed on a piece of clean paper on a glass plate. This powder was attached to the GCE in the same way as before.

The $\mathrm{OCP}$ of the $\mathrm{GCE}+\mathrm{CaC}_{2}$ varied from -0.051 to $-0.013 \mathrm{~V}$ over five minutes. Figure 6.19 show five $\mathrm{CVs}$ of the $\mathrm{CaC}_{2}$ modified GCE compared with five blank CVs. There are no features indicating faradaic processes in any of the voltammograms. The first scan of the $\mathrm{CaC}_{2}$ modified GCE (orange, Scan 1) in Figure 6.19 shows elevated background current compared with the blank CVs. After the first scan the background current decreases, indicating passivating process has taken place. The lack of electrochemical features in the voltammograms indicate that the calcium carbide is either electrochemically inactive in this potential window or that the contact between the calcium carbide particles and the GCE was insufficient, i.e. the calcium carbide did not adhere to the GCE surface. 


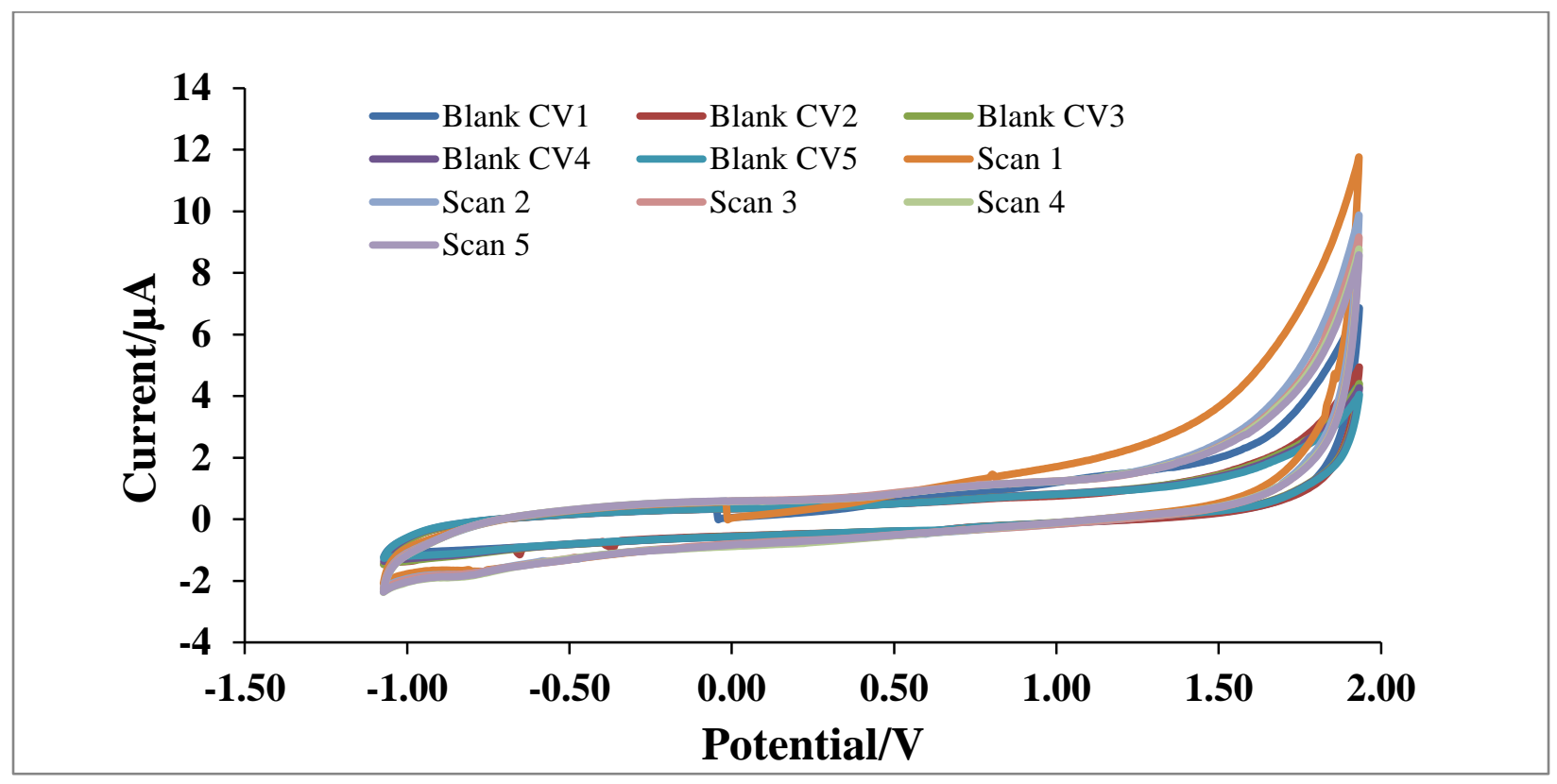

Figure 6.19 CVs of GCE1 modified with calcium carbide compared to blank CVs of unmodified GCE1. Scan rate $=10 \mathrm{mV} / \mathrm{s}$, scans initiated in the positive direction from the $\mathrm{OCP}=\mathbf{- 0 . 0 1 3 V}$ (for CaC2 modified electrode).

\subsubsection{Analysis of $\mathrm{CaC}_{2}$ in 0.1M CaTf/MeCN immobilized on a GCE}

Calcium carbide microparticles were also analyzed in a $0.1 \mathrm{M} \mathrm{CaTf} / \mathrm{MeCN}$ electrolyte at a

GCE. Processing of the calcium carbide to a powder and immobilization of the powder to the GCE was achieved in the same way as described earlier. It was hypothesized that the oxidation and reduction of calcium carbide may be a reversible process due to the anisotropic arrangement of the acetylide anions in calcium carbide's structure (R 6.20). The supporting electrolyte calcium triflate, provides the calcium cation to test this hypothesis.

$$
\mathrm{CaC}_{2} \leftrightarrow \mathrm{Ca}^{2+}+2 e^{-}+2 C(\mathrm{gr} .)
$$

Figure 6.20 shows five CVs of the GCE post calcium carbide modification compared with a CV of the unmodified GCE (teal, Blank CV5) in $0.1 \mathrm{M} \mathrm{CaTriflate} / \mathrm{MeCN}$ at $10 \mathrm{mV} / \mathrm{s}$. The scans were initiated in the positive direction from the OCP to $2.102 \mathrm{~V}$, scanned in the negative direction to $-2.398 \mathrm{~V}$ and back to the OCP. Similar to the $\mathrm{CV}$ s in the TBAHFP/MeCN electrolyte, there are no faradaic peaks in the CVs post modification with calcium carbide. The first scan (orange, Scan 
1) shows elevated background current in the positive potential region and the impurity oxidation peaks are suppressed. In the following scans the background current decreases to the level observed in the blank CVs and the oxidation peaks attributed to impurities are once again visible.

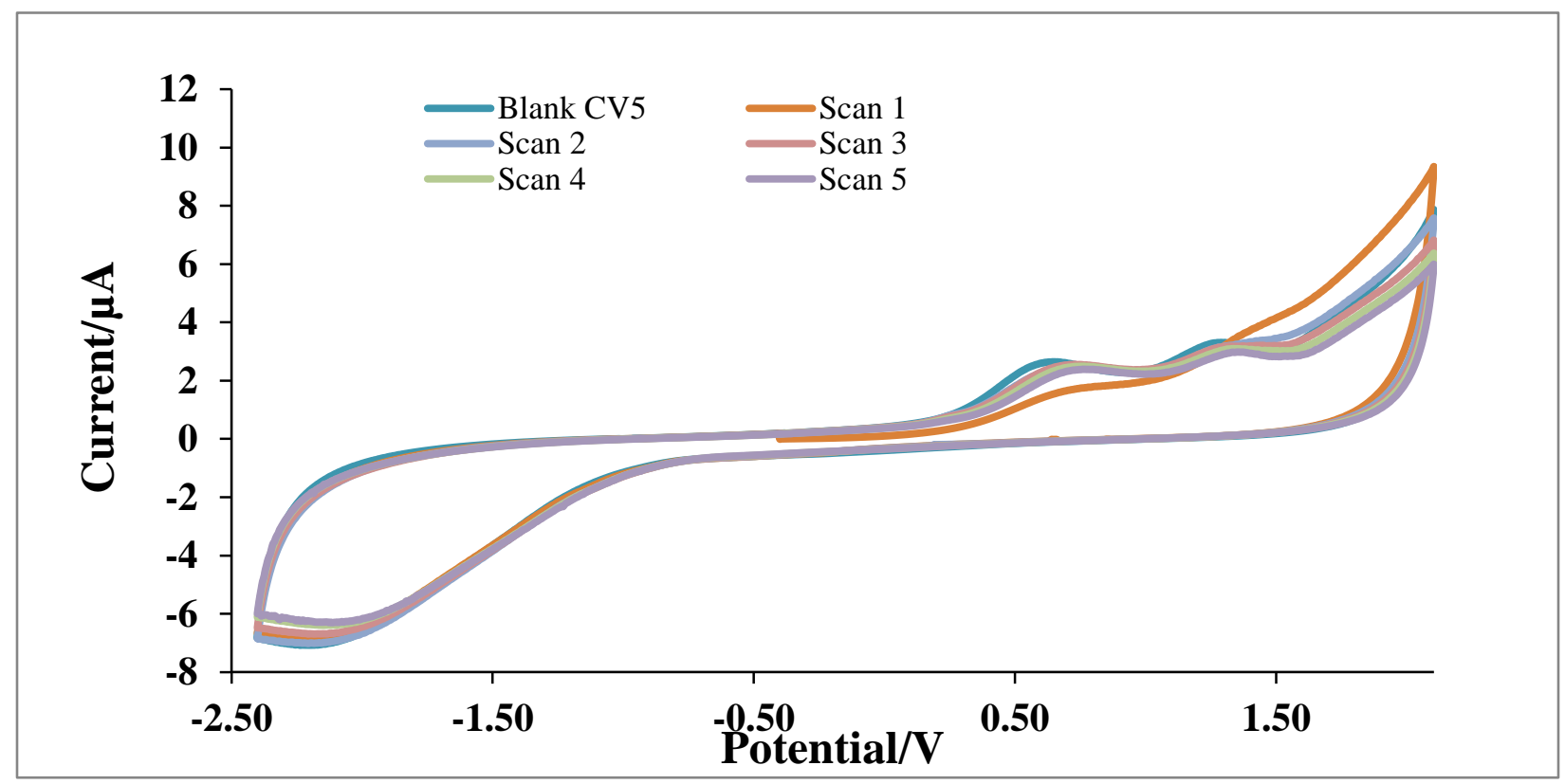

Figure 6.20 Blank CVs of GCE1, scan rate $=10 \mathrm{mV} / \mathrm{s}$, scans initiated in the positive direction from the OCP $=-\mathbf{- 0 . 3 7 7 V}$.

The lack of electrochemical features in the voltammograms also indicate that the calcium carbide is either electrochemically inactive in this potential window or that the contact between the calcium carbide particles and the GCE was insufficient, i.e. the calcium carbide did not adhere to the GCE surface. However, the fact that the impurity oxidation peaks were suppressed in the first scan post calcium carbide attachment suggests that the surface of the electrode was covered with the carbide. It is possible that the activity of the calcium carbide is hidden by processes due to the impurities. It is worth emphasizing the preliminary nature of these results. Further experimentation is required. 


\section{References}

(1) Pons, S.; Fleischmann, M. Anal. Chem. 1987, 59 (24), 1391A-1399A.

(2) Tallman, D. E.; Petersen, S. L. Electroanalysis 1990, 2, 499-510.

(3) Scholz, Fritz and Meyer, B. In Electroanalytical Chemistry Vol. 20; Bard, Allen J. and Rubinstein, I., Ed.; Marcel Dekker, Inc., 1998; pp 1-59.

(4) Besenhard, J. O.; Fritz, H. P. Angew. Chemie Int. Ed. English 1983, 22 (12), 950-975.

(5) Morris, D. R.; Aksaranan, C.; Waldron, B. S.; White, S. H. J. Electrochem. Soc. 1973, 120 (4), 570.

(6) Bonomi, A.; Hadate, M.; Gentaz, C. J. Electrochem. Soc. 1977, 124 (7), 982.

(7) Sydow, U.; Schneider, M.; Herrmann, M.; Kleebe, H. J.; Michaelis, A. Mater. Corros. 2010, 61 (8), 657-664.

(8) Sydow, U.; Sempf, K.; Herrmann, M.; Schneider, M.; Kleebe, H. J.; Michaelis, A. Mater. Corros. 2013, 64 (3), 218-224.

(9) Wijesundara, M. B. J.; Azevedo, R. 2011, 22 (8).

(10) Weidman, M. C.; Esposito, D. V.; Hsu, I. J.; Chen, J. G. J. Electrochem. Soc. 2010, 157 (12), F179.

(11) Hunt, S. T.; Kokumai, T. M.; Zanchet, D.; Román-Leshkov, Y. J. Phys. Chem. C 2015, 119 (24), 13691-13699.

(12) Göhl, D.; Mingers, A. M.; Geiger, S.; Schalenbach, M.; Cherevko, S.; Knossalla, J.; Jalalpoor, D.; Schüth, F.; Mayrhofer, K. J. J.; Ledendecker, M. Electrochim. Acta 2018, 270, 70-76.

(13) Benck, J. D.; Pinaud, B. A.; Gorlin, Y.; Jaramillo, T. F. PLoS One 2014, 9 (10).

(14) Zhang, L.; Elias, A.; Chen, W.; Gao, K. Ceram. Int. 2015, 41 (9), 11075-11079.

(15) Groudeva-Zotova, S.; Vitchev, R. G.; Blanpain, B. Surf. Interface Anal. 2000, 30, 544548.

(16) Sun, Y.-M.; Lee, S. .; Lemonds, a. .; Engbrecht, E. .; Veldman, S.; Lozano, J.; White, J. .; Ekerdt, J. .; Emesh, I.; Pfeifer, K. Thin Solid Films 2001, 397 (1-2), 109-115.

(17) Schmuecker, S. M.; Clouser, D.; Kraus, T. J.; Leonard, B. M. Dalt. Trans. 2017, 46 (39), 13524-13530.

(18) Regmi, Y. N.; Waetzig, G. R.; Duffee, K. D.; Schmuecker, S. M.; Thode, J. M.; Leonard, B. M. J. Mater. Chem. A 2015, 3 (18), 10085-10091.

(19) Kamal, S.; Jayaganthan, R.; Prakash, S.; Kumar, S. J. Alloys Compd. 2008, 463 (1-2), 358-372.

(20) Toma, D. U.; Brandl, W.; Marginean, G. Surf. Coatings Technol. 2001, 138 (2-3), 149158. 
(21) Pagounis, E.; Lindroos, V. . Mater. Sci. Eng. A 1998, 246 (1), 221-234.

(22) Xiang, M. A. Chin. J. Met. Sci. Technol. 1988, 4, 228-231.

(23) Alar, Ž.; Alar, V.; Fabijanić, T. Metals (Basel). 2017, 7 (3), 69.

(24) Wan, W.; Xiong, J.; Yang, M.; Guo, Z.; Dong, G.; Yi, C. Int. J. Refract. Met. Hard Mater. 2012, 31, 179-186.

(25) Tyurin, A. G. Prot. Met. 2003, 39 (5), 435-442.

(26) Castillejo, F. E.; Marulanda, D. M.; Olaya, J. J.; Alfonso, J. E. Surf. Coatings Technol. 2014, 254, 104-111.

(27) Wu, S.; Fei, Y.; Guo, B.; Jing, L. Corros. Sci. 2015, 100, 306-310.

(28) Lee, J.; Duh, J.; Tsai, S. Surf. Coatings Technol. 2002, 153, 59-66.

(29) Xu, J.; Zhuo, C.; Han, D.; Tao, J.; Liu, L.; Jiang, S. Corros. Sci. 2009, 51 (5), 1055-1068.

(30) Sancakoglu, O.; Ungan, G.; Celik, E.; Aksoy, T. Int. J. Appl. Ceram. Technol. 2015, 12 (4), 830-836. 


\section{Chapter 7: Conclusion and Future Work}

We have reported on explorations of the oxidation of calcium carbide in late transition

metal halide salt melts first reported by Barber and Sloane. ${ }^{1}$ We expanded on this work by reporting on the characterization and analysis of the carbon produced from these reactions. Moreover, we have also investigated the oxidation of aluminum carbide in tin chloride melts and described the characterization and analyses of the reaction products. To the best of our knowledge, this is the first report on the salt melt synthesis of carbon material from aluminum carbide. In the future, salt melt mixtures utilizing eutectics for lowering the reaction temperature could be explored. Data in the literature indicates that calcium carbide is somewhat soluble in lithium halides, which should improve mass transport; therefore, syntheses in lithium halide melts should be investigated.

Further characterization of the carbon products materials properties, such as resistivity, thermal and chemical stability, etc., must be carried out to determine their potential for application in electrochemical devices. For example, Antonetti et al. ${ }^{2}$ have noted that salt melts can act as activators and porogens in the synthesis of microporous carbons from biomass, polymer and other hydrocarbon precursors. Thus, it should be determined whether the salt melts also take on this additional role in the oxidation of calcium carbide and aluminum carbide.

We also describe explorations of the oxidation of ionic carbides by metal cations in solution via galvanic reaction and controlled potential electrolysis between a calcium carbide cell in an ethanol solution of saturated calcium chloride and a zinc cell in an ethanol solution of saturated zinc chloride. Results on a controlled potential electrolysis experiment are also reported. Although results from solution state experiments indicated that calcium carbide had been oxidized to elemental carbon, many questions remained unanswered and problems originating from 
experimental design remained unresolved. The observation of the oxidation of calcium carbide in the solution state to graphite coupled together with calcium carbide's structural similarity with graphite led to the question of whether the oxidation of calcium carbide and the assumed deintercalation of the calcium cation was reversible. This observation would be significant considering recent interest in identifying and investigating electrode materials for the development of a calcium ion battery. ${ }^{3-8}$

The voltammetry of microparticles experiments (VMP) were undertaken to explore the possibility of the reversible charge transfer reactions in carbides, as well as the possibility of synthesizing the carbon materials produced via ionic carbides in salt melts but in low temperature salt solutions driven by controlled potential electrolysis. Additionally, we discovered that there were very few studies on pure phase, microparticles of covalent and transition metal carbides despite their growing importance as catalyst support and electrode materials. Therefore, VMP investigations were expanded to include representatives of each category of carbide as well as the ionic carbides.

The VMP results from experiments with the ionic carbides indicated that their electrochemistry in nonaqueous electrolytes was very different from their behavior in melts of transition metal halide salts. Cyclic voltammetric (CV) analyses showed that aluminum carbide microparticles immobilized on a glassy carbon electrode (GCE) only underwent an oxidation after a reduction event. This behavior was reproducible within the limitations of the technique. This contrasts with the oxidation of aluminum carbide to elemental carbon by a tin chloride melt.

The VMP analyses were also conducted on calcium carbide particles immobilized on a GCE in two different nonaqueous electrolytes, $0.1 \mathrm{M}$ tetrabutylammonium hexafluorphosphate in acetonitrile (TBAHFP/MeCN) and $0.1 \mathrm{M}$ calcium triflate in acetonitrile $(\mathrm{CaTf} / \mathrm{MeCN})$. The second 
supporting electrolyte, CaTf, was chosen to provide a source of solvated calcium ions to establish the hypothesized reversible charge transfer equilibria discussed earlier. After modification of the electrode with calcium carbide, higher background currents were observed indicating the passivation of material which had not been there previously. However, no distinct faradaic peaks were observed that could be attributed to the carbide. The lack of electrochemical features post carbide modification suggests that either calcium carbide is electrochemically inactive, signals due to its activity are not observed due to interference with impurities or there was insufficient electrical contact between the calcium carbide particles and the GCE.

We believe the latter is the cause of the apparent inactivity of the calcium carbide modified GCE. Calcium carbide is not commercially available in high purity. Most vendors sell calcium carbide as industrial grade, which is $75-80 \%$ pure. The calcium carbide used for the VMP experiments was industrial grade, and upon initial inspection it was clear the carbide had undergone significant decomposition due to hydrolysis with ambient moisture. Although care was taken to process the carbide to a powder with minimal hydrolysis of the carbide, further decomposition undoubtedly occurred before modification of the electrode. Additionally, comparing the standard free energies and enthalpies of aluminum carbide and calcium carbide, calcium carbide should be more thermodynamically accessible than calcium carbide.

Thus, VMP experiments on the ionic carbides, particularly calcium carbide analyses, posed a significant hinderance. These impurities include contaminants in both the nonaqueous electrolytes and in the calcium carbide, the latter of which we believe prevented observation of its electrochemical activity in this work. Taking this into consideration, we recommend identification and elimination of the impurities in the nonaqueous electrolytes and repeating the VMP experiments with the ionic carbides. Specifically, supporting analyses with SEM/EDS, ICP-OES 
and Raman should be conducted to elucidate the chemistry and mechanisms of the electrochemical behavior of aluminum carbide. We also recommend synthesizing pure calcium carbide for VMP analysis since it cannot be obtained commercially. The author recommends pursuing the microwave assisted, solid-state synthesis method reported by Iyere et al. ${ }^{9}$ This method has a higher yield than the electric arc method and can produce calcium carbide of high purity if graphite is used as the carbon precursor.

Results from VMP experiments on $\mathrm{SiC}$, a covalent carbide, and several transition metal carbides, $\mathrm{WC}, \mathrm{Cr}_{23} \mathrm{C}_{6}$ and $\mathrm{Cr}_{3} \mathrm{C}_{2}$, indicated chemistry very different from the electrochemistry of the ionic carbides. Results indicated that in $0.5 \mathrm{M} \mathrm{H}_{2} \mathrm{SO}_{4} \mathrm{SiC}$ microparticles had very little electrochemical activity, with only a slight increase in background current indicating passivation and $\mathrm{SiO}_{2}$ formation. $\mathrm{CVs}$ of WC microparticles showed the catalysis of the HER in the cathodic potential region and the irreversible, oxidative destruction of $\mathrm{WC}$ to $\mathrm{WO}_{3}$ at $1.18 \mathrm{~V}$. These results are in good agreement with the work of others on the subject. ${ }^{10,11}$ The VMP analyses of the chromium carbides showed the catalysis of the HER in the cathodic region and the irreversible, oxidative destruction of the chromium carbides, $\mathrm{Cr}_{3} \mathrm{C}_{2}$ oxidation at $1.5 \mathrm{~V}$ and $\mathrm{Cr}_{23} \mathrm{C}_{6}$ oxidation at $1.4 \mathrm{~V}$. Although there have been some corrosion studies on chromium carbide coatings, ${ }^{12,13}$ alloys ${ }^{14}$ and composites, ${ }^{15}$ to date there have been few electrochemical studies on pure phase microparticles of chromium carbides.

In their electrochemical analyses of WC nanoparticles, both Roman-Leshkov et al. and Ledendecker et al. observed two oxidation peaks which they attributed to differences in the electrochemical activity of two different crystal planes of WC. The onset of WC oxidation in Ledendecker's work was at more positive potentials than those reported in the work of RomanLeshkov. Ledendecker postulated that this difference in potential to the larger particle size of the 
WC. These suppositions merit further exploration to determine the effects of crystal size on the electrochemical behavior and appearance of the voltammogram and to confirm the differences in electrochemical activity of different crystal planes. VMP of single crystals with in situ XRD could shed light on these matters.

Finally, in a broader scope, the author hopes to bring more attention to the voltammetry of microparticles as an electrochemical technique. Although VMP for the electrochemical analysis of solids was first reported in $1989,{ }^{16}$ use of this technique seems to have remained limited to two groups: the Scholz group and the Doménech group. Both groups have decisively established the versatility of this technique. Demonstrations of VMP's universal applicability include but are not limited to the phase identification and quantification of alloys, ${ }^{17}$ and metal salts, ${ }^{18}$ the in-situ monitoring of solid-state structural changes in oxides that are driven electrochemically ${ }^{19}$ and the immobilization of organic droplets and thin films for measuring the free energy of ion transfer across the interface of two immiscible liquids. ${ }^{20}$

Perhaps VMP has been overshadowed by the electrode and sample preparation of composite electrodes which are standard practice in battery research. Although these composite electrodes demonstrate clearly how these materials would perform as electrodes in batteries, VMP has several advantages which should not be overlooked. As Besenhard ${ }^{21}$ noted, analysis of micro and nanocrystals immobilized on an electrode that are free of a porous matrix will faster. Additionally, VMP analyses may better enable the elucidation of the electrochemical mechanisms inherent to the material as a pure phase, and allows for the observation of topotactic, solid-state phase transformation driven electrochemically via in situ techniques.

Investigation of structural changes that are instigated electrochemically are very important in the research of electrochemical devices. For example, it was once accepted in the lithium ion 
battery field that fast, reversible $\mathrm{Li}^{+}$intercalation required the that the electrode material consist of a single structural phase. However, it has recently been demonstrated that fast, reversible intercalation can proceed unhindered in solids that undergo simultaneous phase transitions. ${ }^{22}$ This has led to the pursuit of conversion electrodes, which are materials that change crystal structures while undergoing a solid-state redox reaction and lithiation/de-lithiation ${ }^{23}$. In this category specifically, metal halides are predicted to have high theoretical and volumetric capacities, however their realization as electrodes are hindered by their poor electronic conductivities. We envision that VMP may be a powerful technique for studying conversion electrodes because of the techniques demonstrated applicability for the analysis of insulating solids. 


\section{References}

1. Barber, W. A. \& Sloan, C. L. Solubility of Calcium Carbide in Fused Salt Systems. $J$. Phys. Chem. 65, 2026-2028 (1961).

2. Fechler, N., Fellinger, T. P. \& Antonietti, M. 'salt templating': A simple and sustainable pathway toward highly porous functional carbons from ionic liquids. Adv. Mater. 25, 7579 (2013).

3. Lipson, A. L. et al. Current Collector Corrosion in Ca-Ion Batteries. J. Electrochem. Soc. 162, A1574-A1578 (2015).

4. Shiga, T., Kondo, H., Kato, Y. \& Inoue, M. Insertion of Calcium Ion into Prussian Blue Analogue in Nonaqueous Solutions and Its Application to a Rechargeable Battery with Dual Carriers. J. Phys. Chem. C 119, 27946-27953 (2015).

5. Ponrouch, A. et al. Assessing Si-based anodes for Ca-ion batteries: Electrochemical decalciation of CaSi2. Electrochem. commun. 66, 75-78 (2016).

6. Lipson, A. L. et al. Calcium intercalation into layered fluorinated sodium iron phosphate. J. Power Sources 369, 133-137 (2017).

7. Cabello, M. et al. Advancing towards a veritable calcium-ion battery: CaCo2O4positive electrode material. Electrochem. commun. 67, 59-64 (2016).

8. Datta, D., Li, J. \& Shenoy, V. B. Defective graphene as a high-capacity anode material for Na- and Ca-ion batteries. ACS Appl. Mater. Interfaces 6, 1788-1795 (2014).

9. Iyere, P. E. Solid-State Formation of Calcium Carbide. (West Virginia University, 2013).

10. Göhl, D. et al. Electrochemical stability of hexagonal tungsten carbide in the potential window of fuel cells and water electrolyzers investigated in a half-cell configuration. Electrochim. Acta 270, 70-76 (2018).

11. Hunt, S. T., Kokumai, T. M., Zanchet, D. \& Román-Leshkov, Y. Alloying tungsten carbide nanoparticles with tantalum: Impact on electrochemical oxidation resistance and hydrogen evolution activity. J. Phys. Chem. C 119, 13691-13699 (2015).

12. Alar, Ž., Alar, V. \& Fabijanić, T. Electrochemical Corrosion Behavior of Near-Nano and Nanostructured WC-Co Cemented Carbides. Metals (Basel). 7, 69 (2017).

13. Wu, S., Fei, Y., Guo, B. \& Jing, L. Corrosion of Cr23C6coated Q235 steel in wet atmospheres containing Na2SO4at $750^{\circ}$ C. Corros. Sci. 100, 306-310 (2015).

14. Wan, W. et al. Effects of $\mathrm{Cr} 3 \mathrm{C} 2$ addition on the corrosion behavior of $\operatorname{Ti}(\mathrm{C}, \mathrm{N})$-based cermets. Int. J. Refract. Met. Hard Mater. 31, 179-186 (2012).

15. $\mathrm{Xu}, \mathrm{J}$. et al. Erosion-corrosion behavior of nano-particle-reinforced Ni matrix composite alloying layer by duplex surface treatment in aqueous slurry environment. Corros. Sci. 51, 1055-1068 (2009).

16. Scholz, F., Nitschke, L., Henrion, G. \& Damaschun, F. A technique to study the electrochemistry of minerals. Naturwissenschaften 76, 167-168 (1989). 
17. Doménech-Carbó, A., Labuda, J. \& Scholz, F. Electroanalytical chemistry for the analysis of solids: Characterization and classification (IUPAC Technical Report)*. Pure Appl. Chem 85, 609-631 (2013).

18. Bond, A. M. \& Scholz, F. Electrochemical, Thermodynamic, and Mechanistic Data Derived from Voltammetric Studies on Insoluble Metallocenes, Mercury Halide and Sulfide Compounds, Mixed Silver Halide Crystals, and Other Metal Complexes following Their Mechanical Transfer to a Graphi. Langmuir 7, 3197-3204 (1991).

19. Meyer, B., Ziemer, B. \& Scholz, F. In situ X-ray diffraction study of the electrochemical reduction of tetragonal lead oxide and orthorhombic $\mathrm{Pb}(\mathrm{OH}) \mathrm{Cl}$ mechanically immobilized on a graphite electrode. J. Electroanal. Chem. 392, 79-83 (1995).

20. Mirčeski, V., Quentel, F., L’Her, M. \& Scholz, F. Studying the coupled electron-ion transfer reaction at a thin film-modified electrode by means of square-wave voltammetry. J. Electroanal. Chem. 586, 86-97 (2006).

21. Fiedler, D. A., Besenhard, J. O. \& Fooken, M. H. Rapid electrochemical characterization of battery electrode materials in the solid state. J. Power Sources 69, 157-160 (1997).

22. Arico, A. S., Bruce, P., Scrosati, B., Tarascon, J.-M. \& Schalkwijk, W. van. Nanostructured Materials for Advanced Energy Conversion and Storage Devices. Nat. Mater. 4, 366-377 (2005).

23. Nitta, N., Wu, F., Lee, J. T. \& Yushin, G. Li-ion battery materials: Present and future. Mater. Today 18, 252-264 (2015). 


\section{Appendix A. Analysis of Calcium Carbide and Aluminum Carbide and Their Impurities}

Calcium carbide is most commonly produced in an electric arc furnace from a mixture of lime, a source of $\mathrm{CaO}$, and coke, a source of elemental carbon. This reaction (see below) is carried out at approximately $2200^{\circ} \mathrm{C}$.

$$
\mathrm{CaO}+3 \mathrm{C} \rightarrow \mathrm{CaC}_{2}+\mathrm{CO}
$$

R 0.1

Calcium carbide for industrial use ranges from 70-85\% purity. Typical impurities leftover from lime feedstock include but are not limited to $\mathrm{CaCO}_{3}, \mathrm{Na}_{2} \mathrm{O}, \mathrm{MgO}, \mathrm{P}_{2} \mathrm{O}_{5}, \mathrm{SiO}_{2}, \mathrm{SO}_{3}, \mathrm{Al}_{2} \mathrm{O}_{3}, \mathrm{Fe}_{2} \mathrm{O}_{3}$, and $\mathrm{K}_{2} \mathrm{O}^{1}$. Impurities from the bituminous coal used to make the coke feed stock may include arsenate and pyrite minerals, iron oxides and magnesium and aluminum oxides and silicates ${ }^{2-5}$.

The most common uses for calcium carbide are the production of acetylene and calcium cyanimide, which is a fertilizer. These processes do not require high purity starting material, so it is very difficult to find "reagent grade" quality calcium carbide, if not impossible. In the pastFor example, we procured calcium carbide from Fisher Scientific that was advertised as $97+\%$ pure based on a water titration assay but not a trace metals analysis. Upon purchase and inspection, large pieces of what appeared to be metallic iron could be seen poking out from the surface of some of the pieces of carbide.

This appendix contains the results the elemental analysis and characterization of the impurities in calcium carbide used in this research. Analysis of these impurities is necessary for two reasons. The first reason is impurities that are electrochemically active must be identified because they may produce electrochemical signals, which interfere with the analysis of the calcium carbide. Secondly, one of the impurities in calcium carbide is elemental carbon from unreacted coke (R 7.1). Characterization of this carbon impurity is important so that we can differentiate it from the carbon produced by the oxidation of calcium carbide in molten salt and solution state 
syntheses. Additionally, the carbon impurity may have an influence on the reaction pathway, nucleation and growth of the carbon product. Therefore, thorough characterization of the composition and morphology of the residual elemental carbon is necessary.

\section{A.1 Methodology for Analysis of Calcium Carbide Impurities}

Three pieces of calcium carbide procured from Carbide Industries, LLC. Each piece was loaded into glass jars with glass lids that met at frosted joints in a glove box under argon atmosphere. The mass of the glass jars were recorded on an analytical balance before and after the addition of carbide. The calcium carbide pieces were hydrolyzed to completion with $6 \mathrm{M}$ hydrochloric acid (R 7.2).

$$
\mathrm{CaC}_{2}+2 \mathrm{HCl} \rightarrow \mathrm{CaCl}_{2}+\mathrm{H}_{2} \mathrm{C}_{2}
$$

\section{R 0.2}

Completion of reaction was assumed when the evolution of acetylene ceased and the solid carbide leaving behind small amounts of gray to black residue. This black residue was assumed to be the elemental carbon contaminant. Silver membrane filters were weighed and used to filter the carbide and acid reactions. The carbon reside, which collected on the silver membrane filters, was washed with distilled water and methanol several times. The carbon residue on the silver filter was allowed a week to dry and the weight of the carbon residue was obtained from the difference. The filtrate was collected and diluted using volumetric glassware until a $\mathrm{pH}$ of approximately 2.0 was obtained. The filtrate was then taken to the analytical lab in the National Research Center for Coal and Energy (NRCCE). The filtrate was tested for the metal cations that would be the most likely impurities in calcium carbide. This was accomplished with inductively coupled plasma optical emission spectroscopy (ICP-OES). The carbon contaminant collected on the silver membrane filter was analyzed using Raman Spectroscopy and scanning electron microscopy (SEM). 


\section{A.2 ICP-OES Results and Analysis}

Table 7.1 shows the mass percent of metal cations calculated from ICP-OES analysis of the calcium carbide after complete hydrolysis. The carbon mass \% was determined by weighing the solid residue remaining after hydrolysis. Treatment with hydrochloric acid is sufficient to remove most metals, salts and other mineral impurities via reaction and dissolution. These impurities were separated into the filtrate and detected by ICP-OES. Therefore, until further analysis it was assumed that composition of the remaining solid residue was pure carbon.

\begin{tabular}{lllllll}
\hline & $\boldsymbol{A l} \boldsymbol{\%}$ & $\boldsymbol{C a} \%$ & $\boldsymbol{F e} \%$ & $\boldsymbol{M g} \%$ & $\boldsymbol{M n} \boldsymbol{\%}$ & $\boldsymbol{C} \%$ \\
\hline Sample 1 & 0.662 & 63.2 & 0.262 & 0.085 & 0.023 & 2.13 \\
Sample 2 & 0.345 & 48.1 & 0.058 & 0.016 & $<0.002$ & 1.02 \\
Sample 3 & 0.441 & 70.3 & 0.033 & 0.033 & $<0.002$ & 0.504 \\
Average & 0.483 & 60.6 & 0.118 & 0.0445 & 0.0089 & 1.22 \\
\hline
\end{tabular}

Table A.1 . Mass percent of elements detected after hydrolysis via ICP-OES elemental analysis. Carbon amount determined by weighing; however, analysis of carbon residue by SEM/EDS indicates the residue is not pure carbon.

\section{A.3 SEM and EDS Analysis of Carbon Residue}

A scanning electron microscope (SEM) was used to obtain images of the carbon contaminant from sample 4 and 5 in order to determine its dominant morphology, which we believe should be amorphous. The energy dispersive x-ray spectroscopy (EDS) capability was not available at the time. Samples were prepared by scraping carbon off silver membrane filters and pressing double sided copper tape to SEM pin and then onto silver filter. It is possible this could have induced changes in the morphology of the samples and introduce some fibers from the filter. However, no fibers were seen during these analyses. $5.0 \mathrm{kV}$ scanning voltage was used to reduce the possibility of damaging the samples. All samples had issues with charging to varying degrees. This could be due to the amorphous nature of the carbon and/or the presence of residual salts and mineral impurities. Therefore, samples were sputter coated for 120 seconds with Au/Pd resulting in a coating of approximately $15 \mathrm{~nm}$. EDS will yield more definitive information. 
Figure 7.1 show SEM images of the carbon contaminant from all three samples. The Morphology of both samples looked mostly amorphous with little long-range order on a 20-30 micron scale. The images on a 5 and 10 micron scale also show what appears to be mostly disordered carbon as well. However, the some images showed more crystalline features Figures $7.1 \mathrm{a})$ and b). These features include flat faces and sharp edges that could have graphitic structure. Figure $7.1 \mathrm{c}$ ) shows a globular crystal with a rough surface morphology. This area of the sample in particular experienced heavy charging even after sputter coating. Figure $7.1 \mathrm{~d}$ ) shows another interesting morphology - a flattened sphere with a smooth surface.

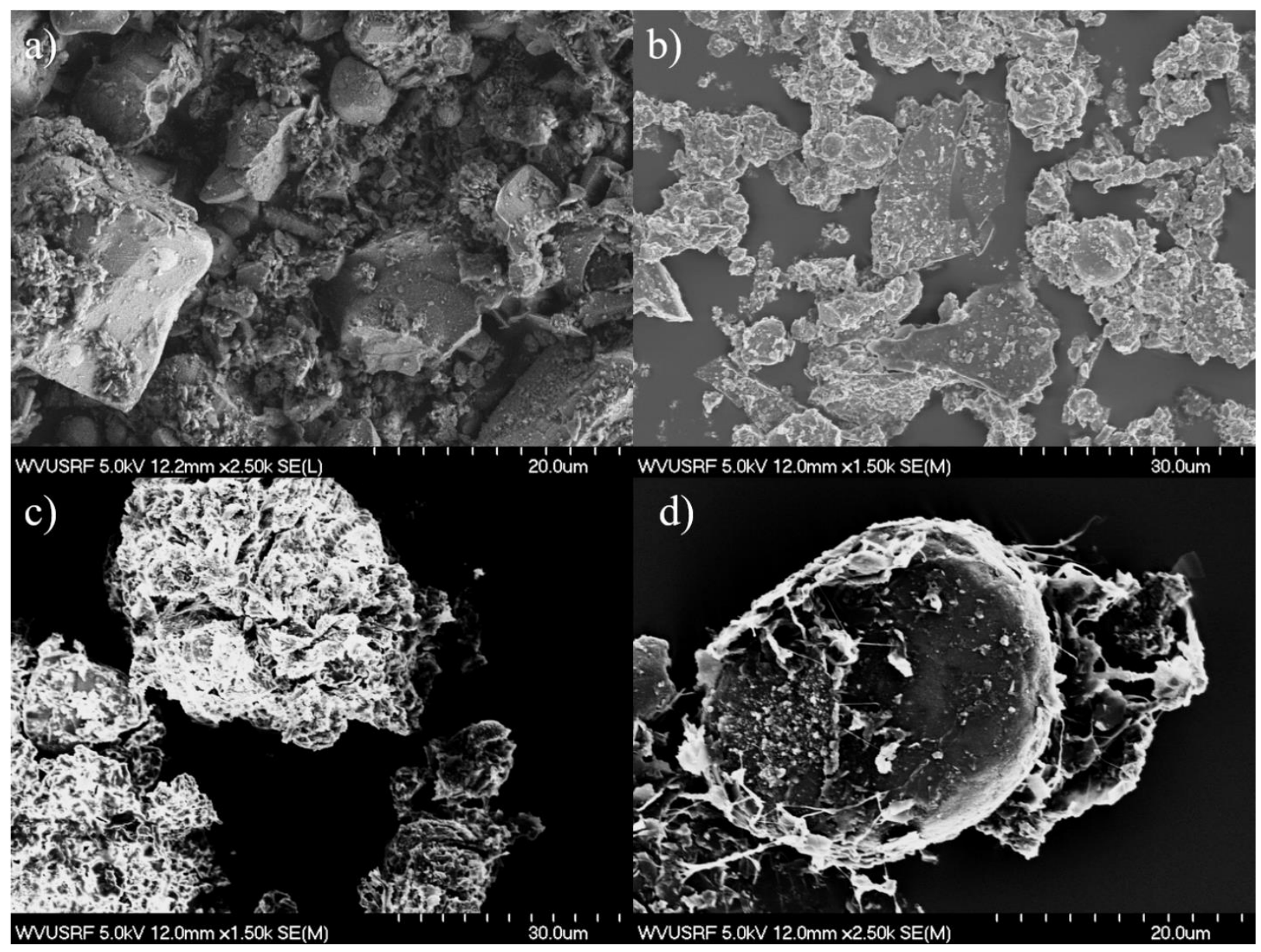

Figure A.1 SEM images of different morphologies observed in the samples of carbon residue remaining after hydrolysis of calcium carbide. Figures a) and b) show features which appear more 
crystalline with flat faces, straight edges and sharp angles. Figures c) and d) show examples of irregular morphologies such as the smooth, spherical shape in d) and the rough globular pieces in c).

The elemental composition of these morphologies was determined by EDS analysis and mapping on specific areas in Figures 7.1 b), c) and d). Figure 7.3 b) shows the EDS spectrum of the crystal in the middle of the SEM image in Figure 7.1 b). Table 7.2 lists the elemental composition of this crystal. Although the crystal has a flat face and sharp edges, only $44.14 \%$ of this crystal is carbon. The remaining composition is $24.00 \%$ silicon, $10.58 \%$ aluminum, $8.42 \%$ oxygen and $7.26 \%$ nitrogen. The gold is from the sputter-coated layer.
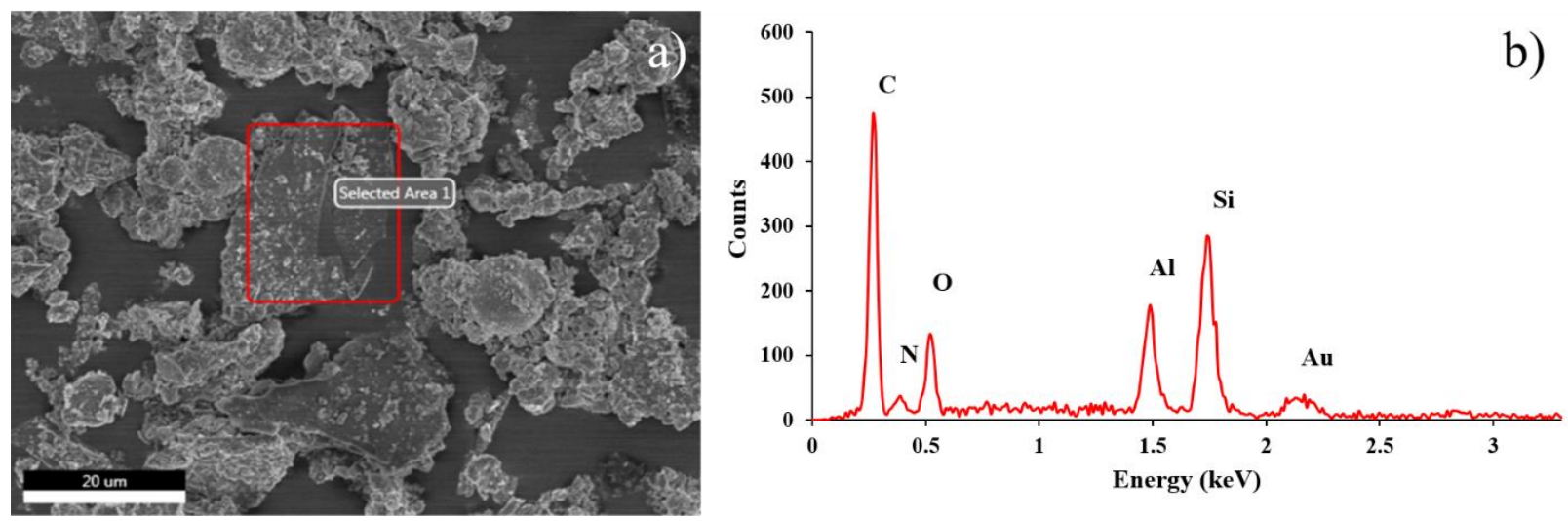

Figure A.2 a) selected area of crystal shown in previous SEM image with b) EDS spectrum of selected area.

\begin{tabular}{lll}
\hline Element & Weight \% & Atomic \% \\
\hline C K & 21.38 & 44.14 \\
N K & 4.10 & 7.26 \\
O K & 5.43 & 8.42 \\
Al K & 11.51 & 10.58 \\
Si K & 27.18 & 24.00 \\
Au M & 13.77 & 1.73 \\
\hline
\end{tabular}

Table A.2 Elemental composition selected area in Figure 7.2 a)

EDS analysis of the spherical particles with rough, heterogeneous surface had even lower carbon content at $34.63 \%$ and higher oxygen $(30.24 \%)$ and silicon content (28.97\%) indicating that these 
spheres may be a mixture of amorphous carbon and silicate minerals. Full elemental composition of particle in Figure 7.3 a) is presented in Table 7.3.
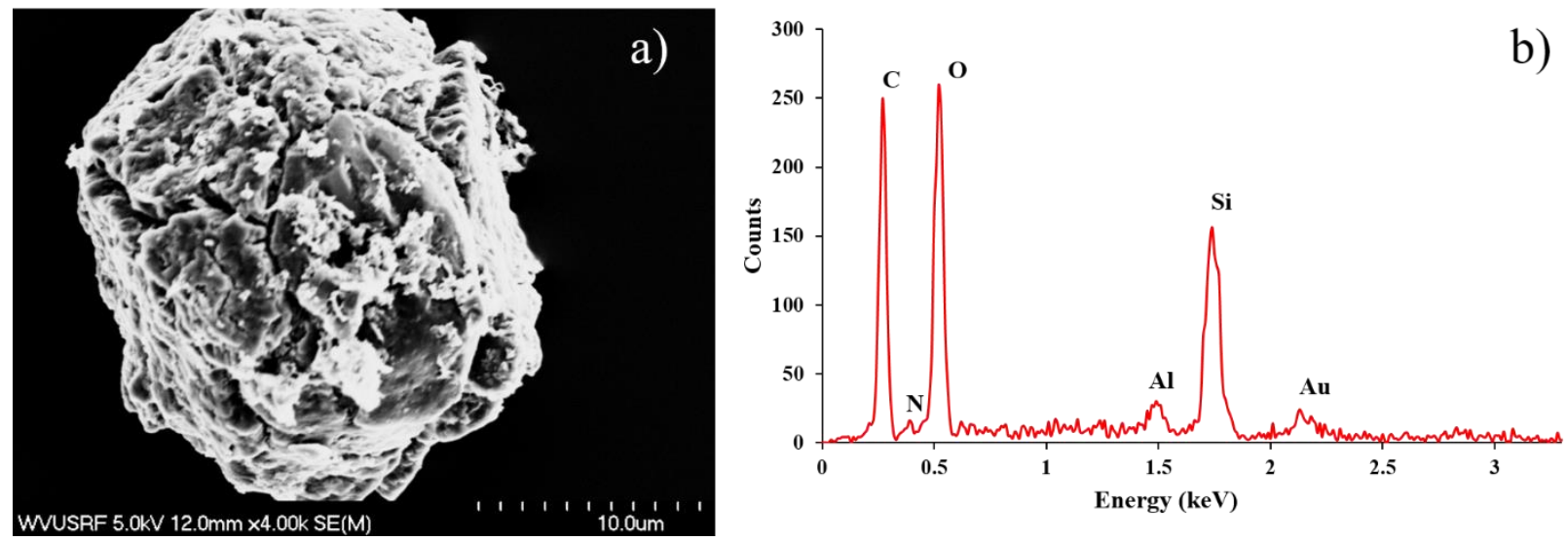

Figure A.3 a) SEM image of one of the particles shown in figure 7.1 c) showing more detailed morphology and b) EDS spectrum of particle shown in a).

\begin{tabular}{lll}
\hline Element & Wt \% & Atomic \% \\
\hline C K & 19.94 & 34.63 \\
N K & 1.70 & 2.54 \\
O K & 23.19 & 30.24 \\
Al K & 2.86 & 2.21 \\
Si K & 39.01 & 28.97 \\
Au M & 13.31 & 1.41 \\
\hline
\end{tabular}

Table A.3 Elemental composition selected area in Figure 7.3 a).

Figure 7.4 a) shows a particle with particle morphology differing than those discussed previously.

This particle is round and has a smooth surface. Interestingly, the EDS spectrum (Figure $7.4 \mathrm{~b}$ )) for this particle had the highest carbon content at $85.95 \%$. Table 7.4 presents total elemental composition of material in SEM image in Figure 7.4 a). 

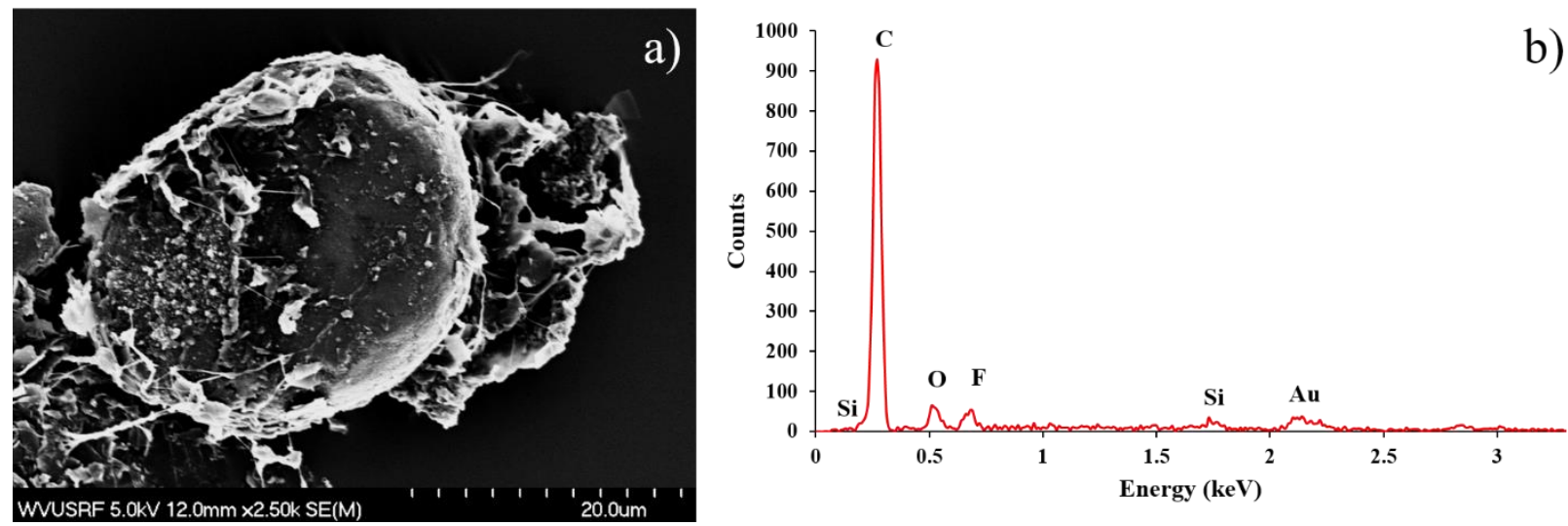

Figure A.4 a) SEM image of one of the particles shown in figure 7.1 d) showing more detailed morphology and b) EDS spectrum of particle shown in a).

\begin{tabular}{ccc}
\hline Element & Weight \% & Atomic \% \\
\hline C K & 61.15 & 85.95 \\
O K & 5.78 & 6.1 \\
F K & 3.73 & 3.32 \\
Si K & 4.11 & 2.47 \\
Au M & 25.23 & 2.16 \\
\hline
\end{tabular}

Table A.4 Elemental composition selected are in Figure 7.4 a).

\section{A.4 Raman and Optical Microscopy Analysis of Carbon Residue}

The carbon residue isolated from the hydrolysis in all three carbide samples was analyzed by micro-Raman spectroscopy. Spectra were collected through the 50x objective on the microscope at $1 \%$ laser power $(532 \mathrm{~nm})$ in order to reduce the possibility of interference from luminescence. Five accumulations for each spectrum were collected to increase the signal to noise ratio of the Raman response. Errant bands due to hot pixels or cosmic rays were removed via the spectra software, and the intensity was normalized on the y-axis. The spectra did not receive any other data processing. Spectra and optical microscope images were collected from four different areas of each sample in an effort to present data that is representative of the carbon residue.

The optical images (Figure 7.5) show that the morphology of the surface appeared rough with irregular surface heights making it difficult to focus the microscope. There were areas that 
were reflective, but there were also dark areas that the microscope was unable to bring into focus. It is likely that these dark, unfocused areas are amorphous material, e.g. the left image. Some areas of the sample had crystalline specimens on which the microscope could be focused. These reflective areas looked more crystalline with straight edges and flat, textured faces (middle and right image in Figure 7.5).
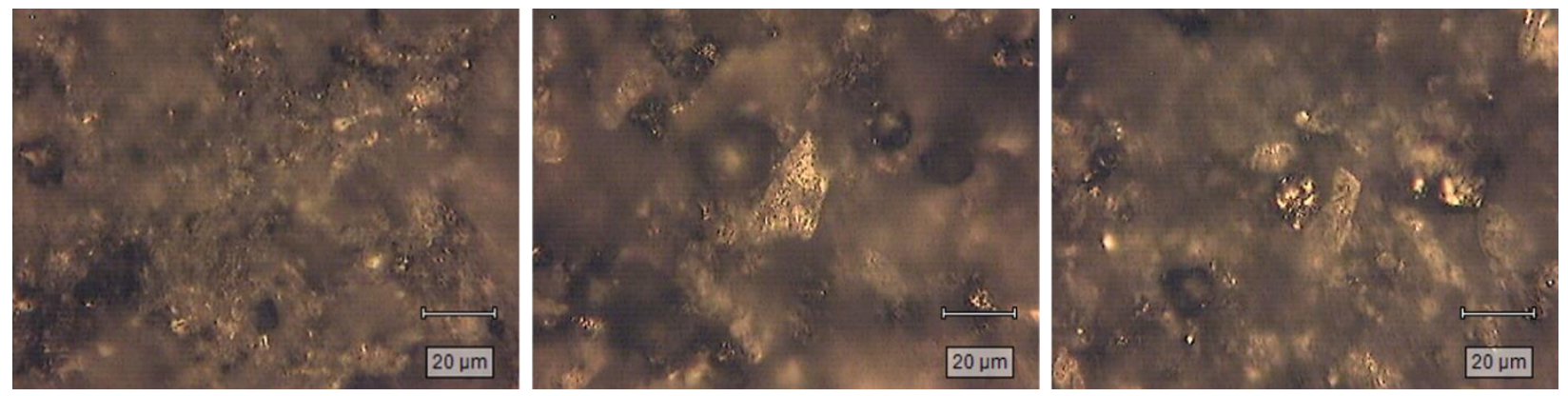

Figure A.5 Optical images of carbon residue remaining after hydrolysis of calcium carbide. Images were captured through the Raman microscope on the 50x objective.

When crystalline specimens were present in the viewing field of the microscope, spectra were collected by focused on these crystalline pieces because it was easier to focus the laser on something that was flat and reflective. The spectra of each carbon sample are shown below in Figures 7.6 a), b) and c). Many of the spectra had broad backgrounds with no identifiable peaks. The few sites that gave some discernable peaks, again appeared around the wavenumbers characteristic of carbon materials, $\sim 1390$ and $\sim 1600 \mathrm{~cm}-1$, but were broad and low in intensity compared to the background. Figure 7.6 d) displays these features in more detail. The broad and mostly featureless spectra seem to imply that the elemental carbon is mostly amorphous, and the peaks that can be resolved suggest the residue is amorphous carbon from unreacted coke in the calcium carbide production process. Literature supports this interpretation showing a correlation between order in carbon materials and the broadening and diminished peak intensity in Raman $\operatorname{spectra}^{6,7}$. 

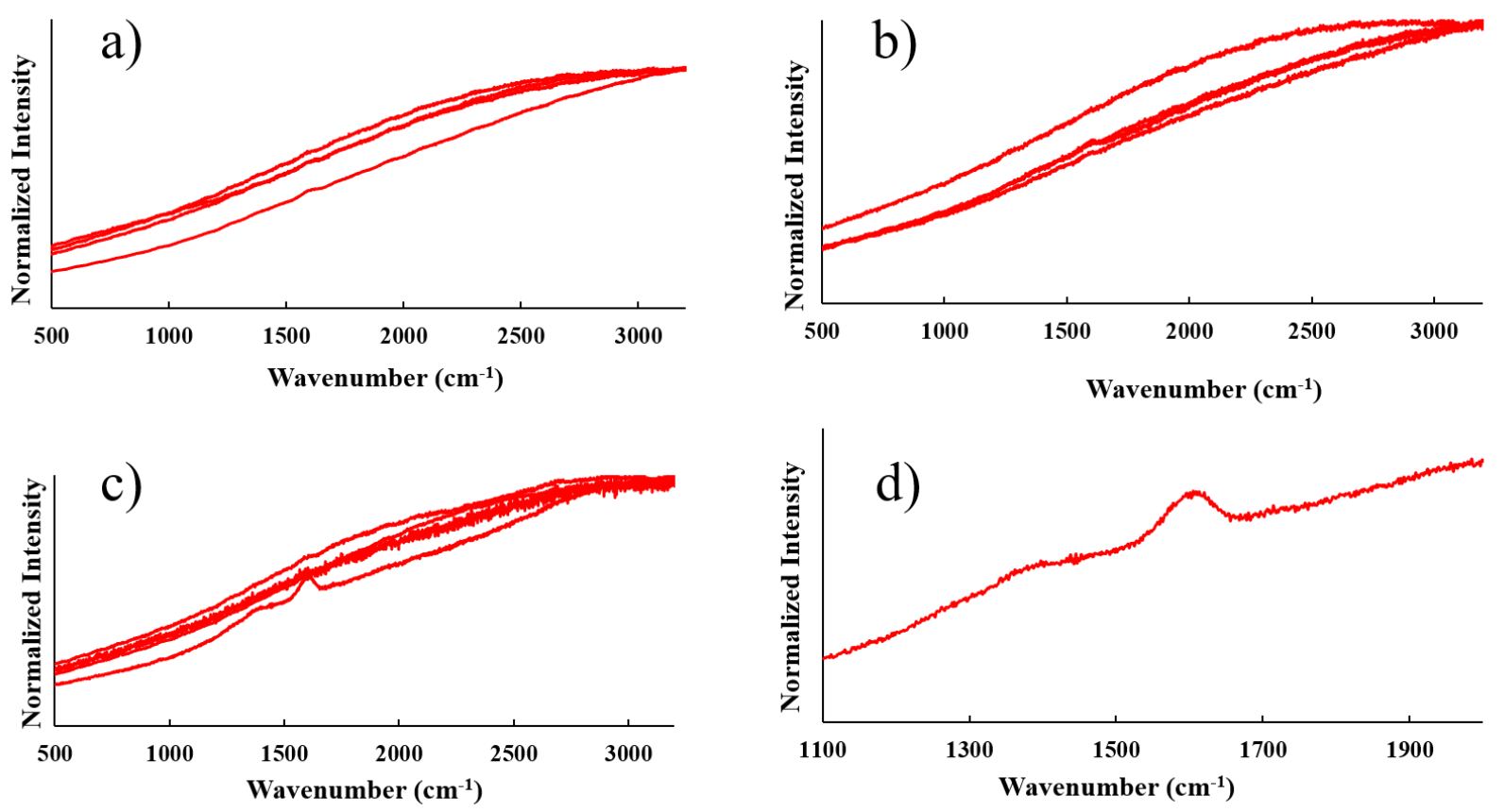

Figure A.6 Raman spectra from four different areas on residue remaining after calcium carbide hydrolysis for a) sample 1, b) sample 2 and c) sample 3 and d) enlargement of Raman bands from spectra in c).

Figure 7.6 d) show Raman bands in one of the spectra in Figure 7.6 c) in to the 1100-2000 $\mathrm{cm}^{-1}$ range. Broad, low intensity peaks can be seen around 1390 and $1600 \mathrm{~cm}^{-1}$ a few of the samples. These coalesced peaks are common to amorphous carbon materials and are reminiscent in appearance of coal and cokes ${ }^{8,9}$ and glassy carbon ${ }^{10}$. However, these bands in the Raman spectra of the carbon residue left over after carbide hydrolysis are much lower in intensity if they appear at all. Niwase has shown the evolution of Raman spectra amorphization of graphite by ionbombardment. The spectrum for graphite becomes broad and featureless with increasing disorder eventually becoming a broad background with no discernable peaks ${ }^{11}$. This supports the hypothesis that the majority of the carbon material contaminating the calcium carbide is disordered and amorphous. However, follow up Raman analyses with lasers of different wavelengths would definitively eliminate the possibility of luminescence interference and confirm the interpretation of these results ${ }^{12,13}$. 


\section{A.5 SEM Analysis of Aluminum Carbide}

Aluminum carbide can be prepared by the reduction of aluminum oxide by carbon reducing agents at temperatures $1400-1900^{\circ} \mathrm{C}$. It can also be obtained by heating aluminum metal with calcium carbide, reducing aluminum oxide with calcium carbide in an electric arc furnace and reducing sodium aluminate with carbon at $2000^{\circ} \mathrm{C}$. Best results come from using graphite as the carbonaceous reducing agent over cokes and coals ${ }^{14}$. This may be why aluminum carbide is available in much higher purity than calcium carbide.

Union Carbide filed a patent in 1957 for the production of aluminum carbide at much lower temperatures. This was done using a catalyst fluoride salts and heating powdered aluminum metal and carbon or lamp black to $700^{\circ} \mathrm{C}^{15}$. The technique used to produce the aluminum carbide we have procured is proprietary information. However, it is likely that it is a method similar to that described in Union Carbide's patent. The elemental composition of aluminum carbide studied in this research, provided by Alfa Aesar the manufacturer, is presented in the Table 7.5 below.

\begin{tabular}{ll}
\hline Element & Atomic \% \\
\hline Carbon & 24.6 \\
Aluminum & 72.0 \\
Iron & 0.1 \\
Oxygen & 0.9 \\
Nitrogen & 1.4 \\
\hline
\end{tabular}

Table A.5 Elemental Composition According to Alfa Aesar's Certificate of Analysis

A sample of aluminum carbide was prepared by pressing an SEM stub with double sided carbon tape into aluminum carbide powder. The stub was quickly inserted into the SEM in order to minimize reaction with ambient moisture. The sample experinced minimal charging with no sputter coating. Figure a) and b) present SEM images of the aluminum carbide powder. The particle size of the aluminum carbide is $\sim 325$ mesh which equates to $\sim 44 \mu \mathrm{m}$. However, the images show that there is a range of particle size, with many crystals less than 44 microns. The morphology 
of the aluminum carbide is crytalline, rhombohedral as expected. Quantitation from EDS spectra (Figure c)) of the aluminum carbide showed an elemental composition of $56.41 \%$ carbon, $33.67 \%$ aluminum, and $9.92 \%$ oxygen. The increased oxygen content indicates the carbide has undergone some hydrolysis due to exporsure to ambient moisture. The extremely high carbon content (higher than $24.6 \%$ in the certificate of analysis, Table 7.5 ) is likely due to the presence of the carbon tape on which the carbide is mounted. Nevertheless, these analyses confirm the high purity of the aluminum carbide.

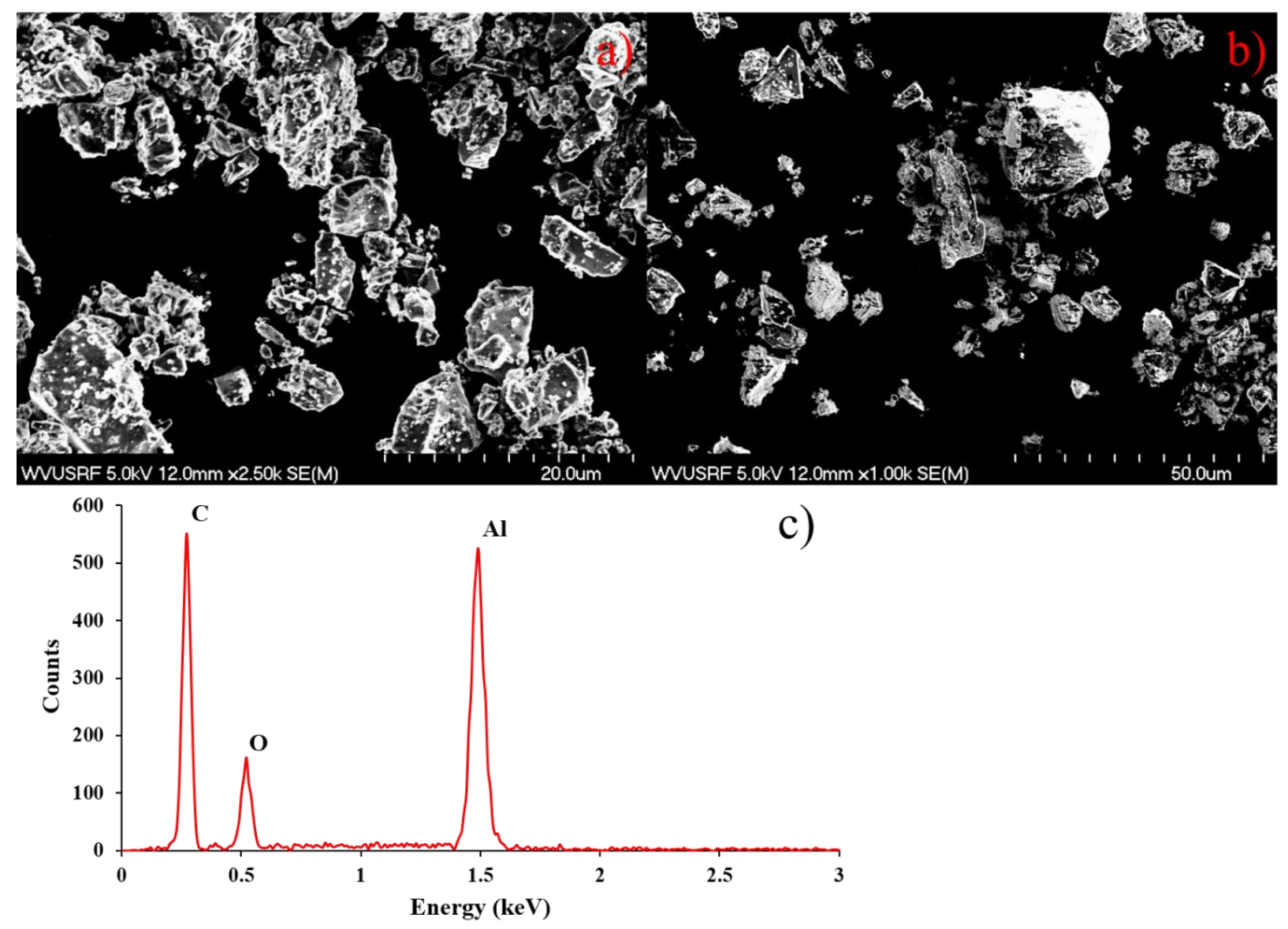

Table A.6 EDS spectrum of aluminum carbide powder

\begin{tabular}{lll}
\hline Element & Weight \% & Atomic \% \\
\hline C K & 38.84 & 56.41 \\
O K & 9.1 & 9.92 \\
Al K & 52.06 & 33.67 \\
\hline
\end{tabular}

Table A.7 Elemental Composition Determined via EDS 


\section{References}

(1) Tran, H. In Tappi Craft Recovery Short Course; St. Petersburg, Florida, 2008.

(2) Yang, H.; Cao, J.; Wang, Z.; Chen, H.; Gong, X. Int. J. Miner. Process. 2014, 130, 66-73.

(3) Kolker, A.; Palmer, C. A.; Bragg, L. J.; Bunnell, J. E. Arsenic in Coal; 2006; Vol. 3055.

(4) Thomas, L. Coal Geology, 2nd ed.; Wiley-Blackwell: Chichester [u.a.], 2002.

(5) Cameron, W. In Kirk-Othmer Encyclopedia of Chemical Technology; Seidel, A., Ed.; Wiley, 2010; pp 1-55.

(6) Cuesta, A.; Dhamelincourt, P.; Laureyns, J.; Martinez-Alonso, A.; Tascon, J. M. D. Carbon N. Y. 1994, 32 (8), 1523-1532.

(7) Ferrari, A. C.; Robertson, J. Phys. Rev. B 2000, 61 (20), 14095-14107.

(8) Tsu, R.; Gonzalez, J. H.; Hernandes, I. C.; Luengo, C. A. Solid State Commun. 1977, 24 (12), 809-812.

(9) Green, P. D.; Johnson, C. A.; Thomas, K. M. Fuel 1983.

(10) Nathan, M. I. J. Appl. Phys. 1974, 45 (5), 2370.

(11) Niwase, K. Int. J. Spectrosc. 2012, 2012.

(12) Yvon, H. J. Fluoresc. 01 2014, 2-3.

(13) Zhou, P. 2015, 1 (855), 6.

(14) Kosolapova, T. J. Carbides; Plenum Pr: New York, 1971.

(15) Wright, S. G.; Fowler, R. M. Method for the Production of Aluminum Carbide. 2942951, 1960 . 


\section{Appendix B. Experiments to Establish Working Potential Window of Each System}

\section{B.1 Working Potential Window of PIGE in $0.5 \mathrm{M} \mathrm{H}_{2} \mathrm{SO}_{4}$}

The following methodology, adapted from the work of Jaramillo et al ${ }^{1}$, was used to establish the inert potential window for the PIGE $0.5 \mathrm{M} \mathrm{H}_{2} \mathrm{SO}_{4}$ system prior to VMP experiments. The open circuit potential (OCP) was determined by measuring the potential at zero current. The OCP of an unmodified PIGE or GCE usually stabilized within 5 minutes. Progressive potential scans were applied in increasing potential increments of $100 \mathrm{mV}$ from the OCP at $25 \mathrm{mV} / \mathrm{s}$. The anodic and cathodic potential limits were increased until a current density of $2 \mathrm{~mA} / \mathrm{cm}^{2}$ or $-2 \mathrm{~mA} / \mathrm{V}$ was achieved respectively. Jaramillo et al. consider current density of $50 \mu \mathrm{A} / \mathrm{cm}^{2}$ above the baseline capacitance as the limit at which the system is no longer electrochemically inactive. This electrochemical inactivity refers to whether there are any redox features or changes in background current.

Figure 8.1 shows $\mathrm{CV}$ curves generated using the described methodology in $0.5 \mathrm{M} \mathrm{H}_{2} \mathrm{SO}_{4}$ electrolyte with a PIGE WE. Oxidative current did not significantly increase until potentials more positive than $1.532 \mathrm{~V}$. The sweep over the largest potential range (red curve in Figure 8.1) shows large anodic current at the positive limit corresponding to the oxidation of the electrolyte or oxygen evolution reaction (OER, R 8.1).

$$
2 \mathrm{H}_{2} \mathrm{O} \rightarrow 4 e^{-}+4 \mathrm{H}^{+}+\mathrm{O}_{2}
$$

There is also a small reductive feature that may be due to the reduction of the evolved oxygen. 


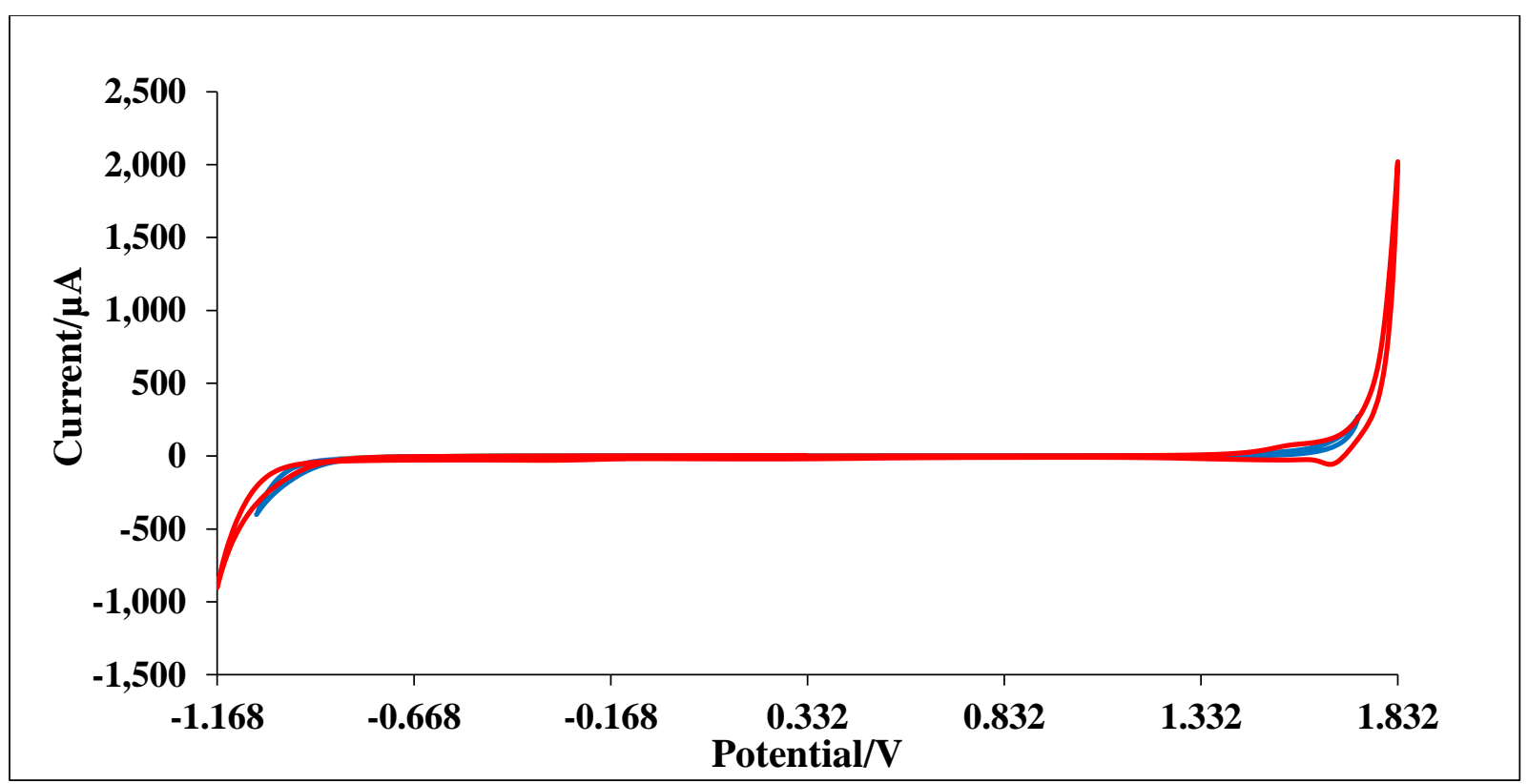

Figure B.1 Progressive CV scans at PIGE in $0.5 \mathrm{M} \mathrm{H}_{2} \mathrm{SO}_{4}$ at $25 \mathrm{mV} / \mathrm{s}$, initiated from the OCP vs. $\mathrm{Ag} / \mathrm{AgCl} 3 \mathrm{M} \mathrm{NaCl}$ reference electrode.

Cathodic current due to the hydrogen evolution reaction (HER, R 8.2) caused by the breakdown of the electrolyte does not dramatically increase until $-0.778 \mathrm{~V}$.

$$
2 \mathrm{H}_{2} \mathrm{O}+2 e^{-} \rightarrow 2 \mathrm{OH}^{-}+\mathrm{H}_{2}
$$

However, a reductive shoulder appears when potentials are scanned past $-0.568 \mathrm{~V}$ (Figure 8.2). This reductive shoulder may be due to the reduction of oxide groups on the surface of the graphite or proton intercalation. This reductive shoulder has also been observed at highly oriented pyrolytic graphite (HOPG) electrodes sulfuric acid ${ }^{1}$. The reductive shoulder was always present in blank CVs scanned to a cathodic limit of $-0.778 \mathrm{~V}$ in $\mathrm{H}_{2} \mathrm{SO}_{4}$ electrolytes. 


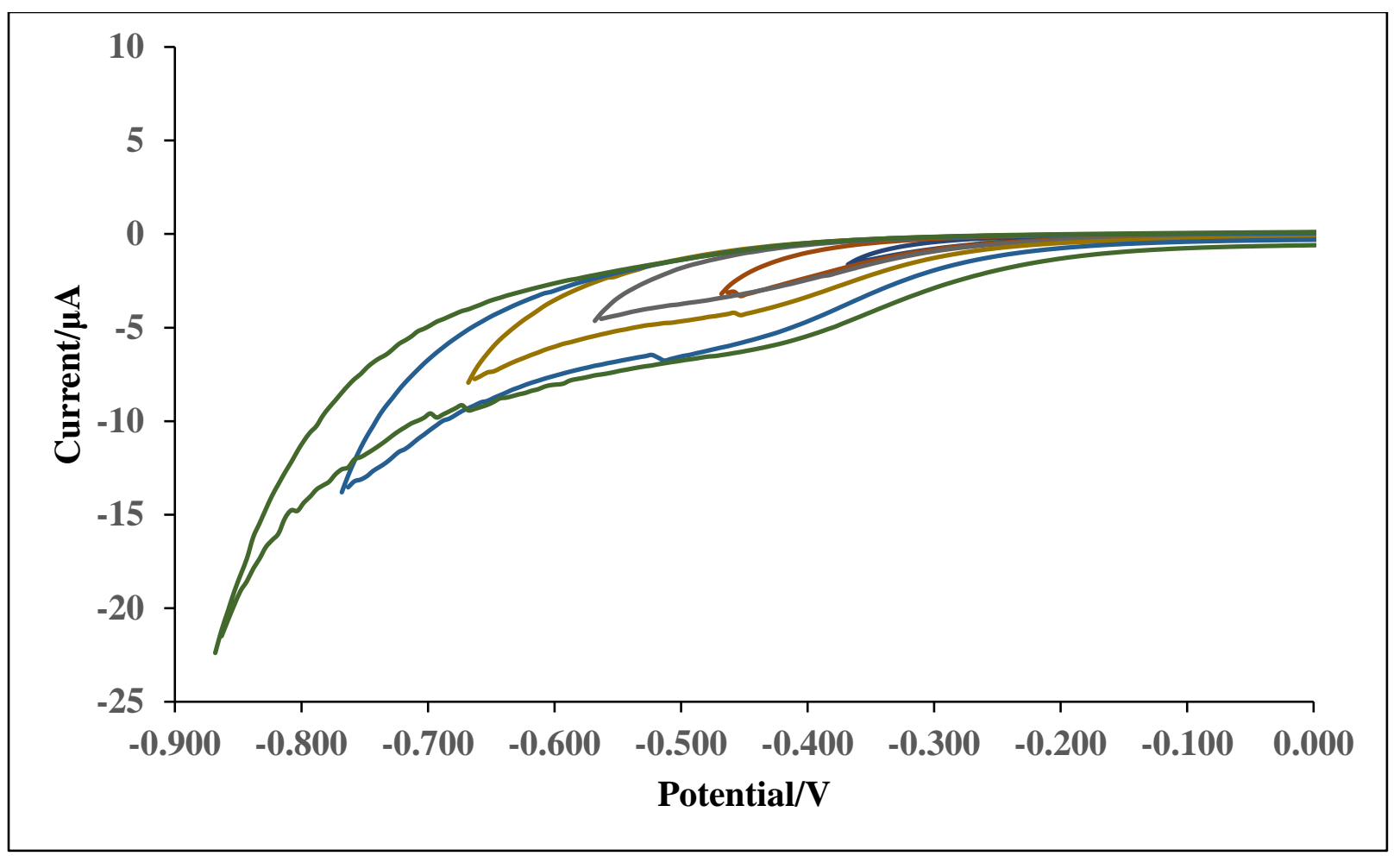

Figure B.2 Enlargment of CVs in cathodic region in Figure 8.1 showing the evolution of the reductive shoulder.

Based on the results of these experiments, the potential window chosen for the analysis of covalent and transition metal carbides in $0.5 \mathrm{M} \mathrm{H}_{2} \mathrm{SO}_{4}$ at a PIGE WE was $-0.768 \mathrm{~V}$ to $+1.528 \mathrm{~V}$.

\section{B2. Working Potential Window of GCE in $0.1 \mathrm{M} \mathrm{KPF} / \mathrm{MeCN}$}

The working potential window of the glassy carbon electrode (GCE) in $0.1 \mathrm{M} \mathrm{KPF}_{6} / \mathrm{MeCN}$ was determined by a similar method. The open circuit potential (OCP) of the system was measured at zero current. Progressive CV scans were initiated from the OCP in the positive and negative directions in increments of $0.10 \mathrm{~V}$ at a scan rate of $25 \mathrm{mV} / \mathrm{s}$. The general electrochemical behavior of this system was reproducible. Figure 8.3 displays progressive CV scans over the potential range from -1.951 to $1.549 \mathrm{~V}$ that is representative of the electrochemical features typically observed in this system.

A reduction peak first appears around $-0.8 \mathrm{~V}$ which is followed by an oxidation peak that decreases and eventually disappears upon subsequent scans. However, the reduction peak 
decreases but remains stable over 5 cycles. A small peak which may be an oxidation peak appears around $+1.3 \mathrm{~V}$.

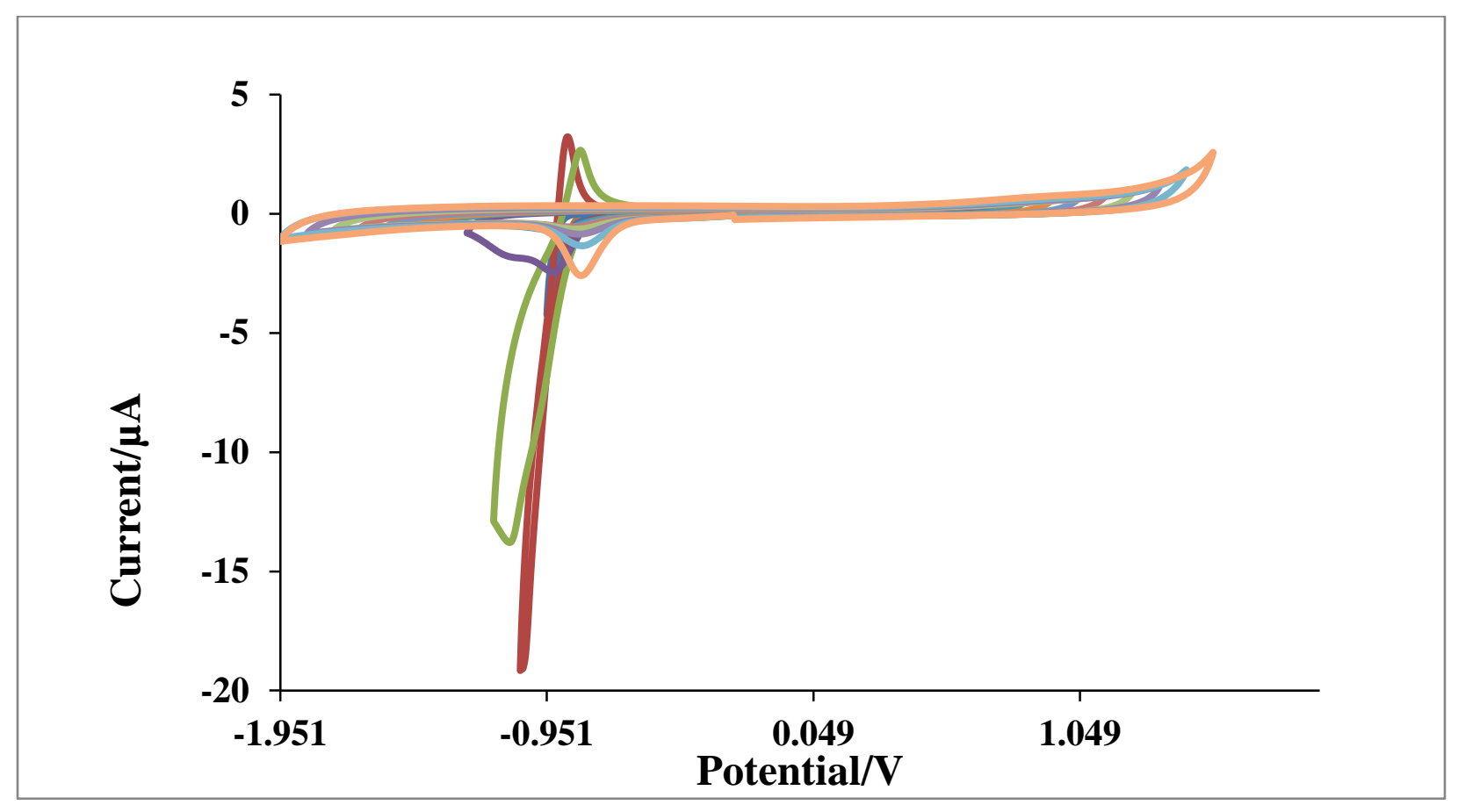

Figure B.3 Progressive CV scans at a GCE in 0.1M KPF $/ \mathrm{MeCN}$ at $25 \mathrm{mV} / \mathrm{s}$, initiated from the OCP $=-0.251 \mathrm{~V}$ vs. a Pt pseudo reference electrode.

It is also important to note that in voltammograms with scan rates of $10 \mathrm{mV} / \mathrm{s}$ the oxidation peak appeared to split into two peaks (Figure 8.4). These two oxidation peaks decreased to background levels on subsequent scan with only the decreased reduction peak remaining, similar to CV scans performed at $100 \mathrm{mV} / \mathrm{s}$ and $25 \mathrm{mV} / \mathrm{s}$. 


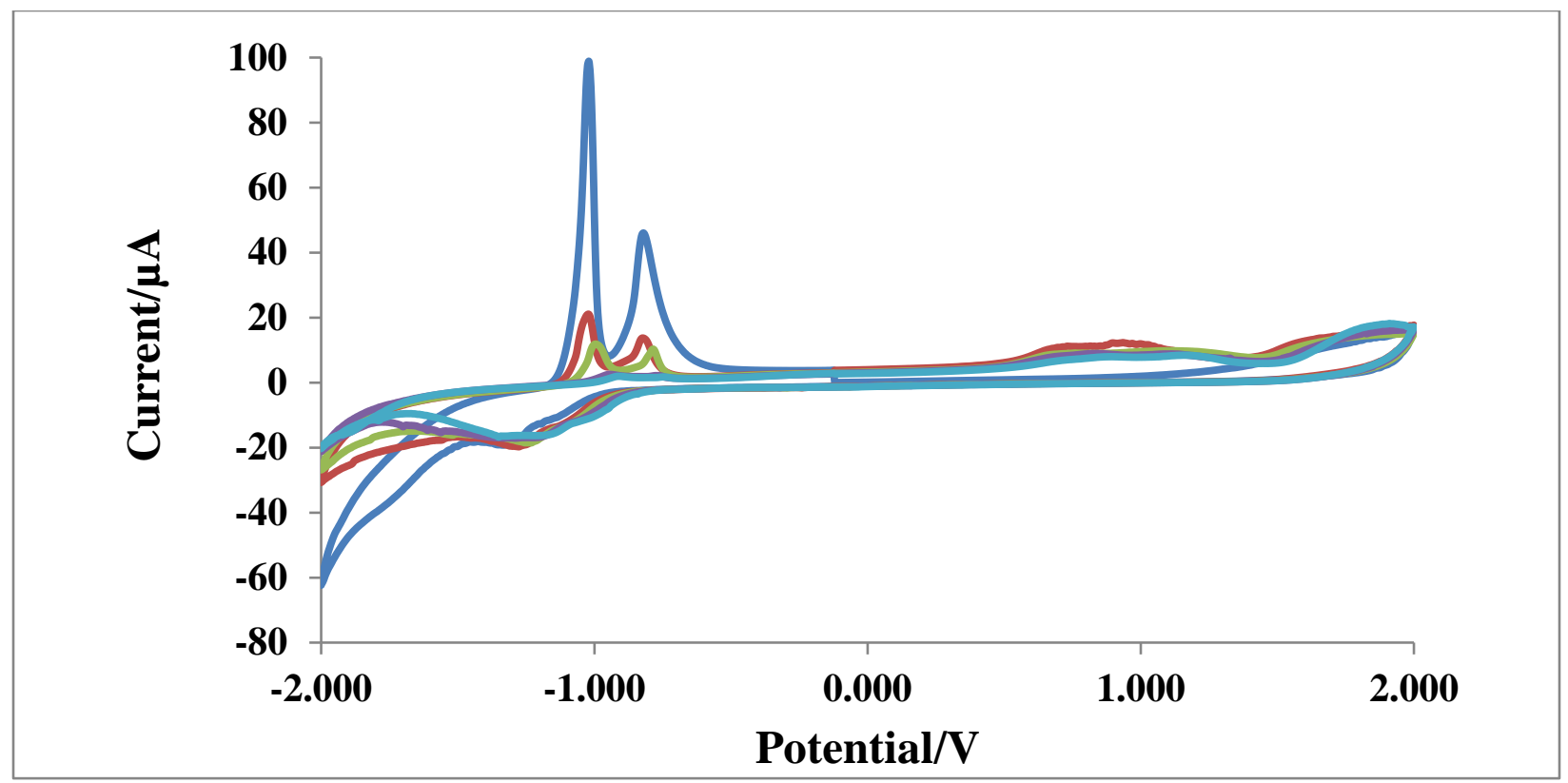

Figure B.4 CV scans at a GCE in 0.1M KPF $/ \mathrm{MeCN}$ initiated in the positive direction from $\mathrm{OCP}=$ $0.120 \mathrm{~V}$ over +2.0 to $-2.0 \mathrm{~V}$. Scan rate $=10 \mathrm{mV} / \mathrm{s}$, vs. Pt pseudo reference

Ideally, the potential window of an electrochemical system is the range of potentials where working electrode and electrolyte are completely inert. Our results indicate that the potential window of $\mathrm{GCE}$ in $0.1 \mathrm{M} \mathrm{KPF}_{6} / \mathrm{MeCN}$ is especially limited in the negative potential region. According to the literature, the inert potential window of acetonitrile electrolytes should extend to at least $-2.0 \mathrm{~V}$ in the negative direction ${ }^{2,3}$. Thus, the features in the cathodic region are likely due to impurities in the electrolyte. Experiments with a commercially available GCE eliminated the possibility of our home made GCE as the source of the impurities. Nevertheless, these experiments have shown that cycling the GCE in $0.1 \mathrm{M} \mathrm{KPF}_{6} / \mathrm{MeCN}$ can reduce the electrochemical behavior of the impurities to a stable, reproducible response. Therefore, VMP analyses of aluminum carbide were carried out in this system over the potential window $-2.0 \mathrm{~V}$ to $+2.0 \mathrm{~V}$ after cycling the unmodified GCE in $0.1 \mathrm{M} \mathrm{KPF}_{6} / \mathrm{MeCN}$ five times to reduce contributions from the impurity.

\section{B3. Working Potential Window of GCE in 0.1M TBAHFP/MeCN}

A methodology similar to the one outlined previously was used to establish the potential window of the GCE in $0.1 \mathrm{M}$ TBAHFP/MeCN. The open circuit potential (OCP) was determined 
by measuring the potential at zero current. Progressive potential scans were applied in increasing potential increments of $100 \mathrm{mV}$ in the positive direction from the $\mathrm{OCP}$ at $25 \mathrm{mV} / \mathrm{s}$. The positive potential limit was increased until the current significantly increased. When a new feature appeared, the scan was repeated 3 times to determine whether it was stable over time. Once significant current was observed at the positive limit. The same process is repeated in the negative direction.

Figure 8.4 shows all the progressive $\mathrm{CV}$ scans in both the negative and positive directions at a GCE in $0.1 \mathrm{M}$ TBAHFP/MeCN. There are no significant features in the positive scans.

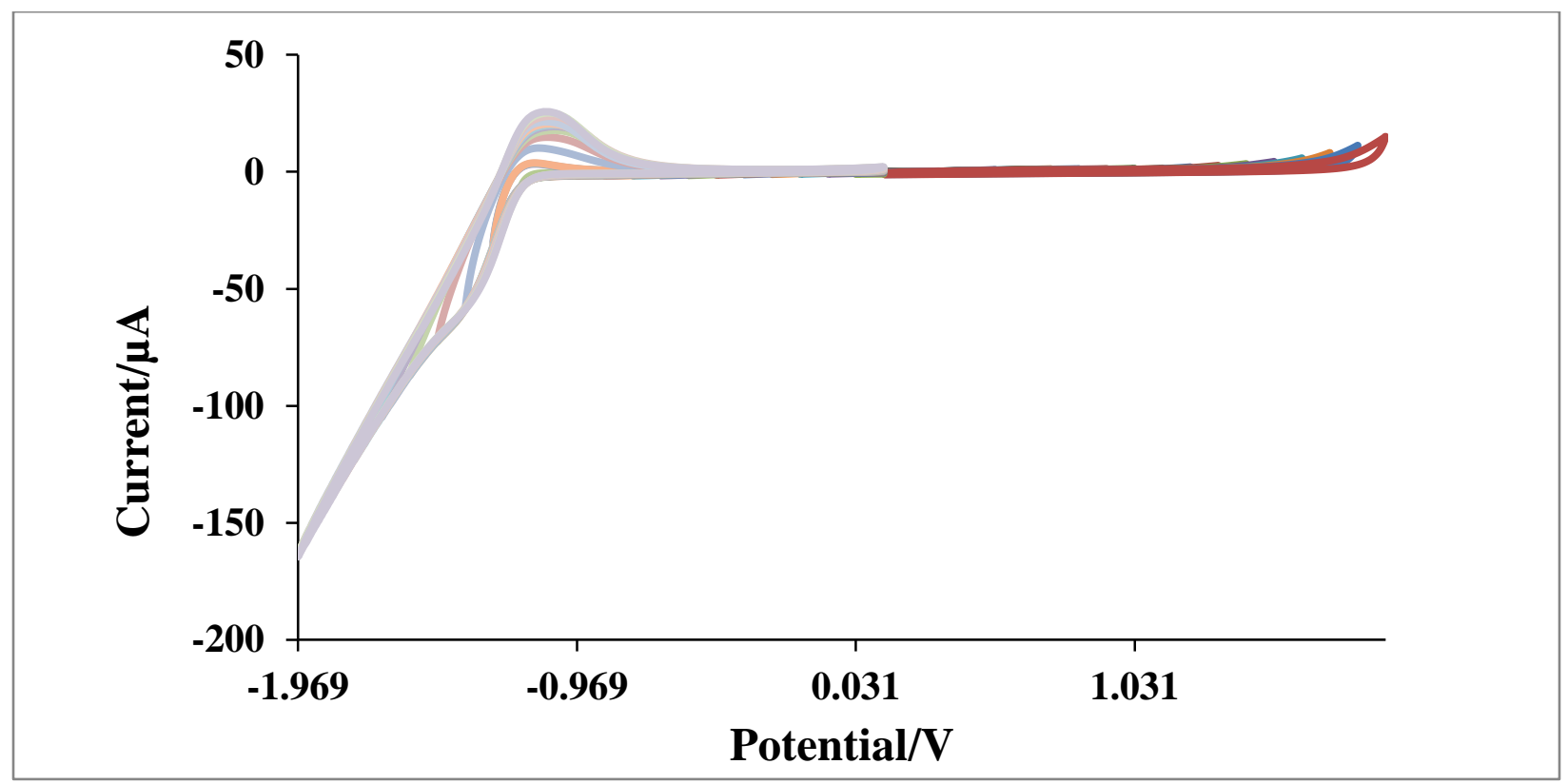

Figure B.5 Progressive CV scans at a GCE in 0.1M TBAHFP/MeCN initiated in the positive direction and the negative direction from the OCP at $25 \mathrm{mV} / \mathrm{s}$ vs. Pt pseudo reference electrode. Potential range is $\mathbf{- 1 . 9 6 9 V}$ to $+1.931 \mathrm{~V}$.

The positive-going scans are shown in more detail in Figure $8.5 \mathrm{~b}$ ). There is a quasireversible redox couple in the cathodic region of the CVs (Figure $8.5 \mathrm{c}$ )). The electrochemical processes in the cathodic region are shown in more detail in Figures 8.5 a) and c). Figure 8.5 a) shows the onset of the reduction at $\sim 1.17 \mathrm{~V}$ of the redox couple. As the potential is scanned to 
values more negative than $-1.17 \mathrm{~V}$, the reduction peak increases and broadens. After a negative limit of -1.27 an oxidation peak appears around $-1.11 \mathrm{~V}$. This oxidation peak also grows and shifts to more positive potentials $(\sim-1.10 \mathrm{~V})$ as the potential limit is widened to more negative potentials. The peaks due to this redox couple are stable over 3 scans (Figure $8.5 \mathrm{c}$ )).
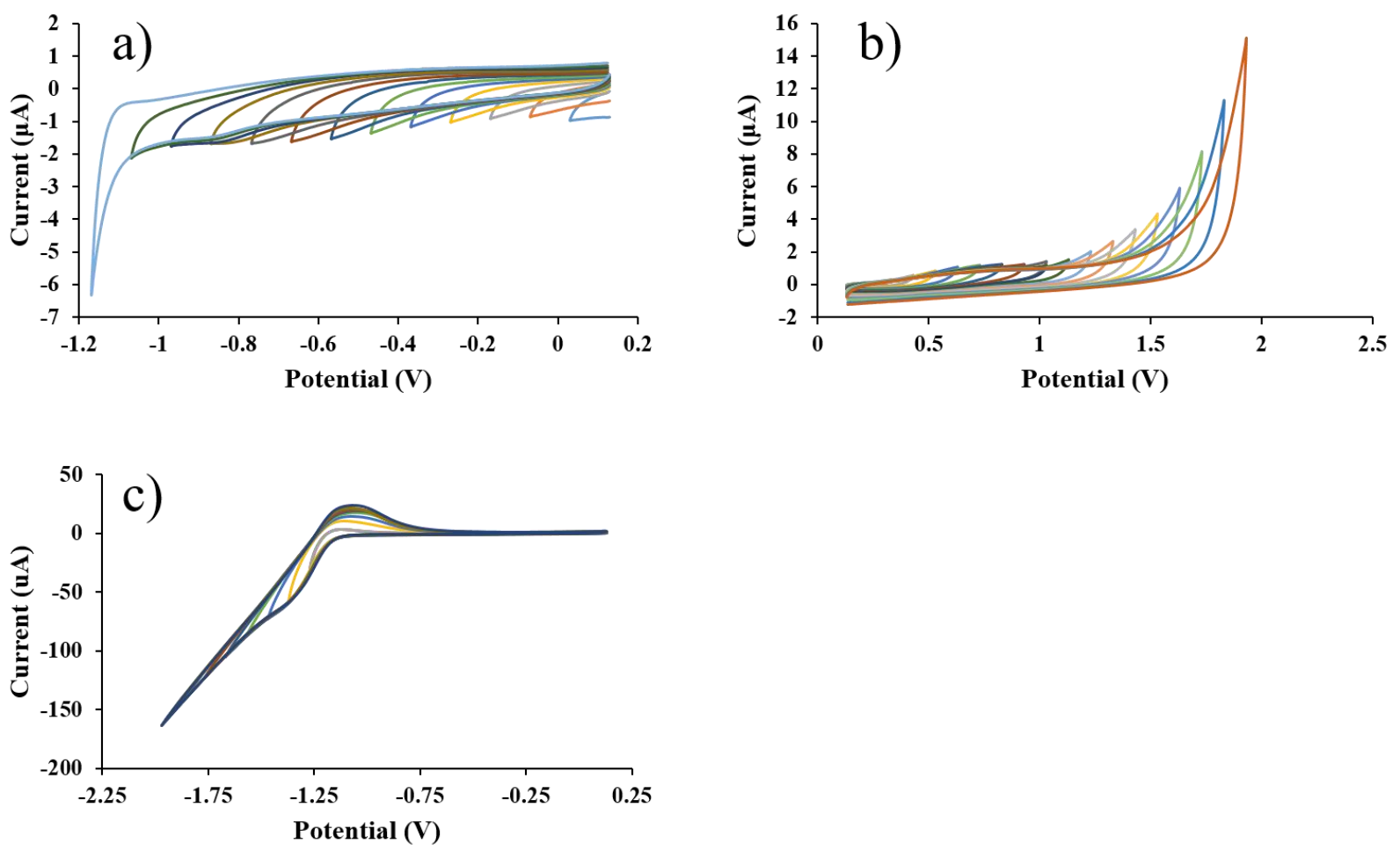

Figure B.6 Enlargments of a) progressive scans in the negative direction showing the onset of reduction, b) progressive scans in the positive direction, and c) the quasi-revserisble redox couple in the cathodic region.

The results indicate that an electroactive impurity also restricts the working potential window of this system in the negative direction. This impurity may be the same impurity observed in the $0.1 \mathrm{M} \mathrm{KPF}_{6} / \mathrm{MeCN}$ electrolyte. However, the electrochemical behavior is markedly different. The onset of reduction is at a more negative potential and oxidation signal which follows does not decrease. Instead, the impurity has a stable, quasi-reversible redox response and the peak currents were relatively high, e.g. cathodic peak current $\sim 150 \mu \mathrm{A}$. Therefore, the potential window used 
for $\mathrm{VMP}$ experiments was $-1.069 \mathrm{~V}$ to $+1.931 \mathrm{~V}$ to see if there would be any change in the $\mathrm{CVs}$ post-calcium carbide modification of the GCE.

\section{B4. Working Potential Window of GCE in 0.1M CaTf/MeCN}

The same methodology outlined previously was used to establish the potential window of the GCE in $0.1 \mathrm{M}$ CaTriflate/MeCN. The open circuit potential (OCP) was determined by measuring the potential at zero current. The OCP ranged from 0.078 to $0.102 \mathrm{~V}$ over five minutes. Progressive potential scans were applied in increasing potential increments of $100 \mathrm{mV}$ in the positive direction from the $\mathrm{OCP}$ at $25 \mathrm{mV} / \mathrm{s}$. The positive potential limit was increased until the current significantly increased. When a new feature appeared, the scan was repeated 3 times to determine whether it was stable over time. Once significant current was observed at the positive limit. The same process is repeated in the negative direction.

Figure 8.6 shows all the progressive $\mathrm{CV}$ scans in both the negative and positive directions at the GCE in 0.1M CaTriflate/MeCN. There are no significant features in the positive scans when scanned up to $2.102 \mathrm{~V}$. The limiting current increased with the progressively increasing the limiting potential as expected. No electrochemical features were observed in the cathodic region, which were scanned up to $-2.398 \mathrm{~V}$. However, it was noted afterwards that the limiting current increased with increasing limiting potential in the negative direction until $-1.498 \mathrm{~V}$, where it started decreasing with increasing limiting potential. This may indicate that there is a reductive process at this potential. This is supported by the blank CVs shown in Figure 8.8. 


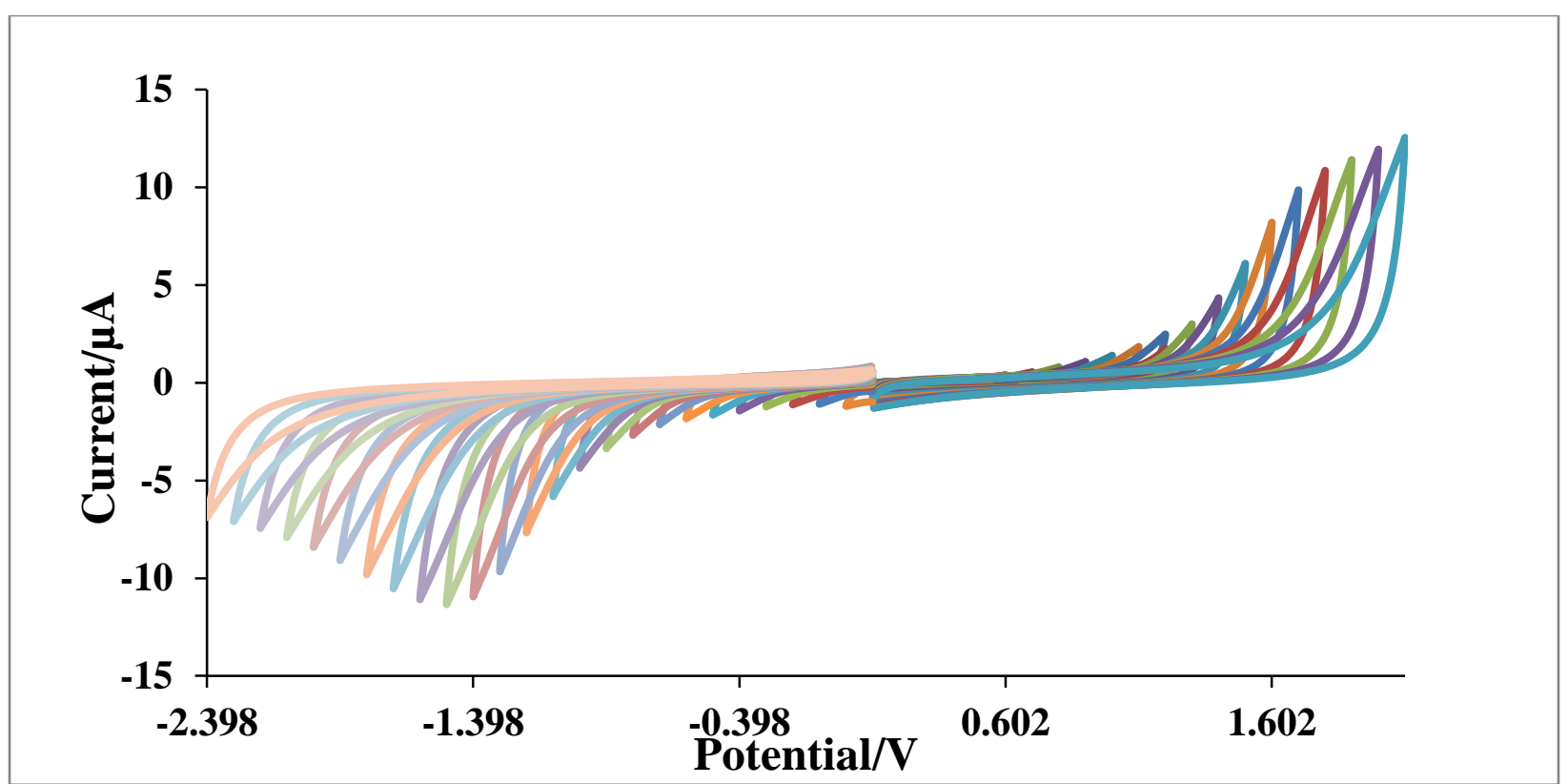

Figure B.7 Progressive CV scans in both the positive and negative directions initiated from the $\mathrm{OCP}=0.102 \mathrm{~V}$ at a GCE in 0.1M CaTf/MeCN. Potential range is from 2.102 to $-2.298 \mathrm{~V}$ in $0.10 \mathrm{~V}$ increments, scan rate $=25 \mathrm{mV} / \mathrm{s}$, vs a Pt pseudo reference electrode.

Figure 8.8 shows five CV scans of the unmodified GCE in $0.1 \mathrm{M}$ CaTriflate/MeCN at a scan rate of $10 \mathrm{mV} / \mathrm{s}$. The scans were initiated in the positive direction from the OCP to $2.102 \mathrm{~V}$, scanned in the negative direction to $-2.398 \mathrm{~V}$ and back to the OCP. The first scan (light blue) shows a sharp oxidation peak at $\sim 1.48 \mathrm{~V}$. This peak is absent in the later four scans. Two small, broad peaks appear after the first scan and appear to be stable over four cycles at $0.63 \mathrm{~V}$ and $1.3 \mathrm{~V}$. All scans have a broad feature in the cathodic region due to an unknown reductive process, which was suggested by the decreasing limiting current with increasing limiting potential in the progressive scans. However, this reductive process was not followed by any oxidation. The three oxidation peaks in the CVs shown in Figure 8.8 were unnoticed in the earlier progressive scans. This may be because the progressive scans were done at a faster scan rate $(25 \mu \mathrm{A})$ or they were not easily recognized due to the nature of the progressive scans. 


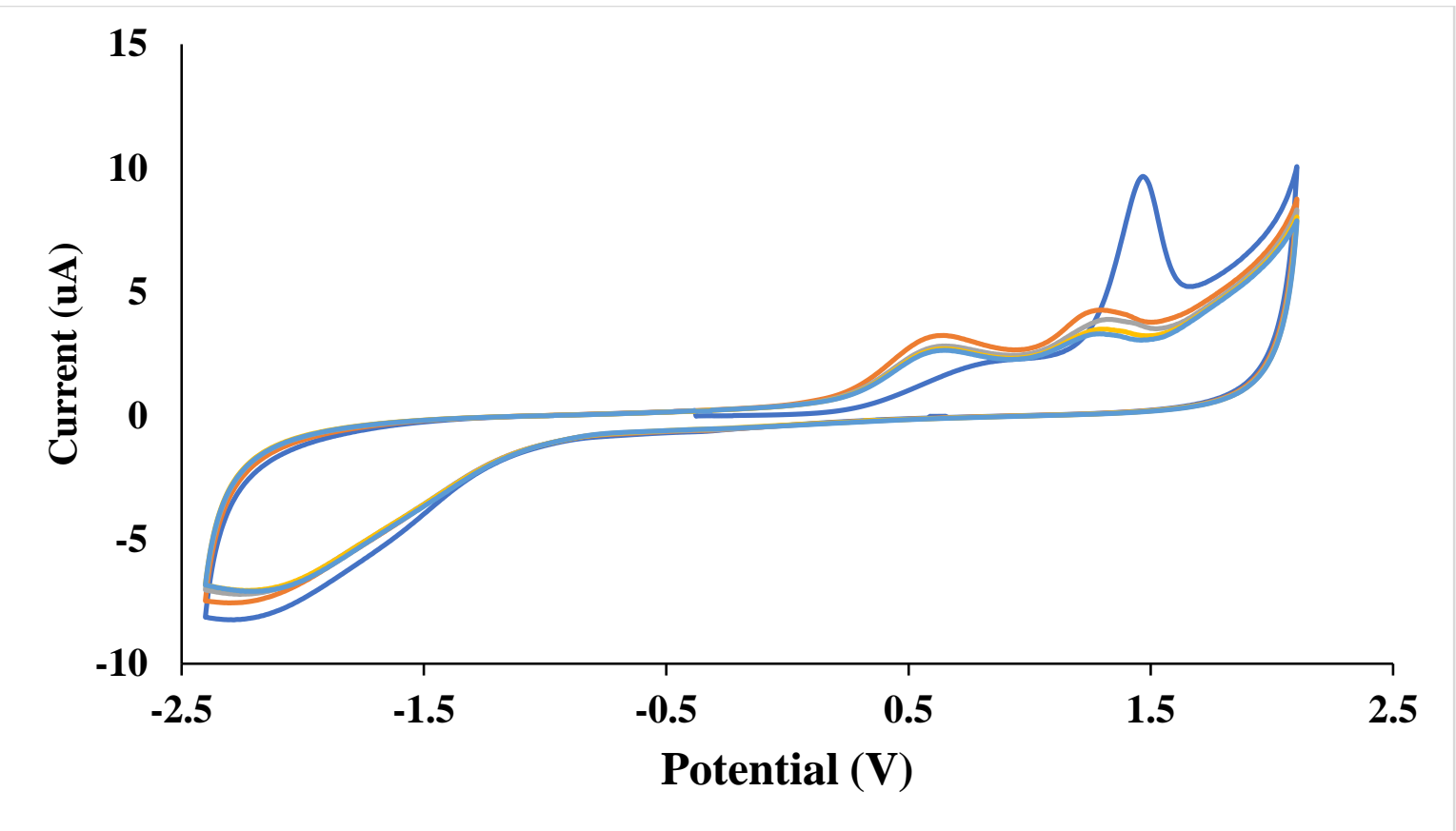

Figure B.8 CVs of GCE vs. Pt pseudo reference electrode, scan rate $=10 \mathrm{mV} / \mathrm{s}$, scans initiated in the positive direction from the $\mathrm{OCP}=-\mathbf{0 . 3 7 7} \mathrm{V}$

These results indicate that there are impurities in the $\mathrm{CaTf} / \mathrm{MeCN}$ electrolyte as well. Nevertheless, the low peak currents indicate the impurities are in low concentration. Therefore, the potential window used for VMP experiments with calcium carbide was $-2.398 \mathrm{~V}$ to $+2.102 \mathrm{~V}$.

All experiments indicate the presence of impurities in the acetonitrile electrolytes that limit the working potential window of the systems and may cause interference with electrochemical analyses of the carbides. Experiments with a gold working electrode further suggests the presence of impurities. Presently, the origin of these impurities is still unclear. The electrochemical response of the impurities changes depending on the working electrode used, e.g. gold WE vs. PIGE or GCE. The unwanted faradaic peaks limiting the potential window with carbon electrodes may be due to intercalation phenomena due to surface roughness of the homemade carbon electrodes. However, experiments with a commercial GCE indicate this may not be the case. It has been noted in the literature that freshly polished GCE's have a tendency to adsorb organic impurities in 
nonaqueous electrolytes due to activation of the carbon surface ${ }^{4,5}$. However, it is unlikely that the impurities are trace organics because the acetonitrile used was HPLC grade.

The electrochemical response also seems to vary with different supporting electrolytes. One possibility could be contamination of dissolved oxygen in the acetonitrile. The reversible reduction of dissolved oxygen ( $\mathrm{R}$ 8.3) in acetonitrile and other nonaqueous media has been investigated by many researchers ${ }^{6-8}$. Different supporting electrolytes affect the reversibility of the $\mathrm{O}_{2} / \mathrm{O}_{2}{ }^{-*}$ couple. For example, the redox couple exhibits ideal reversibility in aprotic solvents containing tetraalkylammonium salts due the increased stabilization of the superoxide anion ${ }^{8}$.

$$
O_{2}+e^{-} \leftrightarrow O_{2}^{-\cdot}
$$

R 0.3

However, all electrolyte solutions were sparged with UHP argon for a minimum of 20 minutes to remove all dissolved oxygen. Additionally, if the impurity was oxygen its reversible reduction would have been observed with a gold working electrode ${ }^{7}$, but this was not the case.

Another possibility for the origin of the unwanted faradaic peaks we attribute to impurites could be intercalation phenomena that is observed with graphitic carbons ${ }^{9-11}$. It is possible that these peaks are due to the reduction of the carbon electrode and intercalation of supporting electrolyte cations into crevices or pores on the due surface roughness. However, the same results were obtained with the commercial GCE that is polished per analytical standards and was used as received. Thus, this explanation seems to be in conflict with glassy carbon's ubiquitous use as a working electrode in nonaqueous electrolytes in the literature. 


\section{References}

(1) Benck, J. D.; Pinaud, B. A.; Gorlin, Y.; Jaramillo, T. F. PLoS One 2014, 9 (10).

(2) Tordera, D.; Pertegás, A.; Shavaleev, N. M.; Scopelliti, R.; Ortí, E.; Bolink, H. J.; Baranoff, E.; Grätzel, M.; Nazeeruddin, M. K. J. Mater. Chem. 2012, 22 (36), 1926419268.

(3) Laboratory Techniques in Electroanalytical Chemistry; Kissinger, P. T., Heinman, W. R., Eds.; Marcel Dekker, Inc.: New York, 1984.

(4) Ranganathan, S.; Kuo, T.-C.; McCreery, R. L. Anal. Chem. 1999, 71 (16), 3574-3580.

(5) R.L. McCreery. Chem. Rev. 2008, 108 (7), 2646-2687.

(6) Zimmermann, M. Oxygen Reduction Reaction Mechanism on Glassy Carbon in Aprotic Organic Solvents, Universite Grenoble Alpes, 2015.

(7) Lorenzola, T. A.; López, B. A.; Giordano, M. C. J. Electrochem. Soc. 1983, 130 (6), 1359-1365.

(8) D. Vasudevan, H. W. J. Electroanal. Chem. 1995, 192, 69-74.

(9) Besenhard, J.; Fritz, H. P. Zeitschrift fur Naturforsch. 1972, 26 (12), 1225-.

(10) Besenhard, J. O.; Fritz, H. P. Angew. Chemie Int. Ed. English 1983, 22 (12), 950-975.

(11) Besenhard, J.; Fritz, H. P. Zeitschrift fur Naturforsch. 1972, 27 (11), 1294-1298. 